\title{
Failure Analysis of Welded Steel Moment Frames Damaged in the Northridge Earthquake
}

Eric J. Kaufmann

John W. Fisher

Lehigh University

ATLSS Engineering Research Center

Bethlehem, Pennsylvania 18015

Roger M. Di Julio, Jr.

California State University, Northridge

Northridge, California 91330

and

John A. Martin and Associates, Inc.

Los Angeles, California 90057

John L. Gross

Building and Fire Research Laboratory Gaithersburg, Maryland 20899

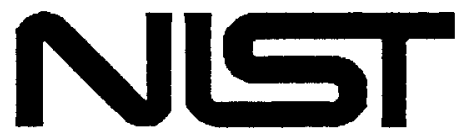

United States Department of Commerce Technology Administration

National Institute of Standards and Technology 


\section{Failure Analysis of Welded Steel Moment Frames Damaged in the Northridge Earthquake}

Eric J. Kaufmann

John W. Fisher

Roger M. Di Julio, Jr.

John L. Gross

January 1997

Building and Fire Research Laboratory

National Institute of Standards and Technology

Gaithersburg, MD 20899

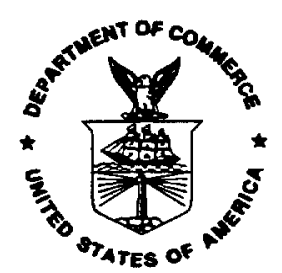

U.S. Department of Commerce

Michael Kantor, Secretary

Technology Administration

Mary L. Good, Under Secretary for Technology

National Institute of Standards and Technology

Arati Prabhakar, Director 


\begin{abstract}
A study was performed to characterize the origin of fracture and material properties of welded steel moment frame (WSMF) connections damaged in the Northridge earthquake. Sixteen connection fractures were obtained from five different buildings in the Los Angeles area which suffered damage in the earthquake. These fractures represented a variety of the types of fractures observed in post-earthquake building inspections. The mechanical and physical properties of the connection members and weld metal were determined including composition, strength, and fracture toughness. A fractographic examination of the fracture surfaces was performed to locate and characterize the fracture origin and determine the fracture mechanism. A fracture analysis was performed using linear elastic fracture mechanics. The analysis indicated that in all cases fracture resulted from crack instability which developed within the weld metal at the weld root at an incomplete fusion flaw contiguous with the notch introduced by the weld backing. The weld metal in all cases was determined to be E70T-4 weld metal and was found to have very poor fracture toughness. The fracture toughness of the weld metal was estimated to be $44 \mathrm{MPa} \sqrt{\mathrm{m}}$ to 65 $\mathrm{MPa} \sqrt{\mathrm{m}}(40 \mathrm{ksi} \sqrt{\mathrm{in}}$ to $60 \mathrm{ksi} \sqrt{\mathrm{in}})$. A fracture mechanics analysis of the defect condition based upon the measured material properties and flaw sizes indicated that the cleavage fracture initiation observed in all the connections would occur without significant yielding in the beam flange and in some cases would occur under elastic stresses. Estimates of stress levels at the sample connections experienced during the earthquake were determined using simulated ground motion spectra for each building site and compared to the fracture analysis model. In all cases the range of estimated stresses exceeded the fracture stress predicted by the fracture model.
\end{abstract}

Keywords: Brittle failure; building technology; connections; earthquake damage; failures; fracture; frames; steel; structural failures; welded joints. 


\section{TABLE OF CONTENTS}

ABSTRACT $\ldots \ldots \ldots \ldots \ldots \ldots \ldots \ldots \ldots \ldots \ldots \ldots \ldots \ldots$

TABLE OF CONTENTS $\ldots \ldots \ldots \ldots \ldots \ldots \ldots \ldots \ldots \ldots$

LIST OF TABLES $\ldots \ldots \ldots \ldots \ldots \ldots \ldots \ldots \ldots \ldots \ldots \ldots \ldots$

LIST OF FIGURES $\ldots \ldots \ldots \ldots \ldots \ldots \ldots \ldots \ldots \ldots \ldots \ldots$

1. INTRODUCTION $\ldots \ldots \ldots \ldots \ldots \ldots \ldots \ldots \ldots \ldots \ldots \ldots \ldots \ldots \ldots$

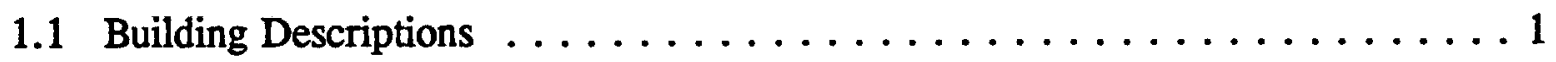

2. BUILDING FRACTURE SAMPLES . . . . . . . . . . . . . . 3

2.1 Sample Removal Procedure $\ldots \ldots \ldots \ldots \ldots \ldots \ldots \ldots \ldots \ldots \ldots$

2.2 Fracture Samples . . . . . . . . . . . . . . . . . . . 4

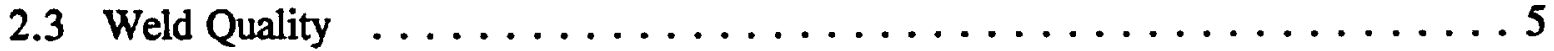

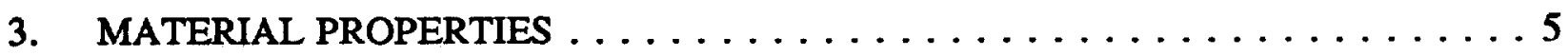

3.1 Base Metal Mechanical Properties ................... . . 6

3.2 Base Metal Composition and Microstructure . . . . . . . . . . . . . 7

3.3 Weld Metal Composition $\ldots \ldots \ldots \ldots \ldots \ldots \ldots$

3.4 Weld Metal Fracture Toughness . . . . . . . . . . . . . . . . . 8

3.5 Material Property - Connection Fracture Correlations . . . . . . . . . . . 8

4. FRACTOGRAPHIC EXAMINATION ... . . . . . . . . . . . 9

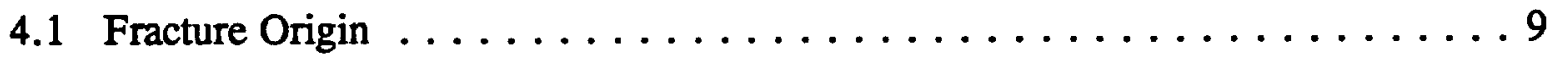

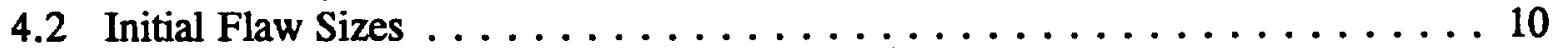

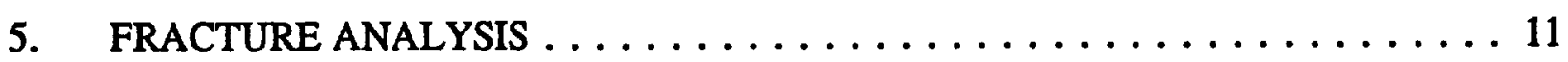

5.1 Weld Metal Fracture Toughness . . . . . . . . . . . . . . . 11

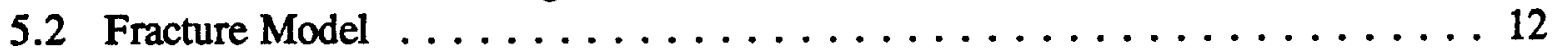

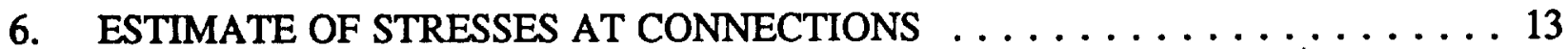

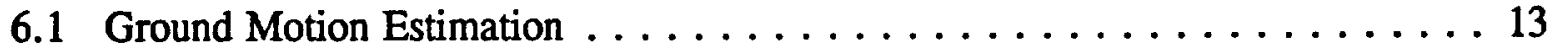

6.2 Structural Modeling Procedure ...................... 14

6.3 Analytical Results .......................... 15

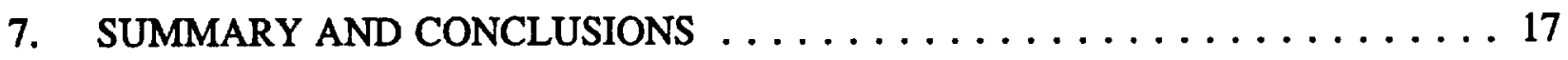

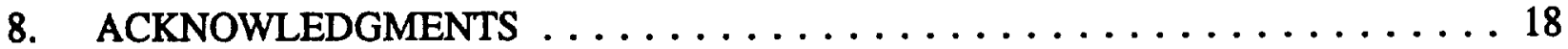

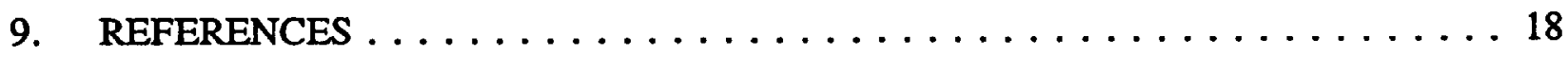




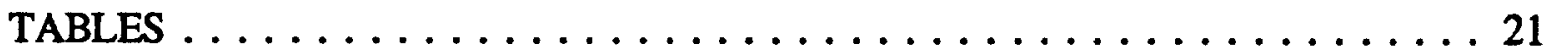

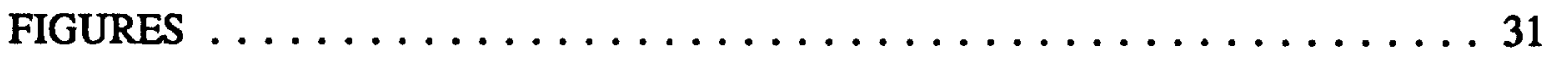

APPENDIX A - Building Drawings and Damage Survey $\ldots \ldots \ldots \ldots \ldots 72$

APPENDIX B - Column Flange CVN Test Data . . . . . . . . . . 148

APPENDIX C - Beam and Column Flange Microstructure $\ldots \ldots \ldots \ldots \ldots 6$ 


\section{LIST OF TABLES}

Table

$1 \quad$ Building Samples and Damage Types . . . . . . . . . . . . . . . 21

2 Beam and Column Flange Mechanical Properties ................ 22

3 Column Flange Charpy V-Notch Test Results . . . . . . . . . . . . 23

4 Chemical Compositions of Members and Weld Metal ............. 25

$5 \quad$ Weld Metal Charpy V-Notch Test Results . . . . . . . . . . . . . . 26

6 Summary of Weld Root Flaw Sizes . . . . . . . . . . . . . . . 27

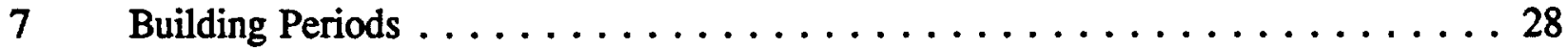

$8 \quad$ Building Base Shears . . . . . . . . . . . . . . . . . . . . 29

9 Computed Beam Flange Stresses at the Sample Locations . . . . . . . . . . . . 30 


\section{LIST OF FIGURES}

Figure

Page

1 Typical welded steel moment frame (WSMF) connection $\ldots \ldots \ldots \ldots \ldots \ldots$ and recommended fracture sample removal procedure

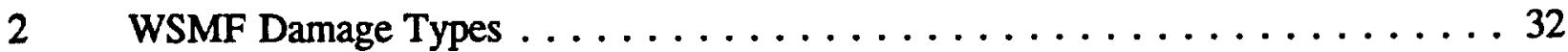

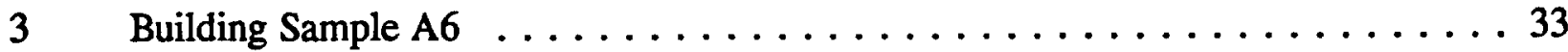

4 Building Sample A33. No cracking is visible $\ldots \ldots \ldots \ldots \ldots \ldots \ldots$

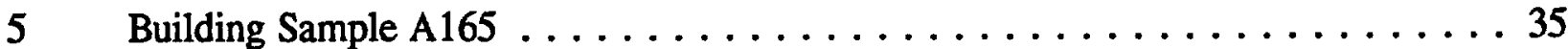

6 Edge view of Sample A165 column flange showing fracture path $\ldots \ldots \ldots \ldots 36$

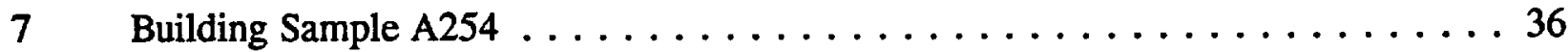

8 Edge view of Sample A254 showing column flange fracture $\ldots \ldots \ldots \ldots \ldots$

9 Building Sample A287. No cracking is visible $\ldots \ldots \ldots \ldots \ldots \ldots \ldots$

10 Building Sample B4 showing beam bottom flange $\ldots \ldots \ldots \ldots \ldots \ldots$ and fracture (Type W4)

11 Building Sample B8 showing beam bottom flange $\ldots \ldots \ldots \ldots \ldots$ and fracture (Type W4)

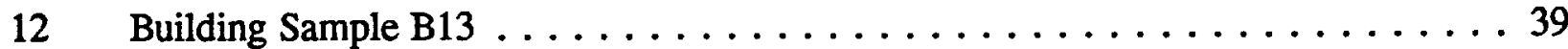

13 Edge view of Sample B13 showing column flange fracture $\ldots \ldots \ldots \ldots$. . . . 39

14 Building Sample B60 . . . . . . . . . . . . . . . . . . 40

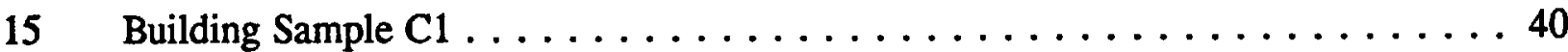

16 Edge view of column flange fracture in Sample $\mathrm{C} 1 \ldots \ldots \ldots \ldots$

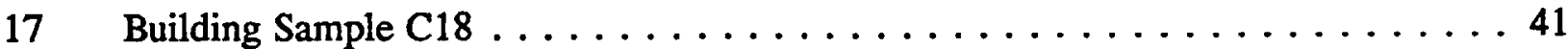

18 Edge view of column flange fracture in Sample $\mathrm{C} 18 \ldots \ldots \ldots \ldots \ldots$

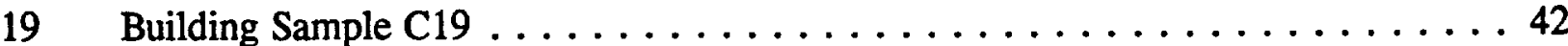


20 Building Sample E150. Note column flange fracture $\ldots \ldots \ldots \ldots \ldots \ldots \ldots$

21 Building Sample E226. Note column flange fracture $\ldots \ldots \ldots \ldots \ldots \ldots \ldots$

22 Building Sample E549. No cracking is visible. $\ldots \ldots \ldots \ldots \ldots \ldots \ldots \ldots$

23 Building Sample F38 showing column flange and cut beam flange weld $\ldots \ldots \ldots \ldots 44$

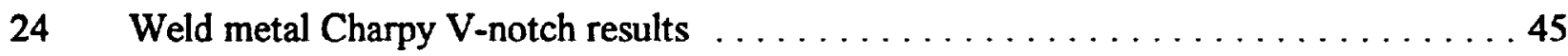

25 Column flange fracture surface from Sample A6. Arrow indicates $\ldots \ldots \ldots \ldots \ldots 6$ location of fracture origin.

26 Column flange fracture surface from Sample A33. Arrow indicates $\ldots \ldots \ldots \ldots \ldots 46$ location of fracture origin

27 Cross-section of fracture in Sample A33 . . . . . . . . . . . . . . . . 47

28 Enlarged view of fracture origin area of Sample A33. Note incomplete . . . . . . 47 fusion along weld root

29 SEM micrograph of the fracture origin (Area marked "A" in Figure 28) . . . . . . 48 showing cleavage fracture (Mag. 500X)

30 Fracture surface of Sample A165. Arrow shows location $\ldots \ldots \ldots \ldots \ldots \ldots$ of fracture origin

31 Enlarged view of fracture origin area at the weld root $\ldots \ldots \ldots \ldots \ldots \ldots$ of Sample A165

32 Fracture surface of Sample A254. Arrow shows location of fracture origin

33 Enlarged view of the fracture origin area at the weld root $\ldots \ldots \ldots \ldots \ldots \ldots$ of Sample A254

34 Low magnification SEM micrograph of the fracture origin area $\ldots \ldots \ldots \ldots \ldots 50$ of Sample A254. (Boxed area seen in Figure 33) (Mag. 6.1X)

35 Higher magnification micrographs of the fracture origin of $\ldots \ldots \ldots \ldots \ldots \ldots 1$ Sample A254 showing cleavage fracture (Mag. 450X)

36 Cross-section of fracture in Sample A254 adjacent to $\ldots \ldots \ldots \ldots \ldots \ldots \ldots \ldots \ldots \ldots$ the fracture origin

37 Fracture surface of Sample A287. Arrow shows location of fracture origin . . . . . 52 
38 Enlarged view of the weld root fracture origin in Sample A287 . . . . . . 53

39 SEM micrographs of the crack surface obtained adjacent to the weld . . . . . . 53 root flaw in Sample A287. (Boxed areas " $A$ " and "B" in Figure 38)

40 Fracture surface from Sample B4 showing arc gouging damage. Fracture . . . . . . 54 path is near the weld fusion line.

41 Fracture surface from Sample B8. Fracture path is near the weld . . . . . . . . . 54 fusion line. Arrow shows location of fracture origin

42 Fracture surface from Sample B13 showing a portion of the divot $\ldots \ldots \ldots \ldots 5$ fracture exposed. The fracture origin is located within the missing area of the surface at the web centerline.

43 Column divot fracture surface from Sample B60. Arrow shows the $\ldots \ldots \ldots \ldots 5$ location of the fracture origin

44 Enlarged view of the fracture origin of Sample B60 showing $\ldots \ldots \ldots \ldots$ a deep weld root incomplete fusion flaw

45 Fracture surface of Sample C1. Arrow shows the location of $\ldots \ldots \ldots \ldots \ldots$ the fracture origin eliminated during removal of the sample

46 Enlarged view of the crack surface from Sample $\mathrm{C} 1$ next to $\ldots \ldots \ldots \ldots 7$ the fracture origin

47 Fracture surface from Sample C18. Arrow shows location of . . . . . . . . . 57 fracture origin eliminated during sample removal

48 Fracture surface from Sample C19. The fracture origin is located within the missing area of the fracture at the web centerline

49 Fracture surface from Sample E150 showing a portion of the divot

fracture exposed. The fracture origin is located along the weld root at a location damaged by arc gouging (see arrow)

50 Fracture surface form Sample E226. Arrow shows the location of the fracture origin

51 Enlarged view of the fracture origin area of Sample E226. The fracture initiates from an incomplete fusion flaw at the weld root

52. Low magnification SEM micrograph of the fracture origin of . . . . . . . . . 60 Sample E226. (Boxed area in Figure 51) (Mag. 6.5X) 
53 SEM micrographs of the crack surface of Sample E226 immediately 60 adjacent to the weld root flaw (Areas "A" and "B" in Figure 52) (Mag. 450X \& 402X)

54 Divot fracture surfaces from Sample E549. Arrow shows the location of the fracture origin. Note the deep incomplete fusion defect along the weld root.

55 Enlarged view of the fracture origin area from Sample E549 62

56 SEM micrographs obtained immediately adjacent to the crack .............62 origin in Sample E549. (Areas "A" and "C" in Figure 55) (Mag. 402X \& 500X)

57 Fracture surface from Sample F38. Arrow shows the location of the 63 fracture origin eliminated during sample removal

58 Distribution of fracture initiating weld flaw sizes

59 Comparison of EDS spectra obtained from (a) weld metal; (b) base metal; 64 and (c) fracture origin surface of Sample A33.

60 EDS spectra obtained from the fracture surface of Samples A254 . . . . . . . . . 65 and $\mathrm{A} 287$ at the fracture origin

61 Fracture toughness of E70T-4 weld metal 66

62 Edge crack model used for the fracture analysis 66

63 Critical applied stress vs. defect size for weld root defects in WMRF connections

64 Estimated ground motion spectra for Building A 68

65 Estimated ground motion spectra for Building B 69

66 Estimated ground motion spectra for Building $\mathrm{C}$ and $\mathrm{F}$ 70

67 Estimated ground motion spectra for Building $\mathrm{E}$ 71 


\section{Introduction}

In the aftermath of the Northridge earthquake, extensive cracking was discovered in welded steel moment frame (WSMF) connections in more than one hundred buildings in the Los Angeles area. Speculation on the reasons for the fractures was widespread and focused on the external appearance of the cracked elements. Based upon the visual appearance of the cracking, a seemingly wide variety of types of fractures were observed and attributed to an equally wide variety of factors including the weld process, quality of workmanship, base metal properties, and connection design (Miller 1994; Campbell 1995; Tide et al. 1996).

This study was undertaken in order to characterize the origin of the fracture and material properties of failed connections thereby permitting a rational failure analysis to be made. The brittle nature of the weld joint fractures, which exhibited little evidence of inelastic behavior in the weldment or base metal, suggested that it was also desirable to ascertain the weld and base metal fracture toughness properties in addition to the traditional material properties of yield and tensile strength. With knowledge of the material fracture behavior and fracture initiation site, a fracture mechanics analysis could then be performed as a means of understanding the observed behavior of these connections (Fisher et al. 1995).

Sixteen connection fractures were obtained from five different buildings in the Los Angeles area which were damaged in the earthquake. The buildings selected were located at different distances and directions from the earthquake epicenter and each suffered a different extent of damage. The buildings were of sizes, designs, and ages representative of a large number of the buildings damaged in the Northridge earthquake.

\subsection{Building Descriptions}

The general layout of the five buildings is shown in the drawings in Appendix $A$. The buildings have been identified by an assigned letter (A, B, C, E, and F). The drawings include elevations of the lateral force resisting moment frames and show member sizes, story heights and locations where samples were taken. Plans of each floor are also included showing an outline of the building, locations of the moment frames, plan dimensions, and the locations of major openings and gravity columns. They do not include the layout of floor framing and slab reinforcing details. The building drawings also include a description of all damage to the moment frames sustained in the Northridge Earthquake. A brief description of each building follows.

\section{Building A}

Building A is a six story office building, designed circa 1980, with typical plan dimensions of 95 $\mathrm{m}(312 \mathrm{ft})$ by $49 \mathrm{~m}(160 \mathrm{ft})$. The plan area is approximately $3900 \mathrm{~m}^{2}\left(42,000 \mathrm{ft}^{2}\right)$. Typical story heights are $4.27 \mathrm{~m}(14 \mathrm{ft})$. 
The building has multi-bay exterior moment frames on all four sides (column lines A, K, 1 and 5 ) and one interior frame in the transverse direction (column line E). All bay widths are $4.88 \mathrm{~m}$ $(16 \mathrm{ft})$. Typical frame beams vary from W24x62 to W30x99 and frame columns vary from W14x99 to W14x211.

The floors are $82.55 \mathrm{~mm}$ ( $3.25 \mathrm{in}$.) of lightweight concrete over $76 \mathrm{~mm}$ ( 3 in.) metal deck. Floor beams and girders span $9.75 \mathrm{~m}(32 \mathrm{ft})$. The building rests on a pile foundation with pile caps. The bases of the frame columns are restrained against rotation by tie beams.

\section{Building B}

Building B is a four story office building with two levels of parking below ground. The building was designed circa 1984 . Typical plan dimensions are $43 \mathrm{~m}(140 \mathrm{ft})$ by $26 \mathrm{~m}(86 \mathrm{ft})$. The typical plan area is approximately $1115 \mathrm{~m}^{2}\left(12,000 \mathrm{ft}^{2}\right)$. Typical story heights are $4.27 \mathrm{~m}(14 \mathrm{ft})$.

The building has single two bay exterior moment frames on Lines 4, A and G. There are a pair of two bay frames on Line 1. Bay widths vary from $4.88 \mathrm{~m}(16 \mathrm{ft})$ to $9.75 \mathrm{~m}(32 \mathrm{ft})$. Frame beams vary from W18x35 to W30x108. Frame columns vary from W14x48 to W14x211. Below grade, in the parking levels, the lateral load resisting system consists of concrete shear walls.

The floors are $82.55 \mathrm{~mm}$ ( $3.25 \mathrm{in}$.) of lightweight concrete over $76 \mathrm{~mm}$ ( 3 in.) metal deck. The floor framing is irregular but floor beams and girders typically span $9.14 \mathrm{~m}$ to $9.75 \mathrm{~m} \mathrm{(30} \mathrm{ft} \mathrm{to}$ $32 \mathrm{ft}$ ). The steel columns continue into the basement and rest on spread footings.

\section{Building C}

Building $\mathrm{C}$ is a four story office building that sits on a single level of parking. The lateral load resisting system for the parking level is reinforced concrete block shear walls. The frame columns terminate at the top of the shear walls. The building was designed circa 1983. Plan dimensions are $52 \mathrm{~m}(170 \mathrm{ft})$ by $30 \mathrm{~m}(98 \mathrm{ft})$. The plan area is approximately $1486 \mathrm{~m}^{2}\left(16,000 \mathrm{ft}^{2}\right)$. The first

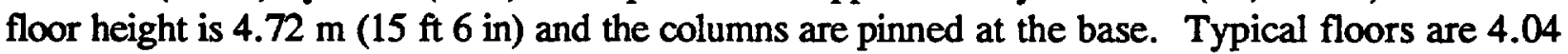
$\mathrm{m}(13 \mathrm{ft} 3$ in).

The building has a combination of one and two bay exterior frames (Lines A, B, E, 1, 3, 4, 7). Bay widths range from 6.7 to $10 \mathrm{~m}$ ( 22 to $33 \mathrm{ft}$ ). Frame beam sizes range from W16x31 to

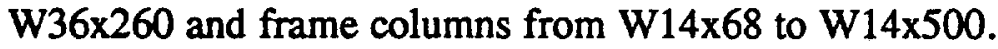

The floors are plywood sheathing over truss joists. Joists and girders typically span $6.7 \mathrm{~m}$ to 10 $\mathrm{m}(22 \mathrm{ft}$ to $33 \mathrm{ft})$. 


\section{Building E}

Building $\mathrm{E}$ is eleven stories tall with six stories of offices above five stories of above grade steel framed parking. The building was designed circa 1984 . The plan is highly irregular. The plan

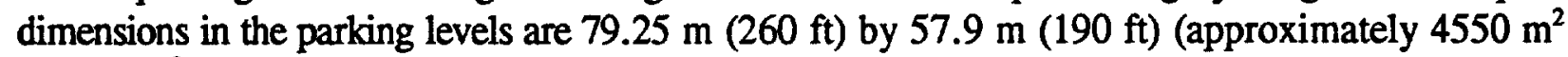
$\left.\left(49,000 \mathrm{ft}^{2}\right)\right)$. The office plan dimensions vary from $79.25 \mathrm{~m}(260 \mathrm{ft})$ by $57.9 \mathrm{~m}(190 \mathrm{ft})$ to 62.5

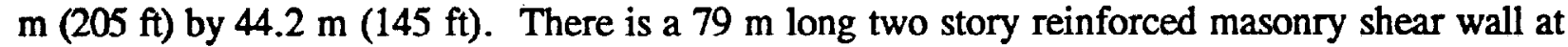
the south side of the structure that also serves as a lateral load resisting element. Typical story

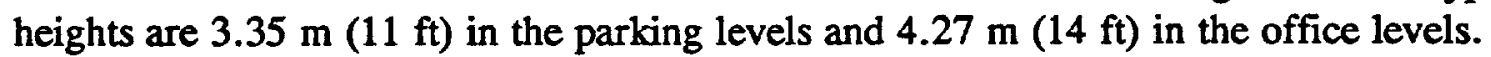

The building has both interior and exterior multi-bay moment frames ( Lines 2, 6, 9, 11, C, E, $H, M)$. Typical frame beam sizes are W36 150 to W36 210 . Large beams were used even in the highest levels. Typical columns sizes are W14×257 to W14x398.

The floors are $63.5 \mathrm{~mm}$ ( $2.5 \mathrm{in})$ of hardrock concrete over $76 \mathrm{~mm}$ ( 3 in) metal deck. Floor beams and girders span $8.84 \mathrm{~m}(29 \mathrm{ft})$. The building rests on a pile foundation with grade beams that fix the base of the columns against rotation.

\section{Building F}

Building $\mathrm{F}$ is a four story office building above three levels of below grade parking. The building was designed circa 1985 . The plan dimensions are $44.5 \mathrm{~m}(146 \mathrm{ft})$ by $33.2 \mathrm{~m}(109 \mathrm{ft})$. The plan area is approximately $1486 \mathrm{~m}^{2}\left(16,000 \mathrm{ft}^{2}\right)$. Story heights range from $4.04 \mathrm{~m}(13 \mathrm{ft} 3 \mathrm{in})$ to 4.72 $\mathrm{m}$ ( $15 \mathrm{ft} 6 \mathrm{in})$ in the office levels and from $3.05 \mathrm{~m}$ to $3.73 \mathrm{~m}$ (10 ft to $12 \mathrm{ft} 3 \mathrm{in})$ in the parking levels.

The building has four single bay exterior frames (Lines A, D, 1 and 6) with bay widths of approximately $12 \mathrm{~m}$ (40 ft). Frame beams are W36x182 and W36x230 and frame columns are W14 257 and $\mathrm{W} 14 \times 311$ sections.

The floors are $82.55 \mathrm{~mm}(3.25 \mathrm{in}$.) of light weight concrete over $76 \mathrm{~mm}(3 \mathrm{in}$.) deck. Floor beams and girders span $10.36 \mathrm{~m}$ to $14.02 \mathrm{~m}$ ( 34 to $46 \mathrm{ft}$ ). The building rests on strip footings.

\section{Building Fracture Samples}

Samples were taken from fractured connections in each building to allow characterization of the base metal, weld metal and fracture surfaces. In this section, results of visual inspection of the fractured connections and descriptions of the samples are presented along with the procedure for removing the samples from the buildings. 


\subsection{Sample Removal Procedure}

A sketch of the WSMF fracture sample and removal procedure desired for the study is shown in Figure 1. The desired sample included the entire fracture, weld joint, and adjacent material for material property evaluation and fractographic examination. The sample is cut from the column flange above and below the weld joint and separated from the beam flange several inches back from the weld joint. This allowed the entire weld joint and fracture to be removed as a single unit.

This sample and removal procedure was ideal for the purposes of the study and was followed in the removal of a number of the fracture samples. However, it was not always adhered to depending upon the particular damage at a connection and the subsequent repair procedure followed. In some cases the column flange was removed in two or three pieces, particularly in connections with heavy columns. Apparently this procedure was followed to reduce the weight of the pieces being removed but unfortunately often damaged key areas of the fracture surface. Also, in separating the beam flange from the column, a cut was sometimes made along the weld joint, eliminating weld metal for mechanical property evaluation. Despite these difficulties many of the fracture samples removed were of good quality with little or no damage to the crack surface or adjacent material during removal.

\subsection{Fracture Samples}

Table 1 provides a summary of the sixteen connection samples removed from the five buildings including the sample identification (building letter identification and numeric code assigned to the connection), damage type and location, member sizes, and description of the sample removed. The location of the sample in the building can be found on the elevation drawings in Appendix A where the sample number corresponds to the circled connection number.

All sixteen samples were removed from bottom flange weld joints. This is partly due to the higher frequency of bottom flange fractures but also because they were more readily accessible for removal. The connection designs were all similar with full penetration groove welded flanges and bolted shear tabs. The samples consisted of a relatively wide variety of beam and column sizes. Beam sizes ranged from W24x76 to as large as W36 210 (Group 2). Column sizes ranged from W14X120 to W14×398 (Groups 2, 3, and 4).

Surveys of building damage after the Northridge earthquake categorized connection damage by fracture type based upon visual and ultrasonic examination (Youssef et al. 1995; Bonowitz 1995). The ten fracture types identified in these surveys are shown diagramatically in Figure 2. The test samples in this study included three types of connection fractures based upon the visual appearance of the fracture. The most frequently represented fracture type among the sixteen fracture samples was Type C3 (10 samples) which resulted in fracture which penetrated across the column flange. Four connection fracture samples also exhibited fracture of the column which formed a "divot" in the column flange (Type C2). Two of the connection samples fractured in the vicinity of the 
weld fusion line in the column flange (Type W4). These three types of connection fractures have been observed frequently and are representative of a large number of damaged connections.

Overall views of the sixteen failed connection samples are shown in Figures 3 through 23 . In all samples the fractures appeared to be brittle with little evidence of plastic deformation of the connection. The crack path was clearly evident in several of the samples where the column flange had completely fractured $(\mathrm{C} 1, \mathrm{C} 18, \mathrm{C} 19, \mathrm{E} 150, \mathrm{E} 226, \mathrm{~F} 38)$ or had been removed in pieces (A6, A165, A254, B13). The cross-sectional views of the column flange resulting from arc gouging through the column flange and weld joint in several of the samples clearly showed the crack which in all samples appeared to originate at the weld root at the notch introduced by the weld backing. Sample B 60 showed evidence of a divot pull-out of column flange material on both sides of the weld joint. Other samples, removed in whole, showed no obvious visual signs of fracture (A33, A287, E549). Damage in these connections apparently had been detected by NDE. It will be noted that several samples ( A6, B4, B8, and F38) were incomplete and missing either the beam portion of the sample or the column flange. In the case of Samples B4 and B8 column material was not removed as part of the connection repair since the fractures occurred close to the column

flange surface. Apparently the repair of connections A6 and F38 did not require removal of a section of the beam flange.

\subsection{Weld Quality}

From a visual inspection, the fabrication quality of the welds in all sixteen samples indicated a level of workmanship which was largely in accordance with AWS D1.1 (1994) and AISC (Manual 1989). Conditions which were less than ideal were observed, however, such as irregularly shaped web cope holes, poor weld tab fit-up, and excessively large cap pass weld beads resulting in acute weld toe geometries. Although not strictly acceptable conditions, they are not unusual conditions and appear to be typical of fabrication practices prior to the Northridge earthquake. Although weld tabs were not always ideally fitted, tabs fitted as end dams were not observed in any of the samples as has been observed in post-earthquake inspections of many buildings.

\section{Material Properties}

Mechanical properties of the beam and column were determined for each sample to identify the grade of steel. The tests also provided information on the strength and strength difference between the beam and column member of each connection for studying the effects of member strength on fracture susceptibility. Similarly, weld metal was analyzed for each sample to determine its composition and mechanical properties in order to identify electrode type. 


\subsection{Base Metal Mechanical Properties}

Standard 0.505 in dia. tension specimens (ASTM A370 1996) were fabricated from the flange material at the test location specified in ASTM A673 (1995) (i.e., 1/6W) where possible. In some samples it was necessary to locate specimens closer to the flange tips in order to avoid damaging the fracture surface.

A summary of the tension test results is given in Table 2. The results show that the mechanical properties of all beam material tested satisfy the mechanical property requirements of ASTM A36 (1996) structural shapes. The yield strengths of all beam flanges were found to be below $345 \mathrm{MPa}$ (50 ksi), and with the exception of Building C samples, were generally in the range of $262 \mathrm{MPa}$ to $290 \mathrm{MPa}$ (38 ksi to $42 \mathrm{ksi}$ ).

The column material in all samples tested satisfied the strength requirements of ASTM A36 (1996). The column material in Buildings $\mathrm{A}$, and $\mathrm{E}$, and $\mathrm{F}$ also satisfied the strength requirements of ASTM A572 (1994) Gr. 50 when the expected reduction in strength between the flange and the web properties measured for material certification was considered. (The yield strength measured in the flange can be as much as $10 \%$ to $15 \%$ less than that measured in the web.) Even considering this reduction, it is unlikely that the column material in Buildings B and C would satisfy Gr. 50 requirements. It is possible that the material in Buildings B and C satisfies ASTM A572 Gr.42 requirements, although the material was not specifically examined for these requirements.

Examining Table 2, one observes that for three of the buildings sampled (Bldgs. A, E, and F) the yield strength of the columns exceeded that of the beams, whereas the opposite was found in the other two buildings (Bldgs. B and C). Whether this was intended by design in the latter cases or whether an incorrect grade of steel was substituted is unclear. Nevertheless, similar fractures developed in both situations and therefore fracture of the connections cannot be attributed to material strength or strength differences alone.

Where material was available, Charpy V-Notch (CVN) specimens were also fabricated from column material. The specimens were taken from at the AISC (Manual 1989) test location for Group 4 and 5 shapes (intersection of the web and flange midway between the inside flange surface and the flange centerline). Specimens were tested in accordance with ASTM E23 (1996) over a range of test temperatures in the transition temperature range. Test results are tabulated in Table 3. CVN transition curves for each column sample are included in Appendix B. The average result of tests at the AISC location for Group 4 and 5 shapes at the required test temperature of $20^{\circ} \mathrm{C}$ is also shown in Table 2 . Although the test requirement only applies to the Group 4 columns from Buildings C, E and F, tests were also performed on the Group 3 column sizes in Buildings $A$ and $B$ for information since column members in these buildings fractured as well. With the exception of Building E, the columns from all buildings satisfied the AISC requirement of $27 \mathrm{~J}$ (20 ft-lbs) @ $20^{\circ} \mathrm{C}$ (Manual 1989). Building E columns showed CVN toughness in the core region of $14 \mathrm{~J}$ to $22 \mathrm{~J}(10 \mathrm{ft}-\mathrm{lb}$ to $16 \mathrm{ft}-\mathrm{lbs}) @ 20^{\circ} \mathrm{C}$. It is noteworthy that columns of similar size in samples from Buildings $\mathrm{C}$ and $\mathrm{E}$ provided substantially different 
toughness in the core region yet both suffered similar fractures of the column flange. This suggests that the column fracture properties are not a primary factor in the connection failure.

\subsection{Base Metal Composition and Microstructure}

The chemical composition of the beam and column member from each of the samples is given in Table 4. These analyses, along with the mechanical property data, enable the identity of the grade of steel (ASTM A36, A572, etc.) to be determined and also provide an indication of the weldability of the material and whether this may have been a factor in the connection fracture.

The compositional requirements of ASTM A36 and A572 Gr. 50 structural shapes are given below for comparison:

$\begin{array}{cll}\text { Element } & \text { ASTM A36 (wt\%) } & \text { ASTM A572 Gr. 50(wt\%) } \\ \mathrm{C} & 0.26 \mathrm{Max} . & 0.23 \mathrm{Max} . \\ \mathrm{Mn} & \text { No Req. } & 1.35 \mathrm{Max} . \\ \mathrm{P} & 0.04 \mathrm{Max} . & 0.04 \mathrm{Max} . \\ \mathrm{S} & 0.05 \mathrm{Max} . & 0.05 \mathrm{Max} . \\ \mathrm{Si} & 0.04 \mathrm{Max} . & 0.40 \mathrm{Max} . \\ \mathrm{Nb} & & 0.005-0.05 \text { (Type 1) } \\ \mathrm{V} & & 0.01-0.15 \text { (Type 2) } \\ \mathrm{Nb}+\mathrm{V} & & 0.02-0.15 \text { (Type 3,Nb 0.05 Max.) }\end{array}$

The principal compositional difference between A36 and A572 is the intentional addition of one or more microalloying elements $(\mathrm{V}$ and $\mathrm{Nb})$. The analyses show that the beam material in all samples meets the chemical requirements of ASTM A36 but does not contain sufficient amounts of either microalloying element to satisfy the requirements of ASTM A572. Considering the strengths measured in the beams and the chemical compositions determined by analyses it can be concluded that all of the beam material satisfied the specification requirements of ASTM A36.

In contrast, the column material in Building A satisfied the compositional requirements of A572 in all but one sample (A287). The sample from building F (F38) also met the compositional requirements of A572 as well as one sample from Building E (E549). The remaining samples from Building $E$ and all the samples from Buildings B and C did not satisfy A572 compositional requirements.

Examination of the composition and mechanical property results of all of the samples indicates that all of the beam samples (where beam samples were available) satisfied the specification requirements of ASTM A36. The column material from Building F and all but one column sample from Building A satisfied the specification requirements of A572 as well as one column sample from Building E. All of the column samples from Buildings B and C satisfied the specification requirements of ASTM 36. 
The microstructure of the column flange and beam flange material was also obtained to verify the metallurgical condition of these materials. A ferritic-pearlitic microstructure was found in all column and beam members. This is the expected microstructure for as-rolled ASTM A36 or A572 material. Micrographs of the microstructures are included in Appendix C.

\subsection{Weld Metal Composition}

Where sufficient weld metal was available to perform analyses, the chemical composition of the weld metal was also determined. The results of the analyses are also given in Table 4 . The results are similar in all eight samples tested and satisfy the compositional requirements of AWS E70T-4 weld metal. The chemical compositions are also typical for this type of weld metal. Required and typical compositions are shown below:

$\begin{array}{lll}\text { Element } & \text { AwS E70T-4 (wt\%) } & \text { Typical (wt\%) } \\ \text { C } & \text { Not Specified } & 0.24 \\ \text { Mn } & 1.75 \text { Max. } & 0.55 \\ \text { P } & 0.04 \text { Max. } & 0.008 \\ \text { S } & 0.03 \text { Max. } & 0.008 \\ \text { Si } & 0.90 \text { Max. } & 0.25 \\ \text { Al } & 1.80 \text { Max. } & 1.38\end{array}$

\subsection{Weld Metal Fracture Toughness}

Charpy V-Notch test specimens were fabricated from weld metal in all samples where the weld metal was not damaged in the process of sample removal. Tests were performed at room temperature and at temperatures in the transition temperature range when a sufficient number of specimens could be fabricated from a sample. Test results are given in Table 5. A combined plot of the test results, shown in Figure 24, indicate a similar and very low level of weld metal toughness in all eight connection welds tested which is consistent with laboratory CVN tests of E70T-4 weld metal (Kaufmann et al. 1996; Xue et al. 1996). The room temperature toughness of the weld metal in all of the samples tested was in the range of $9 \mathrm{~J}$ to $20 \mathrm{~J}$ ( $7 \mathrm{ft}-\mathrm{lbs}$ to $15 \mathrm{ft}-\mathrm{lbs}$ ) and reached an upper shelf toughness of $46 \mathrm{~J}$ to $83 \mathrm{~J}$ ( $34 \mathrm{ft}-1 \mathrm{bs}$ to $61 \mathrm{ft}-\mathrm{lbs}$ ) at $100{ }^{\circ} \mathrm{C}$.

\subsection{Material Property - Connection Fracture Correlations}

Considering the range of beam and column member sizes included within the test sample and the similar types of fractures which developed in these members, there is clearly no correlation between beam or column size and fracture susceptibility or type of fracture of the connection. As noted earlier, susceptibility to fracture also appeared to be unrelated to strength or strength difference between beam and column members or fracture toughness of the column material. For example, identical column flange fractures developed in Building $\mathrm{A}$ in similar size columns with similar member strengths where the column flange fracture toughness varied from $28 \mathrm{~J}$ ( $21 \mathrm{ft}-1 \mathrm{bs}$ ) 
@ $20^{\circ} \mathrm{C}$ to as high as $123 \mathrm{~J}$ (91 ft-lbs). Similarly, fractures from Buildings $\mathrm{C}$ and $\mathrm{E}$ occurred at connections with similar size column members with very different fracture toughness (95 J to 102 $\mathrm{J} @ 20^{\circ} \mathrm{C}$ vs. $14 \mathrm{~J}$ to $22 \mathrm{~J} @ 20^{\circ} \mathrm{C}$ ).

Member strengths or strength differences did not vary widely within the sixteen samples. Beam strengths were found to be less than, equal to, or greater than column strengths. No correlation between strength or strength difference and fracture susceptibility or type was noted.

Low weld metal notch toughness was found to be the only consistent factor in the connection fractures. Eight samples from which CVN specimens were tested all showed low notch toughness. The weld metal composition of these samples was found to be consistent with E70T-4 weld metal. The appearance of the weld deposit in the remaining eight samples was similar to these and suggests that they too were likely welded with an E70T-4 electrode.

\section{Fractographic Examination}

The fracture surfaces of the samples were analyzed to characterize the fractures and to determine the location of fracture origin. Additionally, fracture initiating root flaws were measured.

\subsection{Fracture Origin}

The fracture surfaces of the samples which were not completely separated were exposed by cooling the sample to low temperature in liquid nitrogen and loading the weld joint in a testing machine. The fracture origin was identified in all samples where the origin had not been destroyed in sample removal, and the size and source of the originating defect was recorded. The fracture origins were also examined with a scanning electron microscope (SEM) to obtain information concerning the fracture mechanism at fracture initiation. The fracture surfaces of the sixteen samples and SEM micrographs of selected crack origins are shown in Figures 25 through 57. Also indicated on the photographs is the location where the brittle fracture initiated. This can be determined from examination of the chevron patterns on the crack surface which point back to the fracture origin.

Cleavage fracture was found to be the mechanism of crack propagation in all of the samples regardless of crack propagation path (ie. Type C2, Type C3 or Type W4 fractures). Also, the location and source of fracture initiation was found to be the same in all of the samples regardless

of the path of crack propagation. In all samples where a crack origin could be identified, brittle fracture initiated close to the mid-width of the weld (near the column web centerline) usually from a weld root incomplete fusion flaw in this area. A higher incidence of weld root incomplete fusion is expected in this area due to limited access for welding afforded by the weld access hole. In several samples, however, fracture was observed to initiate at the weld root at a location where 
no visually detectable incomplete fusion flaw was found. In one sample (A33) fracture was found to initiate at the weld root immediately next to a weld root flaw (see Figure 28).

SEM examination of the origin area of Samples A33, A254, A287, E226, and E549 all showed that cleavage fracture initiation occurred directly from the weld root defect (see Figures 29, 35, 39,53 , and 56). No evidence of other fracture mechanisms associated with stable crack growth processes, such as low cycle fatigue from prior load cycles or hydrogen cracking during fabrication, was observed at the crack origin.

Weld cross-sections such as those shown for Samples A33 (Figure 27) and Sample A254 (Figure 36) indicated that fracture initiated from the weld root within weld metal. This is reasonable since the notch tip introduced by the weld backing or any root incomplete fusion flaw must necessarily reside within weld metal and the weld metal is known from CVN tests to have very low toughness. Although in most welds the coarse grained heat-affected-zone (HAZ) possesses the lowest toughness in comparison to unaffected base metal or most weld metals, the low toughness of E70T-4 weld metal provides a ready material to initiate cleavage fracture. Once initiated the dynamic crack can propagate outside of the weld metal into the HAZ or unaffected base metal in response to the principal stresses and material toughness.

In order to provide further evidence of the location of fracture initiation, an EDS (Energy Dispersive Spectroscopy) analysis was performed on the crack surface at the crack origin on several of the fracture samples. The analysis is capable of providing a semi-quantitative compositional analysis of a small volume (several microns in size) of material by $\mathrm{x}$-ray emission spectroscopy. The composition of the column base metal is similar to that of the weld metal with the exception of aluminum (Al) content. The aluminum content of A36 or A572 is negligible in comparison with E7OT-4 weld metal $(1.4 \mathrm{wt} \%$ to $1.8 \mathrm{wt} \%)$ and therefore provides a means of determining the type of material within which the crack resides at the point of initiation. Figure 59 shows EDS spectra obtained from E70T-4 weld metal crack surface, column flange base metal crack surface, and crack origin fracture surface from Sample A33. The position of a peak in the energy spectrum corresponds uniquely to the presence of a particular element and the amplitude of the peak is a function of concentration of that element and other factors. As expected, the peak corresponding to $\mathrm{Al}$ for weld metal is substantially greater than that for base metal. The crack surface at the fracture origin of Sample A33 shows a peak corresponding to Al which is intermediate between weld metal and base metal but certainly greater than would be found within the HAZ (i.e., base metal). Figure 60 shows similar spectra obtained for Samples A254 and A287. The spectral peak for Al in Sample A254 is stronger and very similar to that in weld metal. The peak in A287, however, is weaker and more like base metal in amplitude. Although not conclusive, the tests provide additional evidence that the fracture origin lies within weld metal and taken with other evidence supports the conclusion that the fracture initiated within the weld metal.

\subsection{Initial Flaw Sizes}

The depths of all fracture initiating root flaws, as well as the thickness of the weld backing, were measured. Table 6 provides a summary of the measurements. Also shown is the sum of the weld 
backing thickness and flaw depth which represents the effective flaw depth. A large range of flaw sizes $(0.8 \mathrm{~mm}$ to $10 \mathrm{~mm})$ which initiated fracture of connections was found within the test samples. This sugessts that the weld root flaw itself is not the primary reason for fracture but when coupled with the weld backing provides a large effective flaw depth of $10 \mathrm{~mm}$ to $20 \mathrm{~mm}$. Figure 58 shows the distribution of fracture initiating effective flaw sizes within the limited test sample. The minimum effective flaw size is represented by the weld backing thickness $(9.53$ $\mathrm{mm}$ ). The most frequent fracture initiating effective flaw size is seen to be between $10 \mathrm{~mm}$ to 13 $\mathrm{mm}(0.4$ in to $0.5 \mathrm{in})$.

\section{Fracture Analysis}

The fracture toughness tests of weld metal removed from the connection samples, other damaged building connections (Tide et al. 1996) and weld metal deposited in laboratory tests (Kaufmann et al. 1996; Xue et al. 1996) have consistently shown that the E70T-4 weld metal, extensively used in WSMF connections prior to the Northridge earthquake, provides a low level of fracture toughness. This is consistent with the preceding fractographic observations that indicate that brittle fracture of all samples examined developed by crack instability from a crack-like flaw located within this low toughness weld metal. In this section, the static and dynamic fracture toughness of the E7OT-4 weld metal are estimated and results of a fracture analysis are reported.

\subsection{Weld Metal Fracture Toughness}

Figure 61 shows a plot of the fracture toughness of E70T-4 weld metal compiled from the Charpy V-notch test data acquired from tests of weld metal removed from the connection samples, other building connections, and specimens from laboratory weldments. The plot shows the dynamic fracture toughness, $\mathrm{K}_{\mathrm{D}}$, of the weld metal obtained by applying the following correlation (Barsom and Rolfe 1987)

$$
\begin{array}{ll}
\mathrm{K}_{\mathrm{ID}}=\sqrt{0.64 \mathrm{E}(\mathrm{CVN})} & (\mathrm{MPa} \sqrt{\mathrm{m}}, \mathrm{MPa}, J) \\
\mathrm{K}_{\mathrm{ID}}=\sqrt{5 \mathrm{E}(\mathrm{CVN})} & (\mathrm{ksi} \sqrt{\mathrm{in}}, \mathrm{ksi}, \mathrm{ft}-\mathrm{lb})
\end{array}
$$

to the existing Charpy V-Notch data for E70T-4 weld metal (CVN is the measured Charpy VNotch energy and $E$ is the modulus of elasticity). The test data shows that the dynamic fracture toughness, $K_{\mathrm{D}}$, of the weld metal is in the range of $27 \mathrm{MPa} \sqrt{\mathrm{m}}$ to $44 \mathrm{MPa} \sqrt{\mathrm{m}}(25 \mathrm{ksi} \sqrt{\text { in }}$ to 40 $\mathrm{ksi} \sqrt{\mathrm{in}})$ at room temperature and reaches an upper shelf toughness of $60 \mathrm{MPa} \sqrt{\mathrm{m}}$ to $76 \mathrm{MPa} \sqrt{\mathrm{m}}$ $(55 \mathrm{ksi} \sqrt{\text { in }}$ to $70 \mathrm{ksi} \sqrt{\text { in }})$ at $100^{\circ} \mathrm{C}$. The band of data arises from the variability of toughness found in multipass welds and normal CVN test scatter. Experience has indicated that toughness estimated from CVN testing represents a lower bound of fracture toughness. Also plotted in 
Figure 61 are the results of $25 \mathrm{~mm}$ thick weld metal compact tension tests (ASTM E399 1990) of E7OT- 4 weld metal welded in the laboratory and tested statically and at intermediate loading rates ( $0.5 \mathrm{sec}$.) similar to those developed during earthquakes (Xue et al. 1996). The static fracture toughness of the weld metal at room temperature was found to be in the range of $65 \mathrm{MPa} \sqrt{\mathrm{m}}$ to $71 \mathrm{MPa} \sqrt{\mathrm{m}}(60 \mathrm{ksi} \sqrt{\text { in }}$ to $65 \mathrm{ksi} \sqrt{\text { in }})$ and was reduced to $60 \mathrm{MPa} \sqrt{\mathrm{m}}$ to $65 \mathrm{MPa} \sqrt{\mathrm{m}}(55 \mathrm{ksi} \sqrt{\text { in }}$ to $60 \mathrm{ksi} \sqrt{\mathrm{in}}$ ) at intermediate loading rates. The test results show that a reasonable estimate of the range of toughness that can be provided by E70T-4 weld metal at intermediate loading rates is 44 $\mathrm{MPa} \sqrt{\mathrm{m}}$ to $65 \mathrm{MPa} \sqrt{\mathrm{m}}(40 \mathrm{ksi} \sqrt{\text { in }}$ to $60 \mathrm{ksi} \sqrt{\text { in }})$ at room temperature and is not appreciably affected by changes in temperature.

Tensile properties of E70T-4 weld metal, determined from laboratory weldments (Xue et al. 1996) show a $0.2 \%$ offset yield point of about $448 \mathrm{MPa}(65 \mathrm{ksi})$. Hence, the strain rate shift between the estimated dynamic toughness, $\mathrm{K}_{\mathrm{ID}}$, and the static fracture toughness, $\mathrm{K}_{\mathrm{I}}$, is (Fisher et al. 1995; Barsom and Rolfe 1987)

$$
\begin{array}{ll}
\mathrm{T}_{\mathrm{s}}=215-1.5 \sigma_{\mathrm{y}} \approx 120{ }^{\circ} \mathrm{F} & \left({ }^{\circ} \mathrm{F}, \mathrm{ksi}\right) \\
\mathrm{T}_{\mathrm{s}}=101-0.12 \sigma_{\mathrm{y}} \approx 47^{\circ} \mathrm{C} & \left({ }^{\circ} \mathrm{C}, \mathrm{MPa}\right)
\end{array}
$$

An examination of the static $\mathrm{K}_{\mathrm{c}}$ tests plotted in Figure 61 shows reasonable agreement between the dynamic toughness band and the static $\mathrm{K}_{\mathrm{C}}$ tests.

The intermediate strain rate tests provide a strain rate shift of about $27^{\circ} \mathrm{C}$ or about $2 / 3$ of the full static to dynamic shift. These results are consistent with the level of shift assumed to occur in structural steel systems.

\subsection{Fracture Model}

The fracture instability that developed from the weld root defect in each of the fracture samples examined can be modeled as a simple edge crack, as shown schematically in Figure 62 . The stress intensity, K, at the crack tip can be expressed as (Barsom and Rolfe1987; Fisher et al. 1995)

$$
\mathrm{K}=1.12 \sigma \sqrt{\pi \mathrm{a}_{\mathrm{eff}}}
$$

where the effective crack depth, $a_{\text {eff }}$, is represented by the sum of the weld backing thickness and the actual depth of the weld root flaw and $\sigma$ is the applied stress. A simple edge crack condition is insured since the length of the backing bar lack of fusion is of the order of the beam flange width and large in comparison to the depth of the notch it introduces. Figure 63 shows a plot of applied stress, $\sigma$, as a function of flaw size using Eq.(3) and the expected range of fracture toughness for E70T-4 weld metal (i.e., $K_{c}=44 \mathrm{MPa} \sqrt{\mathrm{m}}$ to $65 \mathrm{MPa} \sqrt{\mathrm{m}}(40 \mathrm{ksi} \sqrt{\text { in }}$ to 60 $\mathrm{ksi} \sqrt{\mathrm{in}})$ ). The plot shows the conditions of applied stress and flaw size under which crack instability will develop. For example, for flaw sizes on the order of backing bar thickness $(9.5$ $\mathrm{mm}, 0.375 \mathrm{in}$ ) crack instability can occur at applied stresses of $241 \mathrm{MPa}$ to $345 \mathrm{MPa}$ (35 ksi to 
which is in the range of the yield strength of A36 material. The critical stress is further reduced by the presence of weld root flaws. The analysis indicates that the cleavage fracture crack initiation which was observed in every welded connection sample would occur without significant yielding in the beam flange and in cases where a large weld root defect existed could occur under elastic stresses.

Progression of the dynamic expanding crack will be influenced by the principal stresses and variations in material toughness. The combination of tensile stresses in the beam flange and bending stresses in the column flange result in principal stresses that can direct the crack in a variety of directions. This may lead to the development of fractures which extend across the column flange, divot type fractures, or fractures which simply extend along the fusion line of the weld.

The critical applied stress is also influenced by other factors that will increase or decrease the fracture stress. All of the fractures have tended to initiate at the mid-width of the beam flange. This is due in part to the higher probability of weld root defects at this location and also because of the higher stresses at this location; the stress distribution across the beam flange is not uniform with higher stresses at the web-flange junction. Also, variations in weld procedure can introduce either tensile or compressive residual stress at the weld root which will tend to decrease or increase the applied stress at fracture.

\section{Estimate of Stresses at Connections}

The stress levels at each of the sample locations during the Northridge Earthquake were estimated to compare to the critical applied stresses calculated in the fracture analysis. While the estimates do not include weld residual stress or stress distribution effects, they provide an indication of the magnitude of the applied stress at each connection during the earthquake. A summary of the method and results are provided in the following sections.

\subsection{Ground Motion Estimation}

There were no actual ground motion records from the Northridge Earthquake at or near any of the buildings selected in this study. Therefore, the ground motion at each site during the Northridge Earthquake was simulated by two analytically derived spectra.

A common method of arriving at estimates of site-specific ground motion involves the application of attenuation relations. These relations are based on extensive regression analyses of a comprehensive database of earthquake records. More recent attenuation relations provide spectral as well as peak ground motion estimates at a given site. 
The attenuation relationship utilized in this study, developed by Boore, Joyner and Fumal (1993), is based on a set of carefully selected accelerograms with well-known site characteristics. The attenuation functional is of the form:

$$
\log Y=b_{1}+b_{2}(M-6)+b_{3}(M-6)^{2}+b_{4} r+b_{5} \log r+b_{6} G_{B}+b_{7} G_{c} \pm \sigma_{\log Y}
$$

where,

$$
r=\sqrt{d^{2}+h^{2}}
$$

In this equation, $\mathrm{Y}$ is the ground motion parameter (in $\mathrm{cm} / \mathrm{s}$ for response spectra and $\mathrm{g}$ for peak acceleration); the predictor variables are magnitude $(M)$, distance and depth ( $\mathrm{d}$ and $\mathrm{h}$, in $\mathrm{km}$ ), and site classification $\left(G_{B}=1\right.$ for class $B$ and zero otherwise; $G_{C}=1$ for class $C$ and zero otherwise); $\sigma_{\log Y}$ represents the variance of the estimation. Coefficients $b_{1}$ to $b_{7}$ are functions of period of vibration. Site classes are defined in terms of average shear wave velocity in the upper 30 meters of soil and range from less than $180 \mathrm{~m} / \mathrm{s}$ for site class D to greater than $750 \mathrm{~m} / \mathrm{s}$ for class A. Plots and tables of the resulting spectra for the buildings studied are presented in Figure 64-67.

\subsection{Structural Modeling Procedure}

Linear-elastic models of the buildings were constructed using the structural analysis and design program ETABS 6.0 (Habibullah 1994). All floor diaphragms were assumed to be rigid and a rigid panel zone equal to $50 \%$ of the beam and column section depths was assumed. For the purpose of calculating masses, centers of gravity, and mass moments of inertia, the total story weight was assumed to be uniformly distributed over the floor. Typical floor weights, assumed to be equal to the total dead load, were in the range of eighty to ninety pounds per square foot of plan area. The buildings were fixed against translation and rotation at the top of shear walls where they exist and the frame columns were continued to their lowest level and pinned at the base. The spectra were input one direction at a time, oriented in the direction of the frames. The modal responses were combined using the complete quadratic combination (CQC) technique (Naeim et al. 1995) with $5 \%$ of critical damping.

For each building the first three building periods, total base shear, base shear as a percentage of weight and stresses in the beams at the location of each sample are presented. The beam bending stresses were determined at the column faces for dead plus live load, the mean spectrum, and the mean plus one standard deviation (mean $+1 \sigma$ ) spectum. Full dead load plus a best estimate of actual live load was used. In all cases the dead plus live load stresses are insignificant when compared to the magnitude of the seismic stresses and the uncertainty in their estimate. 


\subsection{Analytical Results}

\section{Building A}

The analytically determined building periods are presented in Table 7. For Building $A$ the first periods in the transverse, longitudinal and torsional directions are 1.4, 1.28 and 0.93 seconds.

Comparison with the spectra for this site, shown in Figure 64, indicates that the peak ground accelerations are $0.27 \mathrm{~g}$ for the mean spectrum and $0.43 \mathrm{~g}$ for the mean $+1 \sigma$ spectrum. The base shears for the mean spectrum, shown in Table 8, are 15,692 kN (3528 kips) in the longitudinal and $14,051 \mathrm{kN}$ (3159 kips) in the transverse directions. These correspond to $20.9 \%$ and $18.8 \%$ of the total weight of the building $(\% \mathrm{~g})$. The base shears for the mean $+1 \sigma$ spectrum are 28,267 $\mathrm{kN}(6355 \mathrm{kips})(37.7 \% \mathrm{~g})$ and $25,870 \mathrm{kN}$ (5816 kips) $(34.5 \% \mathrm{~g})$ in the longitudinal and transverse directions respectively.

The bending stresses in the beams are presented in Table $9^{1}$. It can be seen that the Dead plus Live load stresses are all approximately $7 \mathrm{MPa}$ to $14 \mathrm{MPa}(1 \mathrm{ksi}$ to $2 \mathrm{ksi})$. For the mean spectrum, stresses in the sampled joints range from $210 \mathrm{MPa}(30.4 \mathrm{ksi})$ at A254 to $292 \mathrm{MPa}$ (42.3 ksi) at A287. For the mean $+1 \sigma$ spectrum stresses vary from $381 \mathrm{MPa}(55.3 \mathrm{ksi})$ at A254 to 541 MPa (78.5 ksi) at A287. Demand/capacity ratios, defined as calculated stress divided by measured yield stress may be found in Table 9 for all five buildings.

\section{Building B}

For Building B the first periods in the transverse, longitudinal and torsional directions are $1.5 \mathrm{~s}$, $1.49 \mathrm{~s}$ and $0.88 \mathrm{~s}$, respectively. The spectra for this site are shown in Figure 65. The peak ground accelerations are $0.23 \mathrm{~g}$ for the mean spectrum and $0.36 \mathrm{~g}$ for the mean $+1 \sigma$ spectrum. The base shears for the mean spectrum are $2,713 \mathrm{kN}$ (610 kips) in the longitudinal and 2,700 kN (607 kips) in the transverse directions. These correspond to $15.4 \%$ and $15.3 \%$ of the total weight of the building. The base shears for the mean +10 spectrum are $5,035 \mathrm{kN}(1132 \mathrm{kips})(28.6 \% \mathrm{~g})$ and $5,022 \mathrm{kN}$ (1129 kips) (28.5\%g) in the longitudinal and transverse directions, respectively.

The bending stresses in the beams are shown in Table 9. Dead plus live load stresses are all less than $7 \mathrm{MPa}$ (1 ksi) except at B13 where it is $23 \mathrm{MPa}$ (3.4 ksi). For the mean spectrum, stresses in the sampled joints range from $221 \mathrm{MPa}(32.1 \mathrm{ksi})$ at $\mathrm{B} 13$ to $242 \mathrm{MPa}(35.1 \mathrm{ksi})$ at $\mathrm{B} 60$. For the mean $+1 \sigma$ spectrum they vary from $378 \mathrm{MPa}(54.8 \mathrm{ksi})$ at $\mathrm{B} 8$ to $416 \mathrm{MPa}(60.4 \mathrm{ksi})$ at B13.

${ }^{1}$ Locations of the samples may be found on the elevation drawings where they are indicated by their designation (e.g., A287) within a circle. They may also be located on the plans where all of the joints are numbered. Beam sizes may also be found on the elevations. 


\section{Building $\mathbf{C}$}

For Building $\mathrm{C}$ the first periods in the transverse, longitudinal and torsional directions are 1.58 $\mathrm{s}, 1.42 \mathrm{~s}$ and $1.15 \mathrm{~s}$, respectively. The spectra for this site, which are the same as those used for Building F, are presented in Figure 66. The peak ground accelerations are $0.38 \mathrm{~g}$ for the mean spectrum and $0.64 \mathrm{~g}$ for the mean $+1 \sigma$ spectrum. The base shears for the mean spectrum are $4,955 \mathrm{kN}$ (1114 kips) in the longitudinal and 4,288 kN (964 kips) in the transverse directions. These correspond to $29.1 \%$ and $25.2 \%$ of the total weight of the building. The base shears for the mean $+1 \sigma$ spectrum are 9,514 kN (2139 kips) (55.9\%g) and 8,100 kN (1821 kips) (47.6\% g) in the longitudinal and transverse directions respectively.

The bending stresses in the beams are presented in Table 9. Dead plus live load stresses are all less than $14 \mathrm{MPa}(2 \mathrm{ksi})$. For the mean spectrum stresses in the sampled joints range from 248 $\mathrm{MPa}(35.9 \mathrm{ksi})$ at $\mathrm{C} 13$ to $358 \mathrm{MPa}(51.9 \mathrm{ksi})$ at $\mathrm{C} 19$. For the mean $+1 \sigma$ spectrum they vary from $505 \mathrm{MPa}(73.3 \mathrm{ksi})$ at $\mathrm{C} 1$ to $689 \mathrm{MPa}(100 \mathrm{ksi})$ at $\mathrm{C} 19$. These beams are all at the first floor above the ground. The columns to which they are attached do not continue into the basement and are modeled as pinned at the base. The detail at the base plate is one that would normally be modeled as pinned for design purposes but undoubtedly provides some fixity. To the extent this happens the beam stresses would be partially mitigated and the actual stresses may have been somewhat lower than the calculated stresses.

\section{Building $\mathbf{E}$}

For Building $\mathrm{E}$ the first three periods are $1.65 \mathrm{~s}, 1.56 \mathrm{~s}$ and $1.00 \mathrm{~s}$. The first two mode shapes are not aligned with the building axes and hence these two periods represent modes coupled in the transverse and longitudinal directions. The third mode is torsion. The spectra for this site is shown in Figure 67 . The peak ground accelerations are $0.17 \mathrm{~g}$ for the mean spectrum and 0.28 $\mathrm{g}$ for the mean +10 spectrum. The base shears for the mean spectrum are $12,388 \mathrm{kN}$ (2785 kips) in the longitudinal and 13,944 $\mathrm{kN}$ (3135 kips) in the transverse directions. These correspond to $7.9 \%$ and $8.8 \%$ of the total weight of the building. The base shears for the mean $+1 \sigma$ spectrum are $23,152 \mathrm{kN}$ (5205 kips) (14.8\% $)$ and $26,563 \mathrm{kN}$ (5972 kips) (16.8\%g) in the longitudinal and transverse directions respectively.

The bending stresses in the beams are shown in Table 9. Dead plus live load stresses are all less than $14 \mathrm{MPa}(2 \mathrm{ksi})$. For the mean spectrum, stresses in the sampled joints range from $65 \mathrm{MPa}$ (9.4 ksi) at E226 to $130 \mathrm{MPa}(18.8 \mathrm{ksi})$ at E150. For the mean $+1 \sigma$ spectrum, they vary from $125 \mathrm{MPa}(18.1 \mathrm{ksi})$ at E226 to $248 \mathrm{MPa}(36 \mathrm{ksi})$ at E150. These stresses are low relative to the other buildings in the study. Similar results were also found in a study (Naeim et al. 1995).

\section{Building F}

For Building $\mathrm{F}$ the first three periods are $1.51 \mathrm{~s}, 1.54 \mathrm{~s}$ and $0.90 \mathrm{~s}$. These correspond to modes in the transverse and longitudinal directions and torsion respectively. The spectra for this site, 
which are the same as those used for building $C$, are shown in Figure 66. The peak ground accelerations are $0.38 \mathrm{~g}$ for the mean spectrum and $0.64 \mathrm{~g}$ for the mean $+1 \sigma$ spectrum. The base shears for the mean spectrum are 6,441 kN (1448 kips) in the longitudinal and 6,570 kN (1477 kips) in the transverse directions. These correspond to $26.8 \%$ and $27.4 \%$ of the total weight of the building. The base shears for the mean $+1 \sigma$ spectrum are $12,352 \mathrm{kN}$ (2777 kips) $(51.5 \% \mathrm{~g})$ and $12,668 \mathrm{kN}$ (2848 kips) $(52.8 \% \mathrm{~g})$ in the longitudinal and transverse directions respectively.

The bending stresses are presented in Table 9. There was a single sample taken from this building (F38). The dead plus live load stress is $3 \mathrm{MPa}(0.3 \mathrm{ksi})$. For the mean spectrum the stress is 149 $\mathrm{MPa}(21.6 \mathrm{ksi})$ and for the mean $+1 \sigma$ spectrum it is $296 \mathrm{MPa}(43 \mathrm{ksi})$.

\section{Summary and Conclusions}

Results of tests conducted to characterize the mechanical properties and composition of the weld and base metals of samples removed from damaged buildings, a fracture analysis of the weld metal, and results of response spectra analyses providing estimates of critical applied stresses, lead to the following observations and conclusions:

1. Fractographic examination of sixteen WSMF connection fractures from five buildings have shown that the fractures in all cases resulted from crack instability which developed at the weld root of the beam flange-to-column flange groove weld. Cleavage fracture was found to initiate from an incomplete fusion flaw contiguous with the notch introduced by the weld backing in most cases, however, several fractures initiated directly from the notch introduced by the unfused weld backing. The fracture origin location was invariably near the mid-length of the weld near the centerline of the beam web.

2. The weld metal in eight samples tested was found to have very poor fracture toughness (7 $\mathrm{J}$ to $14 \mathrm{~J} @ 20^{\circ} \mathrm{C}$ ). Based upon the CVN impact toughness the static fracture toughness was estimated to be in the range of $44 \mathrm{MPa} \sqrt{\mathrm{m}}$ to $65 \mathrm{MPa} \sqrt{\mathrm{m}}(40 \mathrm{ksi} \sqrt{\text { in }}$ to $60 \mathrm{ksi} \sqrt{\mathrm{in}}$ ). The measured toughness properties and chemical composition indicated that the weld joints in all sixteen samples were welded with an E70T-4 electrode.

3. The mechanical and physical properties of the beam and column material in all samples were in accordance with either ASTM A36 or A572 Gr. 50 steels. With the exception of one building, the fracture toughness of the column material was found to be well in excess of the AISC requirement of $27 \mathrm{~J} @ 20^{\circ} \mathrm{C}$ in the core region. No correlation between member size or base material properties and occurrence or type of fracture which developed in the connection was found.

4. A fracture analysis of the defect condition based upon measured material properties and observed flaw sizes indicated that the cleavage fracture crack initiation that was observed in every welded connection sample would occur without significant yielding in the beam 
flange and in some cases would occur under elastic stresses. Uncertainties in stress conditions in the vicinity of the flaw tip (applied and residual) and the magnitude of the strain rate effect prevent further refinement of the applied loads which resulted in fracture of the connections.

5. Estimates of beam flange stress levels during the earthquake at the sample connections were obtained using an analytically derived ground motion spectra for the building. With the exception of one building (Bldg. E) the analyses indicated a range of stress at connections which were of yield point magnitude and which exceeded the predicted range of fracture stress for the defect condition existing at the connection. Estimates of stresses at several sample connections in Building $E$ were significantly lower in comparison to other buildings and well below yield levels. The range of predicted fracture stress at these connections were marginally higher than the calculated estimates.

\section{Acknowledgements}

This study was supported by a grant to Lehigh University from the National Institute of Standards and Technology (Contract No. 5C8636). The authors gratefully acknowledge John A. Martin Jr. of John A. Martin \& Associates, Inc. and his staff for assistance in acquiring fracture samples for this study and for providing building documentation. The assistance of Prof. Behzad Bavarian of California State University at Northridge is also acknowledged for his efforts in material property evaluation.

\section{References}

ASTM A36/A36M-96 Carbon Structural Steel (1996). American Society for Testing and Materials, West Conshohocken, $\mathrm{Pa}$.

ASTM A370-96 Mechanical Testing of Steel Products (1996). American Society for Testing and Materials, West Conshohocken, Pa.

ASTM A572/A572M-94 High-Strength Low-Alloy Columbium-Vanadium Structural Steel (1994). American Society for Testing and Materials, West Conshohocken, Pa.

ASTM A673/A673M-95 Sampling Procedure for Impact Testing of Structural Steel (1995). American Society for Testing and Materials, West Conshohocken, Pa. 
ASTM E23-96 Notched Bar Impact Testing of Metallic Materials (1996). American Society for Testing and Materials, West Conshohocken, $\mathrm{Pa}$.

ASTM E399-90 Plane-Strain Fracture Toughness of Metallic Materials (1990). American Society for Testing and Materials, West Conshohocken, $\mathrm{Pa}$.

AWS D1.1-94 Structural Welding Code - Steel (1994). American Welding Society, Inc., Miami, Fl.

Barsom, J.M., and Rolfe, S.T. (1987). Fracture and Fatigue Control in Structures: Applications of Fracture Mechanics, Second Edition, Prentice-Hall, Inc., Englewood Cliffs, N.J.

Bonowitz, D., Youssef, N. (1995). "SAC Survey of Steel Moment-Resisting Frame Buildings Affected by the 1994 Northridge Earthquake," Technical Report: Surveys and Assessment of Damage to Buildings Affected by the Northridge Earthquake of January 17, 1994, SAC-95-06, SAC Joint Venture, Sacramento, $\mathrm{Ca}$.

Boore, D.M., Joyner, W.B., and Fumal, T.E. (1993). Estimation of Response Spectra and Peak Accelerations From Western North American Earthquakes: An Interim Report, U.S. Geological Survey Open-File Report 93-509.

Campbell, H.H. (1995). "The Northridge Fractures: Are We Learning the Right Lessons?," Civil Engineering, March 1995.

Fisher, J.W., Dexter, R.D., and Kaufmann, E.J. (1995). Fracture Mechanics of Welded Structural Steel Connections, SAC Joint Venture, Sacramento, Ca.

Habibullah, A. (1994). ETABS Three Dimensional Analysis of Building Systems; User's Manual, Version 6.0, Computers and Structures, Inc., Berkeley, Ca.

Kaufmann, E.J., Xue, M., Lu, L-W, and Fisher, J.W. (1996). “Achieving Ductile Behavior of Moment Connections," Modern Steel Construction, January 1996, AISC, Chicago, Il.

Manual of Steel Construction - Allowable Stress Design, Ninth Edition (1989). American Institute of Steel Construction, Chicago, Il.

Miller, D.K. (1994). "Northridge: The Role of Welding Clarified," Welding Innovation Quarterly, Vol. XI, No.2.

Naeim, F., Di Julio, Jr., R., Benuska, K., Reinhorn, A.M., and Li, C. (1995). "Evaluation of Seismic Performance of an 11-Story Steel Moment Frame Building During the 1994 Northridge Earthquake", Technical Report: Analytical and Field Investigations of Buildings Affected by the Northridge Earthquake of January 17, 1994, SAC 95-04, Part 2, SAC Joint Venture, Sacramento, Ca. 
Tide, R.H.R., Fisher, J.W., and Kaufmann, E.J. (1996). "Substandard Welding Quality Exposed: Northridge, California Earthquake, January 17, 1994," Asian Pacific Welding Congress, Auckland, New Zealand, February, 1996.

Xue, M., Kaufmann, E.J., Fisher, J.W., and Lu, L-W. (1996). Cracking, Repair, and Ductility Enhancement of Large Size Steel Beam-to-Column Connections Subjected to Dynamic Cyclic Loading, ATLSS Report No. 96-??, Lehigh University, Bethlehem, Pa.

Youssef, N.F.G., Bonowitz, D., and Gross, J.L. (1995). A Survey of Steel Moment-Resisting Frame Buildings Affected by the 1994 Northridge Earthquake, NISTR 5625, National Institute of Standards and Technology, Gaithersburg, Md. 


\section{TABLE 1 - BUILDING SAMPLES AND DAMAGE TYPES}

\begin{tabular}{|c|c|c|c|c|c|}
\hline Bldg. & $\begin{array}{c}\text { Sample } \\
\text { No. }\end{array}$ & Member & $\begin{array}{c}\text { Member } \\
\text { Size }\end{array}$ & $\begin{array}{c}\text { Damage } \\
\text { Type }\end{array}$ & $\begin{array}{c}\text { Sample } \\
\text { Removed }\end{array}$ \\
\hline \multirow{10}{*}{$\mathbf{A}$} & \multirow[t]{2}{*}{ A6 } & BEAM & - & \multirow[t]{2}{*}{ C3 (Bottom Flange) } & \multirow{2}{*}{$\begin{array}{l}\text { Column flange with } \\
\text { fracture ( } 2 \text { pcs.) }\end{array}$} \\
\hline & & COLUMN & W $14 \times 193$ & & \\
\hline & \multirow[t]{2}{*}{$\mathbf{A 3 3}$} & BEAM & W $27 \times 94$ & \multirow[t]{2}{*}{ C3 (Bottom Flange) } & \multirow{2}{*}{$\begin{array}{l}\text { Beam and column flange } \\
\text { with fracture ( } 1 \mathrm{pc} \text {.) }\end{array}$} \\
\hline & & COLUMN & w $14 \times 193$ & & \\
\hline & \multirow[t]{2}{*}{ Al65 } & BEAM & W $30 \times 99$ & \multirow[t]{2}{*}{ C3 (Bottom Flange) } & \multirow{2}{*}{$\begin{array}{l}\text { Beam and column flange } \\
\text { with fracture (4 pcs.) }\end{array}$} \\
\hline & & COLUMN & W $14 \times 193$ & & \\
\hline & \multirow[t]{2}{*}{ A254 } & BEAM & $\mathrm{W} 27 \times 94$ & \multirow[t]{2}{*}{ C3 (Bottom Flange) } & \multirow{2}{*}{$\begin{array}{l}\text { Beam and column flange } \\
\text { with fracture ( } 3 \text { pcs.) }\end{array}$} \\
\hline & & COLUMN & W $14 \times 176$ & & \\
\hline & \multirow[t]{2}{*}{ A287 } & BEAM & W $24 \times 76$ & \multirow[t]{2}{*}{ C3 (Bottom Flange) } & \multirow{2}{*}{$\begin{array}{l}\text { Beam and column flange } \\
\text { with fracture }(1 \mathrm{pc} .)\end{array}$} \\
\hline & & COLUMN & W $14 \times 193$ & & \\
\hline \multirow{8}{*}{ B } & \multirow[t]{2}{*}{ B4 } & BEAM & W $30 \times 99$ & \multirow[t]{2}{*}{ W4 (Bottom Flange) } & \multirow[t]{2}{*}{ Beam flange with fracture } \\
\hline & & COLUMN & - & & \\
\hline & \multirow[t]{2}{*}{ B8 } & BEAM & W $30 \times 99$ & \multirow[t]{2}{*}{ W4 (Bottom Flange) } & \multirow[t]{2}{*}{ Beam flange with fracture } \\
\hline & & COLUMN & - & & \\
\hline & \multirow[t]{2}{*}{$\mathrm{B} 13$} & BEAM & W $27 \times 94$ & \multirow[t]{2}{*}{ C2 (Bottom Flange) } & \multirow{2}{*}{$\begin{array}{l}\text { Beam and column flange } \\
\text { with fracture ( } 4 \text { pcs.) }\end{array}$} \\
\hline & & COLUMN & W $14 \times 132$ & & \\
\hline & \multirow[t]{2}{*}{$\mathrm{B} 60$} & BEAM & W $30 \times 99$ & \multirow[t]{2}{*}{ C2 (Bottom Flange) } & \multirow{2}{*}{$\begin{array}{l}\text { Beam and column flange } \\
\text { with fracture ( } 2 \text { pcs.) }\end{array}$} \\
\hline & & COLUMN & $\mathrm{W} 14 \times 120$ & & \\
\hline \multirow{6}{*}{$\mathrm{C}$} & $\mathrm{Cl}$ & BEAM & $W 36 \times 210$ & C3 (Bottom Flange) & Beam and column flange \\
\hline & & COLUMN & $\mathrm{W} 14 \times 398$ & & with fracture (4 pcs.) \\
\hline & $\mathrm{C} 18$ & BEAM & $\mathrm{W} 36 \times 210$ & C3 (Bottom Flange) & Beam and column flange \\
\hline & & COLUMN & W14 $\times 398$ & & with fracture (4 pcs.) \\
\hline & $\mathrm{C} 19$ & BEAM & W36 $\times 210$ & C3 (Bottom Flange) & Column flange with \\
\hline & & COLUMN & $\mathrm{W} 14 \times 370$ & & fracture ( 2 pcs.) \\
\hline & E150 & BEAM & W $36 \times 170$ & C2 (Bottom Flange) & Beam and column flange \\
\hline & & COLUMN & W $14 \times 398$ & & with fracture ( 2 pcs.) \\
\hline $\mathrm{E}$ & E226 & BEAM & W $36 \times 170$ & C3 (Bottom Flange) & Beam and column flange \\
\hline & & COLUMN & W $14 \times 398$ & & with fracture ( 2 pcs.) \\
\hline & E549 & BEAM & W $36 \times 170$ & C2 (Bottom Flange) & Beam and column flange \\
\hline & & COLUMN & W $14 \times 283$ & & with fracture (l pc.) \\
\hline $\mathbf{F}$ & F38 & BEAM & - & C3 (Bottom Flange) & Column flange with \\
\hline & & COLUMN & W $14 \times 311$ & & fracture ( 2 pcs.) \\
\hline
\end{tabular}


TABLE 2 - BEAM AND COLUMN FLANGE MECHANICAL PROPERTIES

\begin{tabular}{|c|c|c|c|c|c|c|c|c|}
\hline \multirow{2}{*}{ Bldg. } & \multirow{2}{*}{$\begin{array}{c}\text { Sample } \\
\text { Na. }\end{array}$} & \multicolumn{3}{|c|}{ Beam } & \multicolumn{4}{|c|}{ Column } \\
\hline & & $\begin{array}{l}\text { Y.S. } \\
\text { MPa } \\
\text { (ksi) }\end{array}$ & $\begin{array}{l}\text { T.S. } \\
\text { MPa } \\
\text { (ksi) }\end{array}$ & $\begin{array}{c}\text { Elong. } \\
\%\end{array}$ & $\begin{array}{l}\text { Y.S. } \\
\text { MPa } \\
\text { (ksi) }\end{array}$ & $\begin{array}{l}\text { T.S. } \\
\text { MPa } \\
\text { (ksi) }\end{array}$ & $\begin{array}{c}\text { Elong. } \\
\%\end{array}$ & $\begin{array}{c}\text { CVN" }^{-*} \\
\text { J (ft-lbs) } \\
@ 20^{\circ} \mathrm{C}\end{array}$ \\
\hline A & $\begin{array}{c}6 \\
33 \\
165 \\
254 \\
287\end{array}$ & $\begin{array}{l}262(38) \\
290(42) \\
276(40) \\
276(40) \\
262(38)\end{array}$ & $\begin{array}{l}482(70) \\
482(70) \\
496(72) \\
490(71) \\
448(65)\end{array}$ & $\begin{array}{l}35 \\
35 \\
35 \\
33 \\
32\end{array}$ & $\begin{array}{l}338(49) \\
317(46) \\
338(49) \\
359(52) \\
290(42)\end{array}$ & $\begin{array}{l}503(73) \\
496(72) \\
510(74) \\
503(73) \\
490(71)\end{array}$ & $\begin{array}{l}28 \\
28 \\
30 \\
31 \\
30\end{array}$ & $\begin{array}{c}28(21) \\
84(62) \\
80(59) \\
123(91) \\
68(50)\end{array}$ \\
\hline B & $\begin{array}{c}4 \\
8 \\
13 \\
60\end{array}$ & $\begin{array}{l}290(42) \\
283(41) \\
269(39) \\
290(42)\end{array}$ & $\begin{array}{l}462(67) \\
462(67) \\
482(70) \\
455(66)\end{array}$ & $\begin{array}{l}36 \\
38 \\
35 \\
26\end{array}$ & $\begin{array}{c}\text { N/A } \\
\text { N/A } \\
262(38) \\
255(37)\end{array}$ & $\begin{array}{c}\text { N/A } \\
\text { N/A } \\
482(70) \\
448(65)\end{array}$ & $\begin{array}{c}\text { N/A } \\
\text { N/A } \\
35 \\
29\end{array}$ & $\begin{array}{c}\text { N/A } \\
\text { N/A } \\
161(119) \\
95(70)\end{array}$ \\
\hline C & $\begin{array}{c}1 \\
18 \\
19\end{array}$ & $\begin{array}{c}338(49) \\
345(50) \\
\text { N/A }\end{array}$ & $\begin{array}{c}482(70) \\
482(70) \\
\text { N/A }\end{array}$ & $\begin{array}{r}35 \\
36 \\
\text { N/A }\end{array}$ & $\begin{array}{l}262(38) \\
255(37) \\
248(36)\end{array}$ & $\begin{array}{l}455(66) \\
448(65) \\
455(66)\end{array}$ & $\begin{array}{l}38 \\
36 \\
38\end{array}$ & $\begin{array}{l}102(75) \\
94(69) \\
95(70)\end{array}$ \\
\hline $\mathrm{E}$ & $\begin{array}{l}150 \\
226 \\
549\end{array}$ & $\begin{array}{l}303(44) \\
283(41) \\
324(47)\end{array}$ & $\begin{array}{l}469(68) \\
441(64) \\
455(66)\end{array}$ & $\begin{array}{l}32 \\
34 \\
31\end{array}$ & $\begin{array}{l}345(50) \\
276(40) \\
352(51)\end{array}$ & $\begin{array}{l}490(71) \\
482(70) \\
531(77)\end{array}$ & $\begin{array}{l}29 \\
31 \\
25\end{array}$ & $\begin{array}{l}22(16) \\
22(16) \\
14(10)\end{array}$ \\
\hline$F$ & 38 & N/A & N/A & N/A & $393(57)$ & $579(84)$ & 32 & $75(55)$ \\
\hline
\end{tabular}

$* \mathrm{~N} / \mathrm{A}=$ Not Available

** Test specimens located at column core region 
TABLE 3 - COLUMN FLANGE CHARPY V-NOTCH TEST RESULTS

\begin{tabular}{|c|c|c|c|}
\hline Bldg. & Sample No. & $\begin{array}{l}\text { Temperature } \\
\text { C }\end{array}$ & $\begin{array}{c}\text { CVN Absorbed Energy } \\
\mathrm{J} \text {, (ft-lbs) }\end{array}$ \\
\hline \multirow{5}{*}{ A } & A6 & $\begin{array}{c}-70 \\
-41 \\
0 \\
25 \\
100\end{array}$ & $\begin{array}{l}3,2,2 \quad(2,1.5,1.5) \\
5,7,5 \quad(3.5,5.5,4) \\
24,14,53 \quad(18,10,39) \\
30,26,31 \quad(22,19,23) \\
103,117,144(76,86,106)\end{array}$ \\
\hline & A33 & $\begin{array}{c}-70 \\
-27 \\
0 \\
25 \\
100\end{array}$ & $\begin{array}{l}5,3,5(4,2,4) \\
8,11,11(6,8,8) \\
96,24,76(71,18,56) \\
153,49,52(113,36,38) \\
153,159,161(113,117,119)\end{array}$ \\
\hline & A165 & $\begin{array}{c}-70 \\
-41 \\
0 \\
25 \\
100\end{array}$ & $\begin{array}{l}3,2,3(2,1.5,2) \\
4,11,4(3,8,3) \\
39,15,25(29,11,18.5) \\
34,163,43(25,120,32) \\
160,140,152(118,103,112)\end{array}$ \\
\hline & A254 & $\begin{array}{c}-70 \\
-41 \\
0 \\
25 \\
25 \\
100\end{array}$ & $\begin{array}{l}3,2,(2,1.5) \\
4,4(3,3) \\
52,35(38,26) \\
69,159,142(51,117,105) \\
161,127(119,94) \\
161,142(119,105)\end{array}$ \\
\hline & A287 & $\begin{array}{c}-72 \\
-44 \\
3 \\
25 \\
100\end{array}$ & $\begin{array}{l}4,4,5(3,3,2.5) \\
7,5,7(5,4,5) \\
20,162,25(14.5,119.5,5) \\
35,98,69(26,72,51) \\
150,145,161 \quad(110.5,107,119)\end{array}$ \\
\hline \multirow{2}{*}{ B } & B13 & $\begin{array}{c}-70 \\
-41 \\
0 \\
25 \\
100\end{array}$ & $\begin{array}{l}3,3,3 \quad(2.5,2,2) \\
5,9,4 \quad(4,7,3) \\
132,161,75 \quad(97,119,55) \\
161,161,161 \quad(119,119,119) \\
163,162,163(120,119.5,120)\end{array}$ \\
\hline & B60 & $\begin{array}{c}-70 \\
-41 \\
0 \\
25 \\
100\end{array}$ & $\begin{array}{l}3,3,3(2,2.5,2) \\
7,7,19 \quad(5,5,14) \\
15,14,11 \quad(11,10,8) \\
111,102,72(82,75,53) \\
153,163,160(113,120,118)\end{array}$ \\
\hline
\end{tabular}


TABLE 3 (CONT'D) - COLUMN FLANGE CHARPY V-NOTCH TEST RESULTS

\begin{tabular}{|c|c|c|c|}
\hline Bldg. & Sample No. & $\begin{array}{c}\text { Temperature } \\
\text { C }\end{array}$ & $\begin{array}{c}\text { CVN Absorbed Energy } \\
\text { J, (ft-lbs) }\end{array}$ \\
\hline \multirow{3}{*}{ C } & $\mathrm{Cl}$ & $\begin{array}{c}-70 \\
-28 \\
0 \\
20 \\
100\end{array}$ & $\begin{array}{l}1,1,2(1,1,1.5) \\
14,20,16(10,15,12) \\
35,46,11 \quad(26,34,8) \\
89,115,99(66,85,73) \\
160,159,145(118,117,107)\end{array}$ \\
\hline & $\mathrm{C} 18$ & $\begin{array}{c}-70 \\
-20 \\
0 \\
20 \\
100\end{array}$ & $\begin{array}{l}1,1,1 \quad(1,1,1) \\
14,24,16 \quad(10,18,12) \\
85,41,41 \quad(63,30,30) \\
119,46,114 \quad(88,34,84) \\
149,161,161 \quad(110,119,119)\end{array}$ \\
\hline & C19 & $\begin{array}{c}-70 \\
-20 \\
0 \\
20 \\
100\end{array}$ & $\begin{array}{l}3,3,3(2,2,2) \\
22,11,12(16,8,9) \\
27,39,69(20,29,51) \\
95,95,94 \quad(70,70,69) \\
161,15,161 \quad(119,11,119)\end{array}$ \\
\hline \multirow{3}{*}{ E } & E150 & $\begin{array}{c}-72 \\
-42 \\
0 \\
25 \\
100\end{array}$ & $\begin{array}{l}3,3,3(2,2,2) \\
4,3,3(3,2,2.5) \\
12,20,9(8.5,14.5,6.5) \\
22,22,23(16,16,17) \\
149,163,108(110,120,80)\end{array}$ \\
\hline & E226 & $\begin{array}{c}-40 \\
0 \\
25 \\
100\end{array}$ & $\begin{array}{l}5,4,4,5 \quad(3.5,3,3,3.5) \\
26,9,12,27 \quad(19.5,7,9,20) \\
31,19,14,20 \quad(23,14,10,15) \\
126,77,96,96 \quad(93,57,71,70.5)\end{array}$ \\
\hline & E549 & $\begin{array}{c}-73 \\
-52 \\
5 \\
25 \\
100\end{array}$ & $\begin{array}{l}3,3,3(2,2,2) \\
3,3,4(2.5,2.5,3) \\
5,5,6(4,4,4.5) \\
16,14,10(12,10,7.5) \\
94,106,83(69,78.5,61)\end{array}$ \\
\hline F & F38 & $\begin{array}{c}-71 \\
-22 \\
0 \\
25 \\
100\end{array}$ & $\begin{array}{l}3,4,4 \quad(2.5,3,3) \\
3,4,6(2.5,3,4.5) \\
7,22,10(5,16,7.5) \\
117,92,15(86,68,11) \\
160,161,161 \quad(118,119,119)\end{array}$ \\
\hline
\end{tabular}


TABLE 4 - CHEMICAL COMPOSITION OF MEMBERS AND WELD METAL (WT\%)

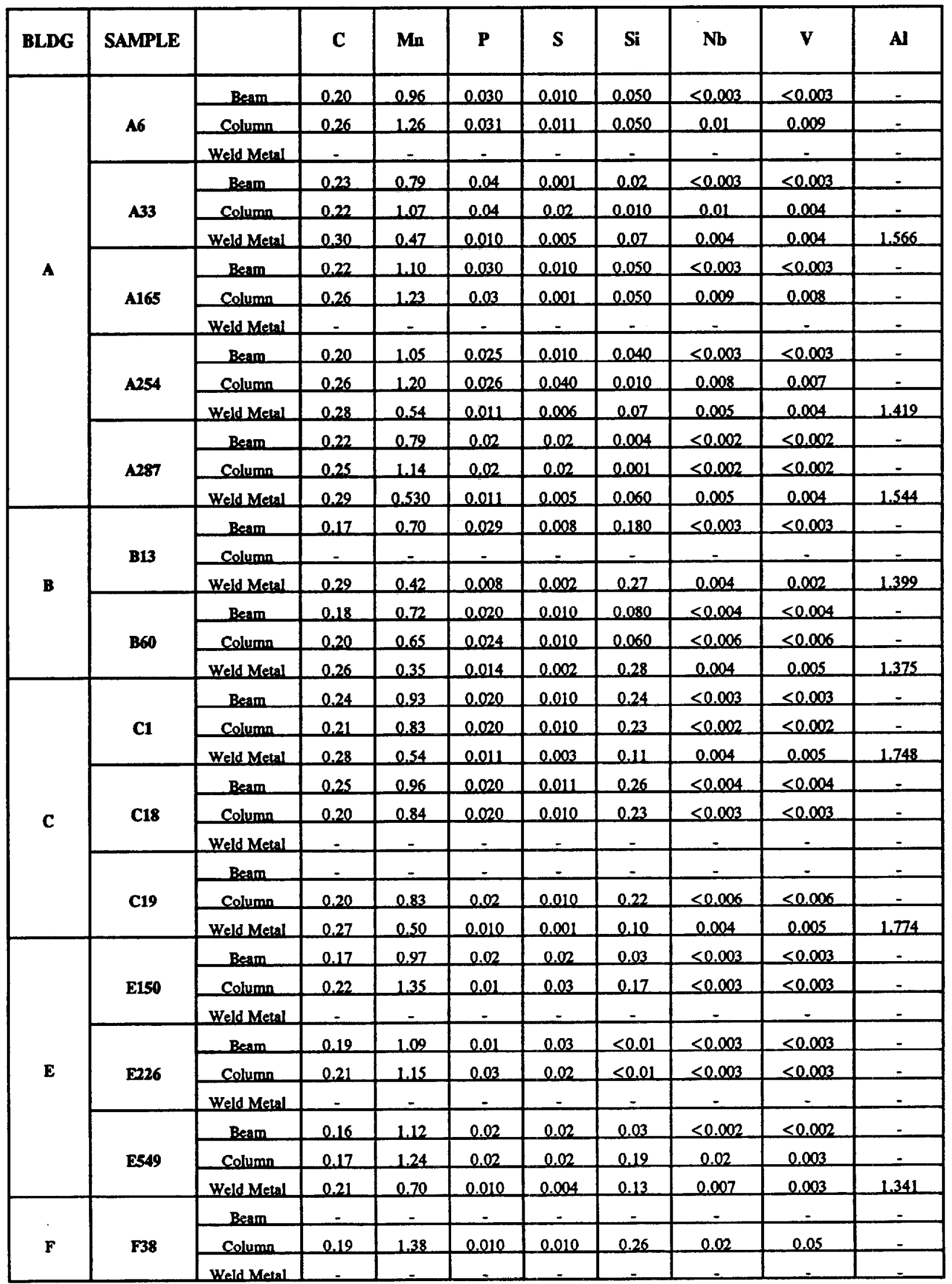


TABLE 5 - WELD METAL CHARPY V-NOTCH TEST RESULTS

\begin{tabular}{|l|c|l|}
\hline Sample No. & $\begin{array}{c}\text { Temperature } \\
\text { C }\end{array}$ & \multicolumn{1}{|c|}{\begin{tabular}{c}
\multicolumn{1}{|c|}{ CVN Absorbed Energy } \\
J, (ft-lbs)
\end{tabular}} \\
\hline A33 & 20 & $11(8)$ \\
\hline A254 & 20 & $16(12)$ \\
\hline A287 & 20 & $14(10)$ \\
\hline B13 & 20 & $9,18,11(7,13,8)$ \\
\hline B60 & 20 & $11,15,12(8,11,9)$ \\
\hline C1 & 20 & $9,16(7,12)$ \\
\hline C19 & 20 & $19,19,18(14,14,13)$ \\
& 65 & $35,46,37(26,34,27)$ \\
$83,69,52(61,51,38)$ \\
\hline
\end{tabular}


TABLE 6 - SUMMARY OF WELD ROOT FLAW SIZES

\begin{tabular}{|c|c|c|c|c|}
\hline Building & $\begin{array}{c}\text { Sample } \\
\text { No. }\end{array}$ & $\begin{array}{l}\text { Weld Backing } \\
\text { Thickness } \\
\text { mm (in.) }\end{array}$ & 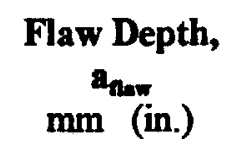 & $\begin{array}{c}\text { Effective } \\
\text { Flaw Depth, a a din } \\
\text { mm (in.) }\end{array}$ \\
\hline \multirow{5}{*}{ A } & A6 & $9.55(0.376)$ & $0.81(0.032)$ & $10.36(0.408)$ \\
\hline & A33 & $9.60(0.378)$ & $1.04(0.041)$ & $10.64(0.419)$ \\
\hline & Al65 & $9.65(0.380)$ & $1.80(0.071)$ & $11.46(0.451)$ \\
\hline & A254 & $10.13(0.399)$ & $0.94(0.037)$ & $11.07(0.436)$ \\
\hline & A287 & $9.58(0.377)$ & $4.67(0.184)$ & $14.25(0.561)$ \\
\hline \multirow{4}{*}{ B } & B4 & $9.55(0.376)$ & $4.88(0.192)$ & $14.43(0.568)$ \\
\hline & B8 & $9.50(0.374)$ & $2.49(0.098)$ & $11.99(0.472)$ \\
\hline & B13 & $9.58(0.377)$ & N/A & N/A \\
\hline & B60 & $9.40(0.370)$ & $10.19(0.401)$ & $19.58(0.771)$ \\
\hline \multirow{3}{*}{ C } & $\mathrm{Cl}$ & $9.50(0.374)$ & N/A & N/A \\
\hline & $\mathrm{C} 18$ & $9.47(0.373)$ & $1.55(0.061)$ & $11.02(0.434)$ \\
\hline & $\mathrm{Cl} 9$ & $9.50(0.374)$ & $4.37(0.172)$ & $13.87(0.546)$ \\
\hline \multirow{3}{*}{ E } & E150 & $9.50(0.374)$ & $4.27(0.168)$ & $13.77(0.542)$ \\
\hline & E226 & $9.50(0.374)$ & $4.72(0.186)$ & $14.22(0.560)$ \\
\hline & E549 & $9.53(0.375)$ & $7.26(0.286)$ & $16.79(0.661)$ \\
\hline \multirow[t]{4}{*}{ F } & F38 & $9.53(0.375)$ & N/A & N/A \\
\hline & Mean & $9.55(0.376)$ & $3.76(0.148)$ & $13.34(0.525)$ \\
\hline & Minimum & $9.47(0.373)$ & $0.81(0.032)$ & $10.29(0.405)$ \\
\hline & Maximum & $10.13(0.399)$ & $10.19(0.401)$ & $20.32(0.800)$ \\
\hline
\end{tabular}


TABLE 7 - BUILDING PERIODS

\begin{tabular}{|c|c|c|c|}
\hline \multirow{2}{*}{ Building } & \multicolumn{3}{|c|}{ Building Period (sec) } \\
\cline { 2 - 4 } & Transverse & Longitudinal & Torsion \\
\hline A & 1.40 & 1.28 & 0.93 \\
\hline B & 1.50 & 1.49 & 0.88 \\
\hline C & 1.58 & 1.42 & 1.15 \\
\hline E & $1.65^{\circ}$ & $1.56^{\circ}$ & 1.00 \\
\hline F & 1.51 & 1.54 & 0.90 \\
\hline
\end{tabular}

- Transverse and longitudinal directions coupled 
TABLE 8 - BUILDING BASE SHEARS

\begin{tabular}{|c|c|c|c|c|}
\hline \multirow{2}{*}{ Building } & \multicolumn{4}{|c|}{ Base Shears $\mathrm{kN}(\mathrm{kips}), \% \mathrm{~g}$} \\
\cline { 2 - 5 } & \multicolumn{2}{|c|}{ Mean } & \multicolumn{2}{c|}{ Mean + 1 Sigma } \\
\cline { 2 - 5 } & Long. & Trans. & Long. & Trans. \\
\hline \multirow{3}{*}{ A } & $15,692(3,528)$ & $14,051(3,159)$ & $28,267(6,355)$ & $25,870(5,816)$ \\
\cline { 2 - 6 } & $20.9 \%$ & $18.8 \%$ & $38.0 \%$ & $35.0 \%$ \\
\hline \multirow{3}{*}{ B } & $2,713(610)$ & $2,700(607)$ & $5,035(1,132)$ & $5,022(1,129)$ \\
\cline { 2 - 6 } & $15.4 \%$ & $15.3 \%$ & $28.6 \%$ & $28.5 \%$ \\
\hline \multirow{3}{*}{ C } & $4,955(1,114)$ & $4,288(964)$ & $9,514(2,139)$ & $8,100(1,821)$ \\
\cline { 2 - 6 } & $29.1 \%$ & $25.2 \%$ & $55.9 \%$ & $47.6 \%$ \\
\hline \multirow{3}{*}{ F } & $12,388(2,785)$ & $13,944(3,135)$ & $23,152(5,205)$ & $26,563(5,972)$ \\
\cline { 2 - 6 } & $7.9 \%$ & $8.8 \%$ & $14.8 \%$ & $16.8 \%$ \\
\hline & $6,441(1,448)$ & $6,570(1,477)$ & $12,352(2,777)$ & $12,668(2,848)$ \\
\hline & $26.8 \%$ & $27.4 \%$ & $51.5 \%$ & $52.8 \%$ \\
\hline
\end{tabular}


TABLE 9 - COMPUTED BEAM FLANGE STRESSES AT THE SAMPLE LOCATIONS

\begin{tabular}{|c|c|c|c|c|c|}
\hline \multirow{2}{*}{ Sample No. } & \multicolumn{2}{|c|}{$\begin{array}{l}\text { Beam Bending Stress MPa } \\
\text { (ksi) }\end{array}$} & \multirow[b]{2}{*}{$\begin{array}{l}\text { Mean + } \\
1 \text { Sigma }\end{array}$} & \multirow{2}{*}{$\begin{array}{c}\mathrm{D} / \mathrm{C}^{+} \\
\text {(Mean) }\end{array}$} & \multirow{2}{*}{$\begin{array}{c}\mathrm{D} / \mathrm{C}^{\dagger} \\
\text { (Mean+1 } \\
\text { Sigma) }\end{array}$} \\
\hline & $\mathbf{D}+\mathbf{L}$ & Mean & & & \\
\hline A6 & $6(0.9)$ & $261(37.9)$ & $483(70.1)$ & 1.00 & 1.84 \\
\hline A33 & $6(0.9)$ & $243(35.3)$ & $452(65.6)$ & 0.84 & 1.56 \\
\hline A165 & $13(1.9)$ & $198(28.7)$ & 334 (48.5) & 0.72 & 1.21 \\
\hline A254 & $14(2.1)$ & $210(30.4)$ & $381(55.3)$ & 0.76 & 1.38 \\
\hline A287 & $9(1.3)$ & $292(42.3)$ & $541(78.5)$ & 0.90 & 2.07 \\
\hline B4 & $6(0.8)$ & $230(33.4)$ & $378(54.8)$ & 0.80 & 1.30 \\
\hline B8 & $5(0.7)$ & $230(33.4)$ & $378(54.8)$ & 0.81 & 1.34 \\
\hline B13 & $23(3.4)$ & $221(32.1)$ & $416(60.4)$ & 0.82 & 1.55 \\
\hline B60 & $5(0.7)$ & $242(35.1)$ & $452(65.6)$ & 0.84 & 1.56 \\
\hline $\mathrm{Cl}$ & $11(1.6)$ & $248(35.9)$ & $505(73.3)$ & 0.73 & 1.50 \\
\hline $\mathrm{C} 18$ & $6(0.8)$ & $314(45.5)$ & $605(87.8)$ & 0.91 & 1.76 \\
\hline C19 & 11 (1.6) & 358 (51.9) & $689(100.0)$ & N/A & N/A \\
\hline E150 & $7(1.0)$ & $130(18.8)$ & $248(36.0)$ & 0.43 & 0.82 \\
\hline E226 & $12(1.7)$ & $65(9.4)$ & $125(18.1)$ & 0.23 & 0.44 \\
\hline E549 & $2(0.3)$ & $70(10.2)$ & $137(19.8)$ & 0.22 & 0.42 \\
\hline F38 & $3(0.5)$ & $149(21.6)$ & $296(43.0)$ & N/A & N/A \\
\hline
\end{tabular}

${ }^{\dagger} \mathrm{D} / \mathrm{C}=$ Demand Capacity Ratio

$=$ Calculated Stress $/$ Measured Yield Stress 


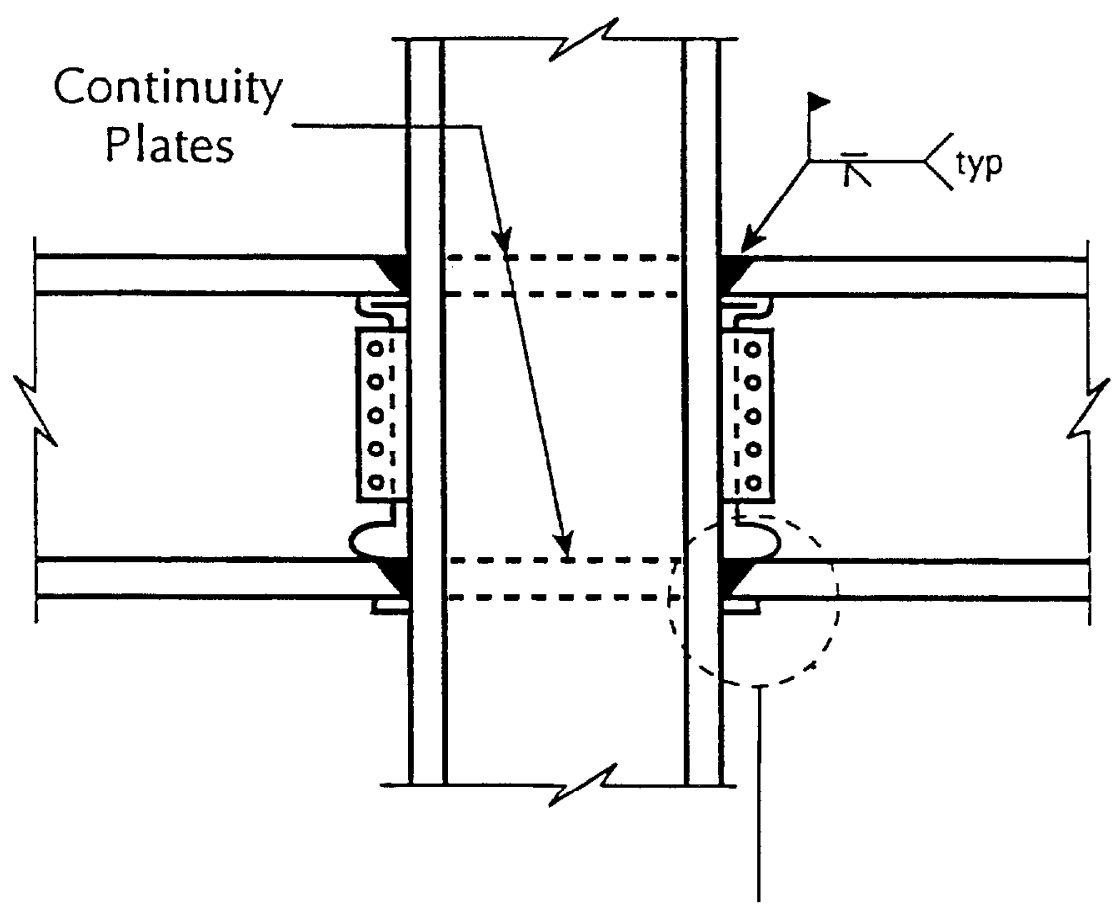

Beam Bottom Flange Deie:!

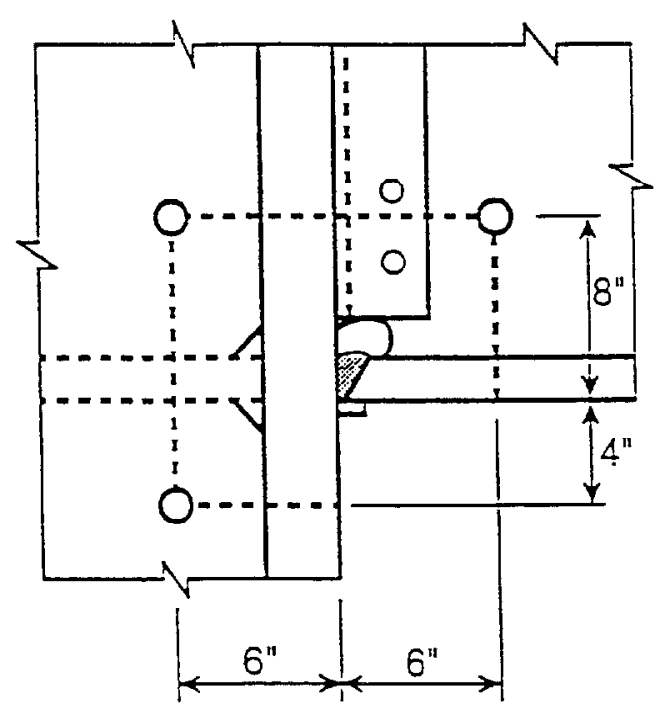

(1) Identify Location

(2) Drill 1" Holes in Web

(3) Cut Straight Lines Eetween Holes in Web and Through Column and Beam Flanges

(4) Provide Full Width of Column and Beam Flanges

(5) Provice any Information Available on Materials and Welding Procedures (base metal \& welds)

Figure 1 - Typical welded steel moment frame (WSMF) connection and recommended fracture sample removal procedure. 


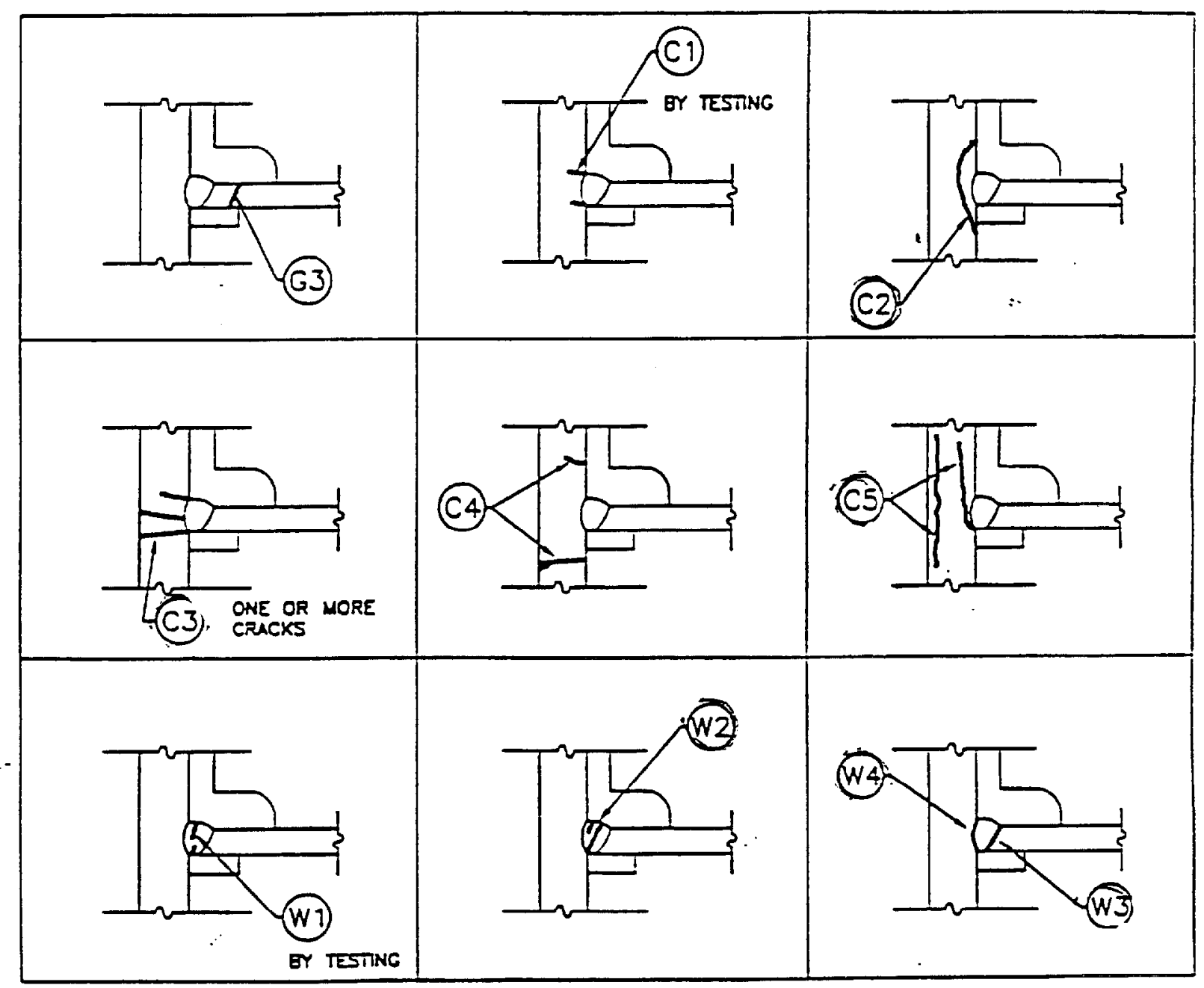

Figure 2 - WSMF Damage Types (Youssef et al.). 

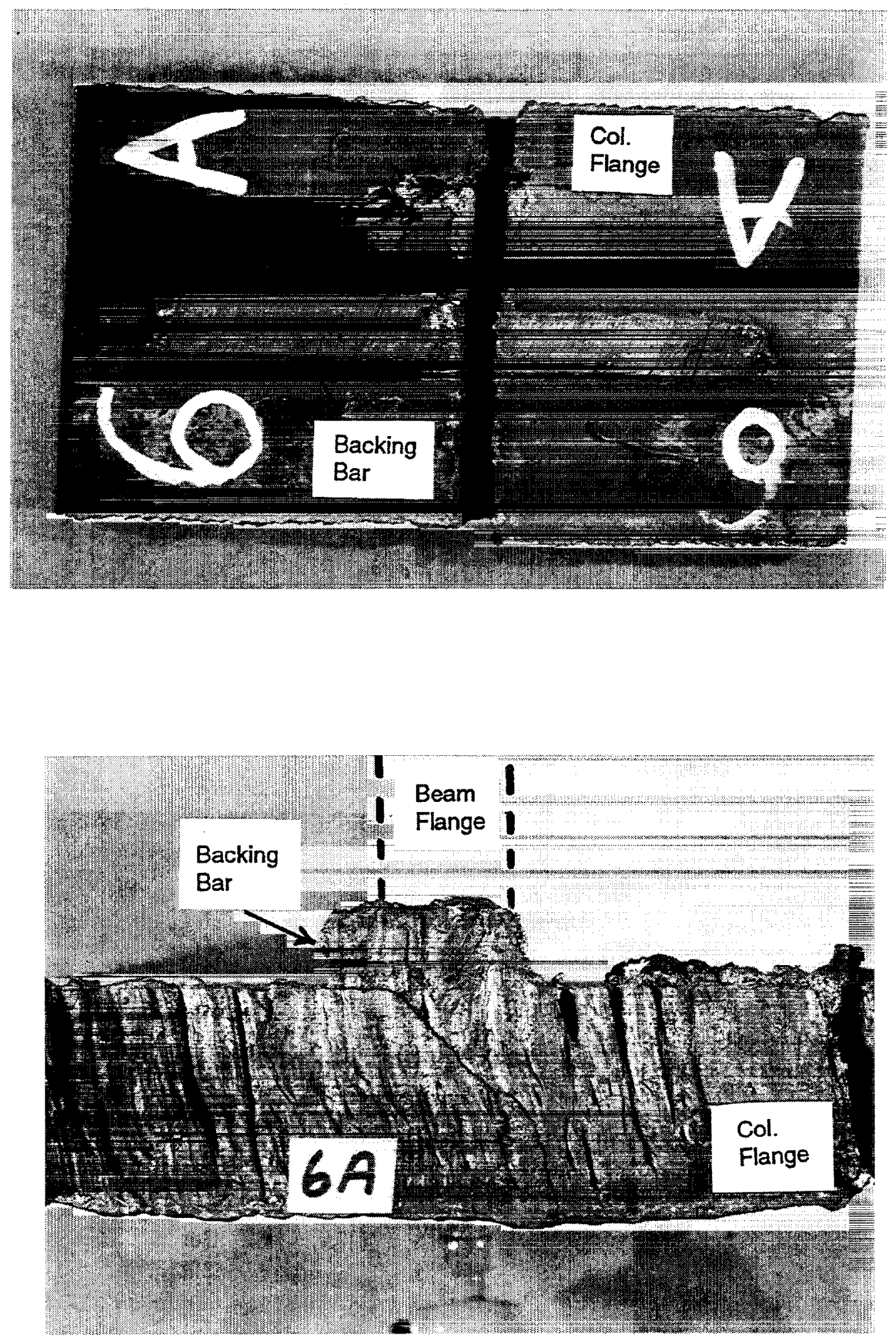

Figure 3 - Building Sample A6.

Top: Column flange face with cut beam flange weld.

Bottom: Edge view showing column flange fracture. 

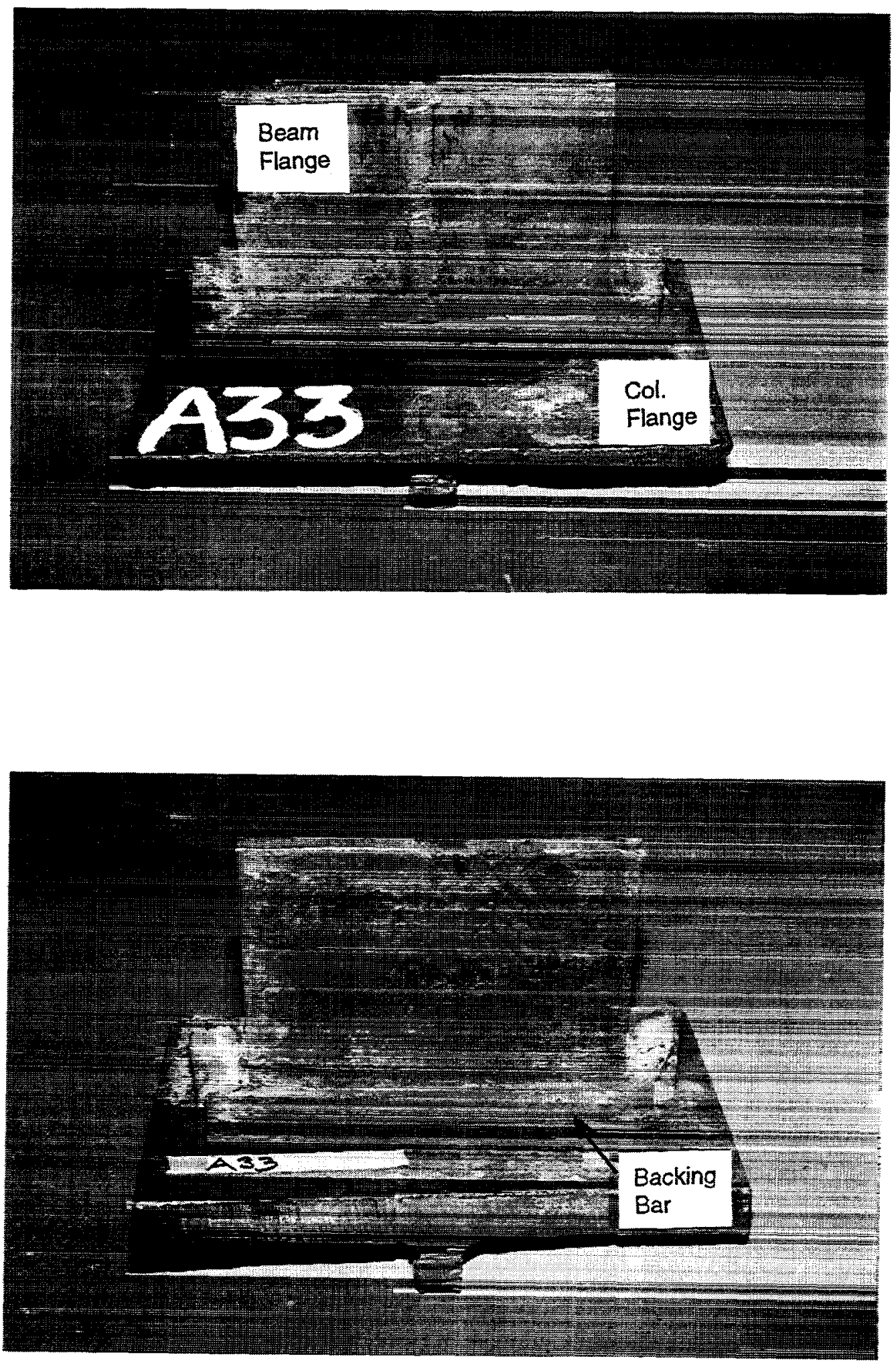

Figure 4 - Building Sample A33. No cracking is visible. 

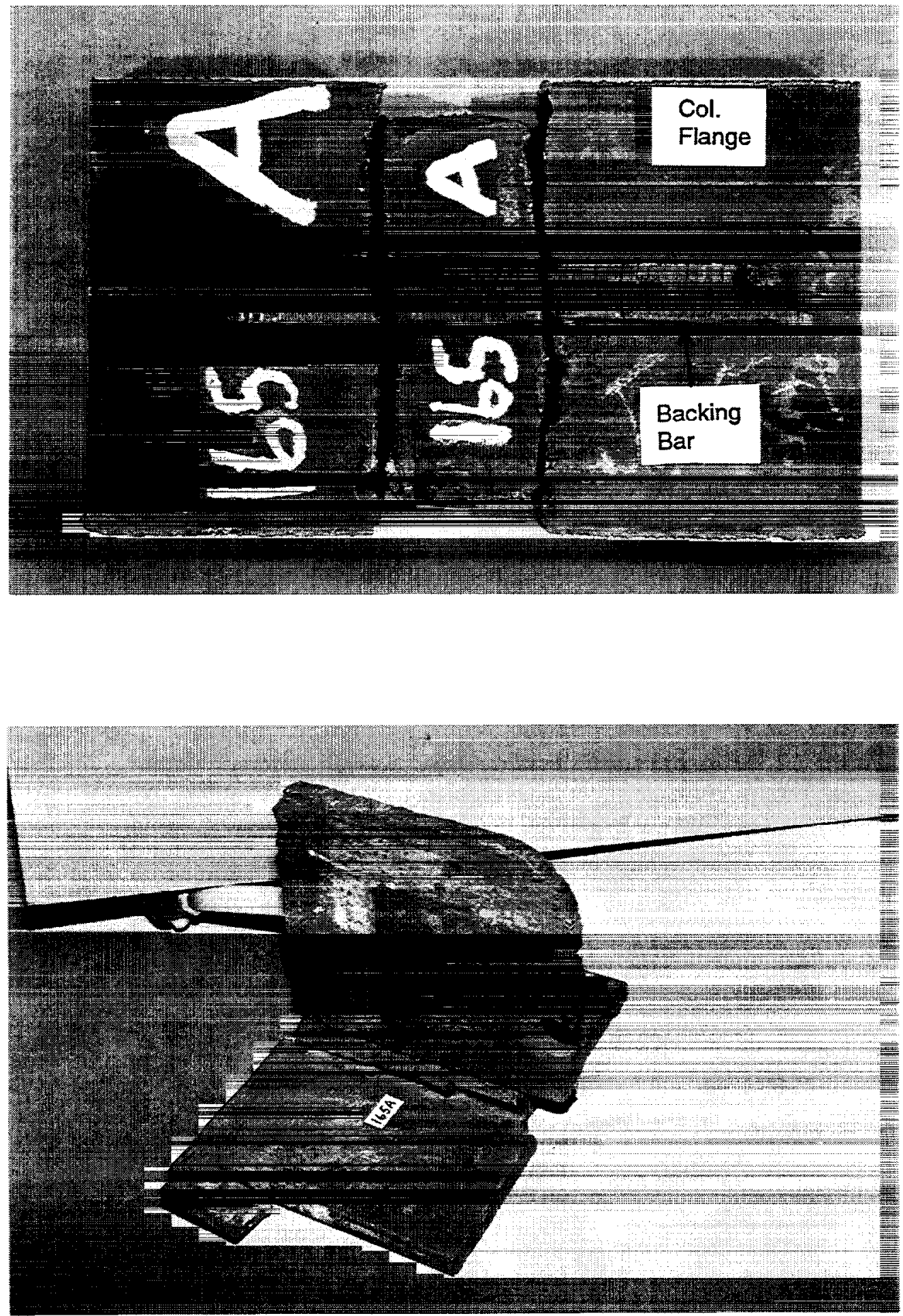

Figure 5 - Building Sample A165.

Top: Column flange face with cut beam flange weld. Bottom: Beam bottom flange. 


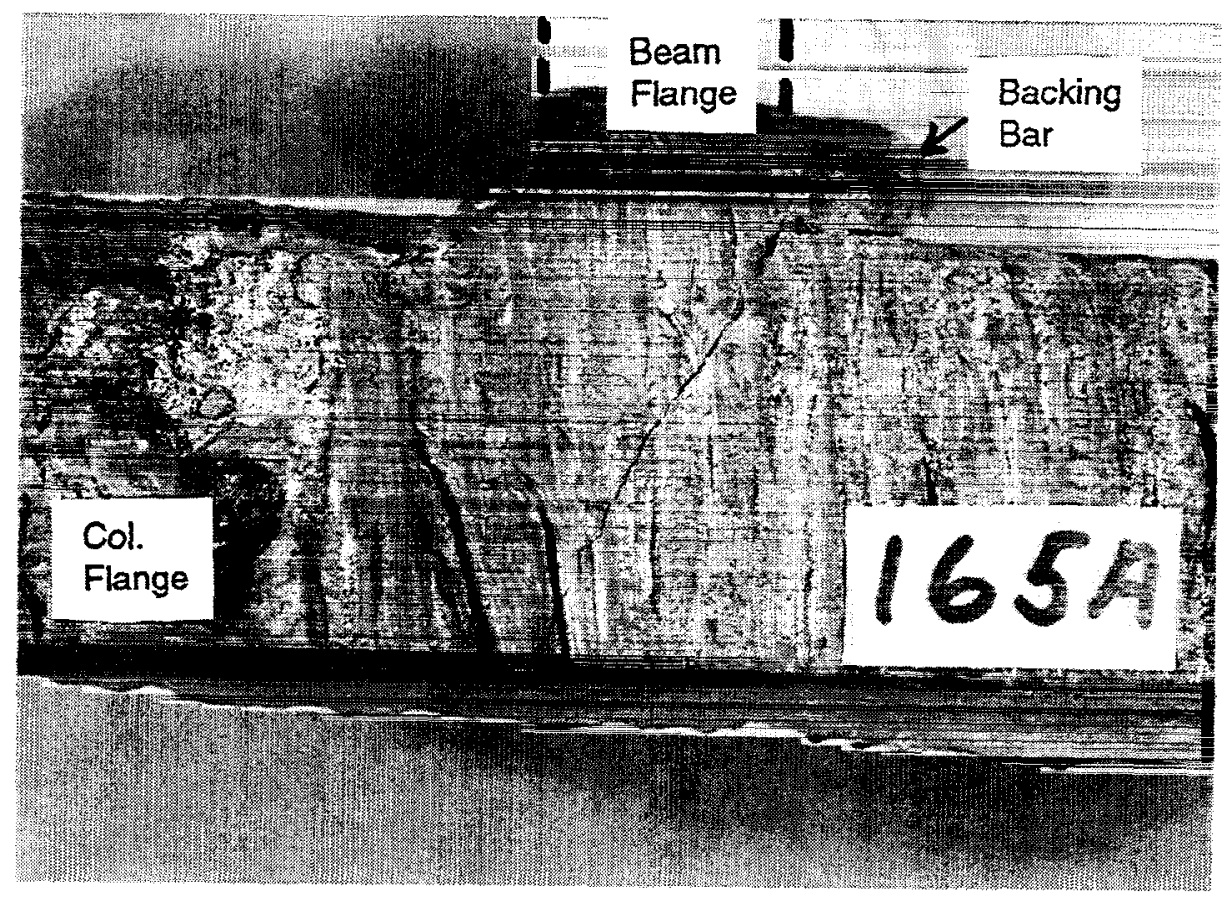

Figure 6 - Edge view of Sample A165 column flange showing fracture path.

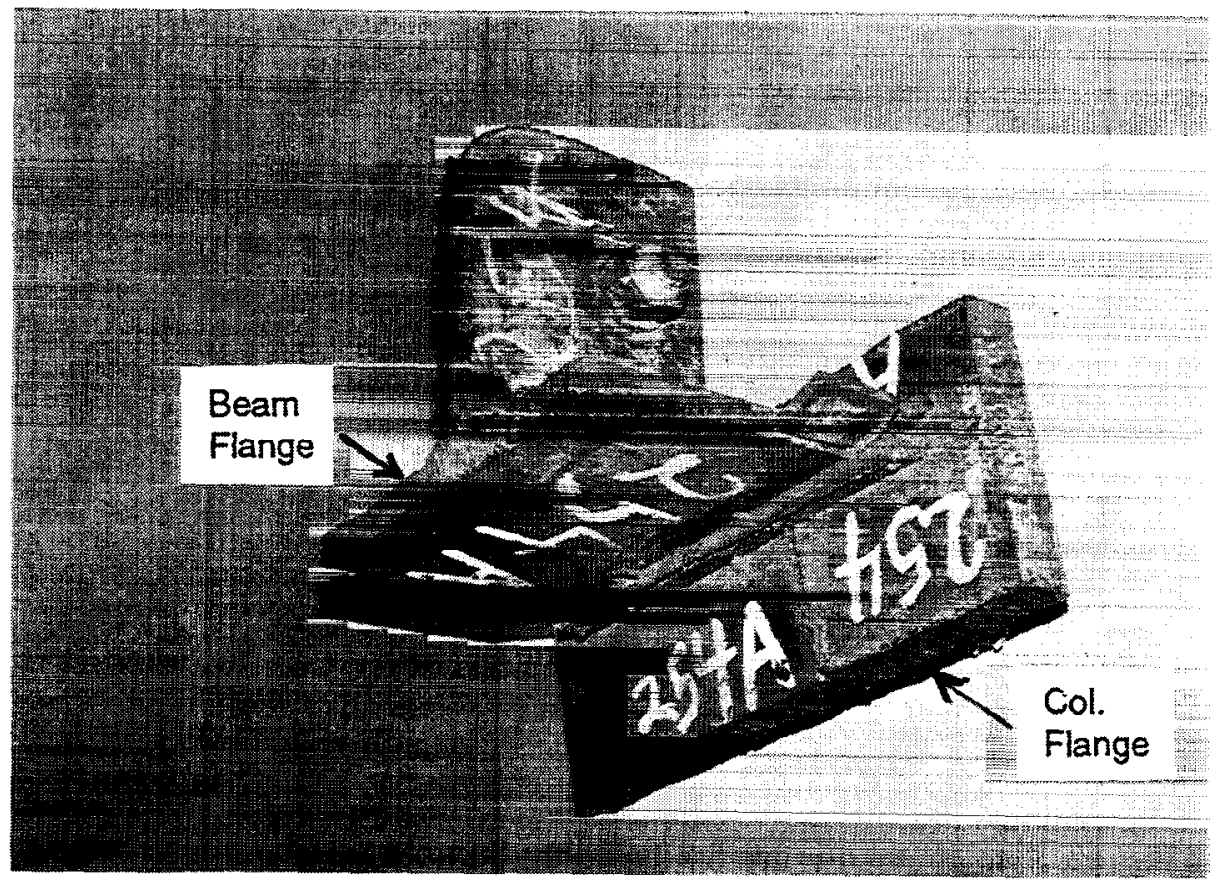

Figure 7 - Building Sample A254. 


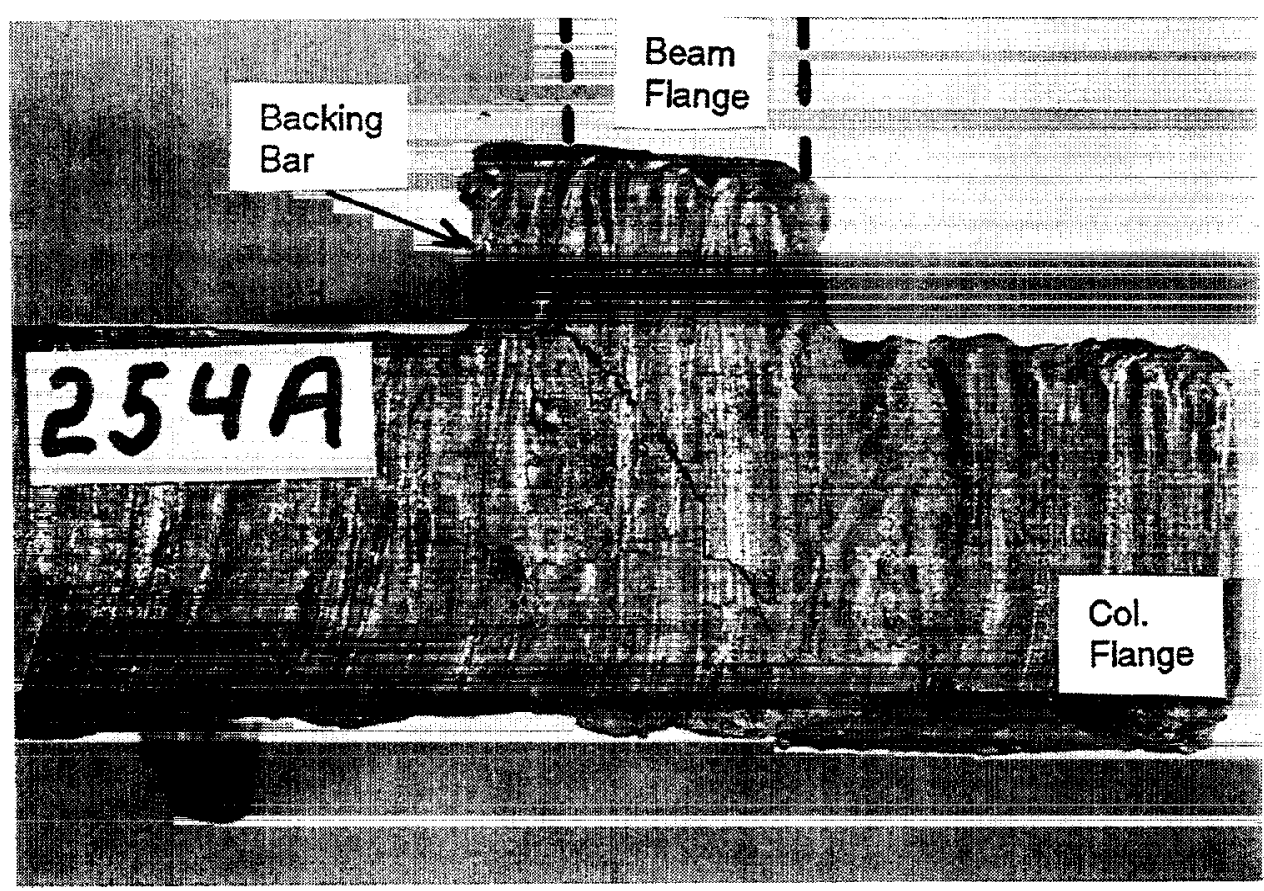

Figure 8 - Edge view of Sample A254 showing column flange fracture.

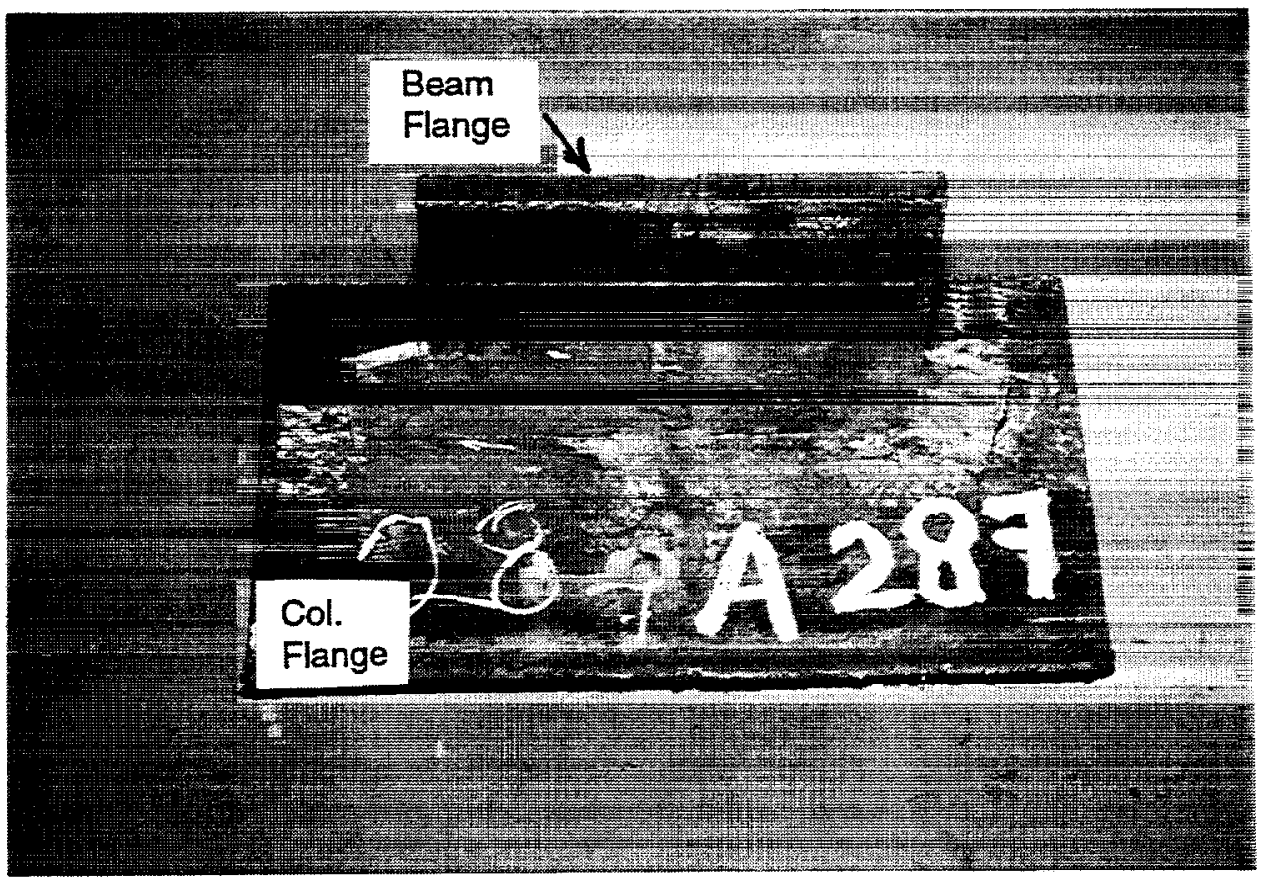

Figure 9 - Building Sample A287. No cracking is visible. 


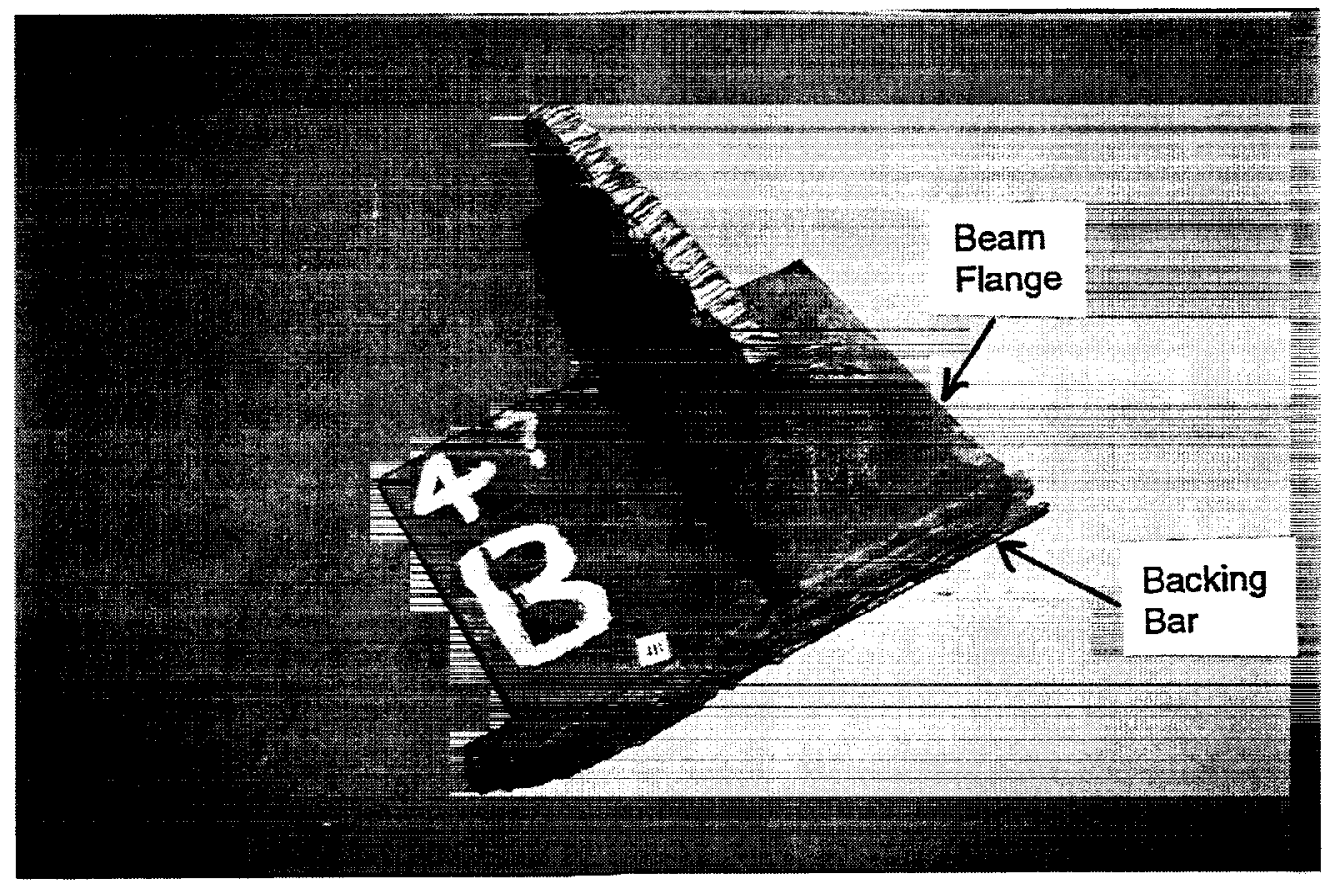

Figure 10 - Building Sample B4 showing beam bottom flange and fracture (Type W4).

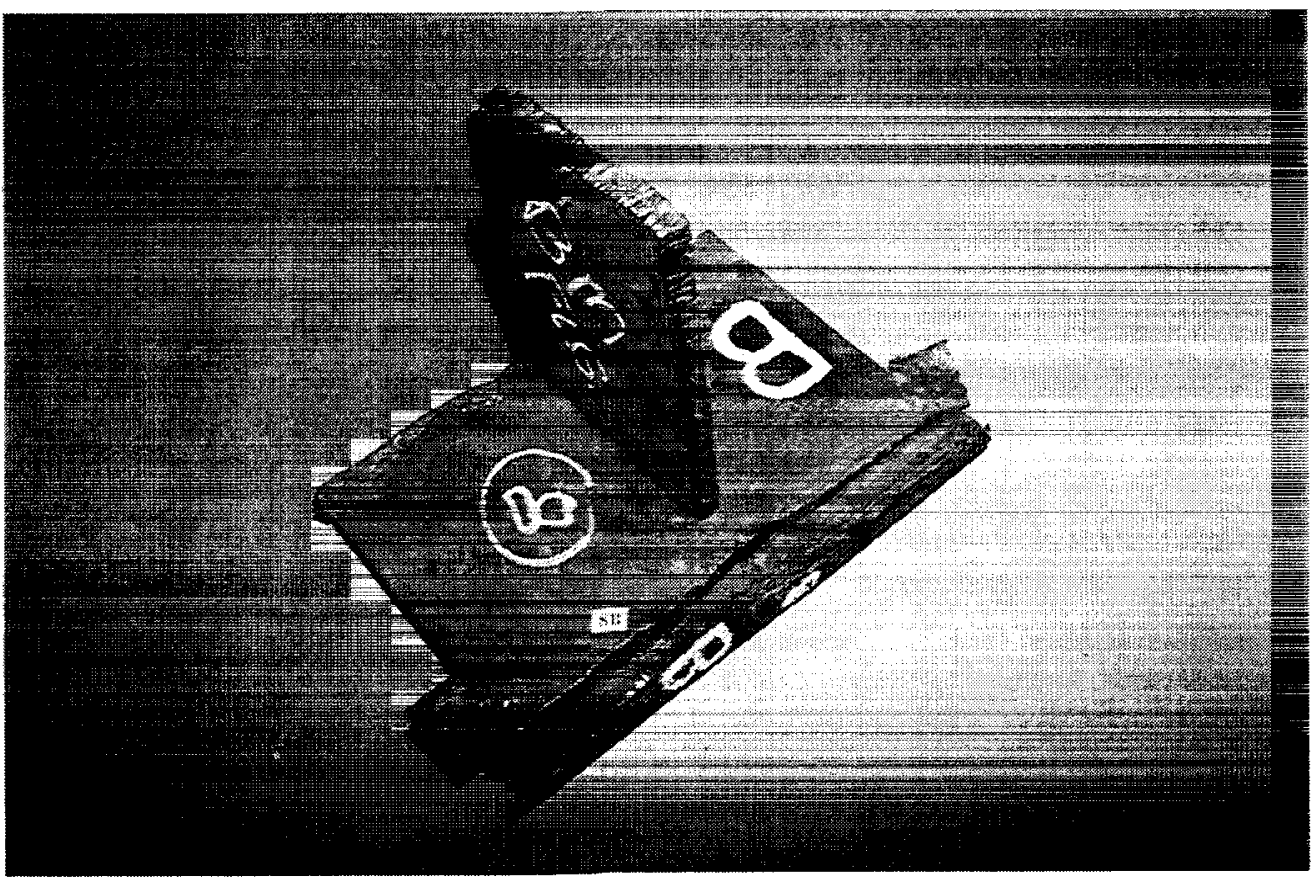

Figure 11 - Building Sample B8 showing beam bottom flange and fracture (Type W4). 


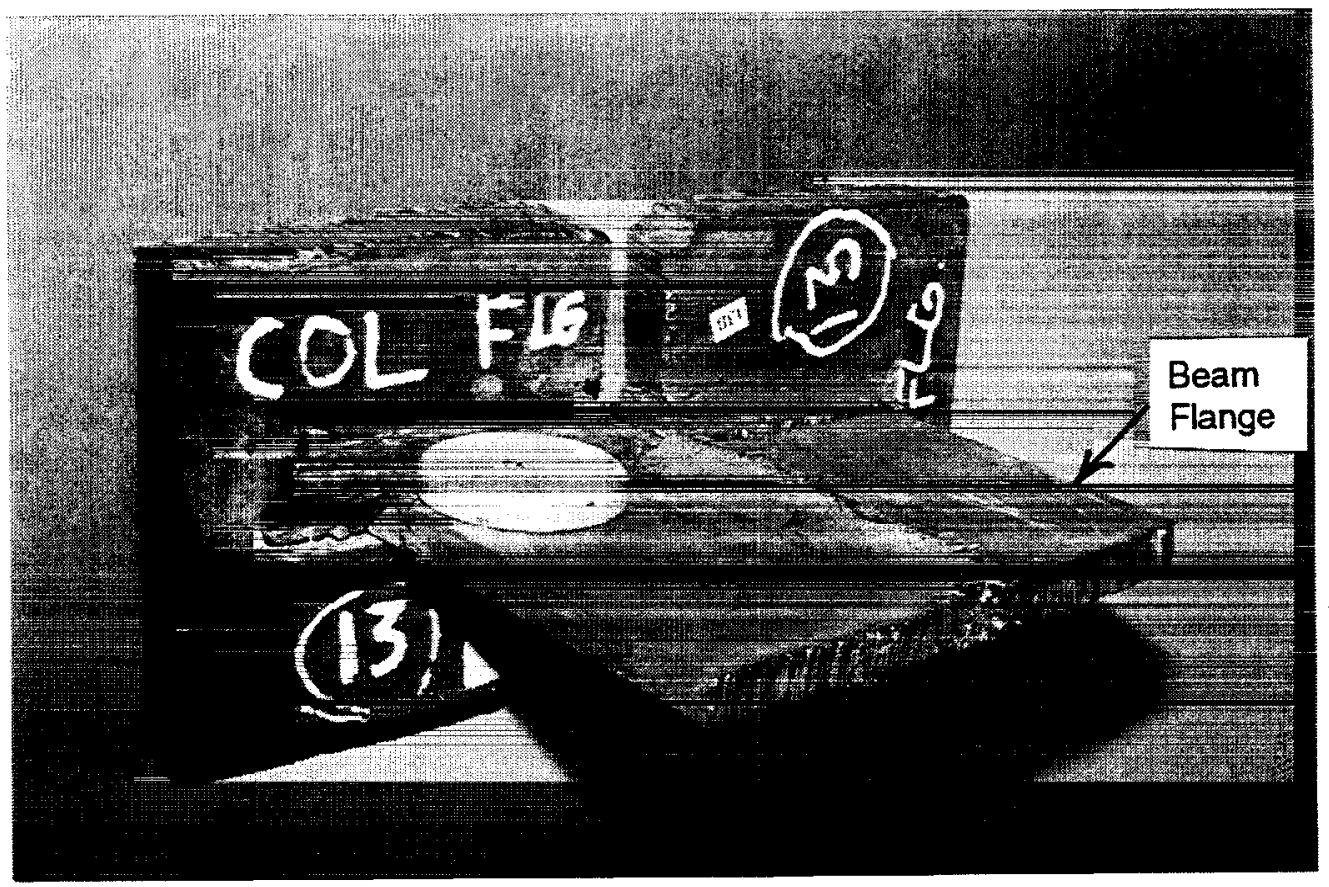

Figure 12 - Building Sample B13.

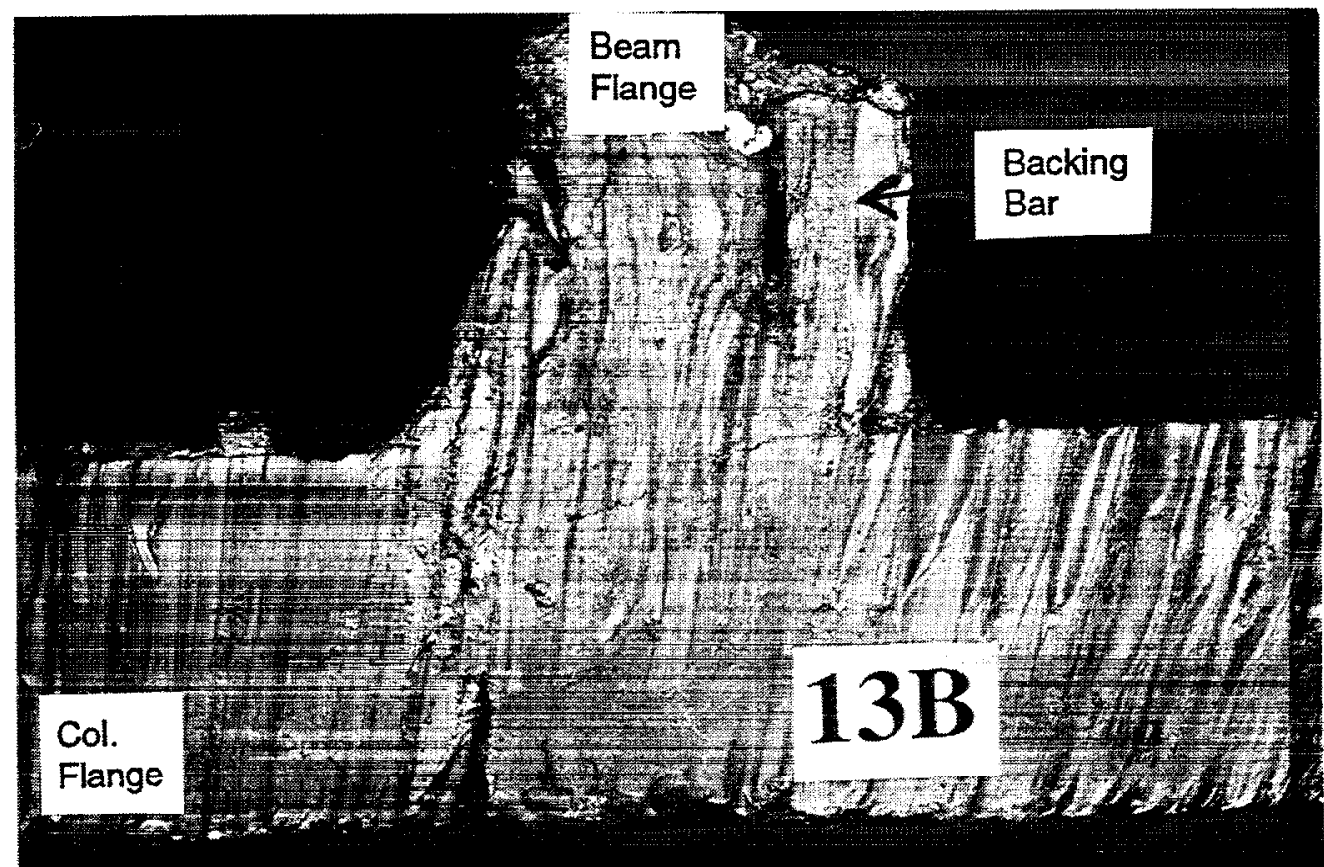

Figure 13 - Edge view of Sample B13 showing column flange fracture. 


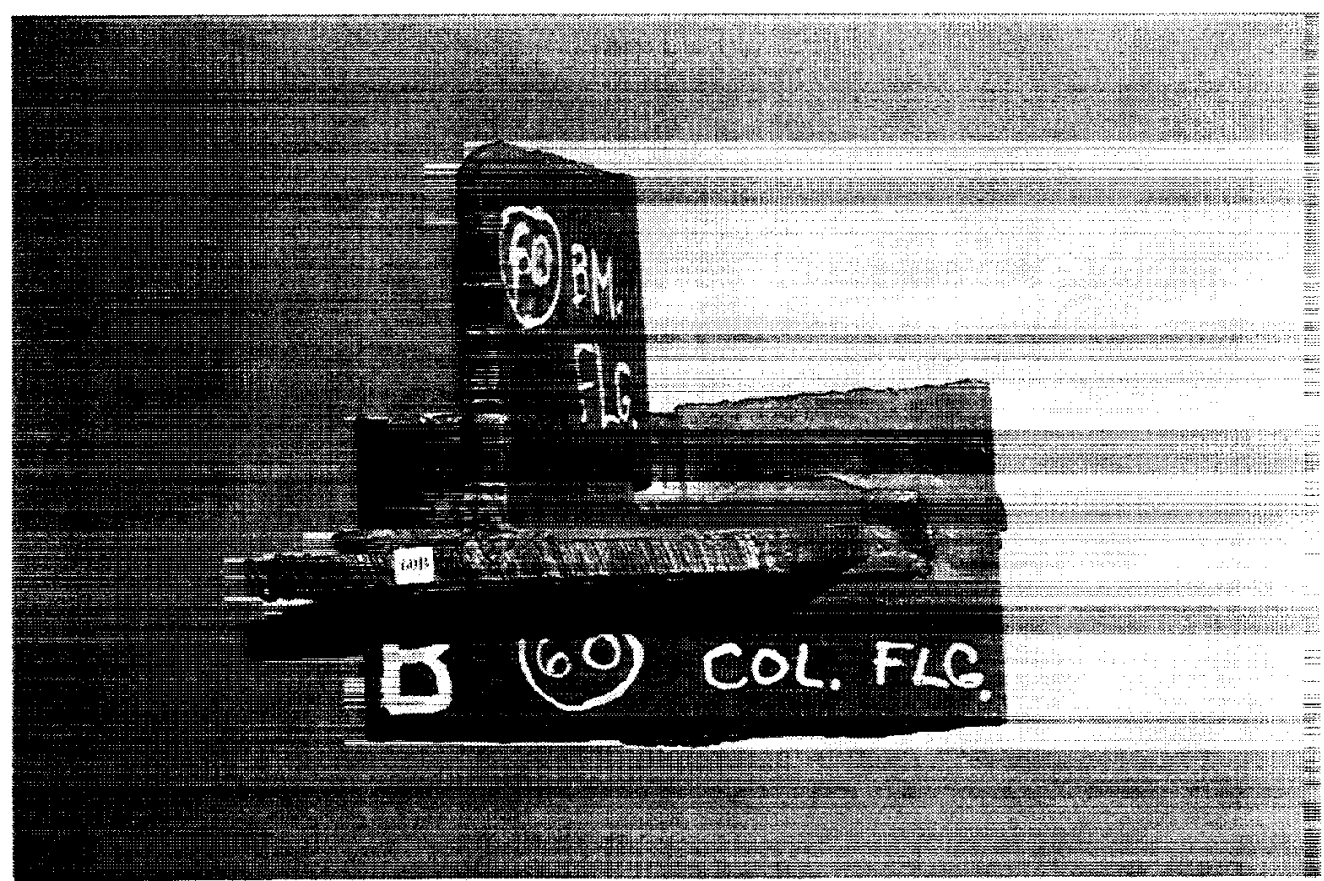

Figure 14 - Building Sample B60.

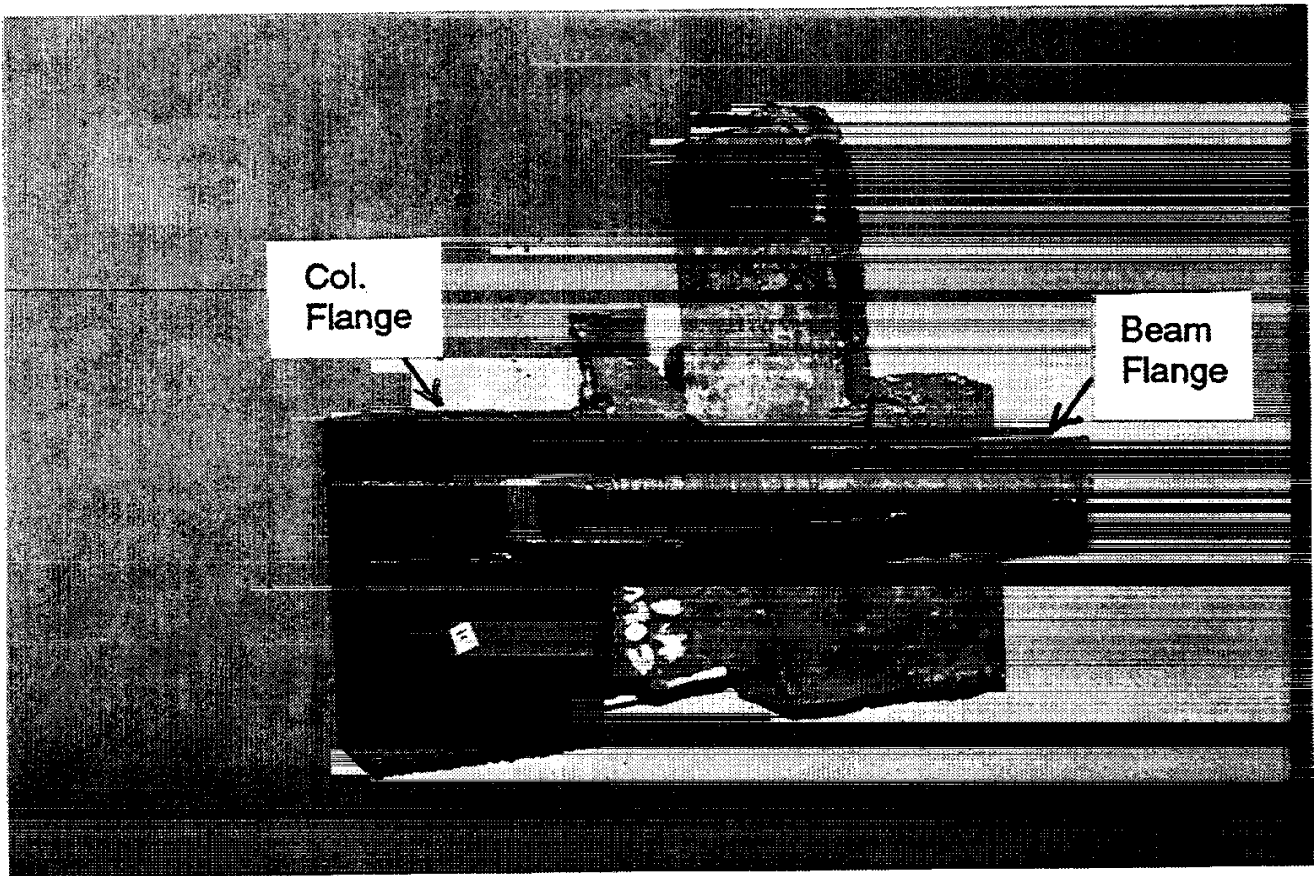

Figure 15 - Building Sample C1. 


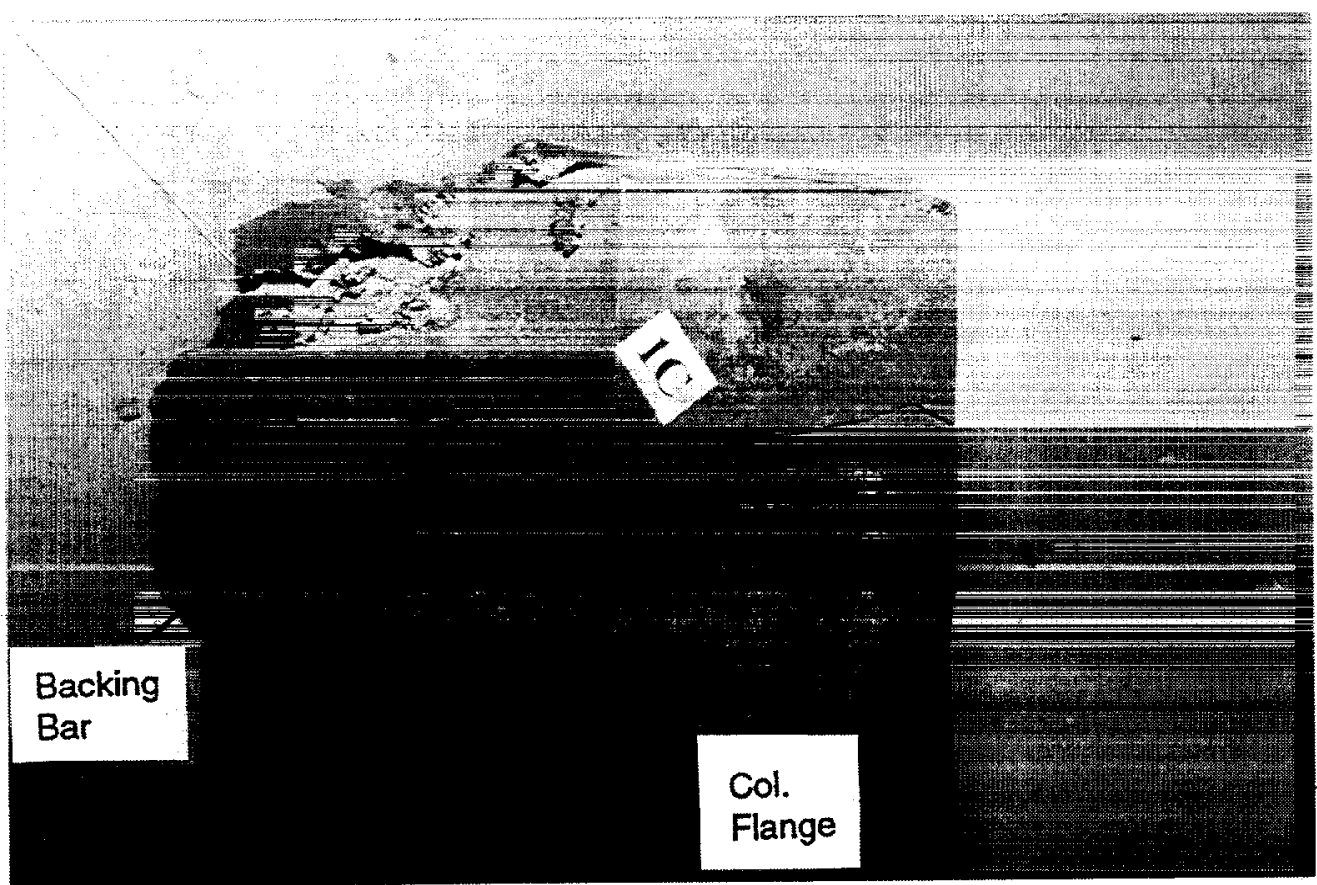

Figure 16 - Edge view of column flange fracture in Sample C1.

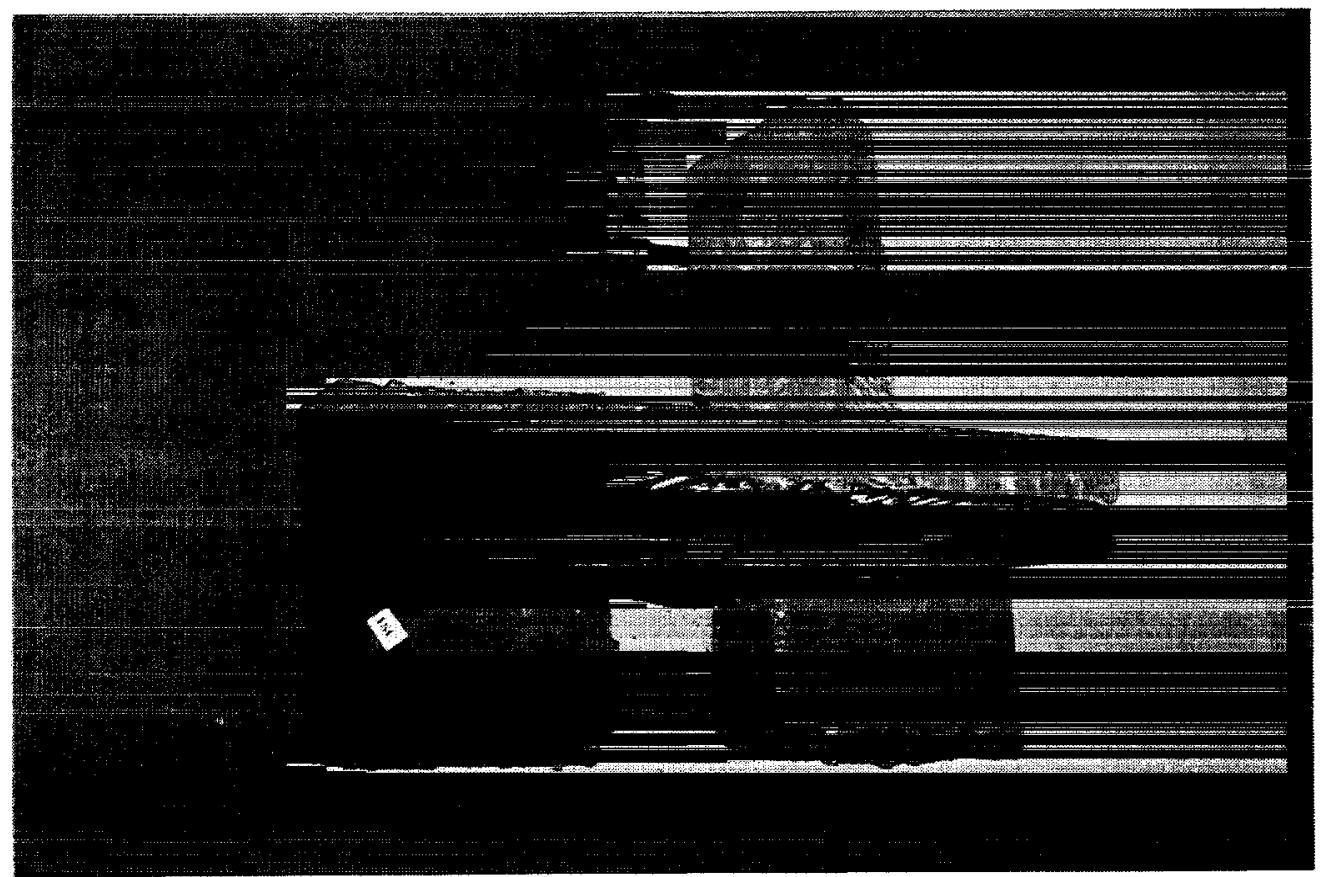

Figure 17 - Building Sample C18. 


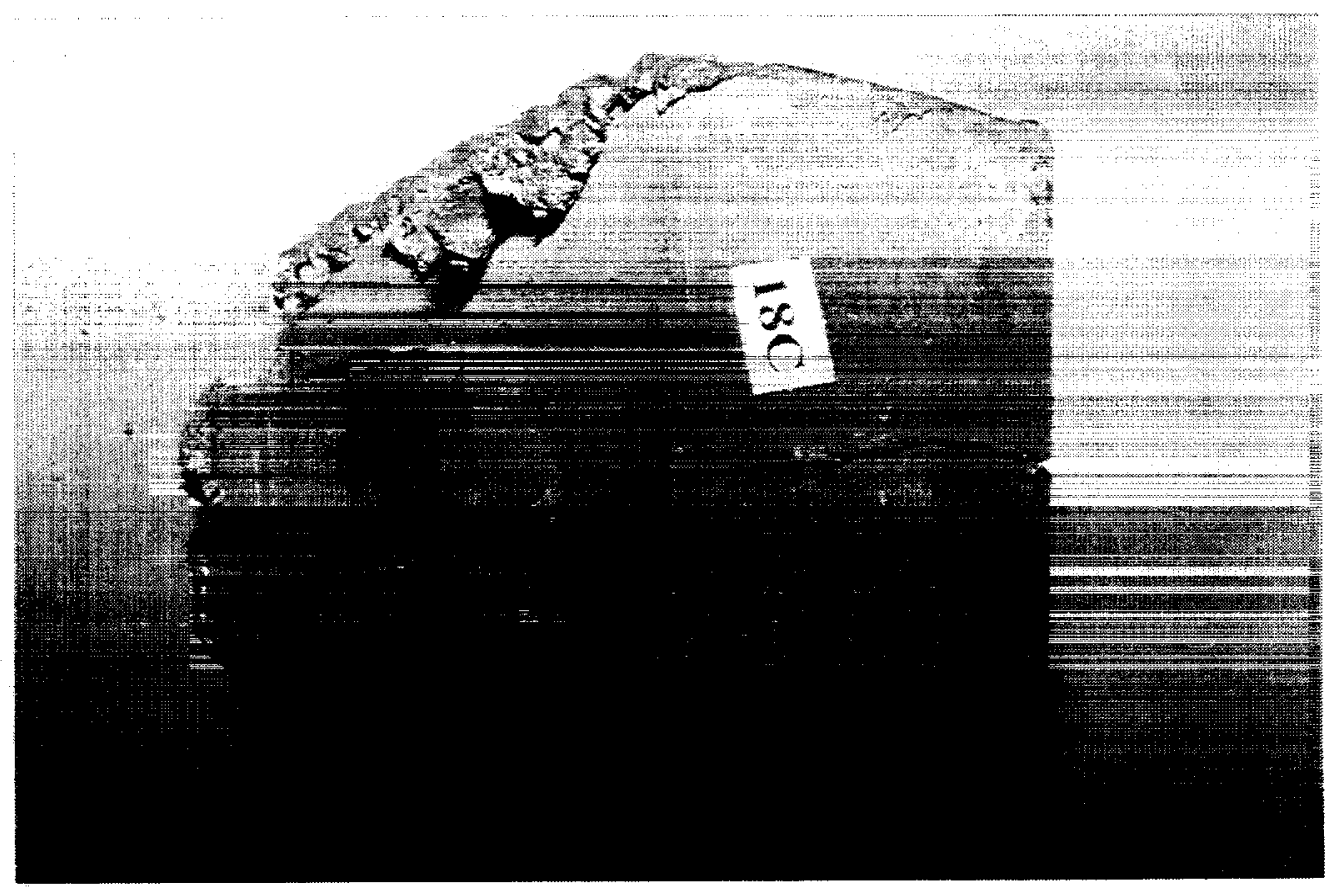

Figure 18 - Edge view of column flange fracture in Sample C18.

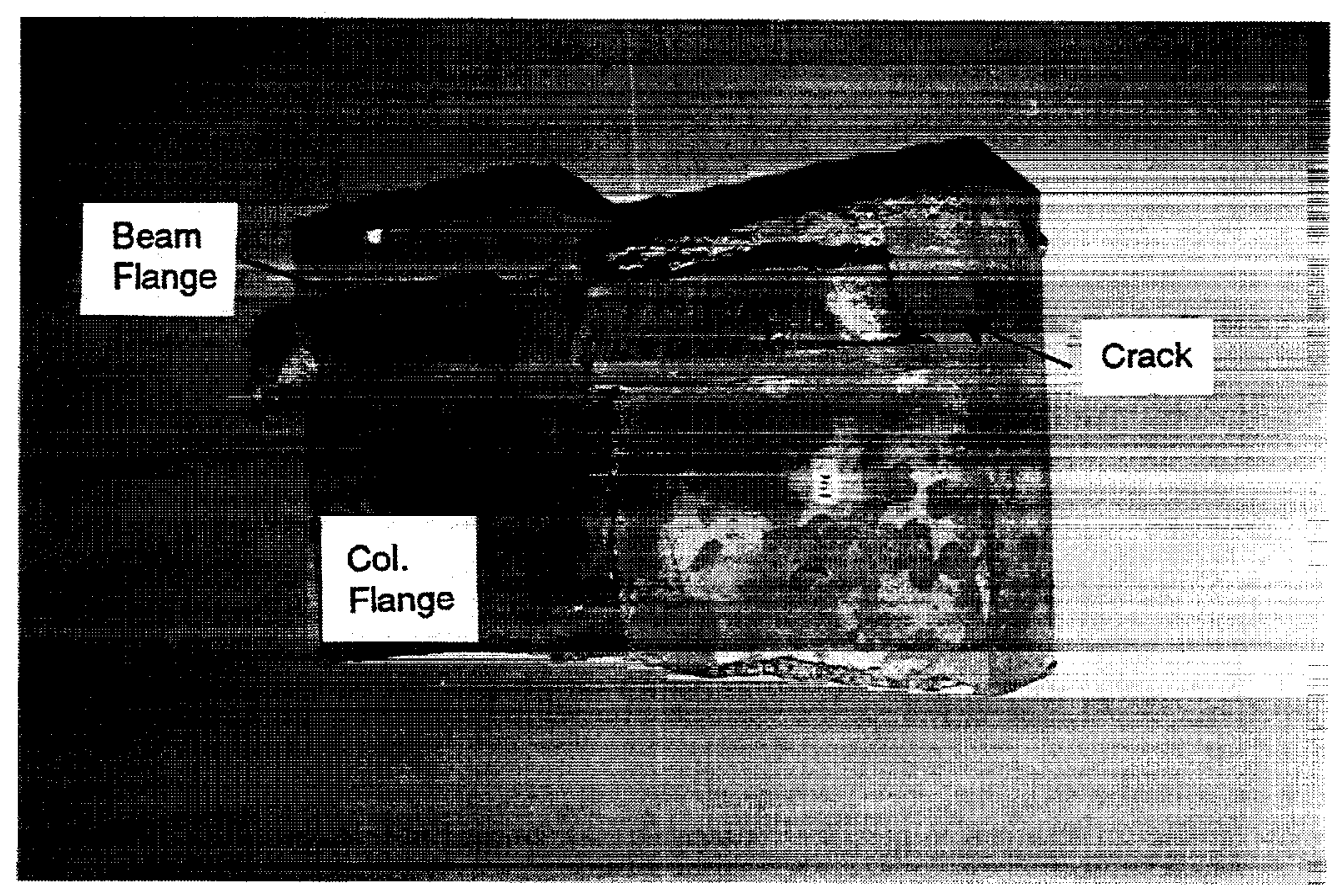

Figure 19 - Building Sample C19. 


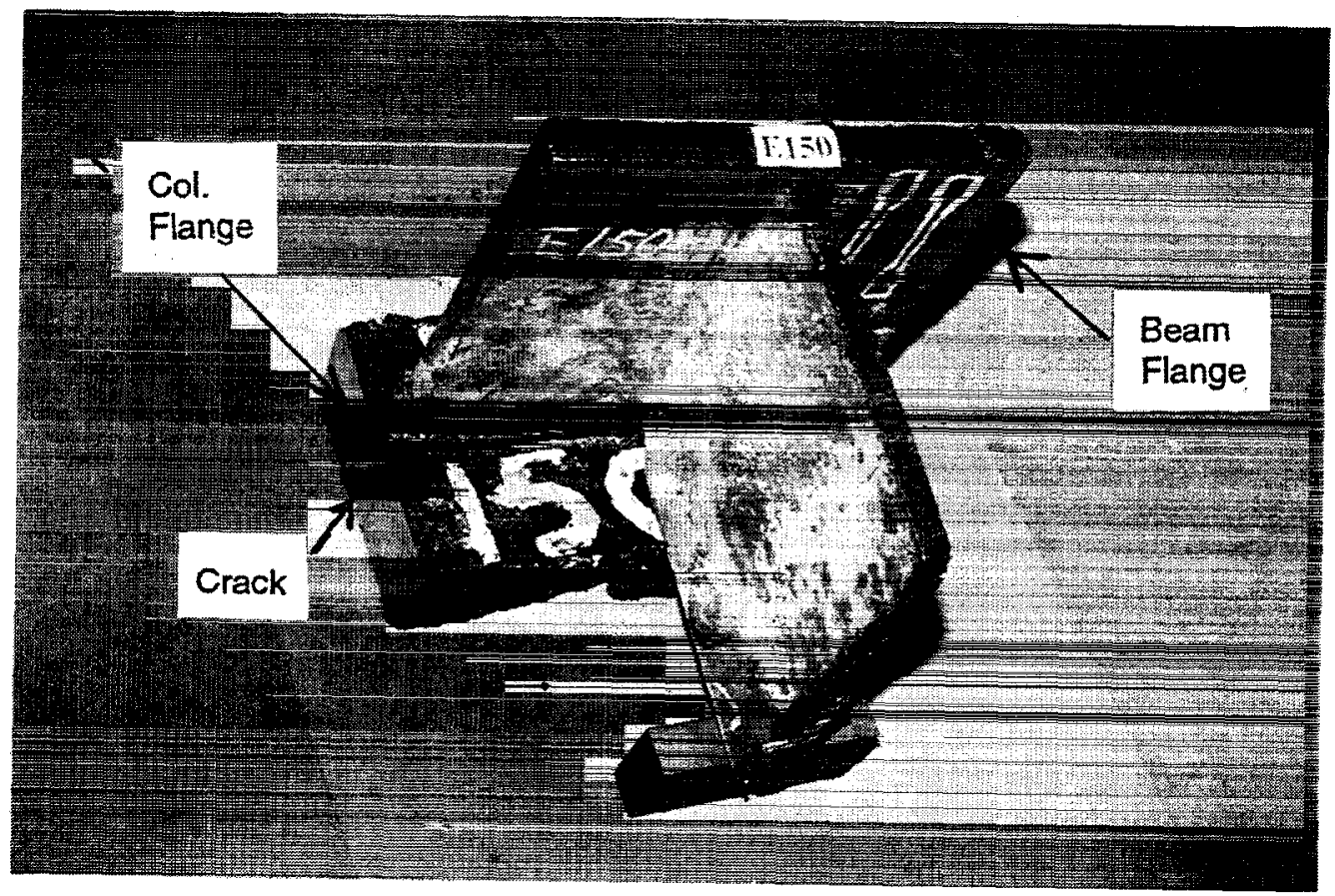

Figure 20 - Building Sample E150. Note column flange fracture.

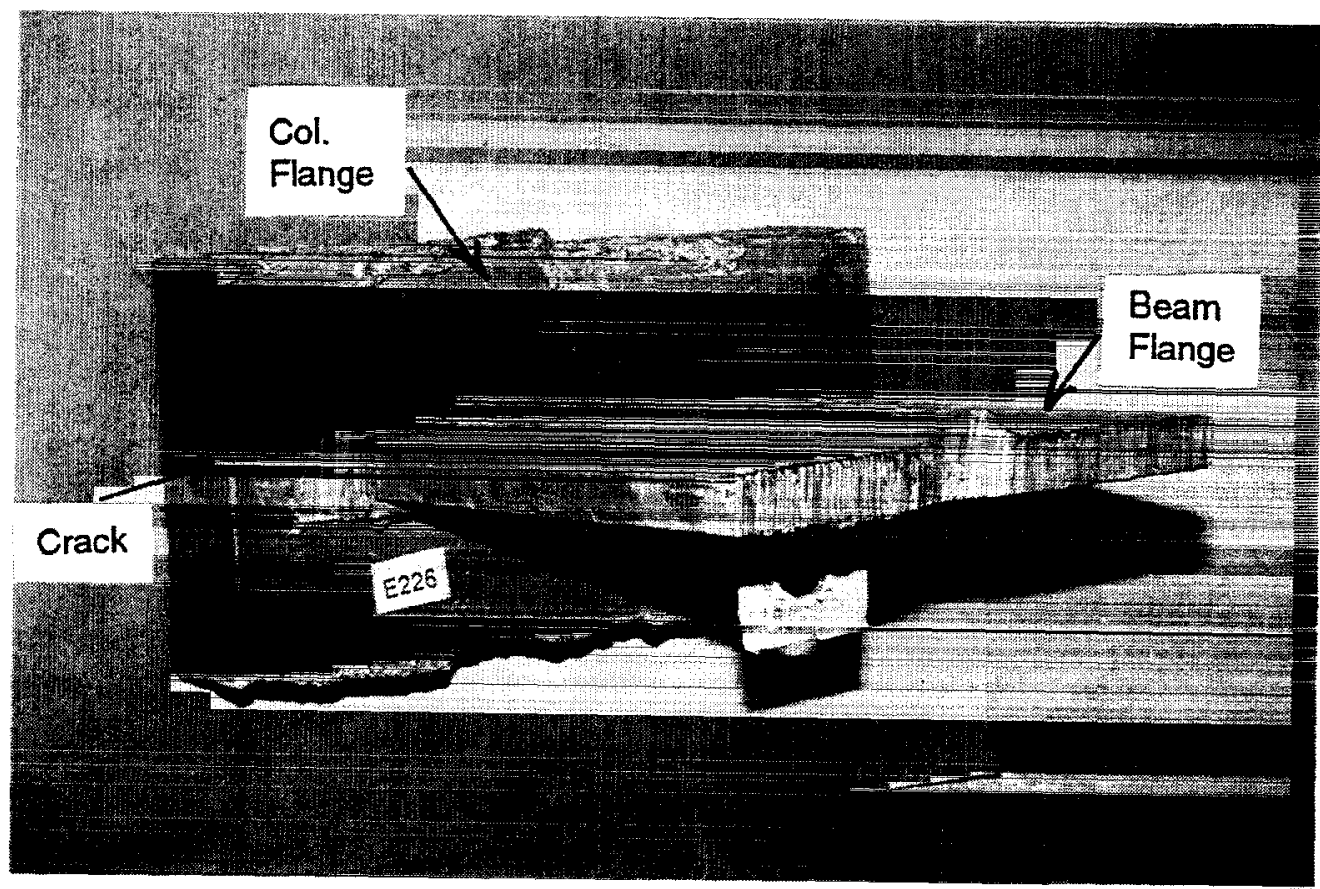

Figure 21 - Building Sample E226. Note column flange fracture. 


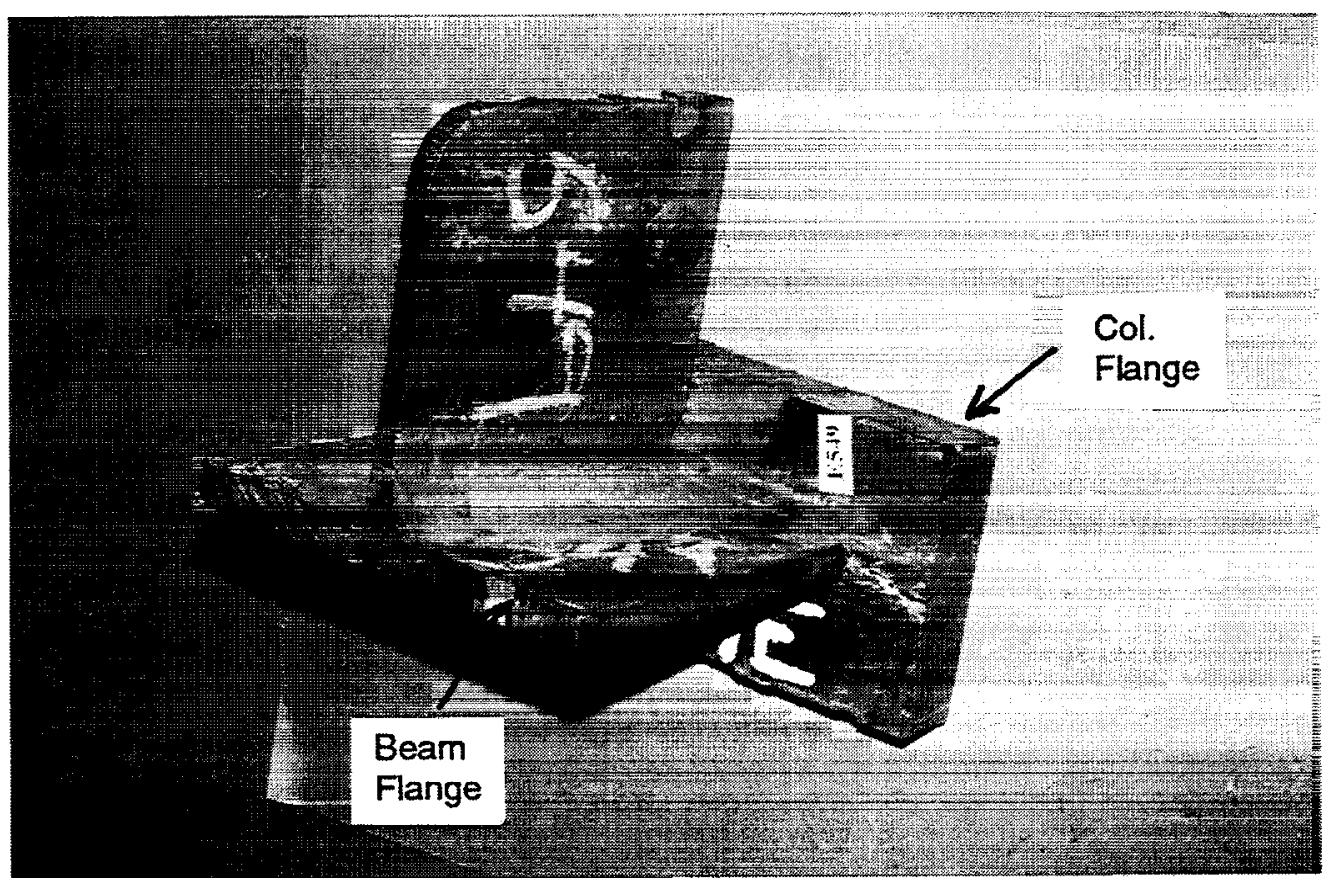

Figure 22 - Building Sample E549. No cracking is visible.

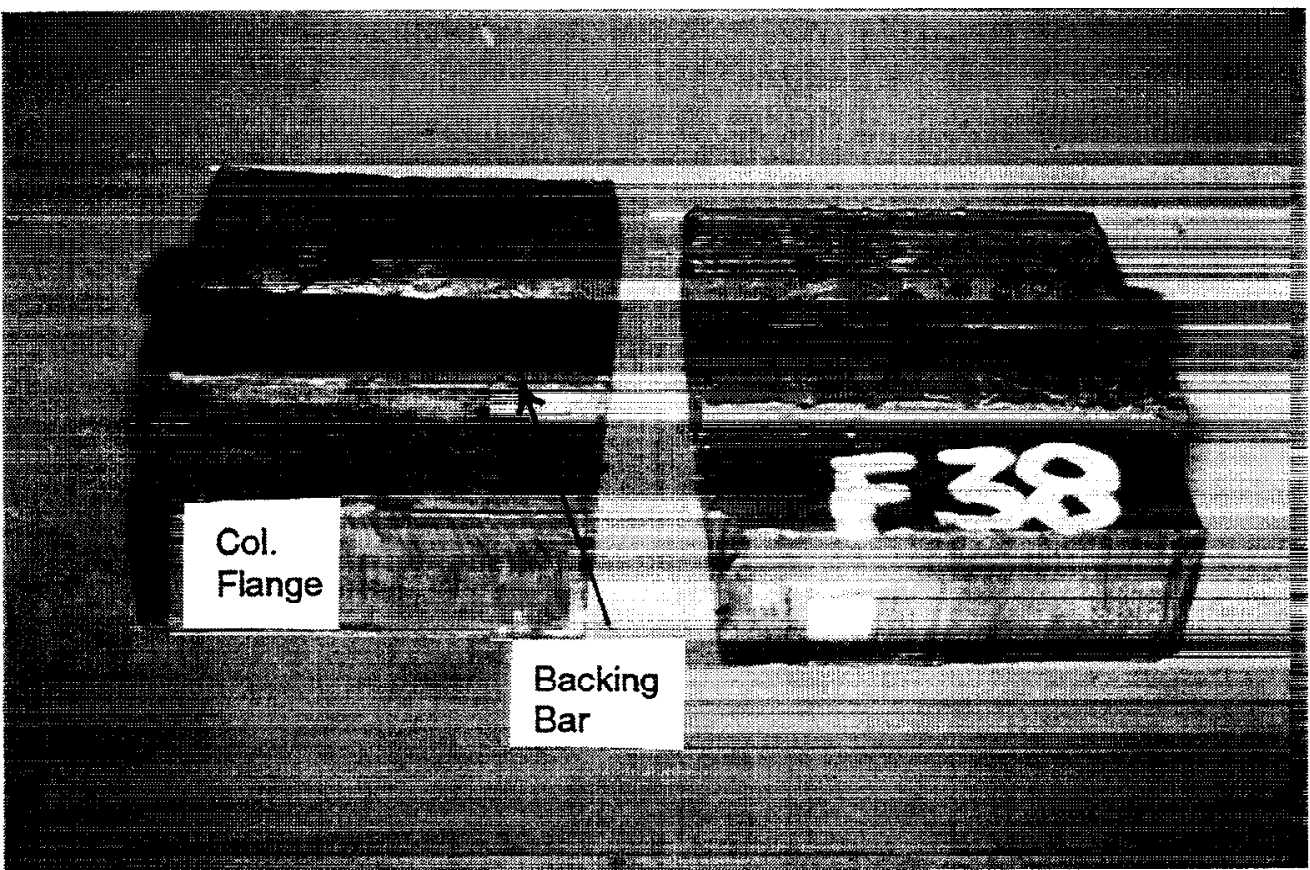

Figure 23 - Building Sample F38 showing column flange and cut beam flange weld. 


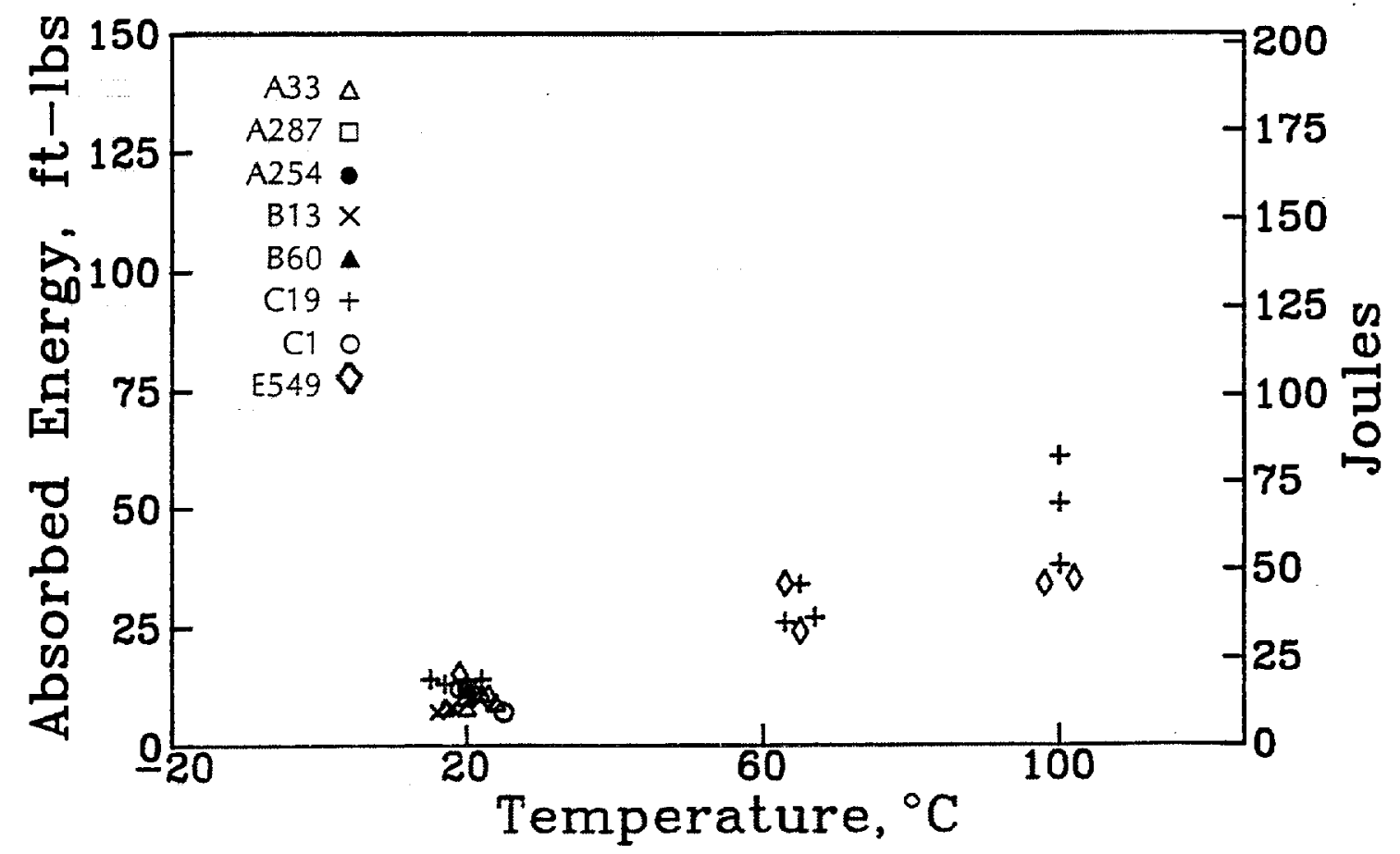

Figure 24 - Weld metal Charpy V-Notch results. 


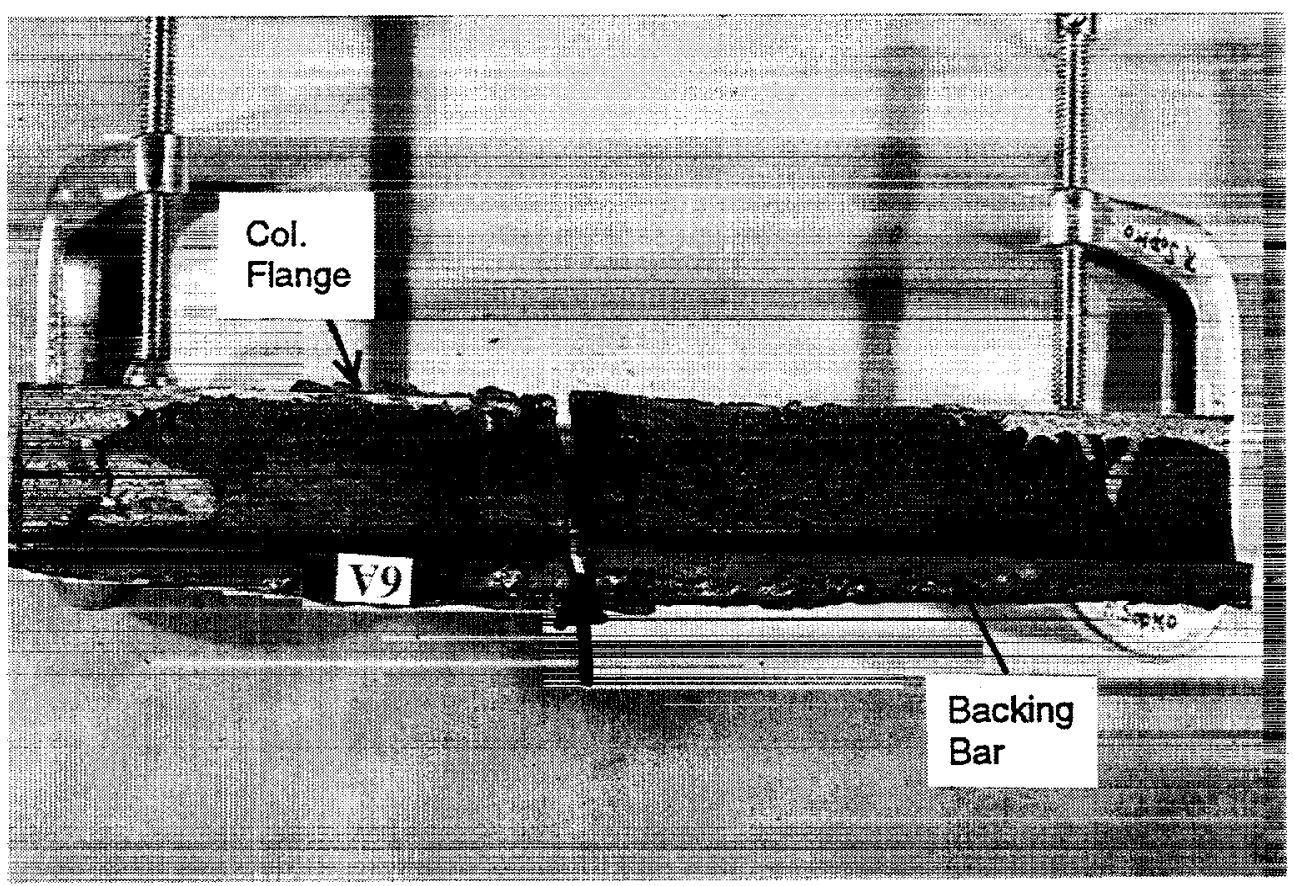

Figure 25 - Column flange fracture surface from Sample A6. Arrow indicates location of fracture origin.

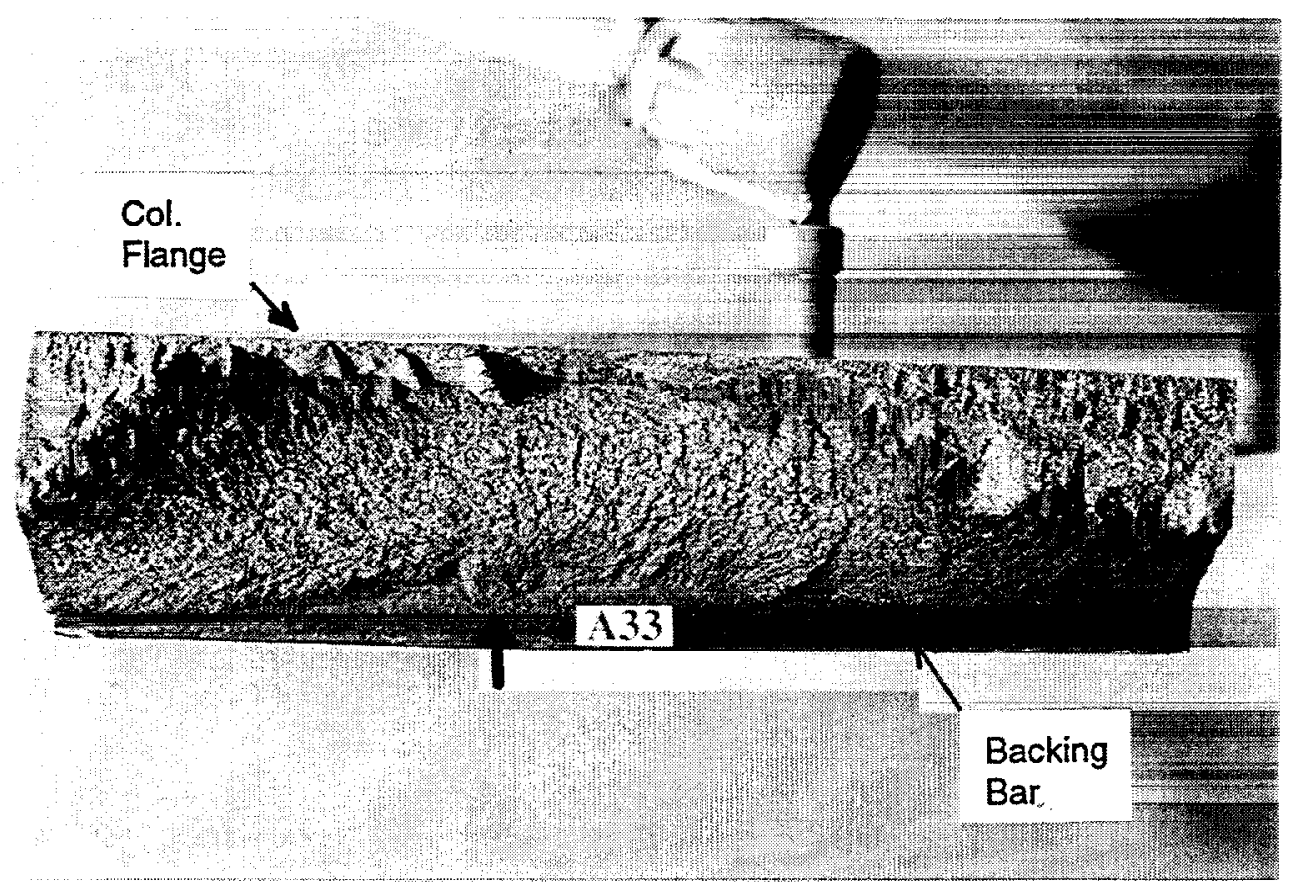

Figure 26 - Column flange fracture surface from Sample A33. Arrow indicates location of fracture origin. 


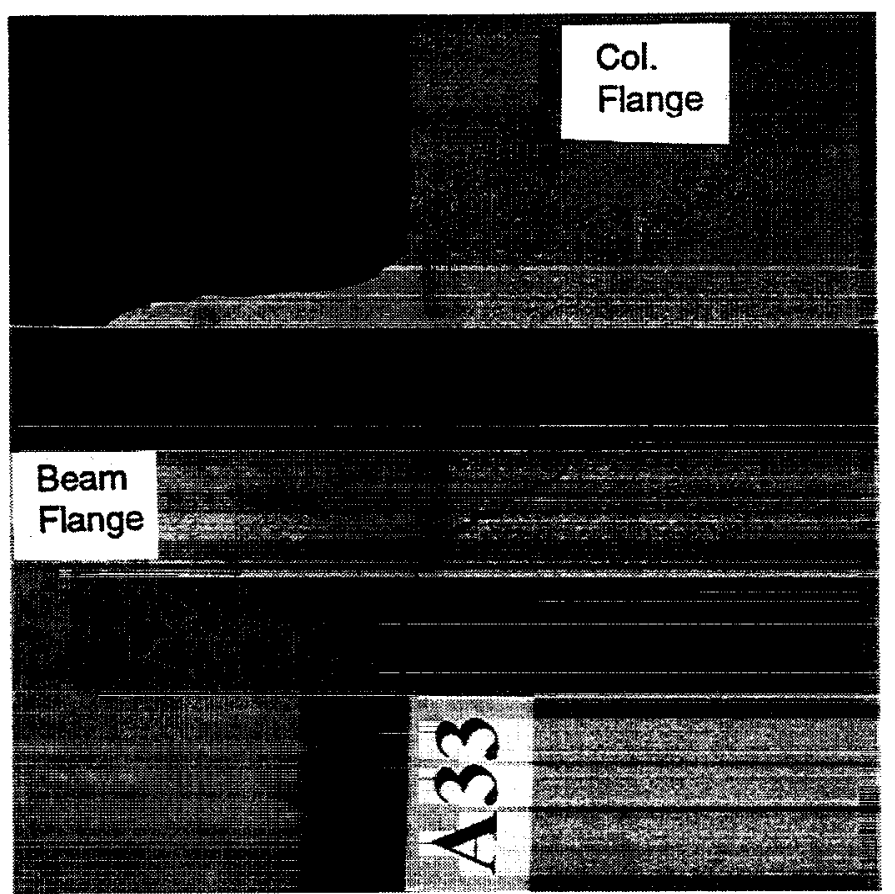

Figure 27 - Cross-section of fracture in Sample A33.

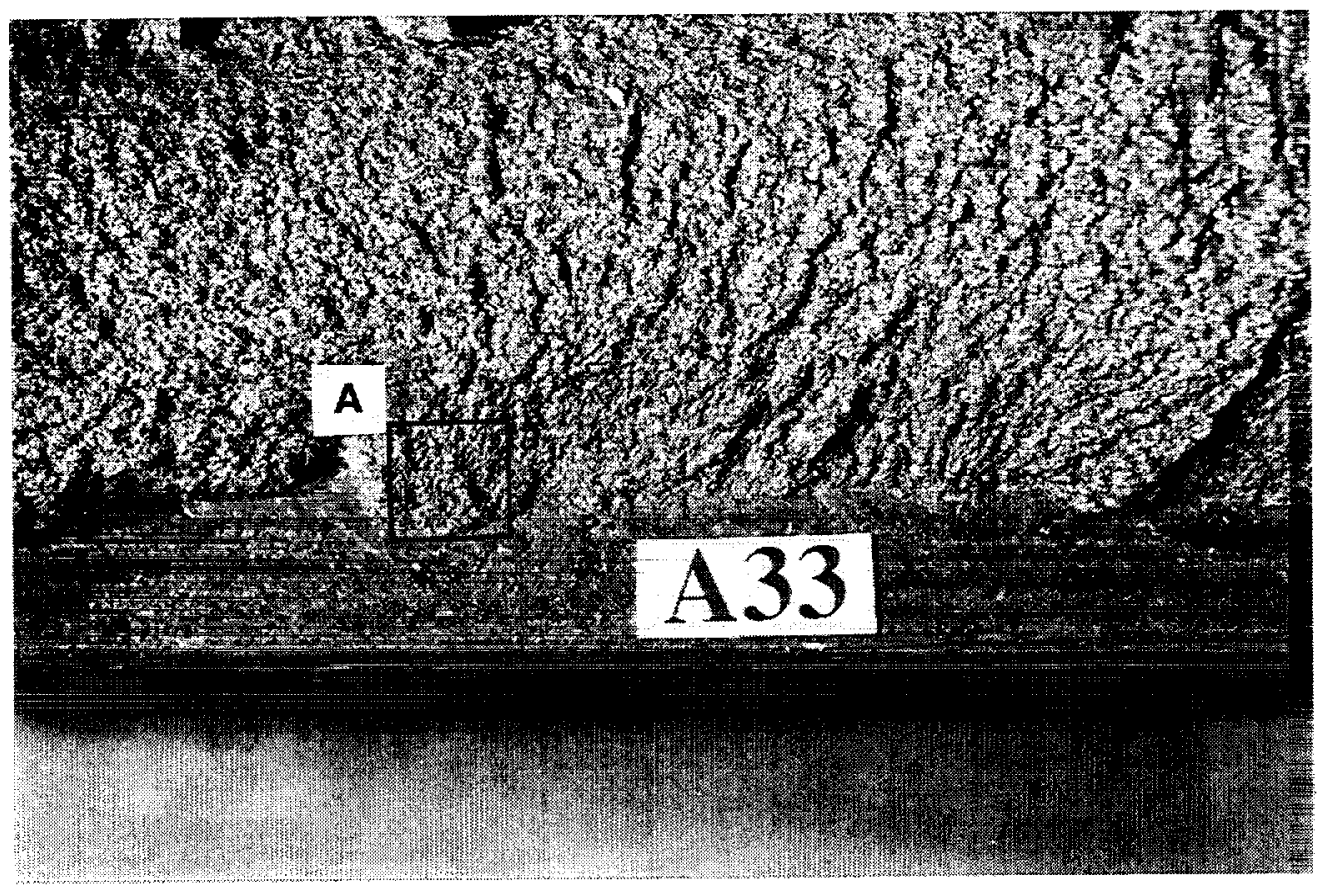

Figure 28 - Enlarged view of fracture origin area of Sample A33. Note incomplete fusion along weld root. 


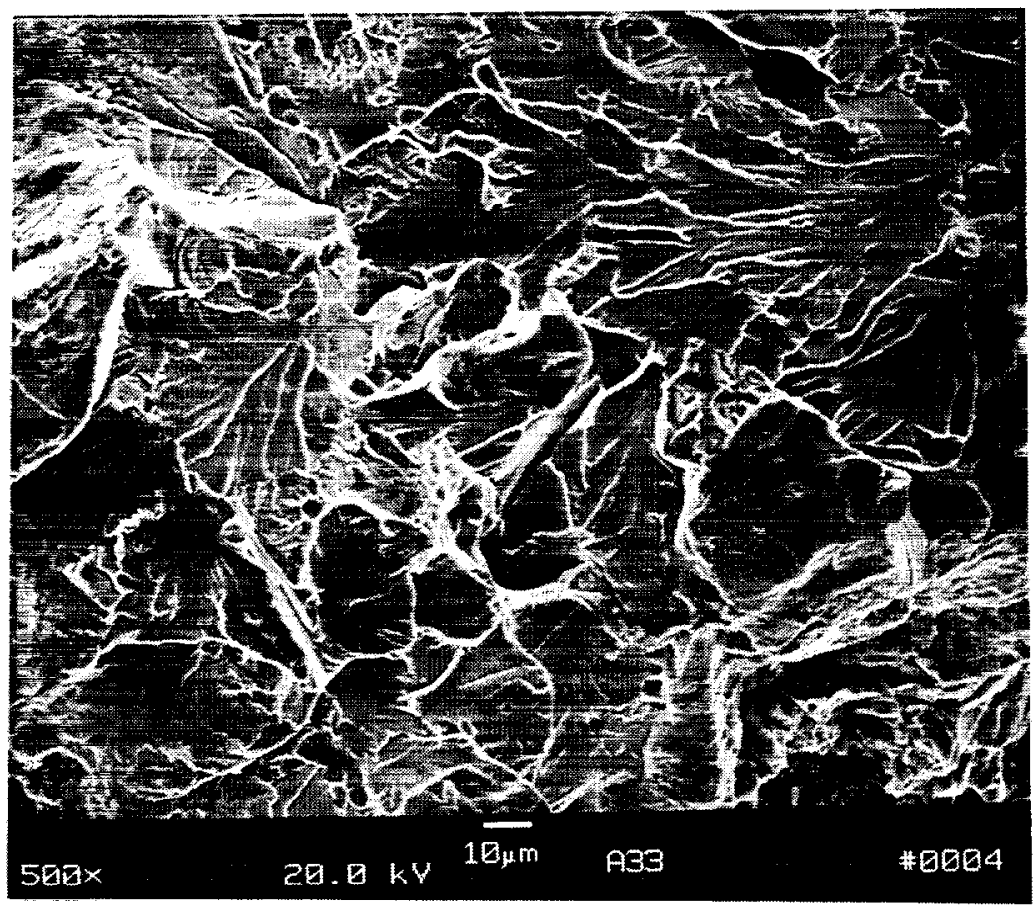

Figure 29 - SEM micrograph of the fracture origin (Area marked "A" in Figure 28) showing cleavage fracture. (Mag. 500X)

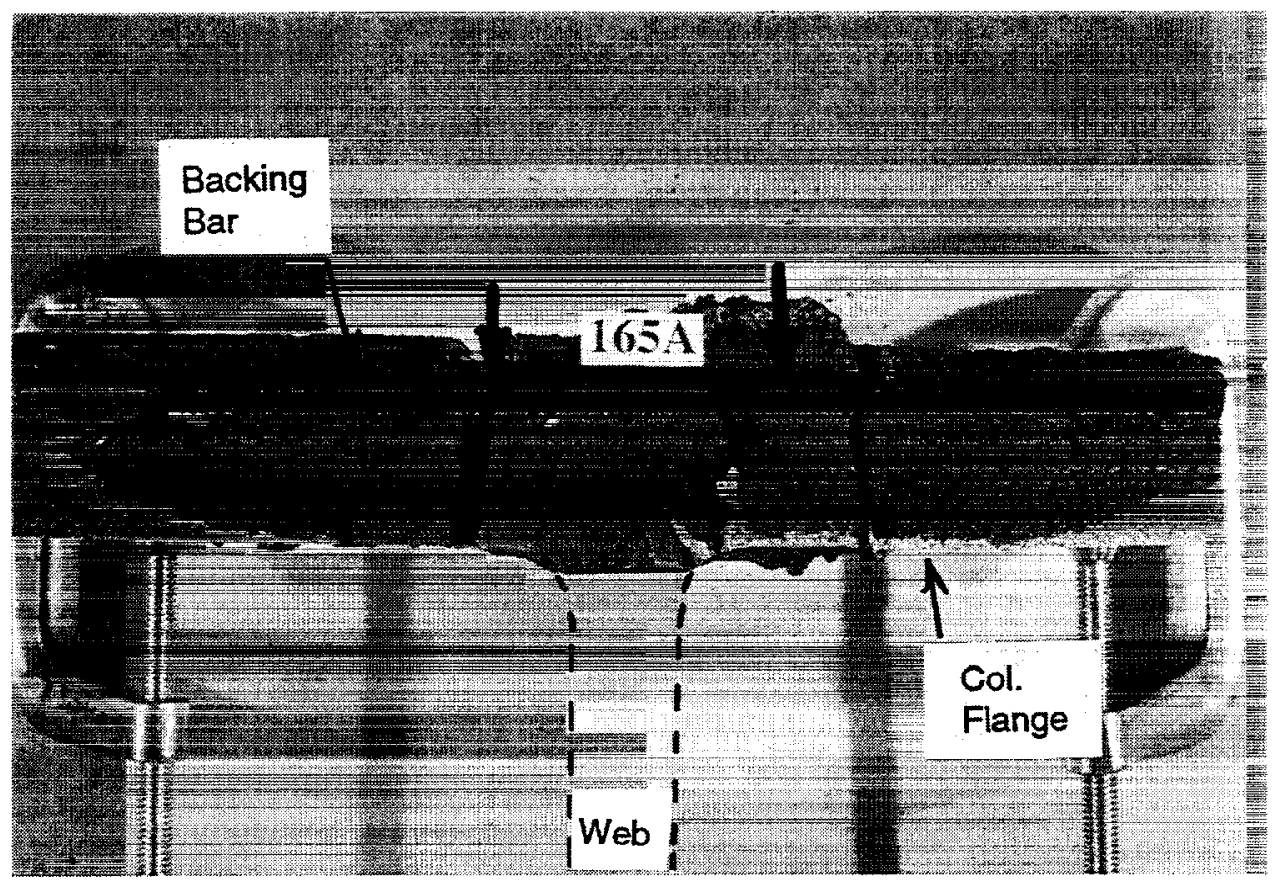

Figure 30 - Fracture surface of Sample A165. Arrow shows location of fracture origin. 


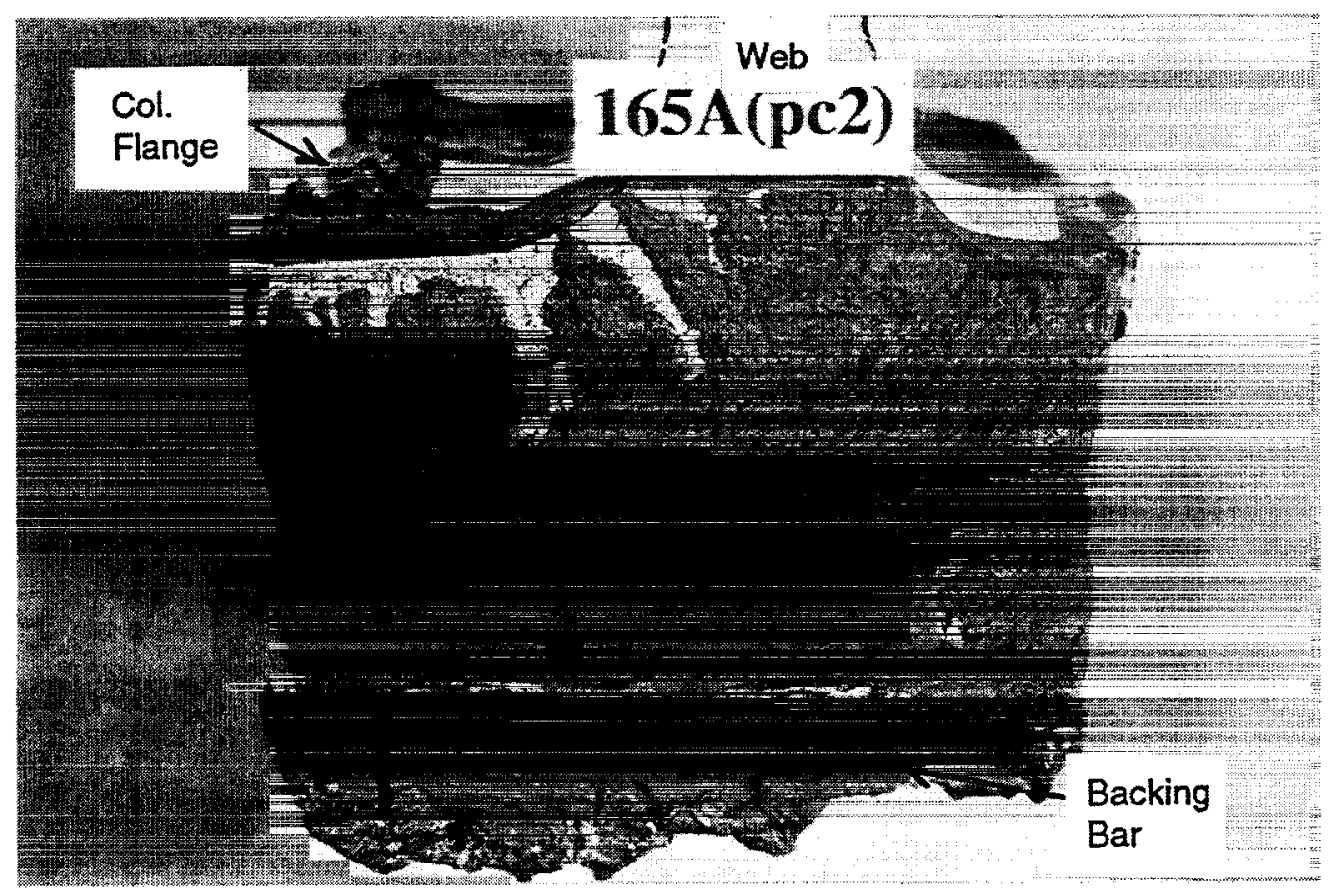

Figure 31 - Enlarged view of the fracture origin area at the weld root of Sample A165.

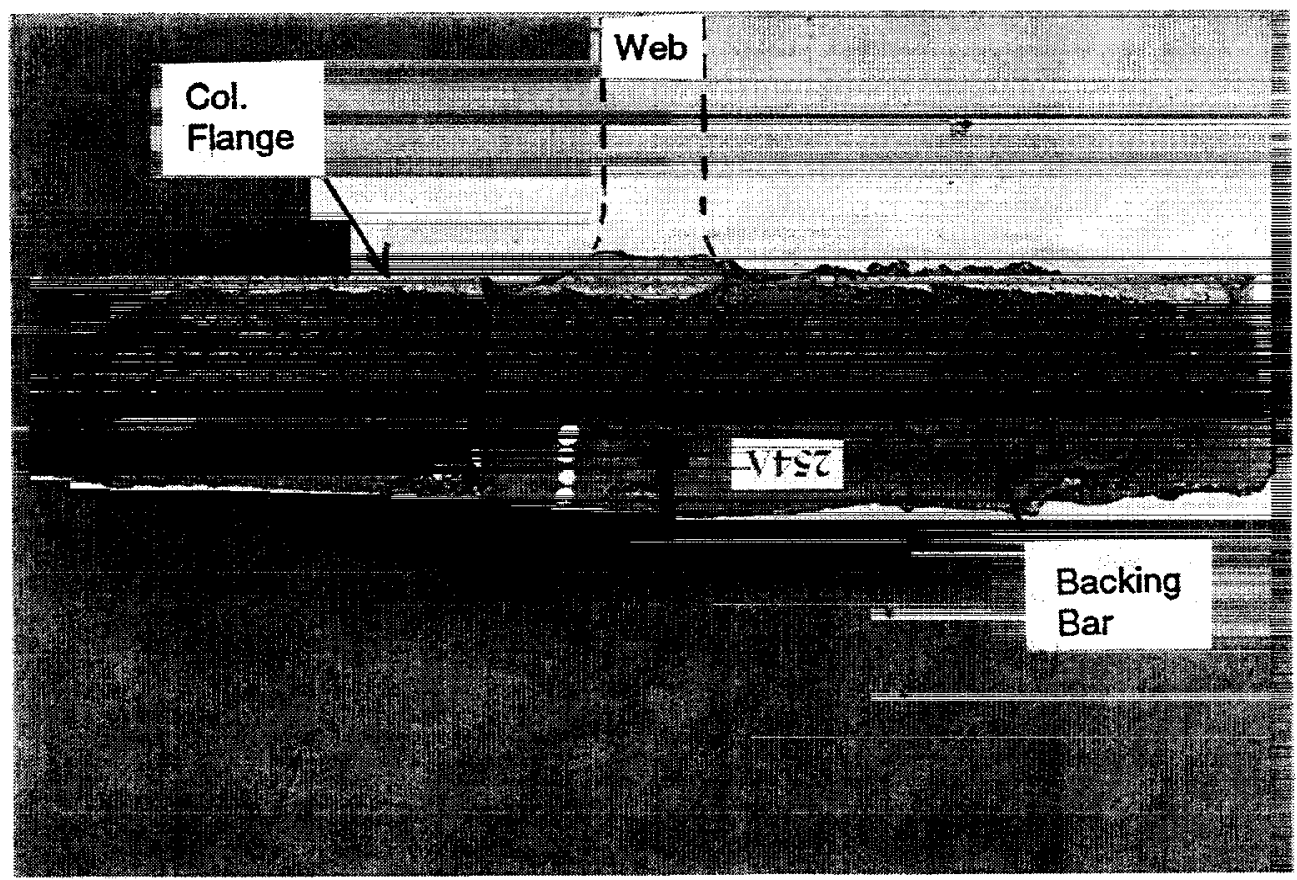

Figure 32 - Fracture surface from Sample A254. Arrow shows location of fracture origin. 


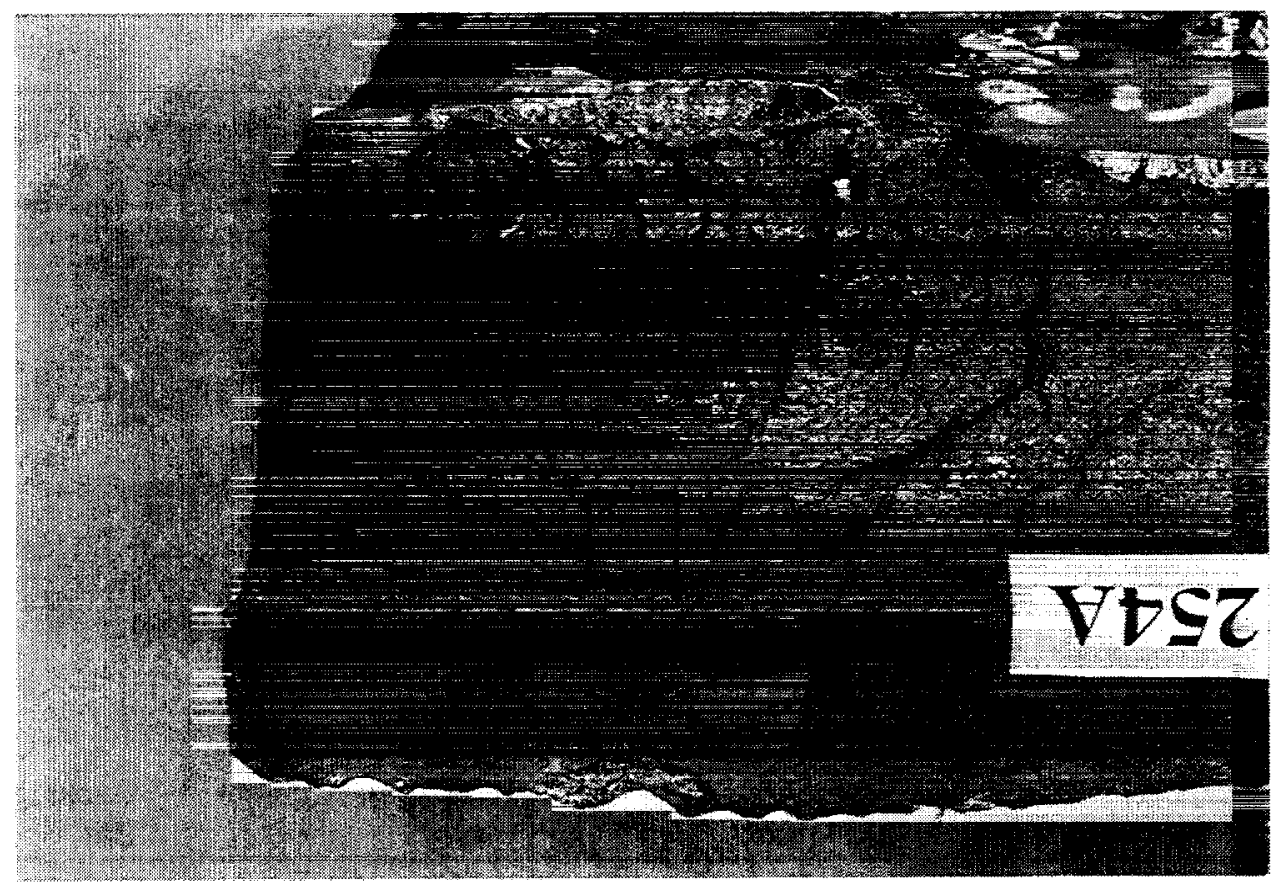

Figure 33 - Enlarged view of the fracture origin area at the weld root of Sample A254.

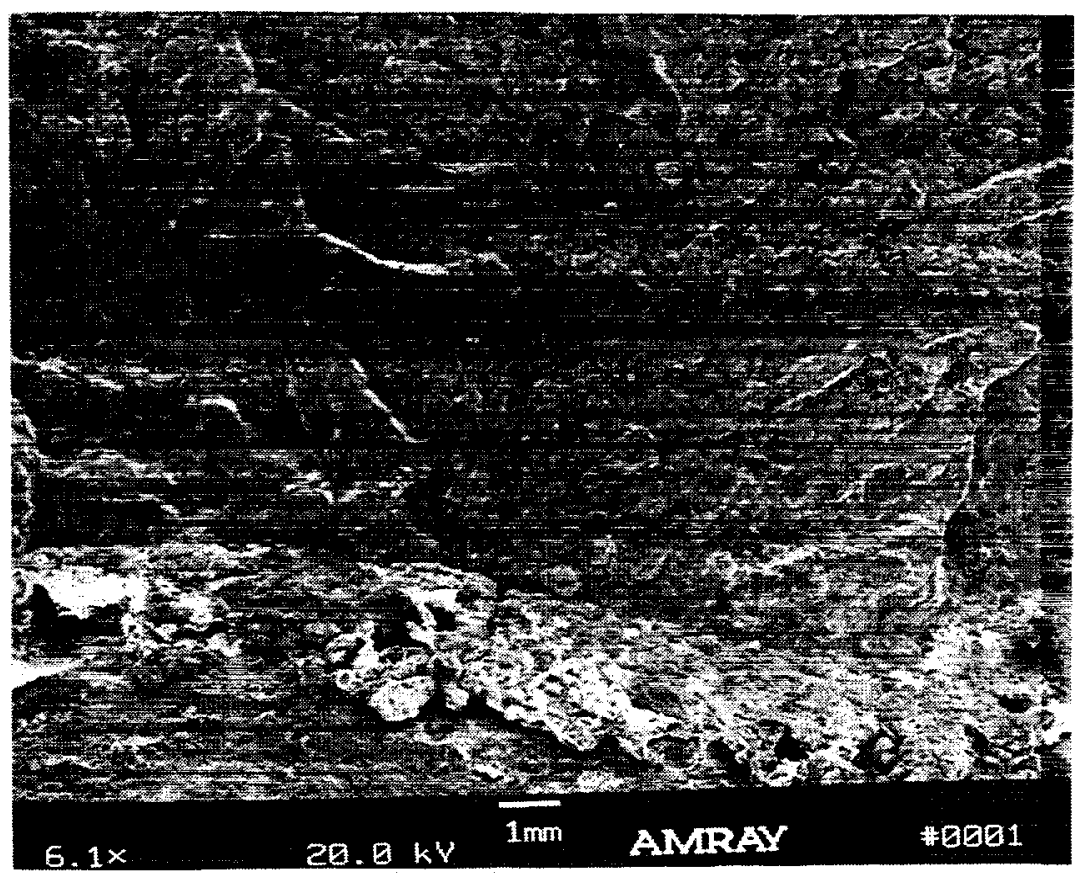

Figure 34 - Low magnification SEM micrograph of the fracture origin area of Sample A254. (Boxed area seen in Figure 33) (Mag. 6.1X). 

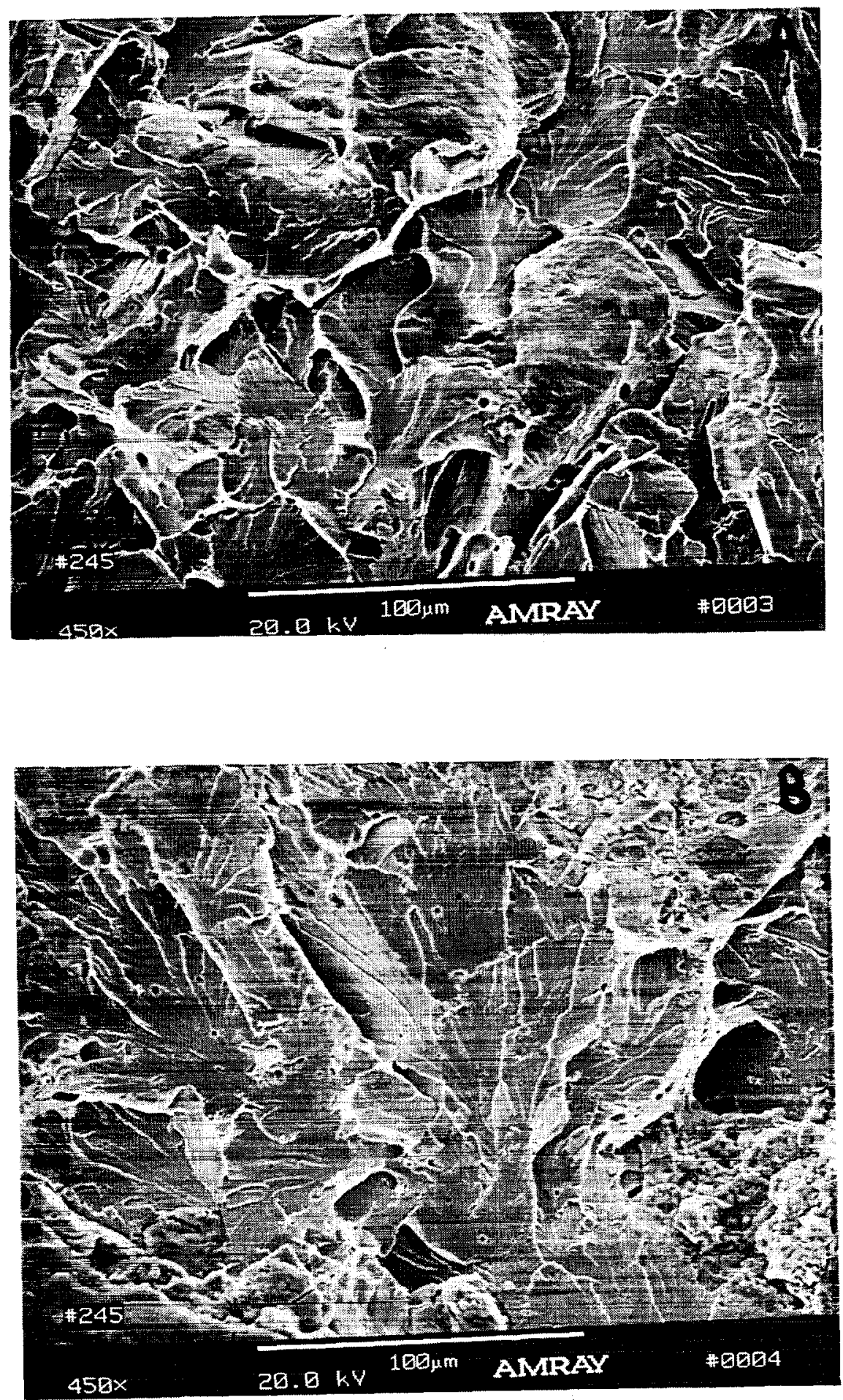

Figure 35 - Higher magnification micrographs of the fracture origin of Sample A254 showing cleavage fracture. (Mag. 450X)

Top: Boxed area "A" in Figure 34. Bottom: Boxed area "B" in Figure 34. 


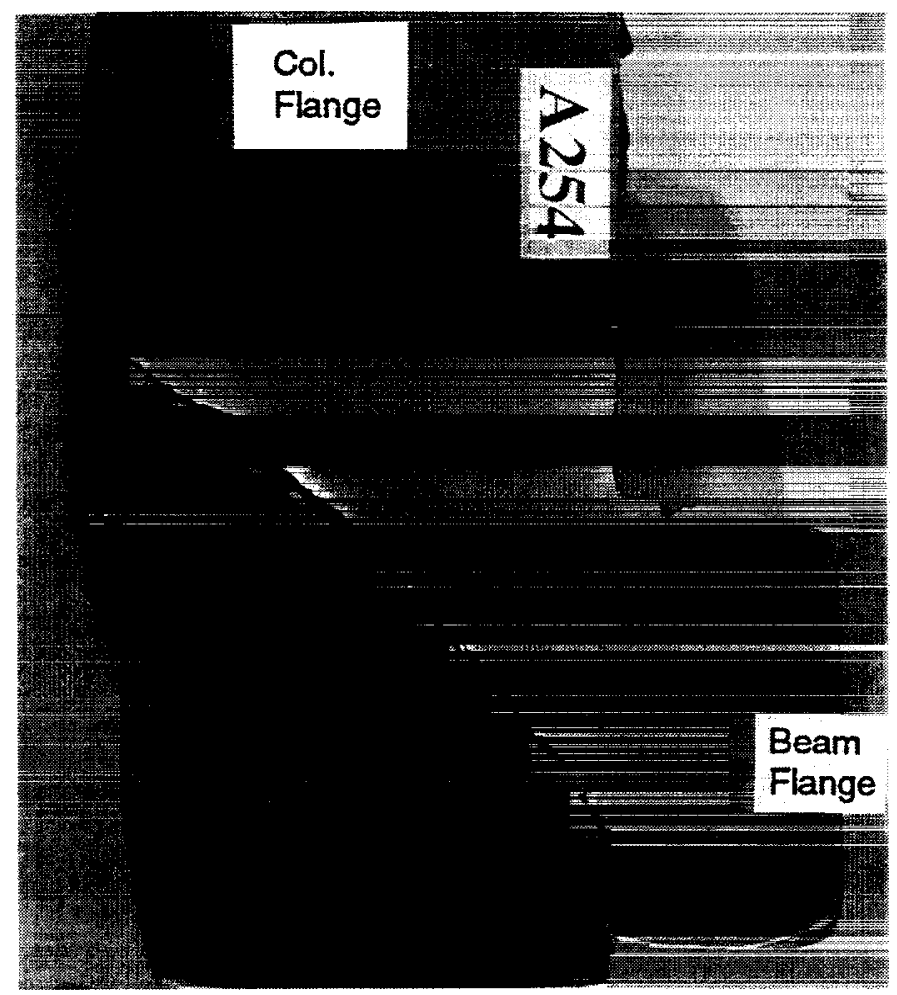

Figure 36 - Cross-section of fracture in Sample A254 adjacent to the fracture origin.

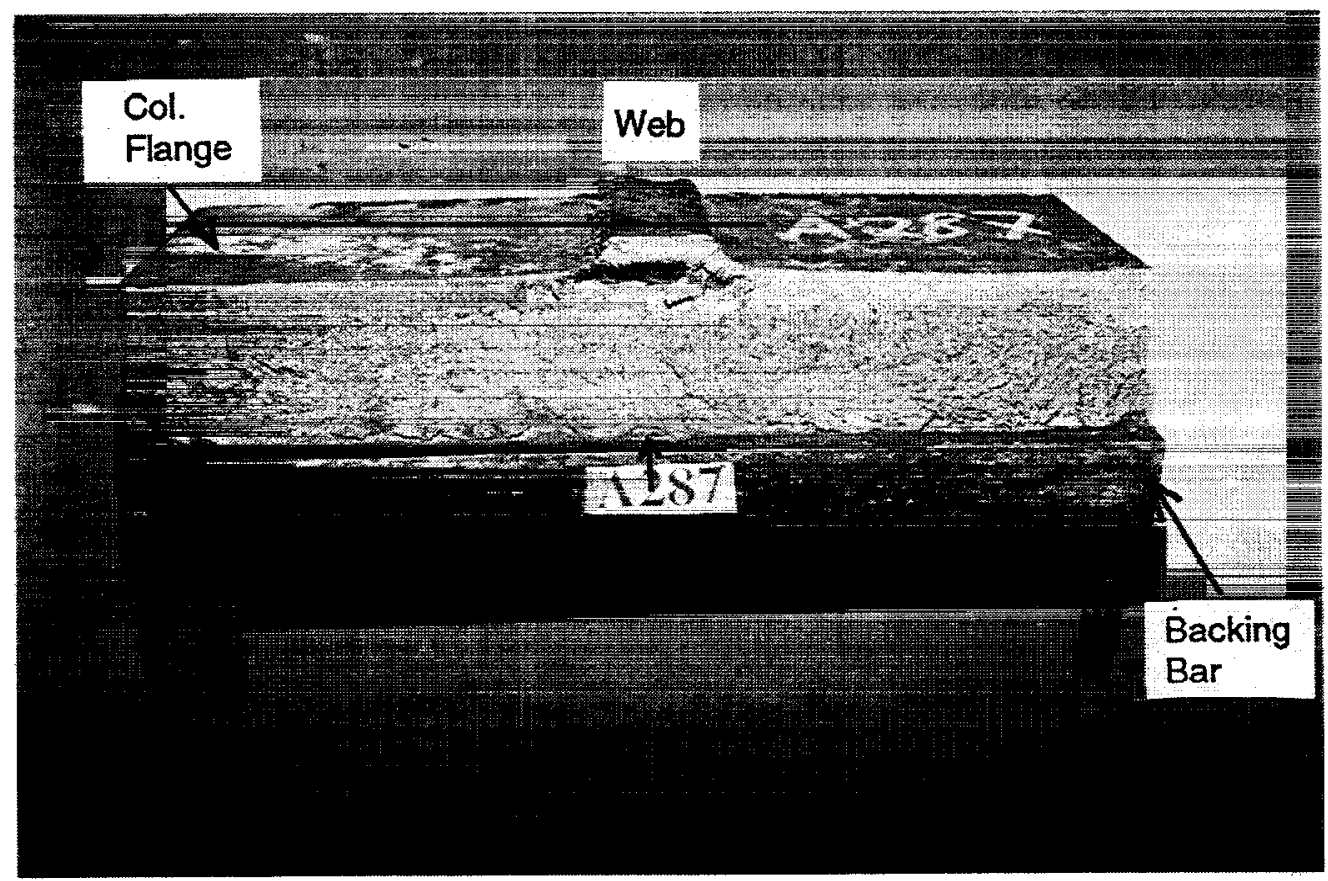

Figure 37 - Fracture surface of Sample A287. Arrow shows location of fracture origin. 


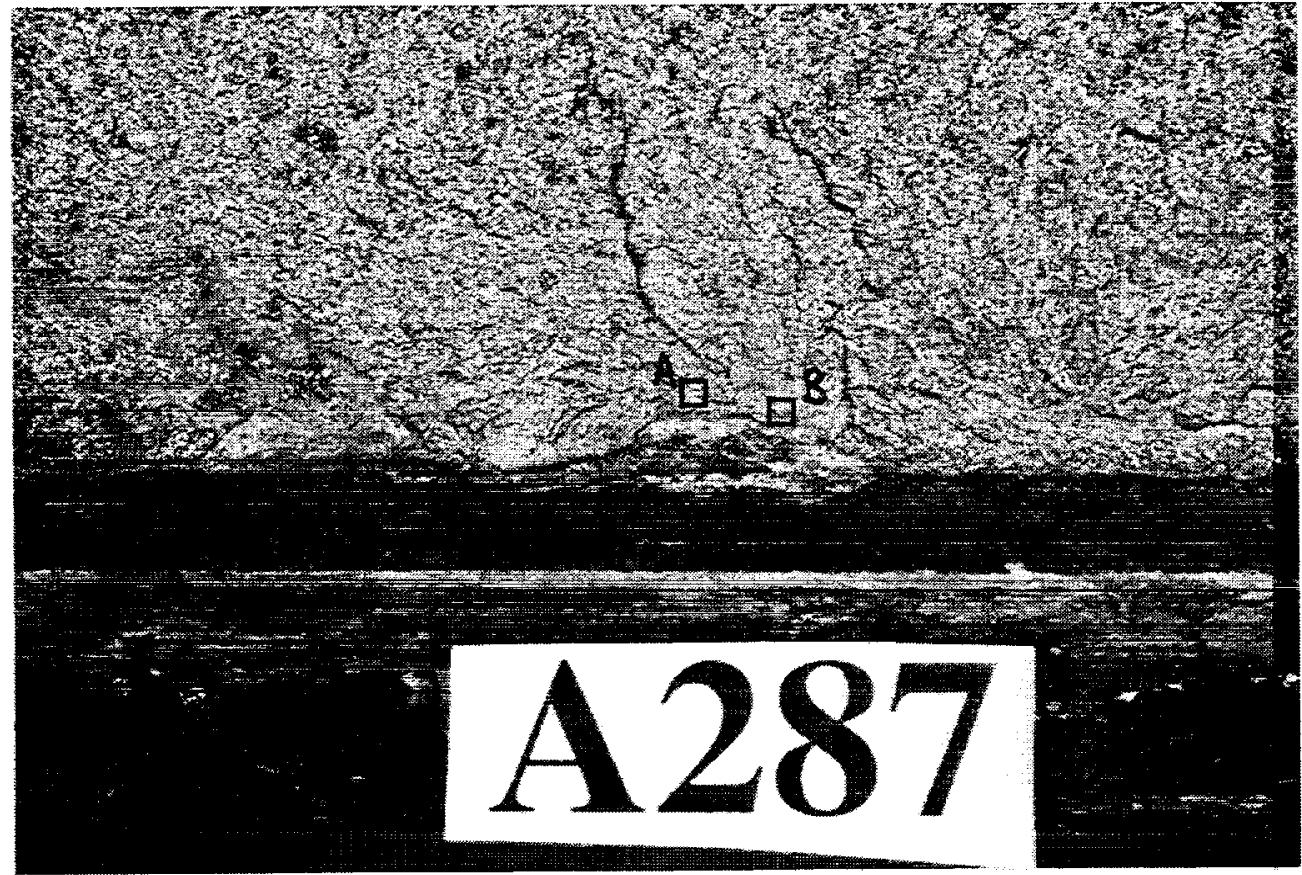

Figure 38 - Enlarged view of the weld root fracture origin in Sample A287.

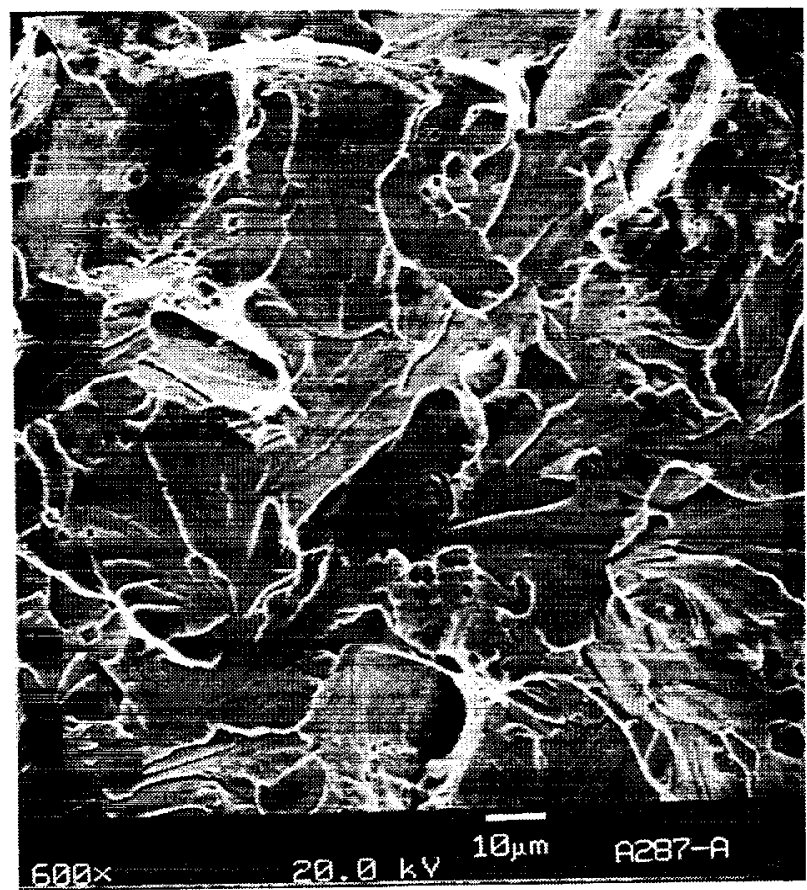

Area A

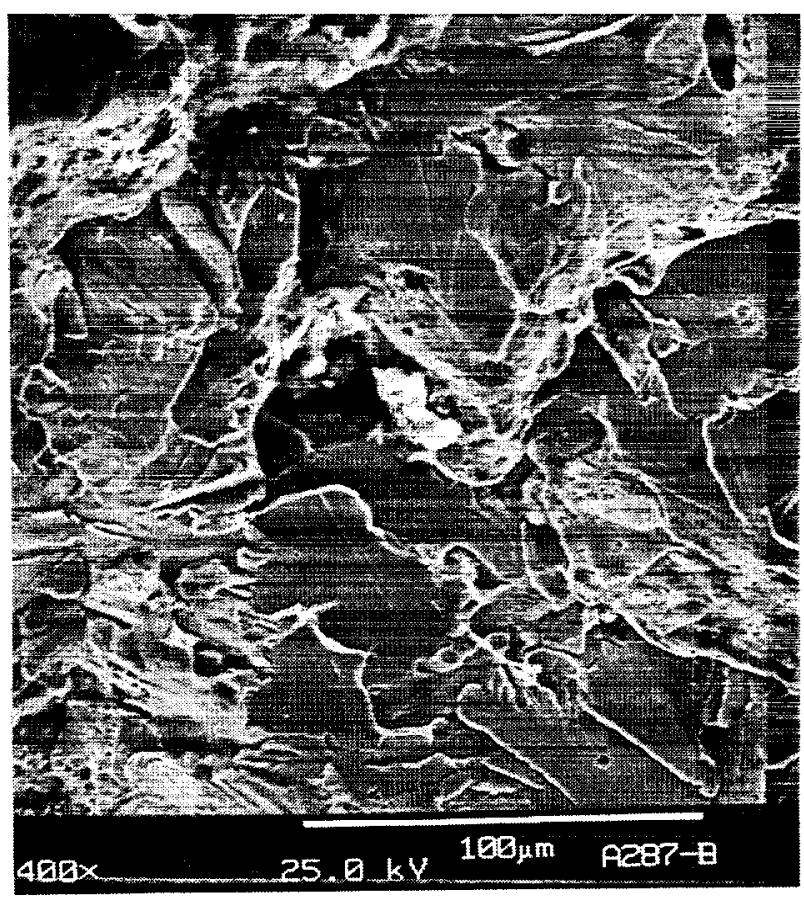

Area B

Figure 39 - SEM micrographs of the crack surface obtained adjacent to the weld root flaw in Sample A287. (Boxed areas "A" and "B" in Figure 38) 


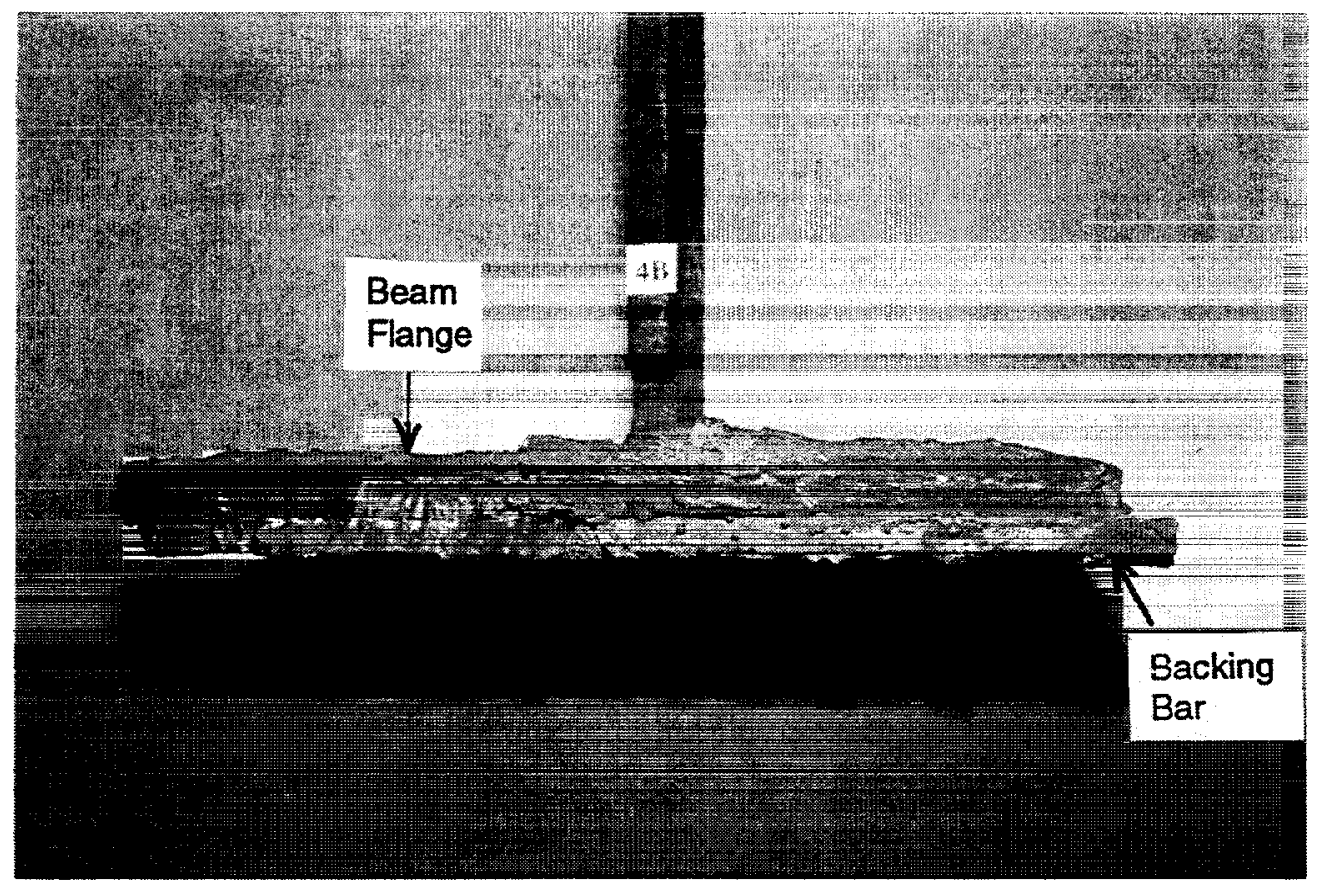

Figure 40 - Fracture surface from Sample B4 showing arc gouging damage. Fracture path is near the weld fusion line.

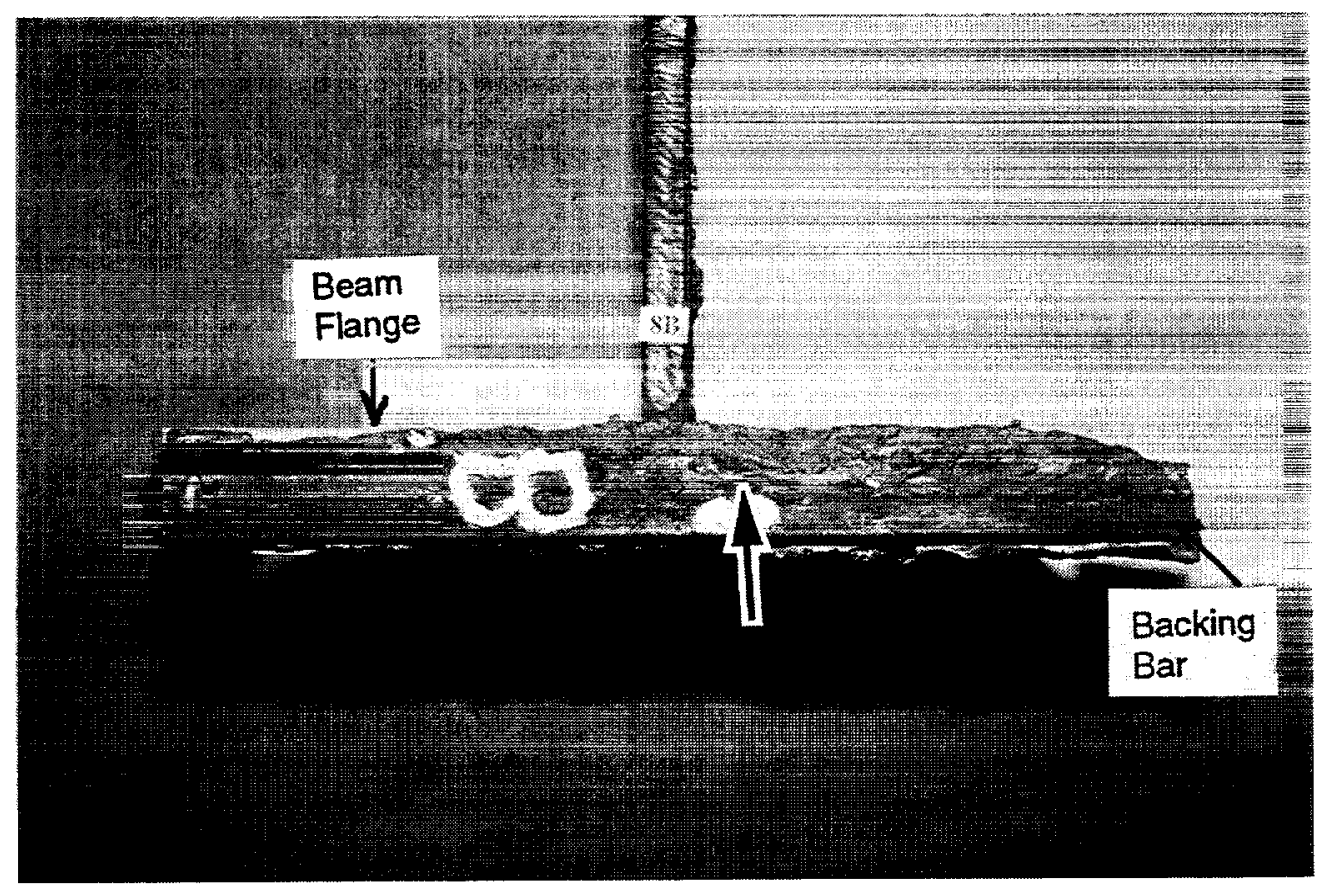

Figure 41 - Fracture surface from Sample B8. Fracture path is near the weld fusion line. Arrow shows location of fracture origin. 


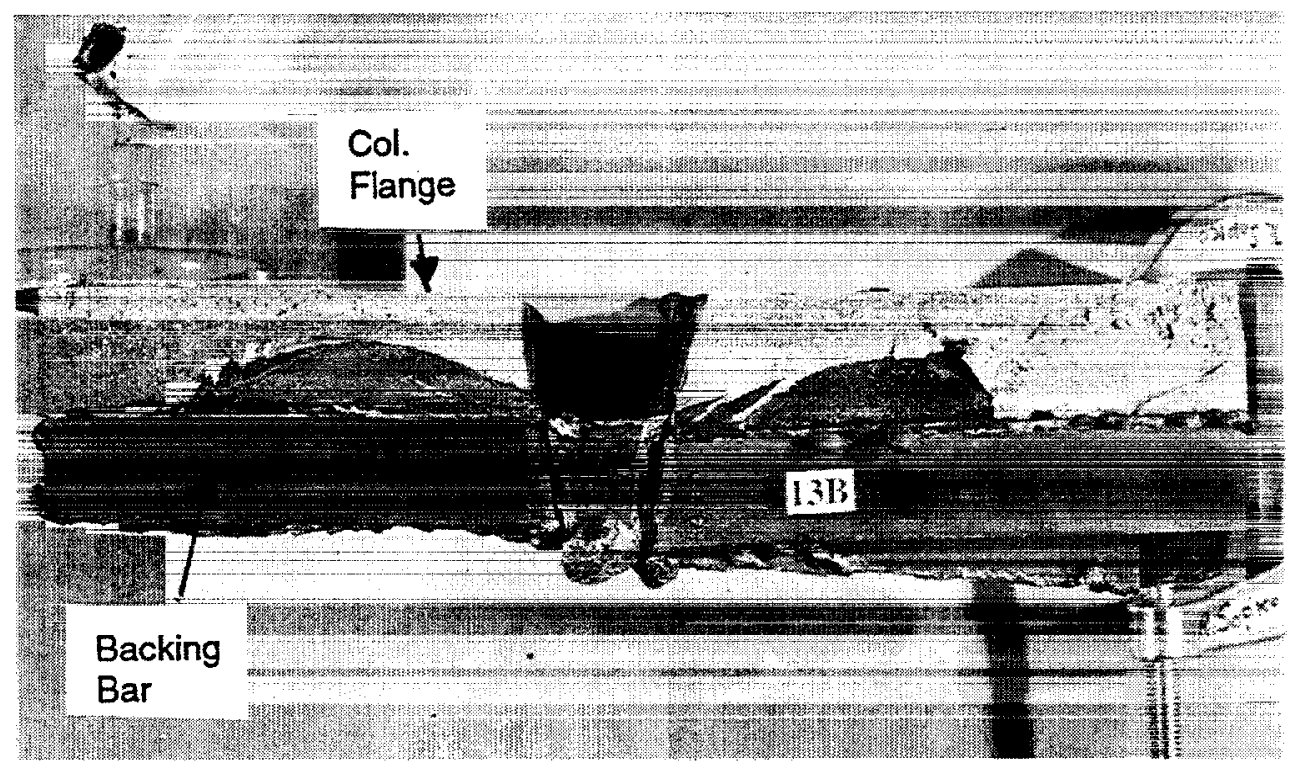

Figure 42 - Fracture surface from Sample B13 showing a portion of the divot fracture exposed. The fracture origin is located within the missing area of the surface at the web centerline.
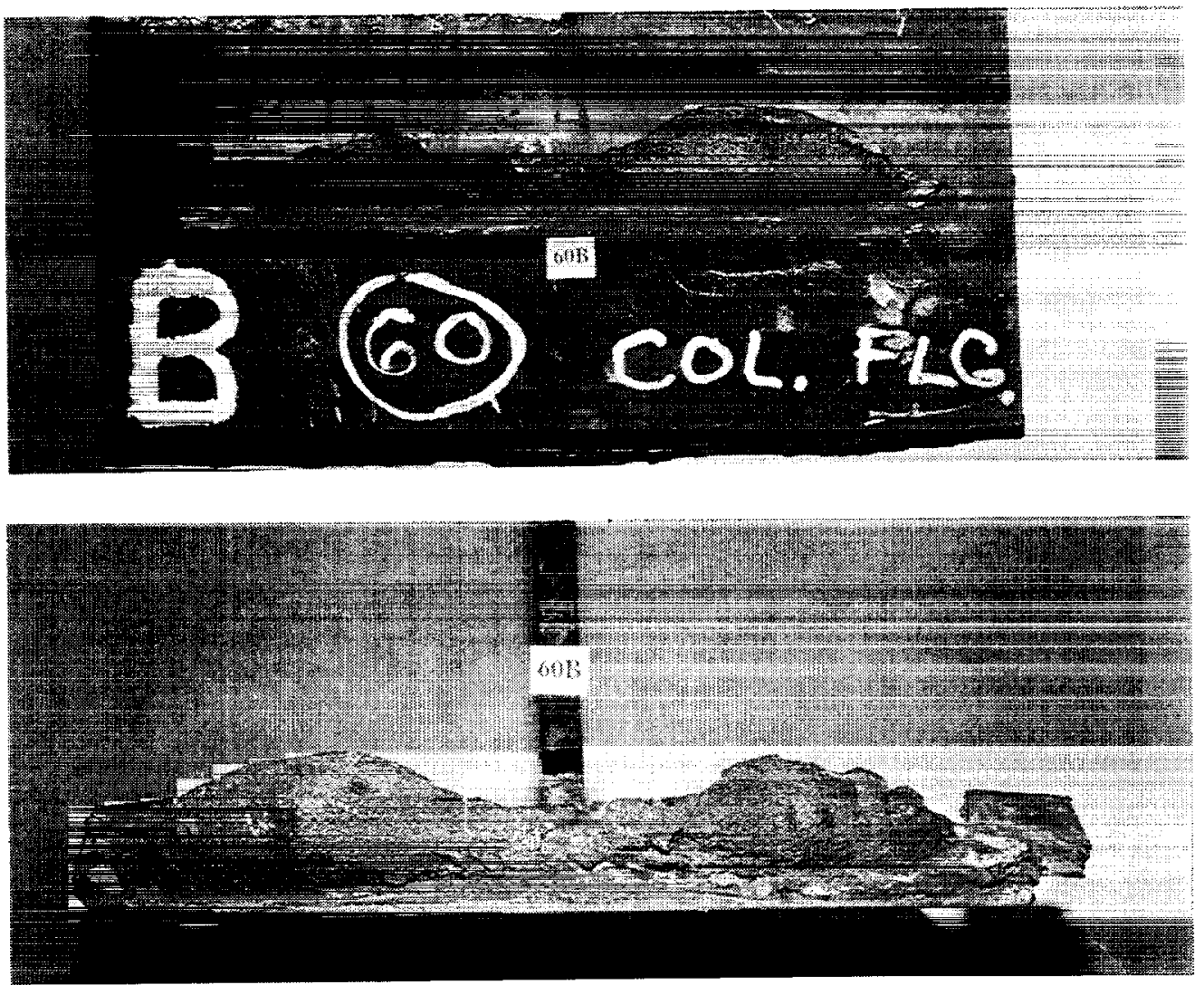

Figure 43 - Column divot fracture surface from Sample B60. Arrow shows the location of the fracture origin. 


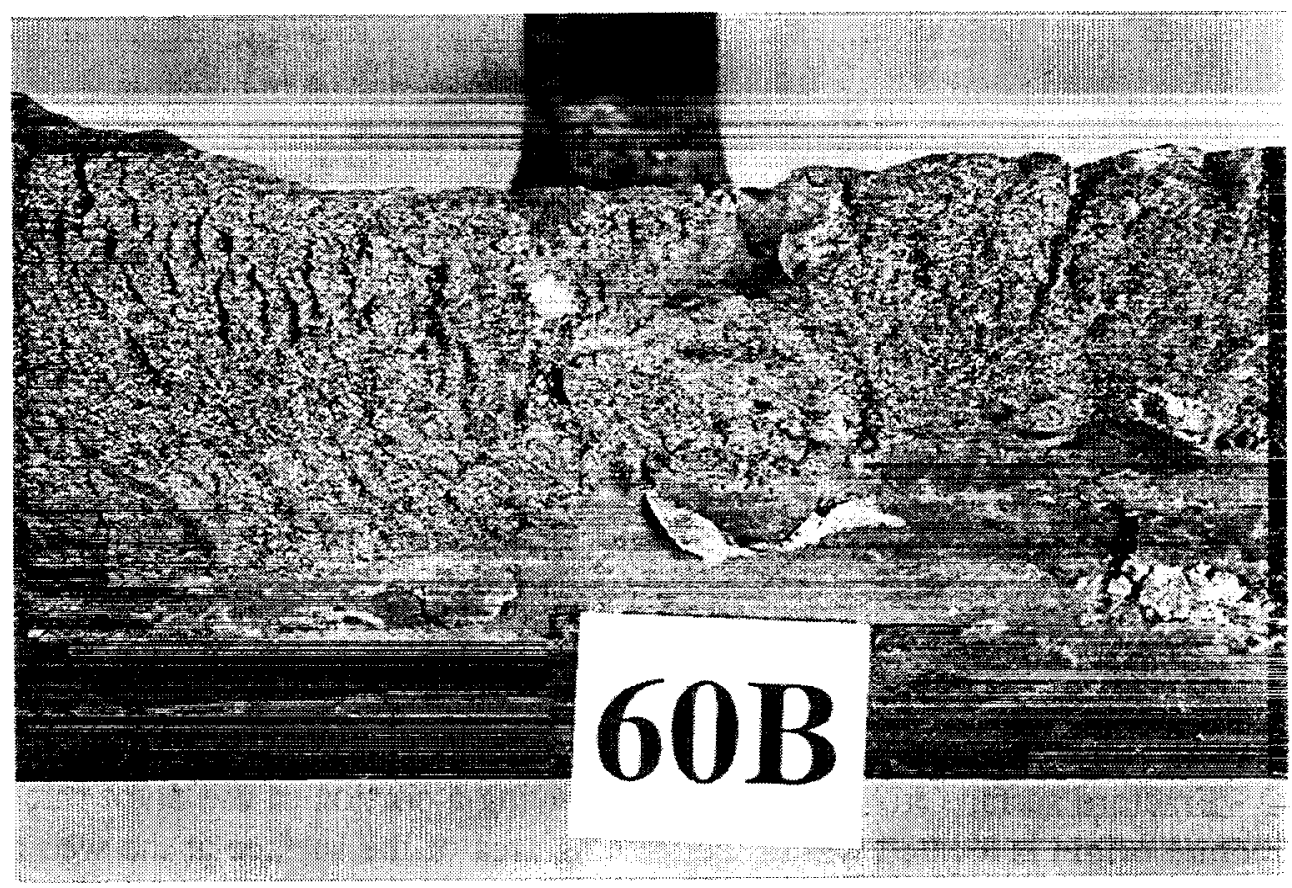

Figure 44 - Enlarged view of the fracture origin of Sample B60 showing a deep weld root incomplete fusion flaw.

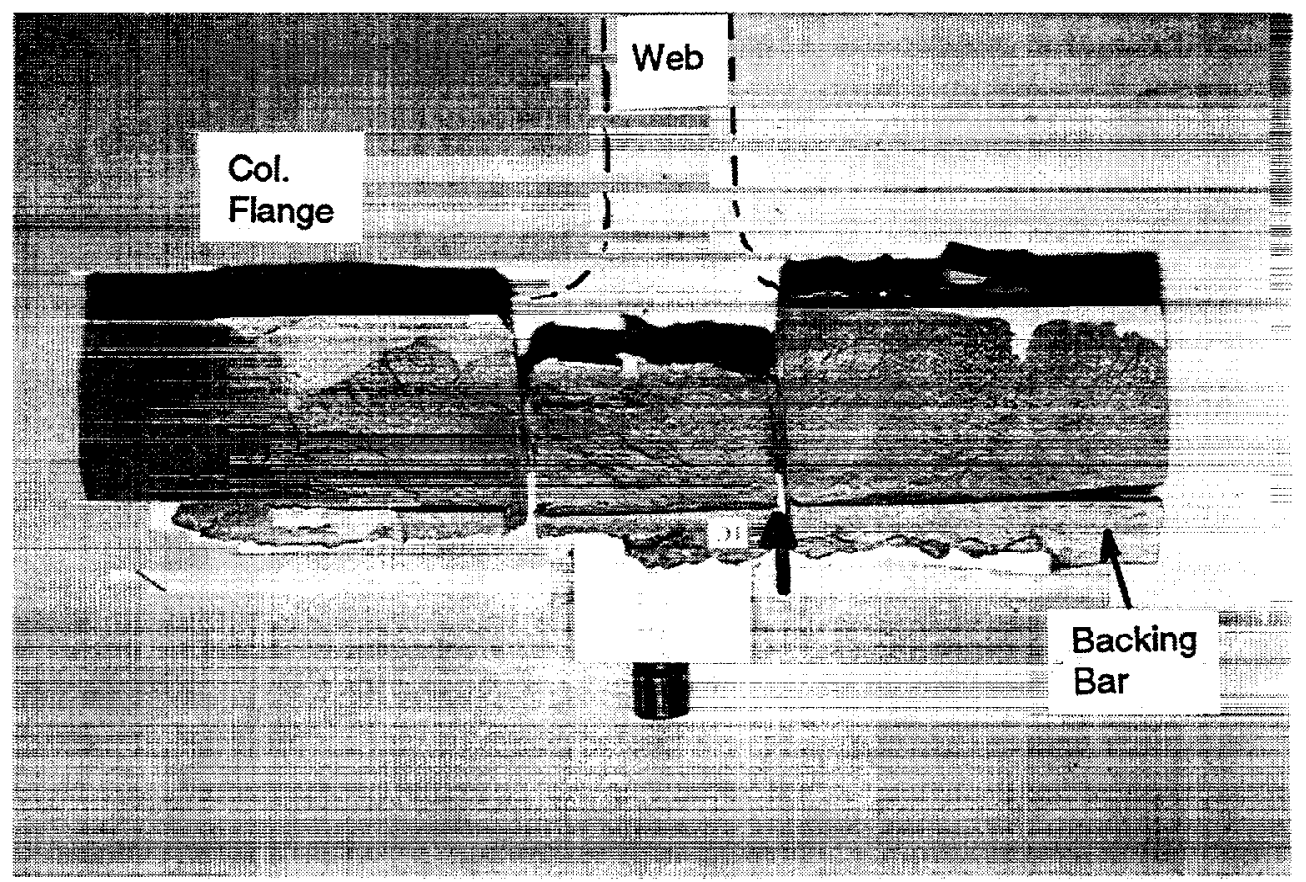

Figure 45 - Fracture surface of Sample C1. Arrow shows the location of the fracture origin eliminated during removal of the sample. 


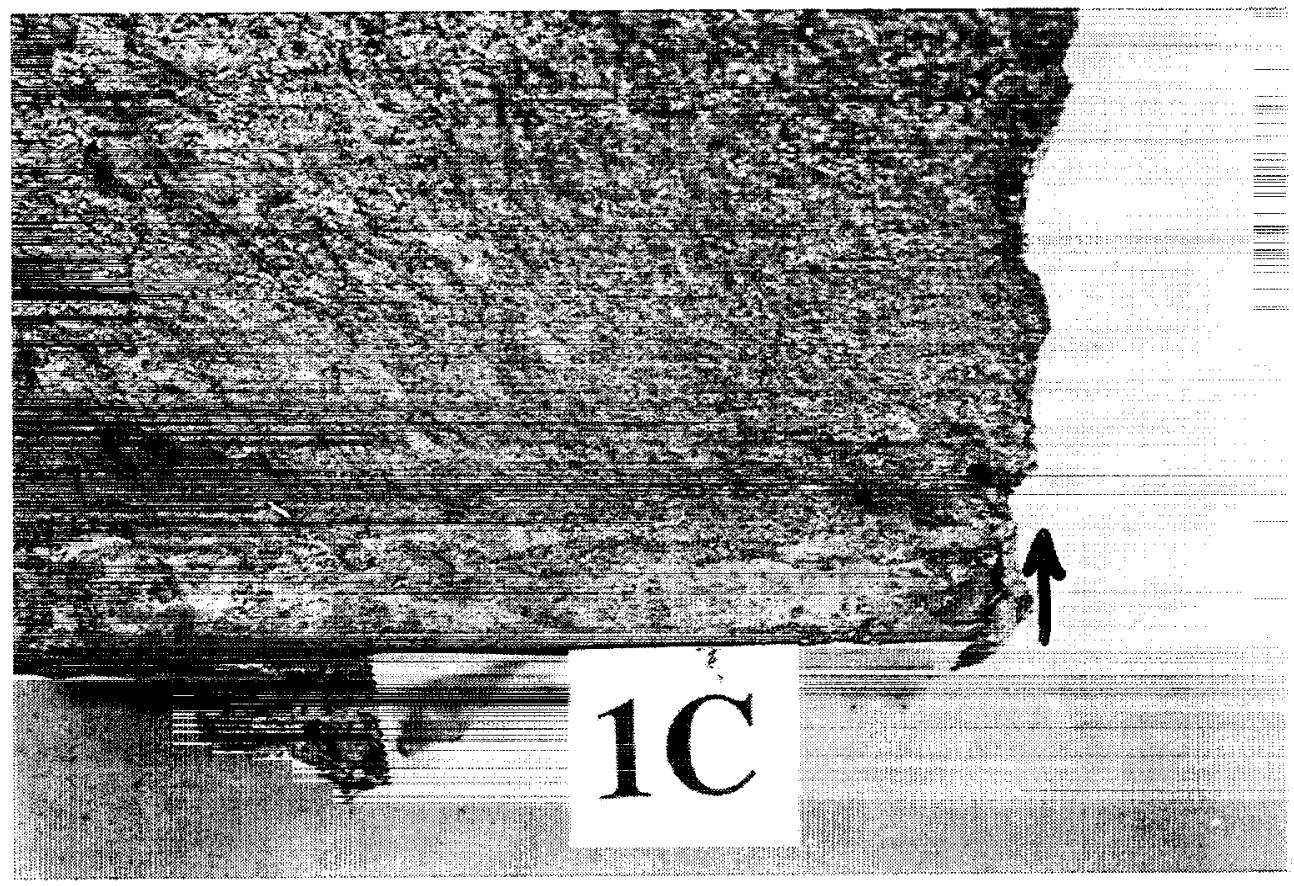

Figure 46 - Enlarged view of the crack surface from Sample C1 next to the fracture origin.

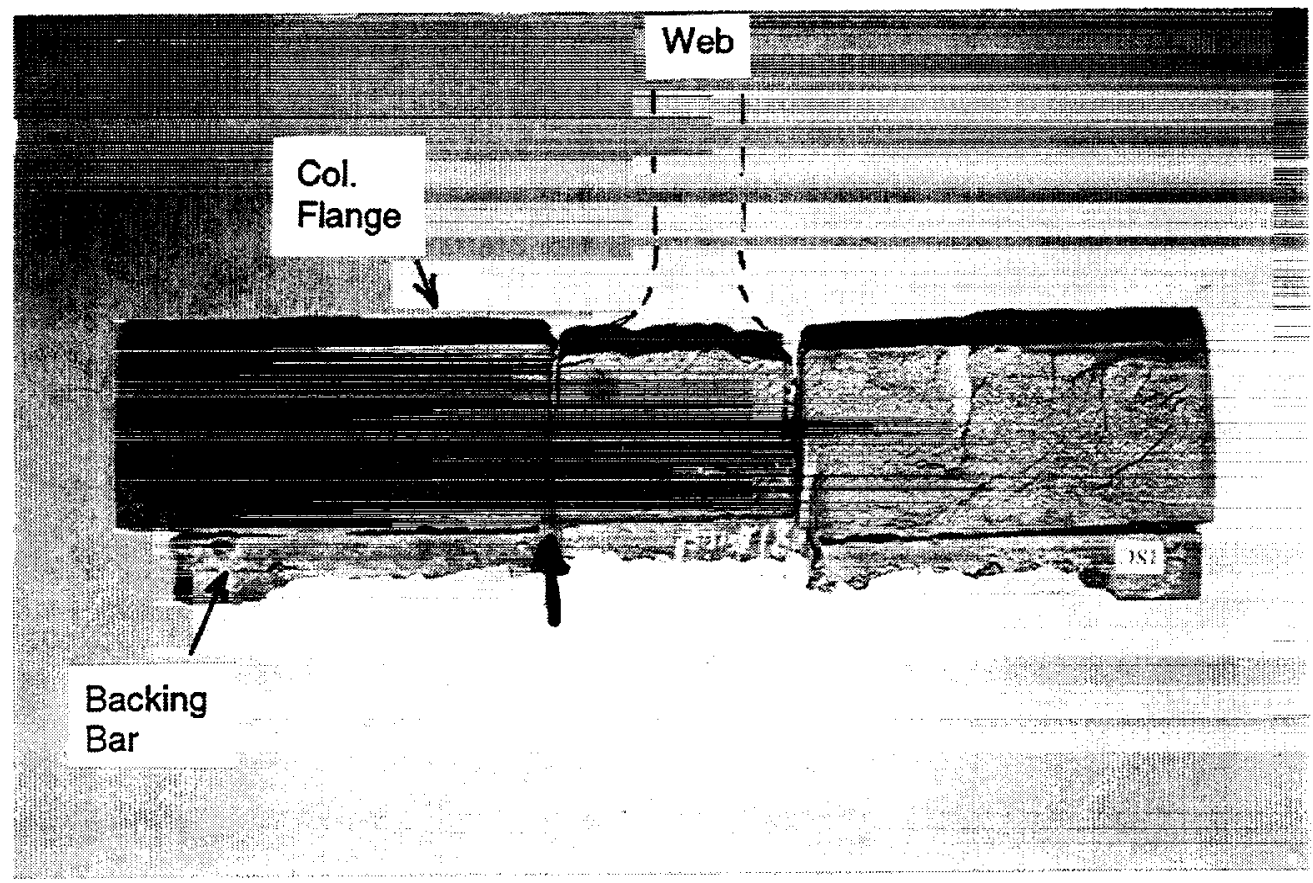

Figure 47 - Fracture surface from Sample C18. Arrow shows location of the fracture origin eliminated during sample removal. 


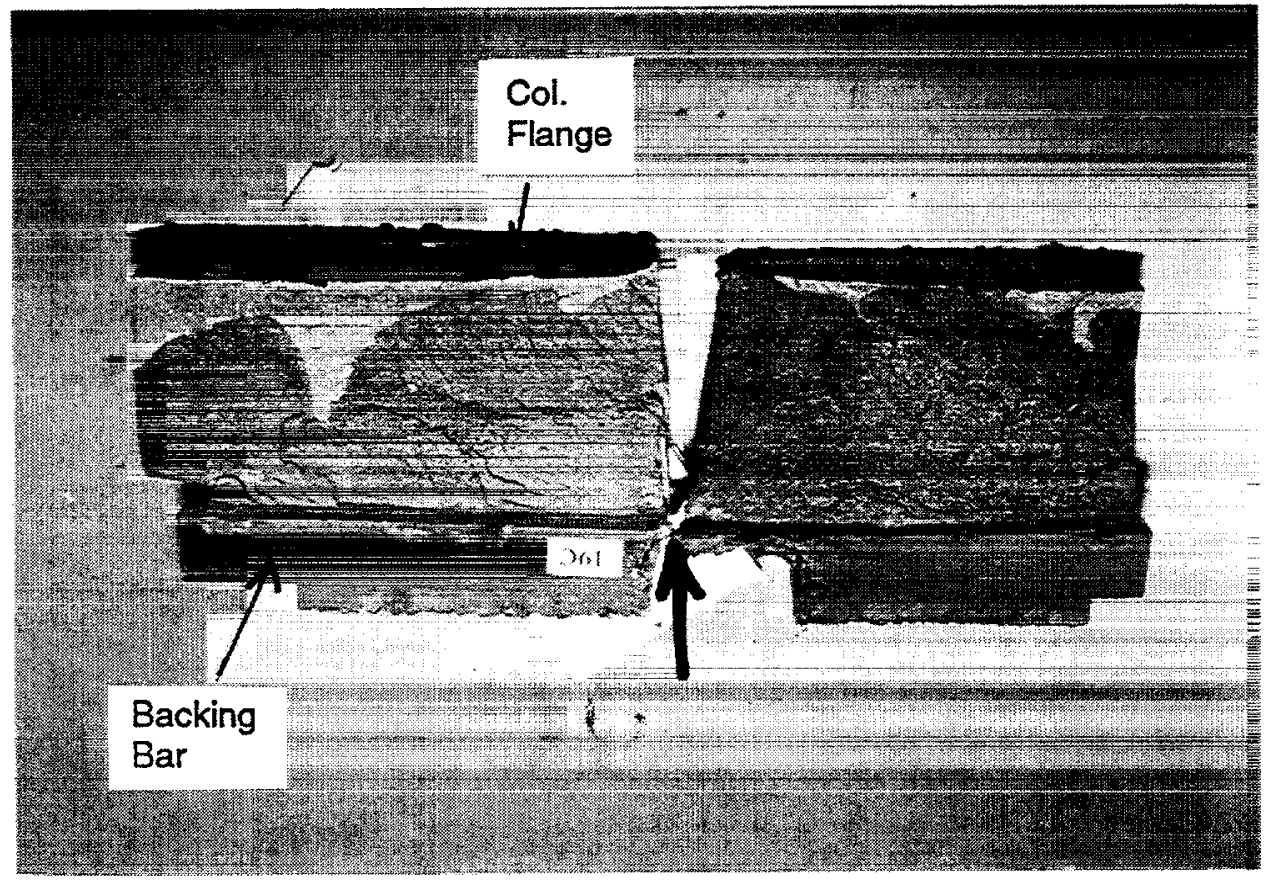

Figure 48 - Fracture surface from Sample C19. The fracture origin is located within the missing area of the fracture at the web centerline.

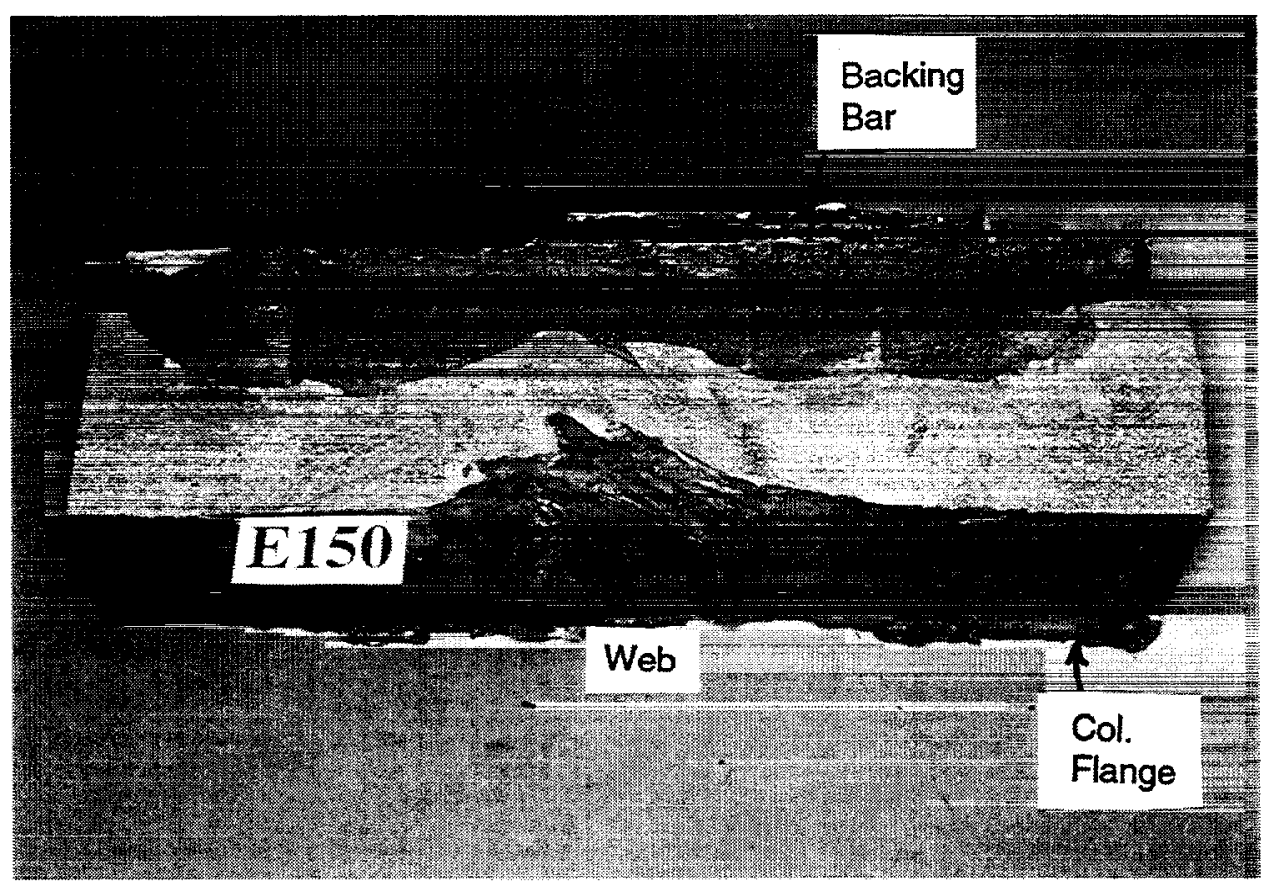

Figure 49 - Fracture surface from Sample E150 showing a portion of the divot fracture exposed. The fracture origin is located along the weld root at a location damaged by arc gouging (see arrow). 


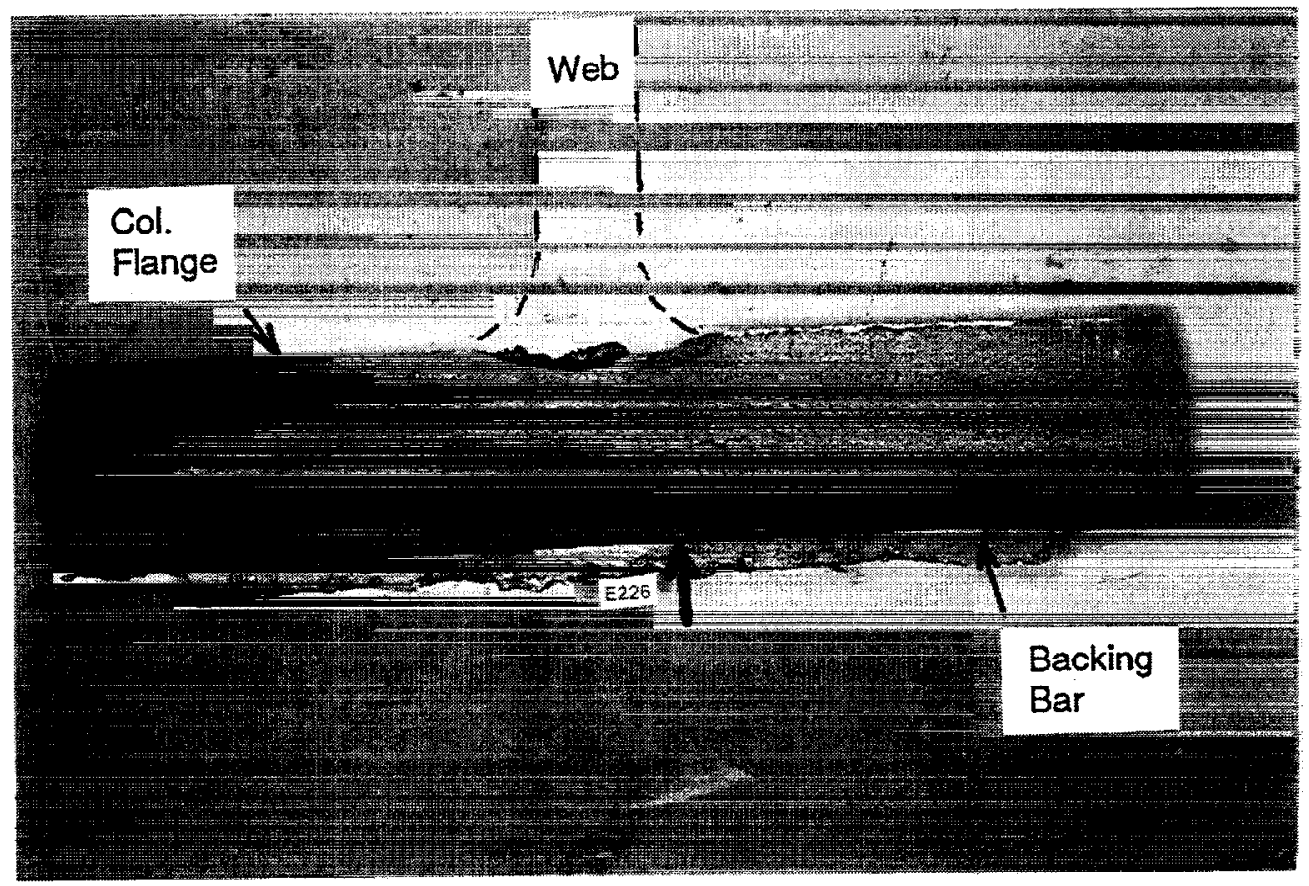

Figure 50 - Fracture surface from Sample E226. Arrow shows the location of the fracture origin.

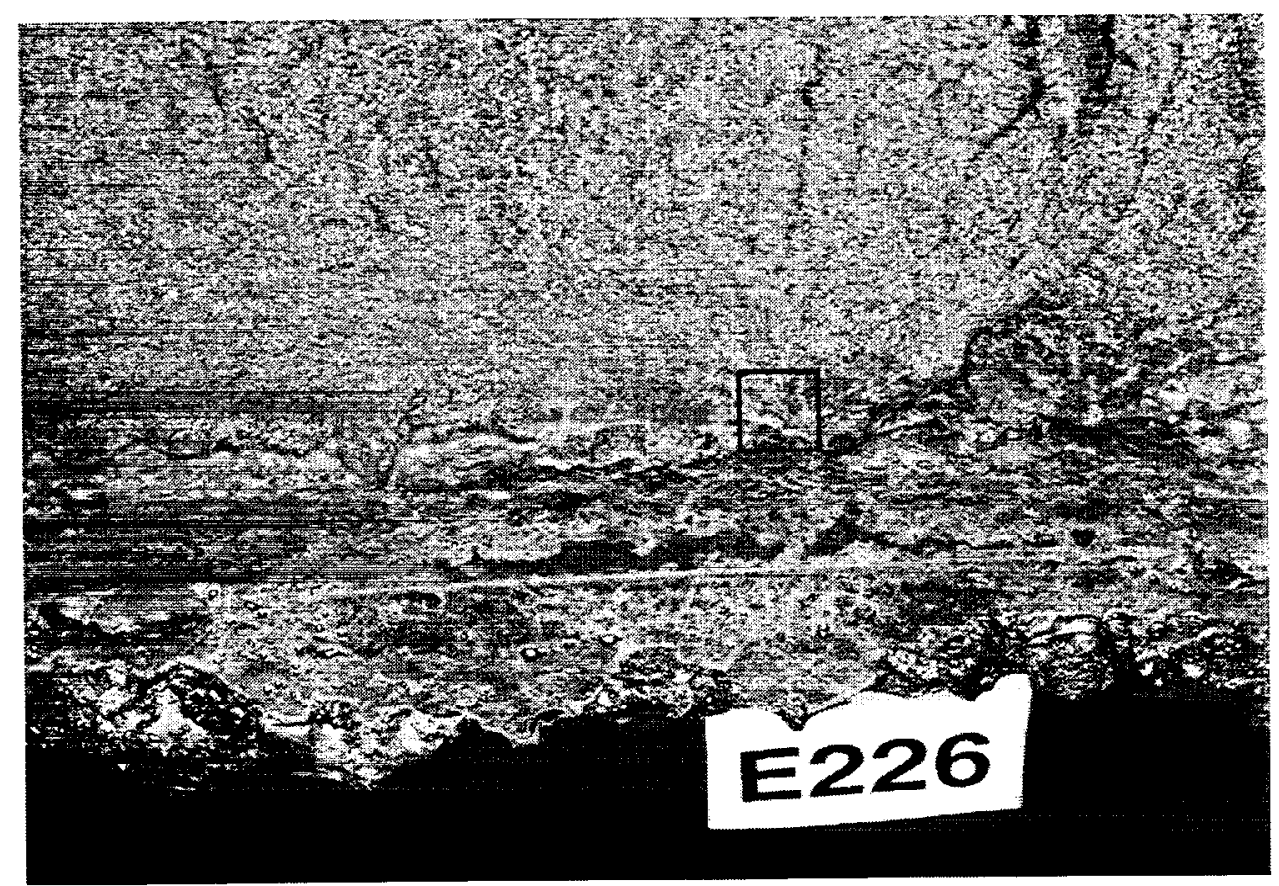

Figure 51 - Enlarged view of the fracture origin area of Sample E226. The fracture initiates from an incomplete fusion flaw at the weld root. 


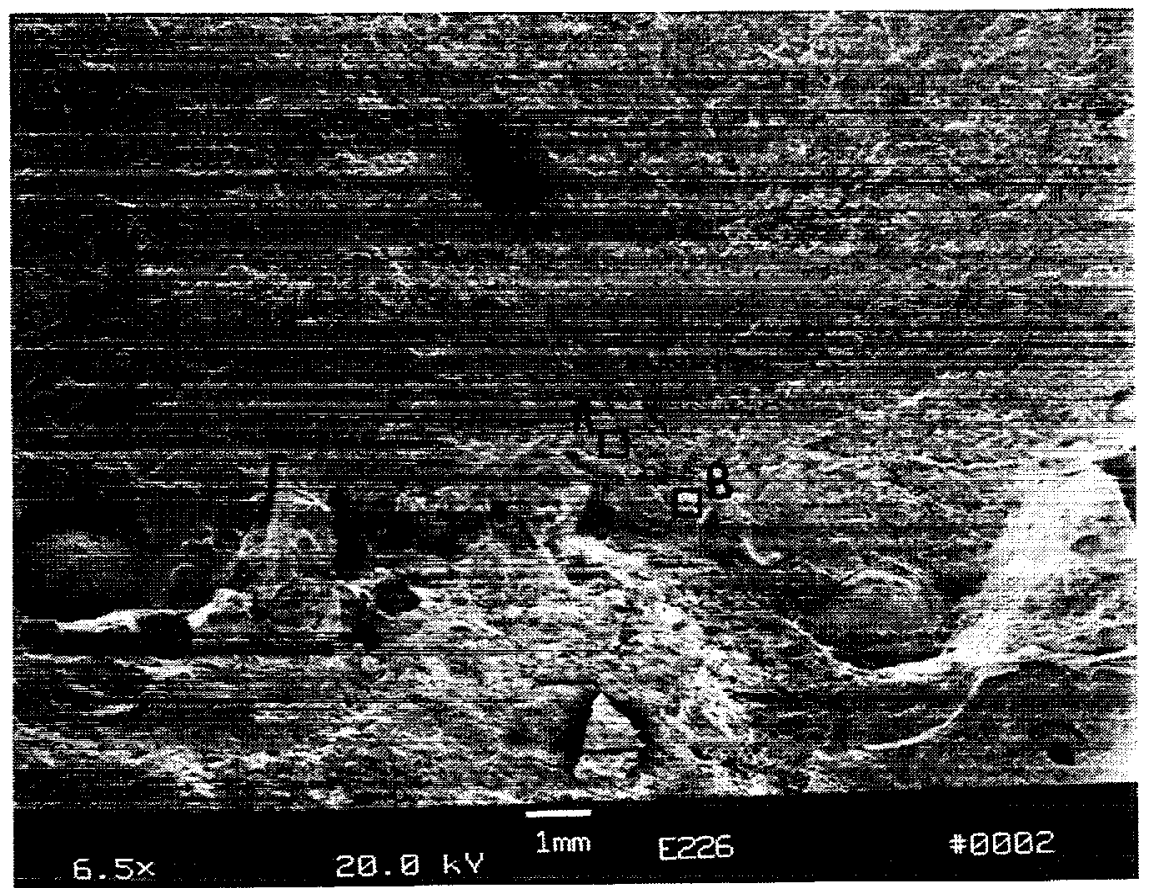

Figure 52 - Low magnification SEM micrograph of the fracture origin of Sample E226. (Boxed area in Figure 51) (Mag. 6.5X)

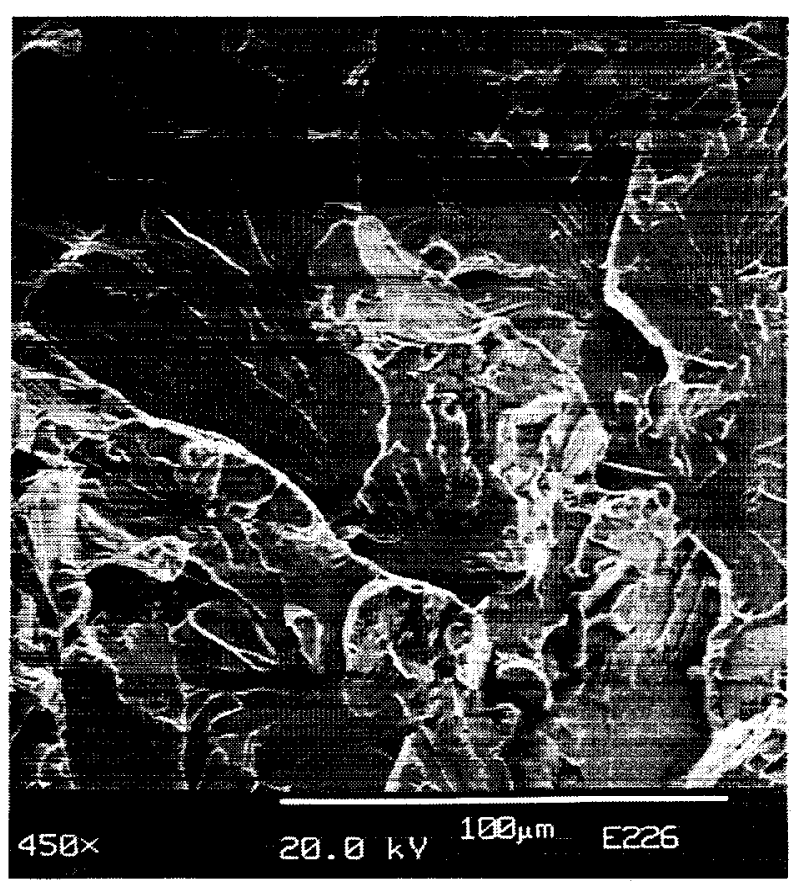

Area A

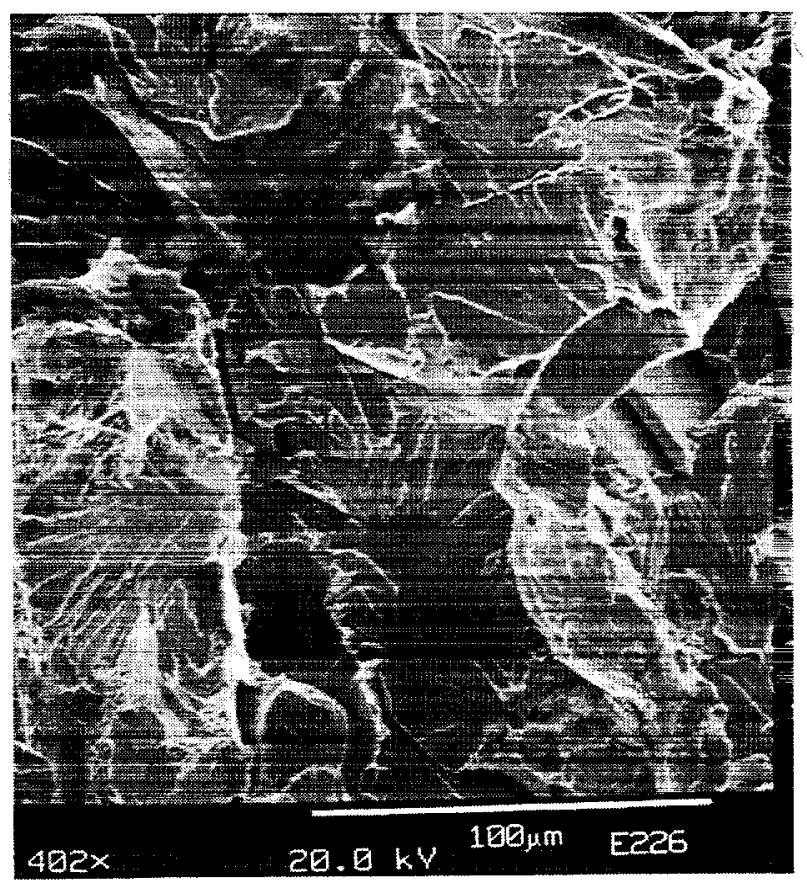

Area B

Figure 53 - SEM micrographs of the crack surface of Sample E226 immediately adjacent to the weld root flaw. (Areas "A" and "B" in Figure 52) (Mag. 450X \& 402X) 

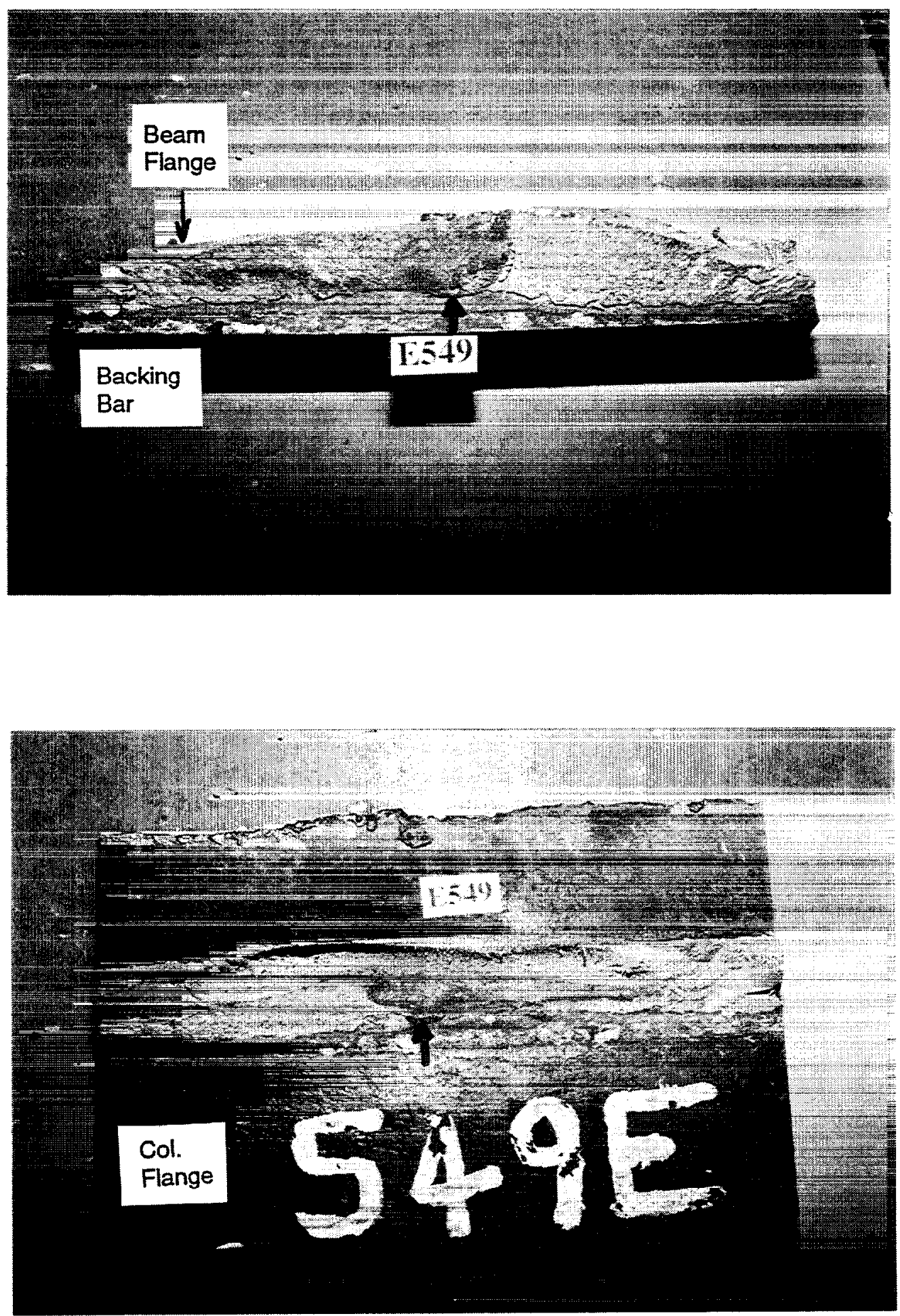

Figure 54 - Divot fracture surfaces from Sample E549. Arrow shows the location of the fracture origin. Note the deep incomplete fusion defect along the weld root. 


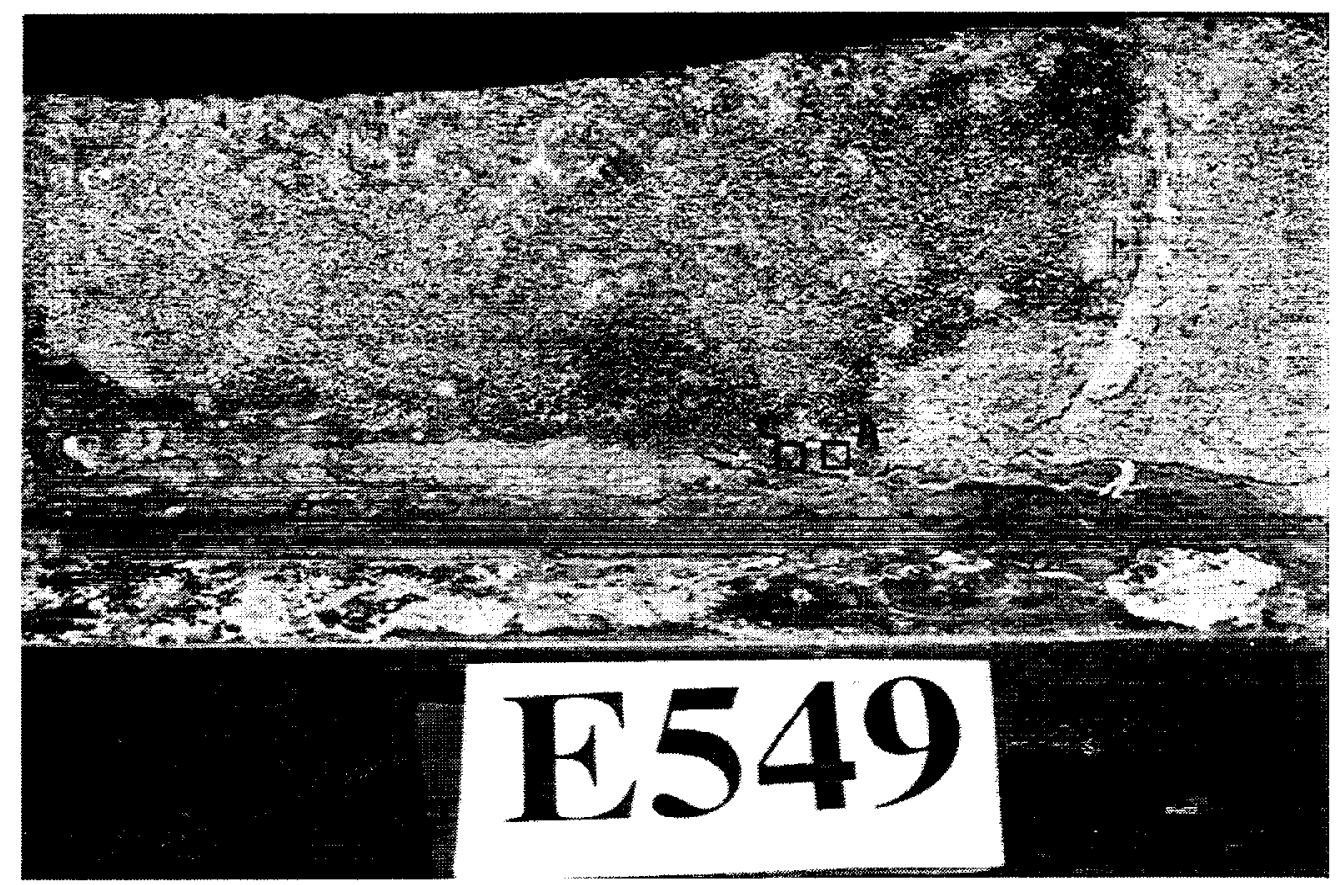

Figure 55 - Enlarged view of the fracture origin area from Sample E549.

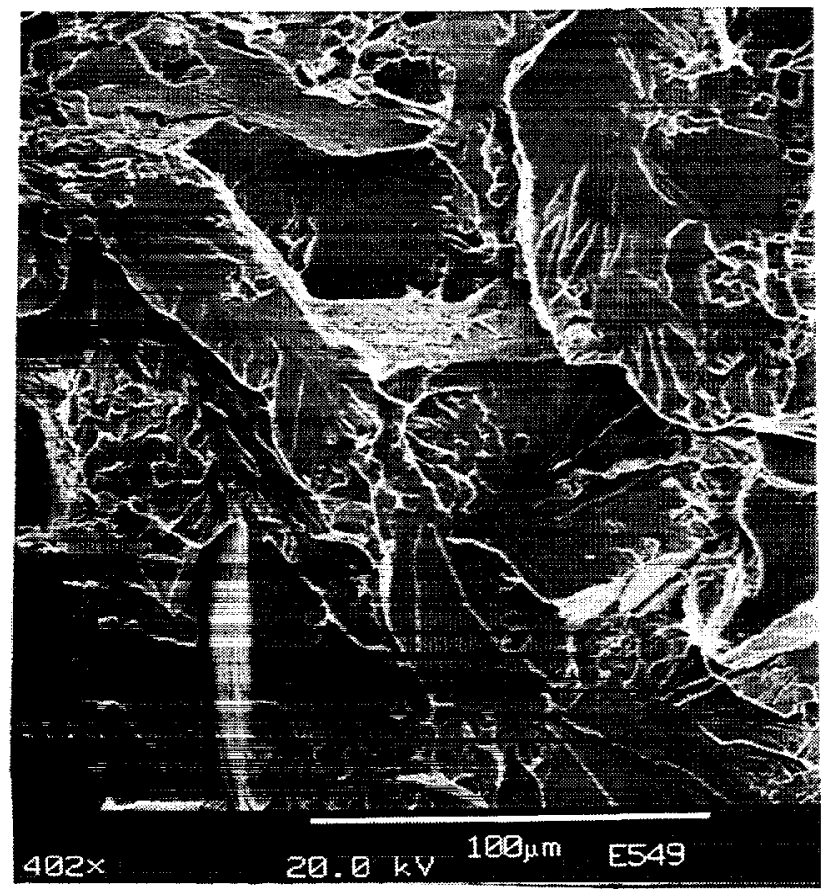

Area A

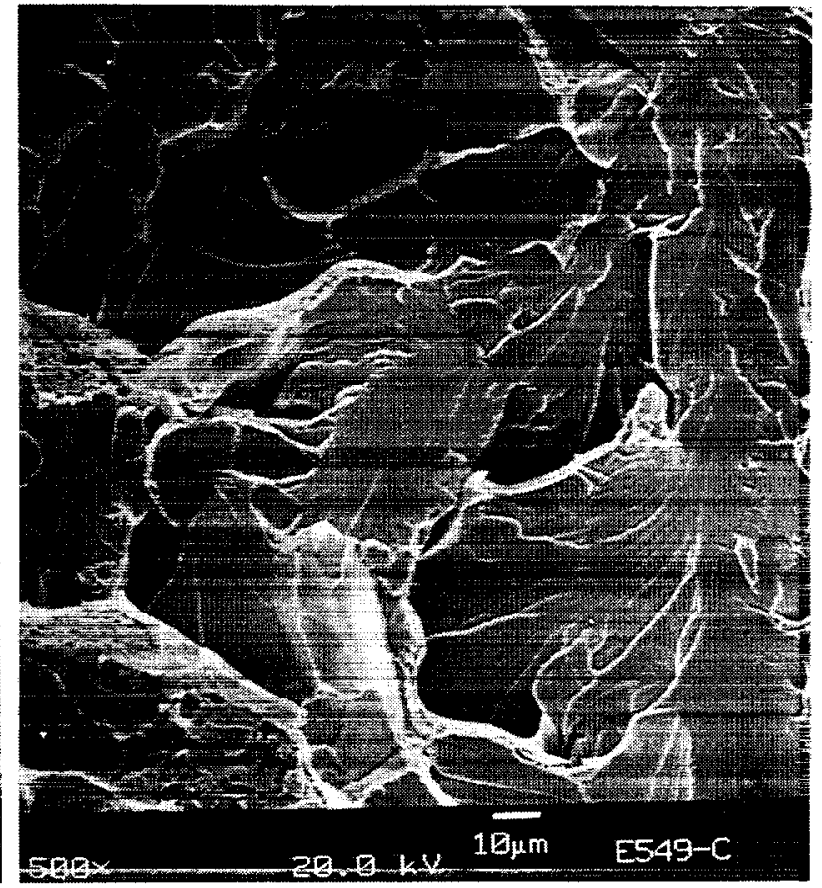

Area C

Figure 56 - SEM micrographs obtained immediately adjacent to the crack origin in Sample E549. (Areas "A" and "C" in Figure 55) (Mag. 402X \& 500X) 


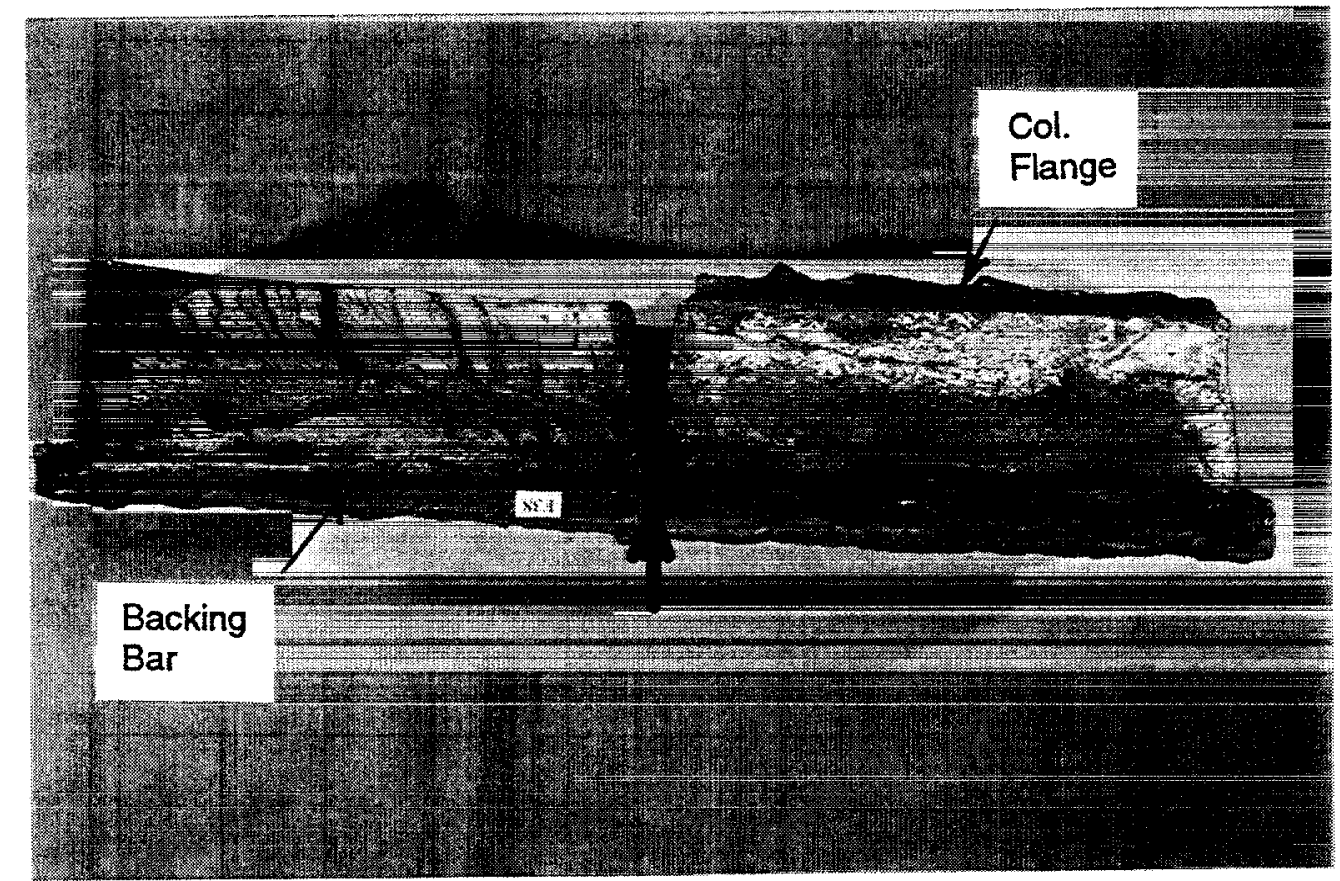

Figure 57 - Fracture surface from Sample F38. Arrow shows the location of the fracture origin eliminated during sample removal.

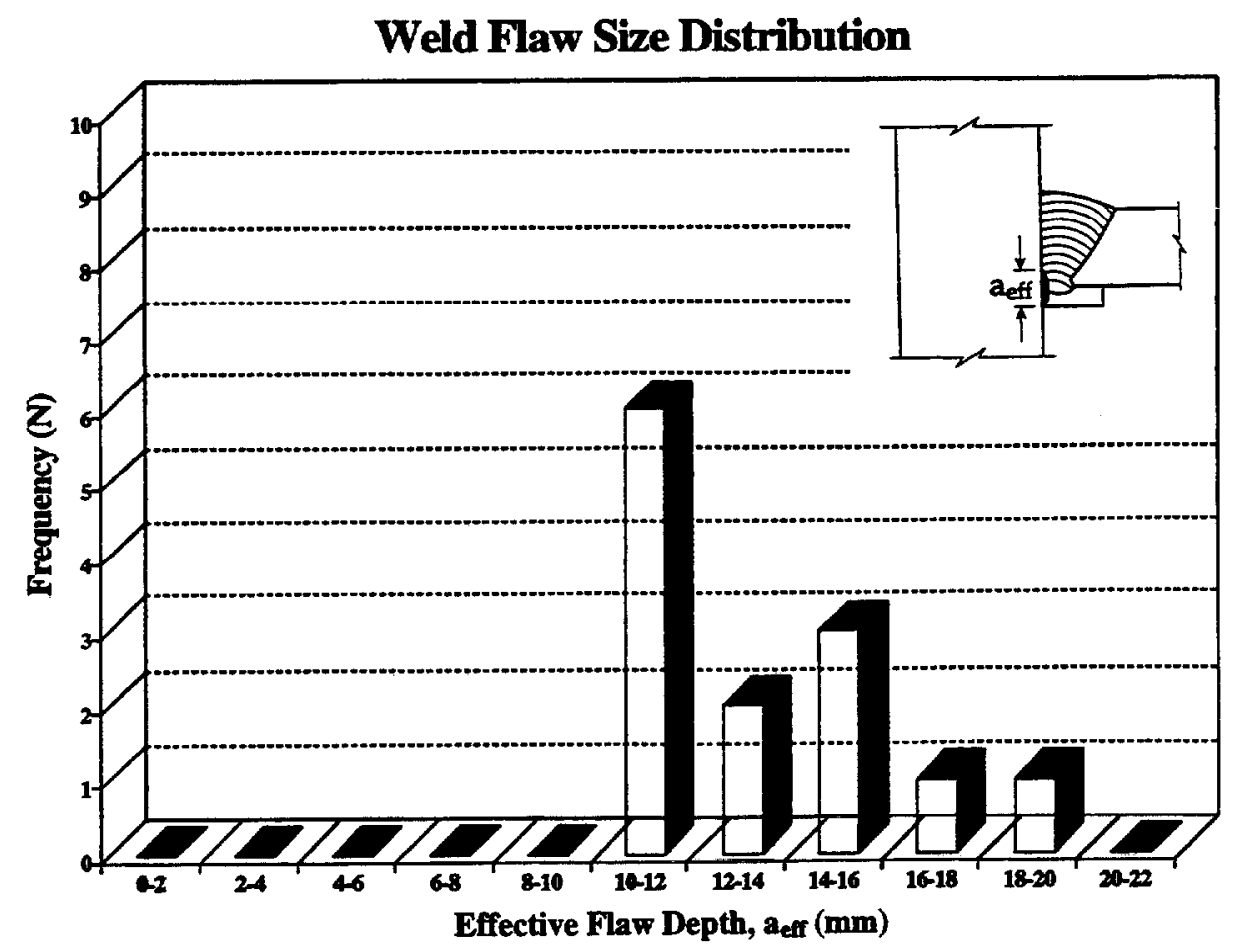

Figure 58 - Distribution of fracture initiating weld flaw sizes. 


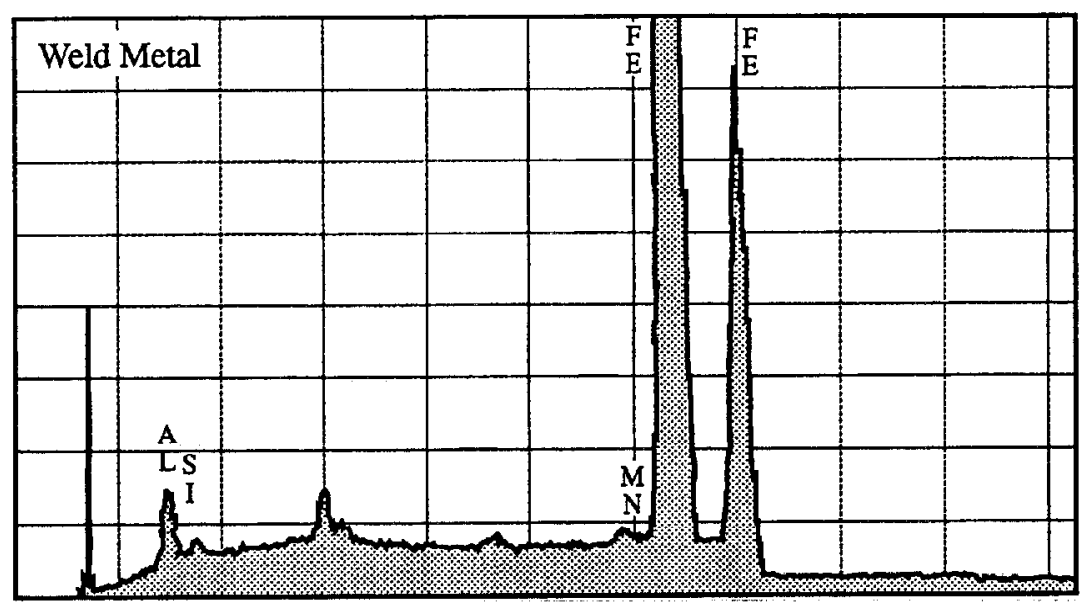

(a)

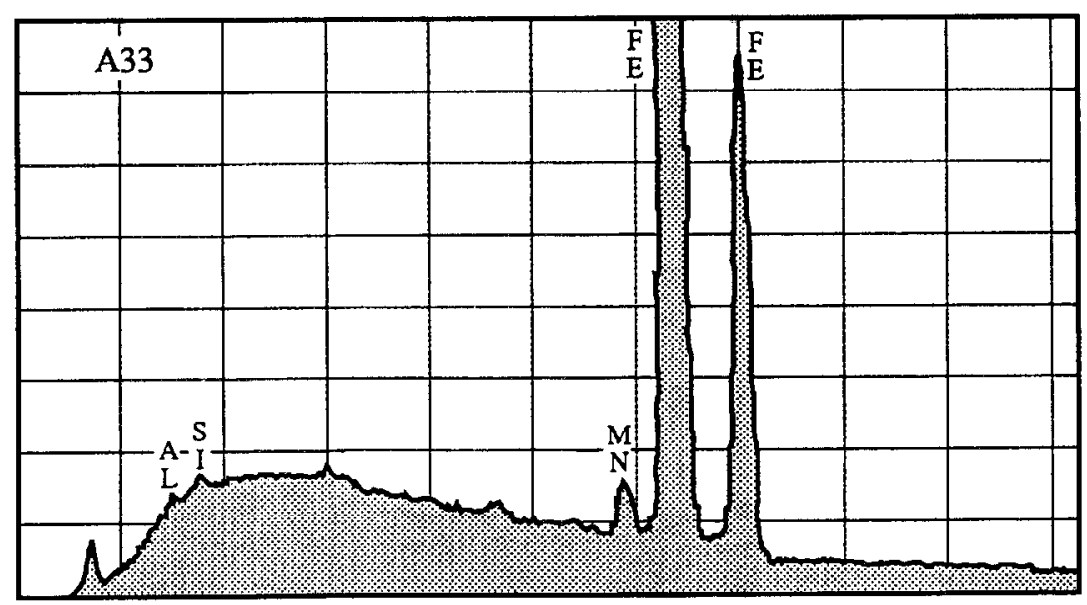

(b)

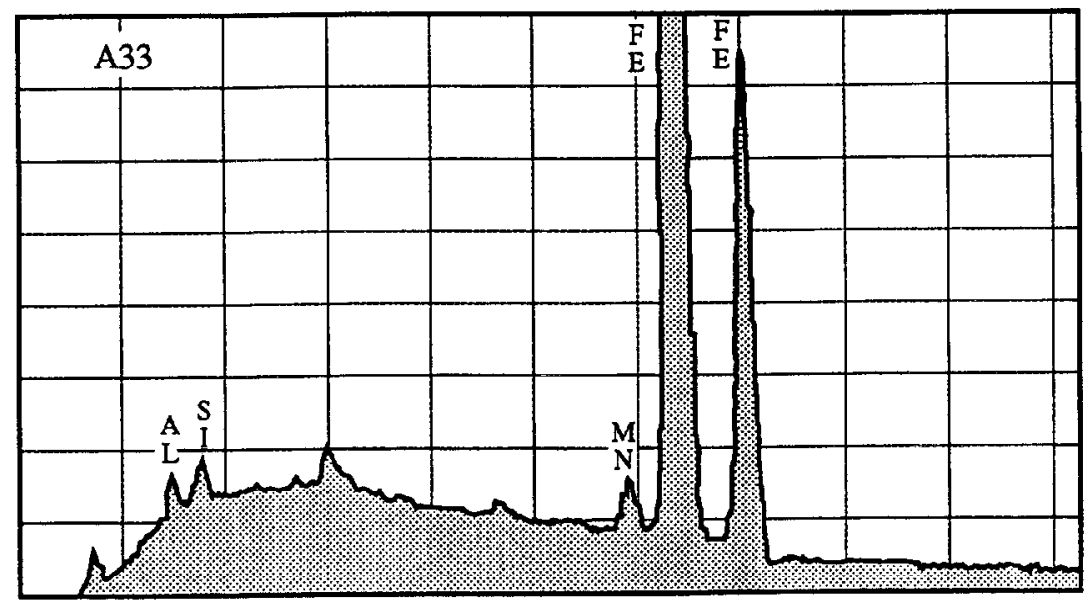

(c)

Figure 59 - Comparison of EDS spectra obtained from a) weld metal; b) base metal; and c) fracture origin surface of Sample A33. 

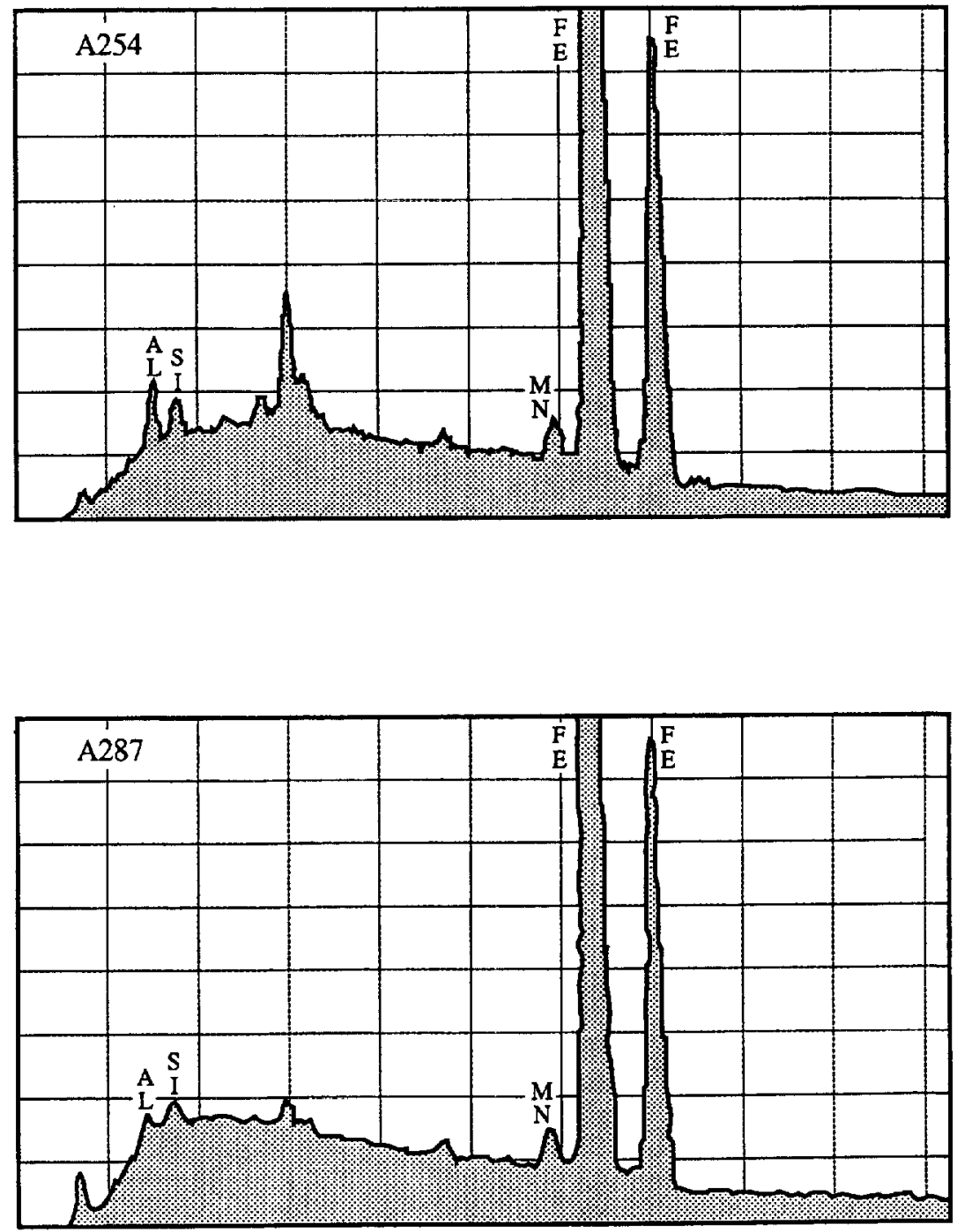

Figure 60 - EDS spectra obtained from the fracture surface of Samples A254 and A287 at the fracture origin. 


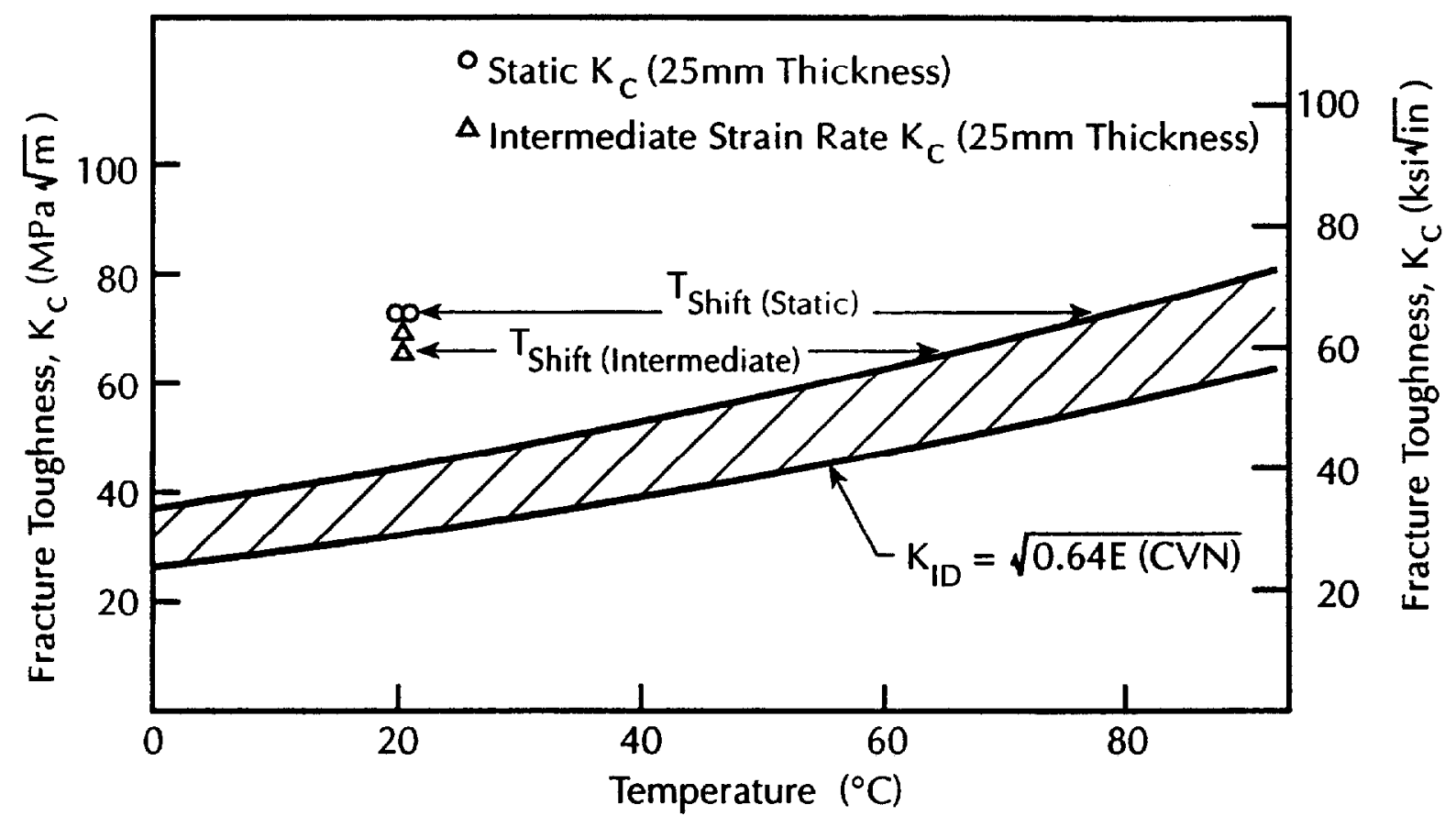

Figure 61 - Fracture toughness of E70T-4 weld metal.
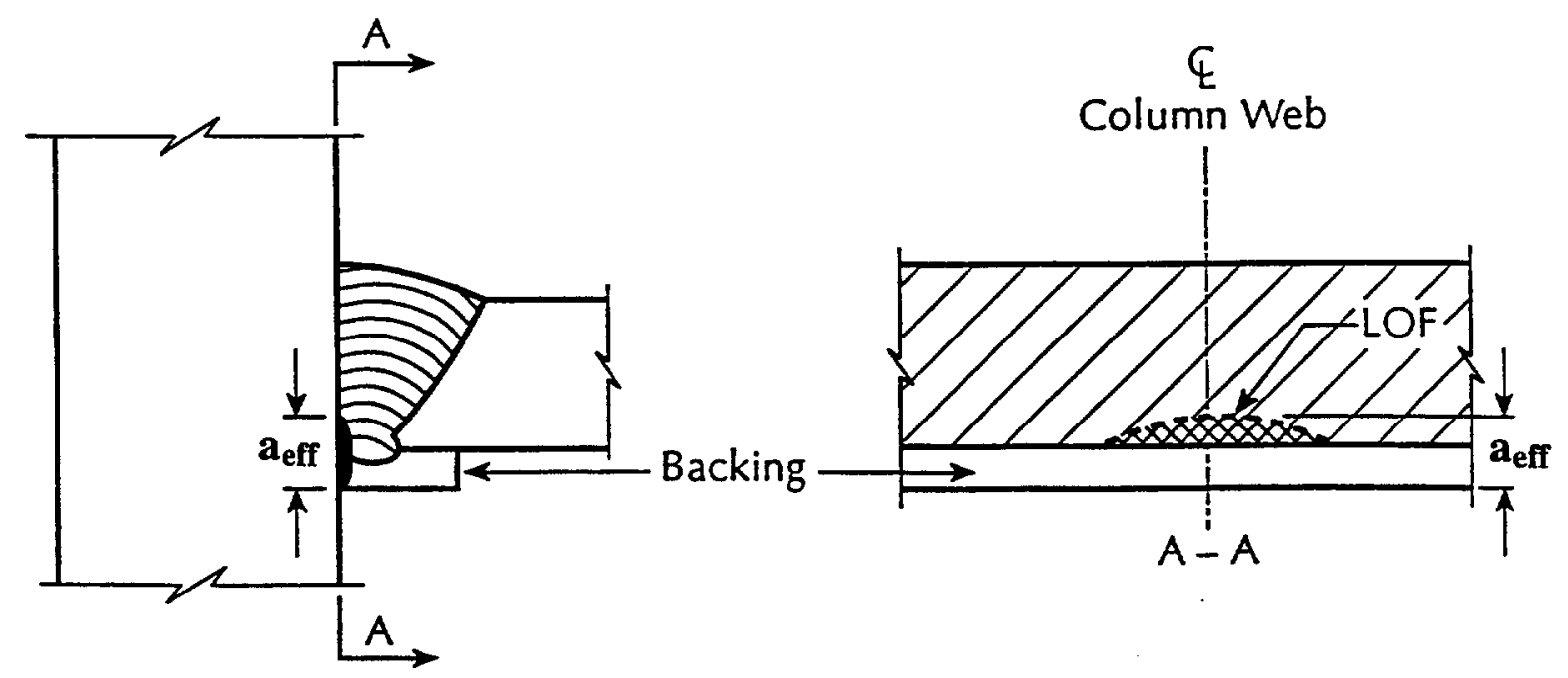

Figure 62 - Edge crack model used for fracture analysis. 


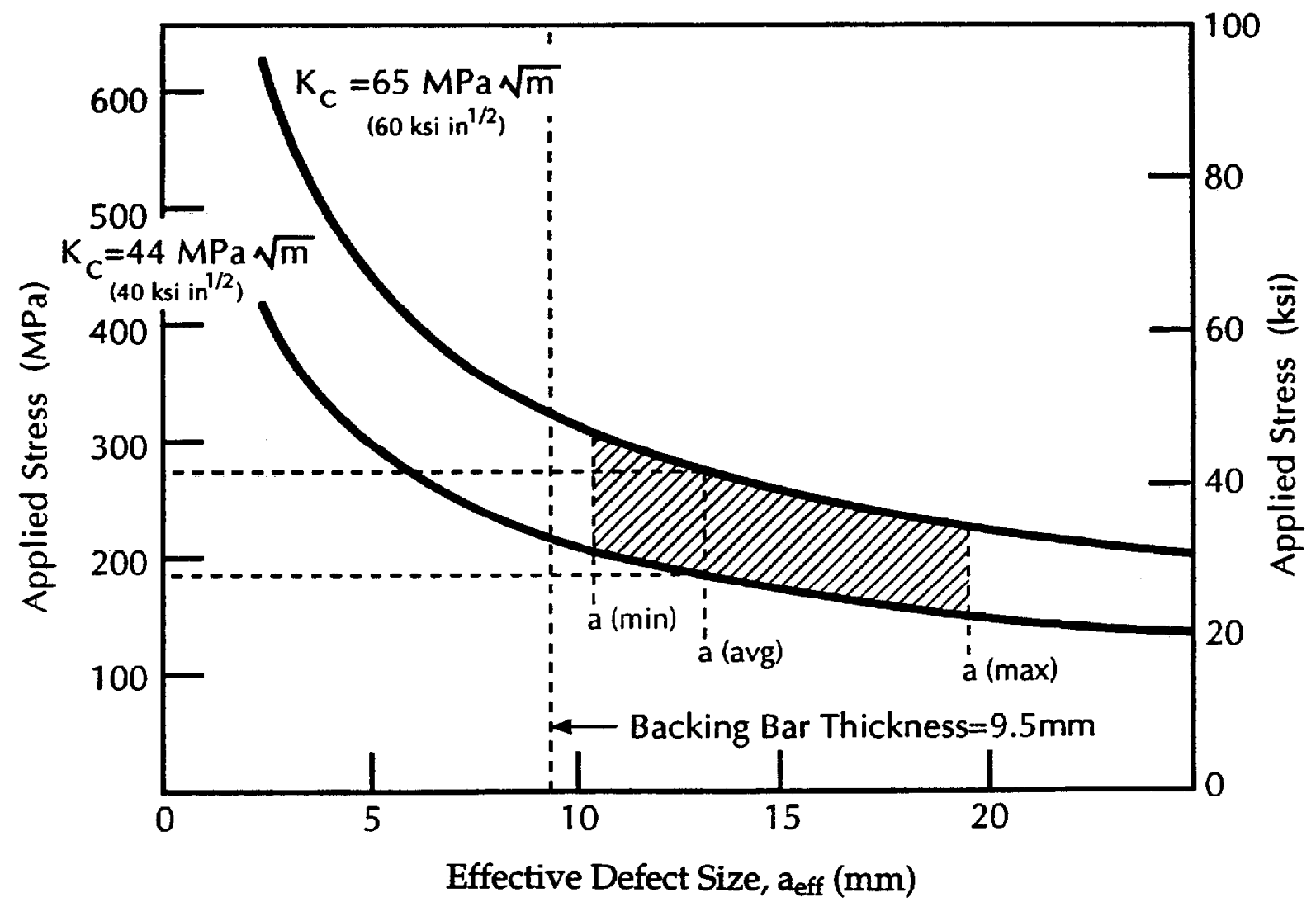

Figure 63 - Critical applied stress vs. defect size for weld root defects in WSMF connections. 


\begin{tabular}{|c|c|c|}
\hline $\begin{array}{c}\text { Period } \\
\text { (sec) }\end{array}$ & $\begin{array}{c}\text { Mean } \\
\text { PSA } \\
\text { Spectra } \\
\text { (g) }\end{array}$ & $\begin{array}{c}\text { Mean+10 } \\
\text { PSA } \\
\text { Spectra } \\
\text { (g) }\end{array}$ \\
\hline 0.010 & 0.27 & 0.43 \\
\hline 0.030 & 0.27 & 0.43 \\
\hline 0.100 & 0.49 & 0.77 \\
\hline 0.110 & 0.54 & 0.85 \\
\hline 0.120 & 0.58 & 0.91 \\
\hline 0.130 & 0.62 & 0.96 \\
\hline 0.140 & 0.65 & 1.01 \\
\hline 0.150 & 0.67 & 1.05 \\
\hline 0.160 & 0.69 & 1.08 \\
\hline 0.170 & 0.70 & 1.10 \\
\hline 0.180 & 0.72 & 1.12 \\
\hline 0.190 & 0.73 & 1.14 \\
\hline 0.200 & 0.73 & 1.15 \\
\hline 0.220 & 0.74 & 1.16 \\
\hline 0.240 & 0.74 & 1.17 \\
\hline 0.260 & 0.73 & 1.16 \\
\hline 0.280 & 0.72 & 1.15 \\
\hline 0.300 & 0.71 & 1.14 \\
\hline 0.320 & 0.69 & 1.11 \\
\hline 0.340 & 0.68 & 1.09 \\
\hline 0.360 & 0.66 & 1.07 \\
\hline 0.380 & 0.65 & 1.04 \\
\hline 0.400 & 0.63 & 1.02 \\
\hline 0.420 & 0.61 & 1.00 \\
\hline 0.440 & 0.60 & 0.97 \\
\hline 0.460 & 0.58 & 0.95 \\
\hline 0.480 & 0.57 & 0.93 \\
\hline 0.500 & 0.55 & 0.91 \\
\hline 0.550 & 0.51 & 0.85 \\
\hline 0.600 & 0.48 & 0.80 \\
\hline 0.650 & 0.45 & 0.76 \\
\hline 0.700 & 0.42 & 0.72 \\
\hline 0.750 & 0.40 & 0.68 \\
\hline 0.800 & 0.38 & 0.65 \\
\hline 0.850 & 0.36 & 0.62 \\
\hline 0.900 & 0.34 & 0.59 \\
\hline 0.950 & 0.32 & 0.56 \\
\hline 1.000 & 0.31 & 0.54 \\
\hline 1.100 & 0.28 & 0.50 \\
\hline 1.200 & 0.26 & 0.46 \\
\hline 1.300 & 0.24 & 0.44 \\
\hline 1.400 & 0.22 & 0.41 \\
\hline 1.500 & 0.21 & 0.39 \\
\hline 1.600 & 0.20 & 0.37 \\
\hline 1.700 & 0.19 & 0.35 \\
\hline 1.800 & 0.18 & 0.34 \\
\hline 1.900 & 0.17 & 0.32 \\
\hline 2.000 & 0.16 & 0.31 \\
\hline & & \\
\hline
\end{tabular}

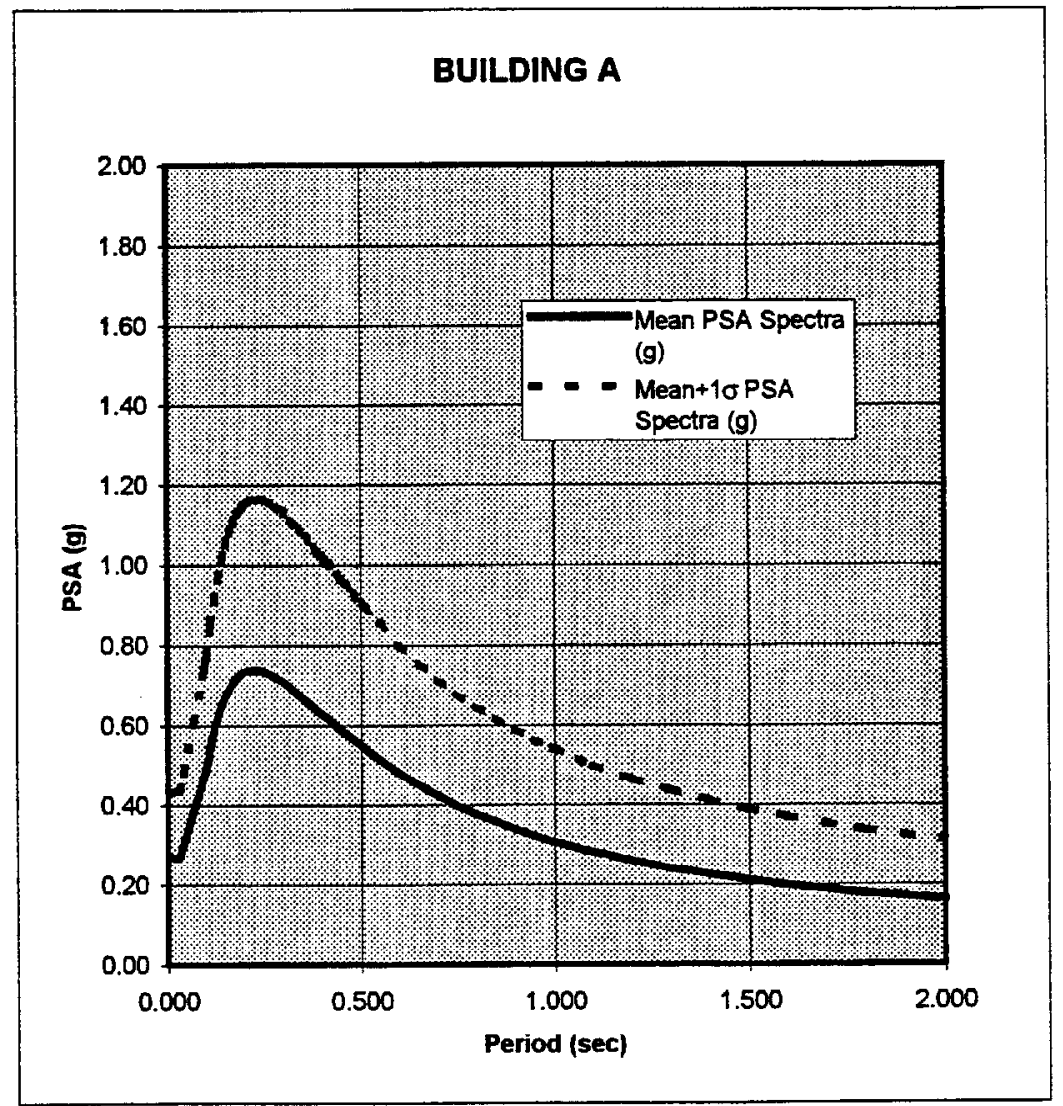

Figure 64 - Estimated ground motion spectra for Building A. 


\begin{tabular}{|c|c|c|}
\hline $\begin{array}{l}\text { Period } \\
\text { (sec) }\end{array}$ & $\begin{array}{c}\text { Mean } \\
\text { PSA } \\
\text { Spectra } \\
\text { (g) } \\
\end{array}$ & 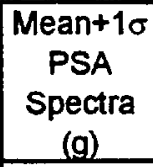 \\
\hline 0.010 & 0.23 & 0.36 \\
\hline 0.030 & 0.23 & 0.36 \\
\hline 0.100 & 0.40 & 0.63 \\
\hline 0.110 & 0.44 & 0.69 \\
\hline 0.120 & 0.48 & 0.74 \\
\hline 0.130 & 0.50 & 0.79 \\
\hline 0.140 & 0.53 & 0.83 \\
\hline 0.150 & 0.55 & 0.86 \\
\hline 0.160 & 0.56 & 0.88 \\
\hline 0.170 & 0.57 & 0.90 \\
\hline 0.180 & 0.59 & 0.92 \\
\hline 0.190 & 0.59 & 0.93 \\
\hline 0.200 & 0.60 & 0.94 \\
\hline 0.220 & 0.60 & 0.95 \\
\hline 0.240 & 0.60 & 0.95 \\
\hline 0.260 & 0.60 & 0.95 \\
\hline 0.280 & 0.59 & 0.94 \\
\hline 0.300 & 0.58 & 0.93 \\
\hline 0.320 & 0.57 & 0.91 \\
\hline 0.340 & 0.55 & 0.89 \\
\hline 0.360 & 0.54 & 0.87 \\
\hline 0.380 & 0.53 & 0.85 \\
\hline 0.400 & 0.51 & 0.83 \\
\hline 0.420 & 0.50 & 0.82 \\
\hline 0.440 & 0.49 & 0.79 \\
\hline 0.460 & 0.47 & 0.78 \\
\hline 0.480 & 0.46 & 0.76 \\
\hline 0.500 & 0.45 & 0.74 \\
\hline 0.550 & 0.42 & 0.70 \\
\hline 0.600 & 0.39 & 0.65 \\
\hline 0.650 & 0.37 & 0.62 \\
\hline 0.700 & 0.34 & 0.58 \\
\hline 0.750 & 0.32 & 0.55 \\
\hline 0.800 & 0.31 & 0.53 \\
\hline 0.850 & 0.29 & 0.50 \\
\hline 0.900 & 0.28 & 0.48 \\
\hline 0.950 & 0.26 & 0.46 \\
\hline 1.000 & 0.25 & 0.44 \\
\hline 1.100 & 0.23 & 0.41 \\
\hline 1.200 & 0.21 & 0.38 \\
\hline 1.300 & 0.20 & 0.36 \\
\hline 1.400 & 0.18 & 0.33 \\
\hline 1.500 & 0.17 & 0.32 \\
\hline 1.600 & 0.16 & 0.30 \\
\hline 1.700 & 0.15 & 0.29 \\
\hline 1.800 & 0.15 & 0.28 \\
\hline 1.900 & 0.14 & 0.27 \\
\hline 2.000 & 0.13 & 0.26 \\
\hline
\end{tabular}

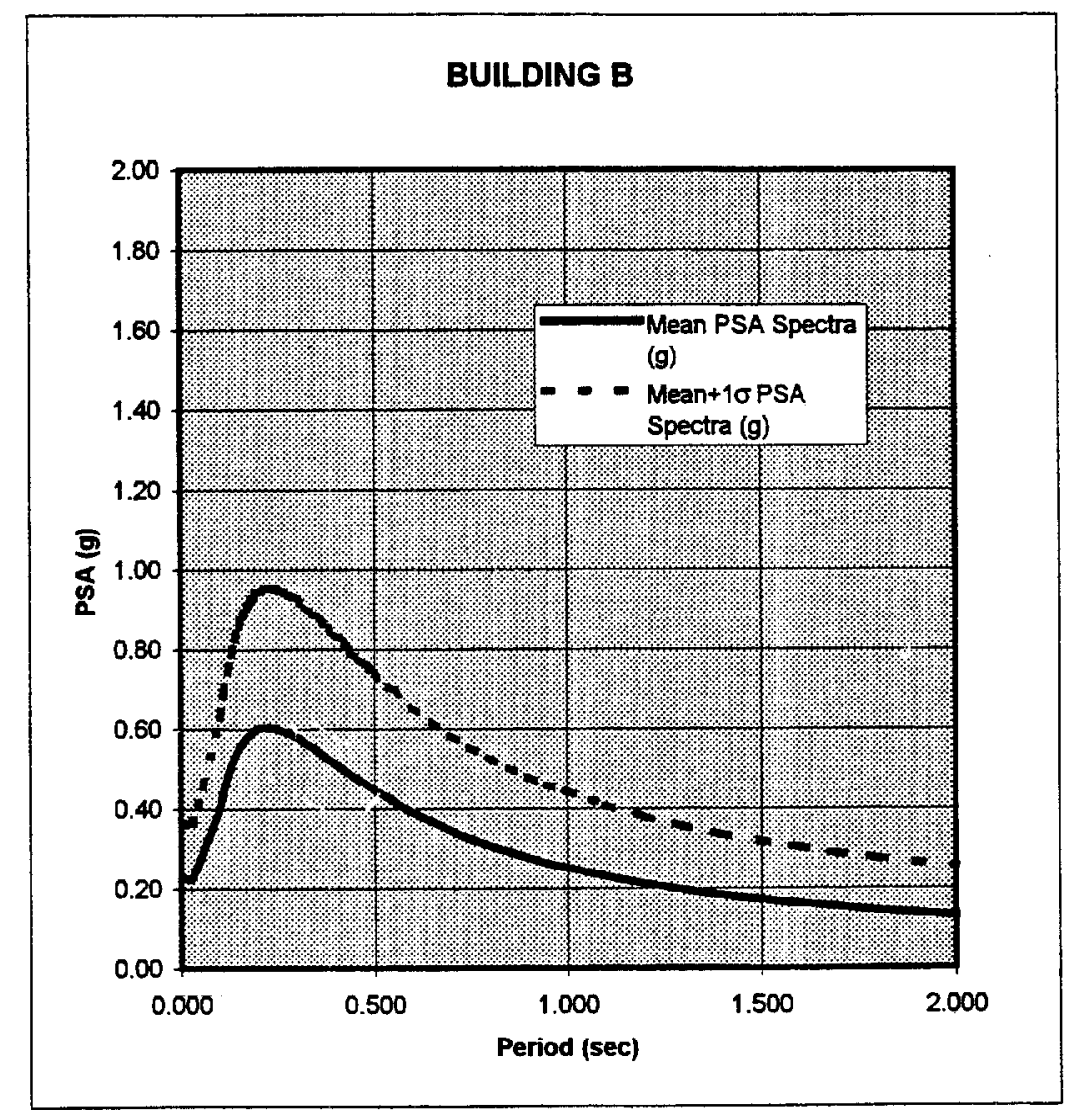

Figure 65 - Estimated ground motion spectra for Building B. 


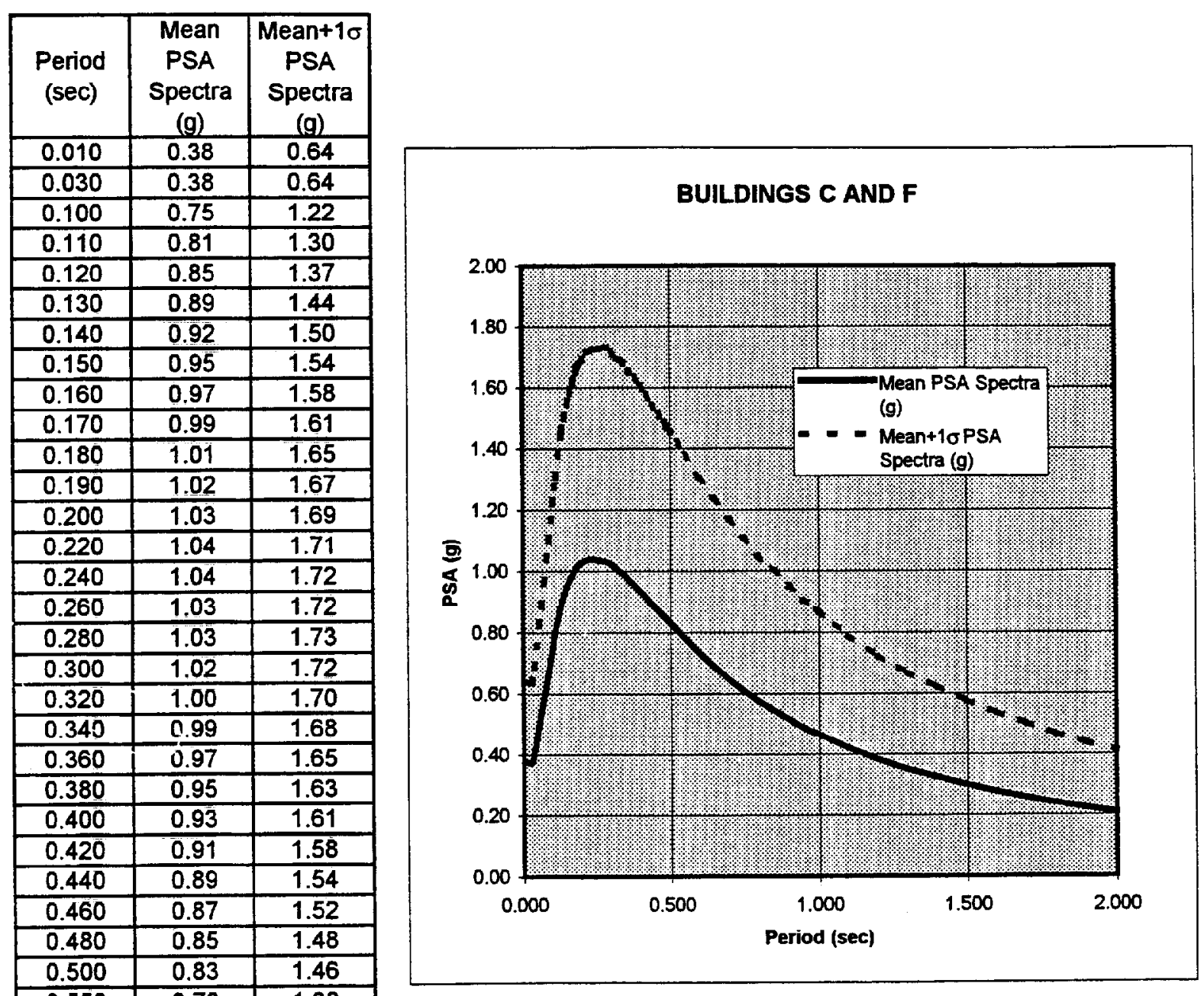

\begin{tabular}{|l|l|l|}
\hline 0.550 & 0.78 & 1.38 \\
\hline 0.600 & 0.73 & 1.30 \\
\hline 0.650 & 0.69 & 1.23 \\
\hline 0.700 & 0.65 & 1.17 \\
\hline 0.750 & 0.61 & 1.11 \\
\hline 0.800 & 0.57 & 1.05 \\
\hline 0.850 & 0.54 & 1.00 \\
\hline 0.900 & 0.52 & 0.95 \\
\hline 0.950 & 0.49 & 0.91 \\
\hline 1.000 & 0.46 & 0.86 \\
\hline 1.100 & 0.42 & 0.79 \\
\hline 1.200 & 0.38 & 0.72 \\
\hline 1.300 & 0.35 & 0.67 \\
\hline 1.400 & 0.32 & 0.62 \\
\hline 1.500 & 0.30 & 0.58 \\
\hline 1.600 & 0.28 & 0.53 \\
\hline 1.700 & 0.26 & 0.50 \\
\hline 1.800 & 0.24 & 0.47 \\
\hline 1.900 & 0.22 & 0.44 \\
\hline 2.000 & 0.21 & 0.41 \\
\hline
\end{tabular}

Figure 66 - Estimated ground motion spectra for Buildings $C$ and $F$. 


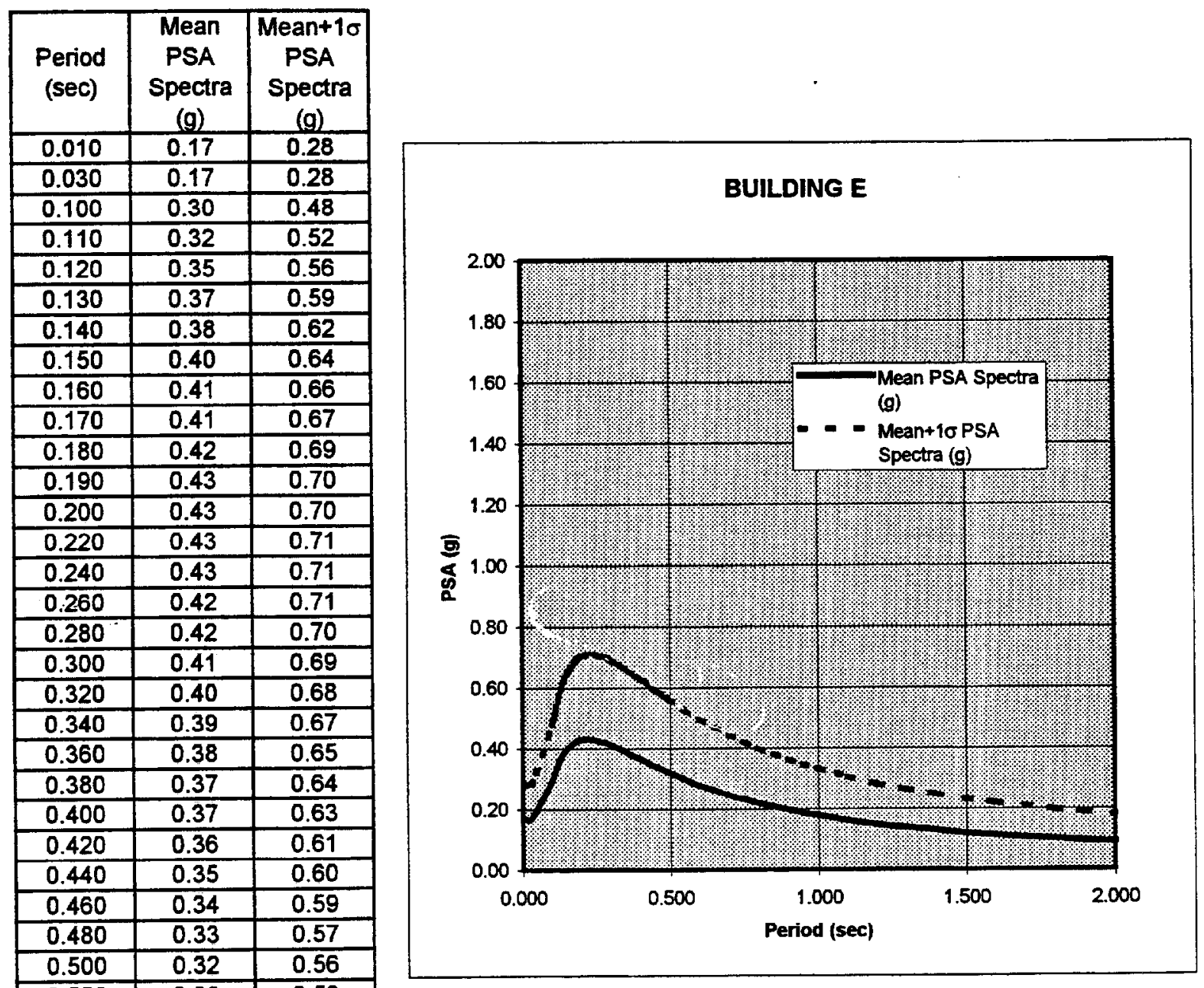

\begin{tabular}{|l|l|l|}
\hline 0.550 & 0.30 & 0.53 \\
\hline 0.600 & 0.28 & 0.50 \\
\hline 0.650 & 0.26 & 0.47 \\
\hline 0.700 & 0.25 & 0.44 \\
\hline 0.750 & 0.23 & 0.42 \\
\hline 0.800 & 0.22 & 0.40 \\
\hline 0.850 & 0.21 & 0.38 \\
\hline 0.900 & 0.20 & 0.36 \\
\hline 0.950 & 0.19 & 0.35 \\
\hline 1.000 & 0.18 & 0.33 \\
\hline 1.100 & 0.16 & 0.31 \\
\hline 1.200 & 0.15 & 0.28 \\
\hline 1.300 & 0.14 & 0.26 \\
\hline 1.400 & 0.13 & 0.25 \\
\hline 1.500 & 0.12 & 0.23 \\
\hline 1.600 & 0.11 & 0.22 \\
\hline 1.700 & 0.11 & 0.21 \\
\hline 1.800 & 0.10 & 0.20 \\
\hline 1.900 & 0.10 & 0.19 \\
\hline 2.000 & 0.09 & 0.18 \\
\hline
\end{tabular}

Figure 67 - Estimated ground motion spectra for Building E 


\section{APPENDIX A \\ BUILDING DRAWINGS AND DAMAGE SURVEY}


Building A 


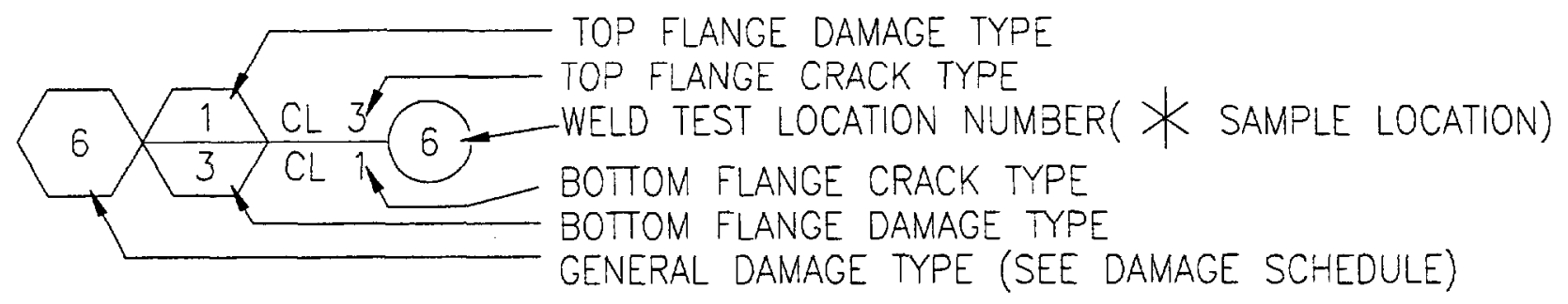

\begin{tabular}{|l|l|c|c|}
\hline \multicolumn{3}{|c|}{ DAMAGE SCHEDULE (BLDG. A) } \\
\hline $\begin{array}{c}|c| \\
\text { DAMAGE } \\
\text { TYPE }\end{array}$ & \multicolumn{1}{|c|}{ DESCRIPTION } & - & - \\
\hline 1 & PARTIAL CRACK IN WELD AT ROOT & - & - \\
\hline 2 & PARTIAL CRACK IN WELD ABOVE ROOT & & \\
\hline 3 & THROUGH CRACK IN WELD & & \\
\hline 4 & SHEAR TAB WELD CRACK & & \\
\hline 5 & SHEAR TAB OR BEAM WEB CRACK & & \\
\hline 6 & BENT SHEAR TAB OR BEAM WEB & & \\
\hline 7 & LOOSE OR MISSING BOLTS & & \\
\hline 8 & $\begin{array}{l}\text { PARTIAL OR THROUGH CRACK IN COLUMN FLANGE } \\
\text { WITHIN 45 ANGLE ZONE }\end{array}$ & & \\
\hline 9 & $\begin{array}{l}\text { PARTIAL OR THROUGH CRACK IN COLUMN FLANGE } \\
\text { OUTSIDE 45 ANGLE ZONE }\end{array}$ & & \\
\hline 10 & COLUMN WEB CRACK & & \\
\hline 11 & LOOSE OR DAMAGED COL. OR BEAM FIREPROOFING & & \\
\hline 12 & BEAM SEAT WELD CRACK & & \\
\hline 13 & COLUMN FLANGE LAMINAR TEARING POTENTIAL & & \\
\hline
\end{tabular}

'CL O' INDICATES NO CRACKS FOUND.

'CL $X$ ' INDICATES FLANGE OR PORTION OF FLANGE INACCESSIBLE DURING INITIAL TESTING. 


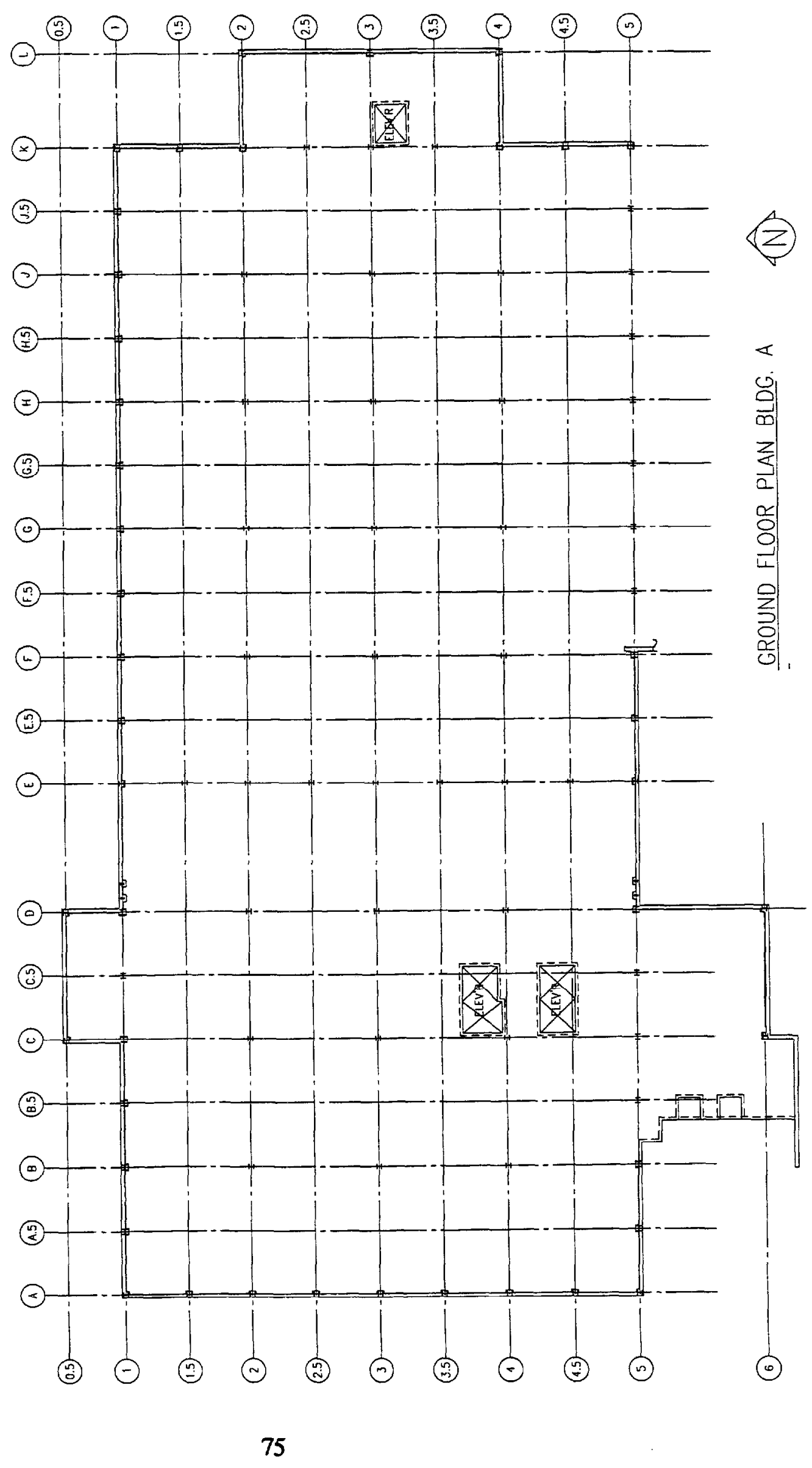




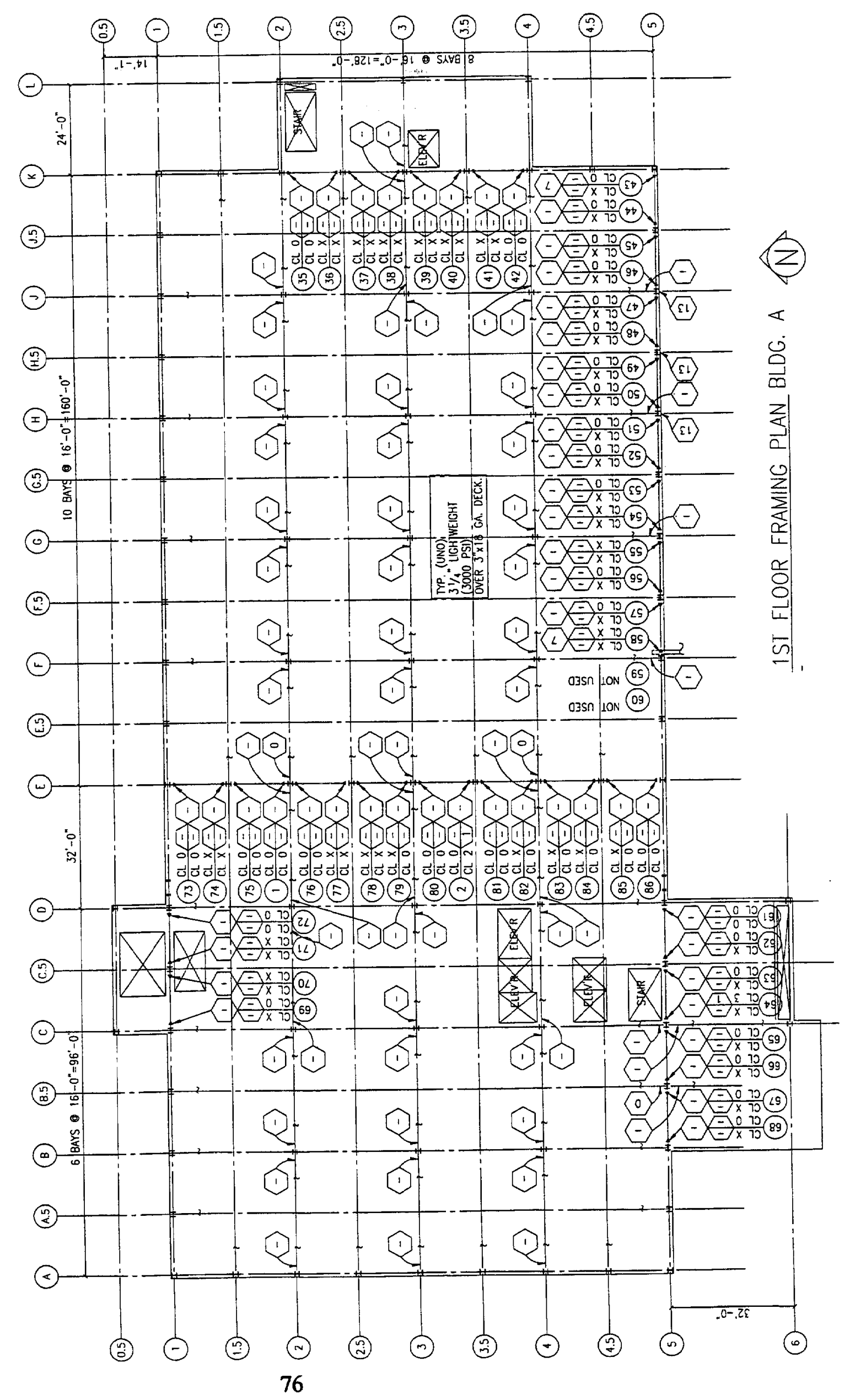




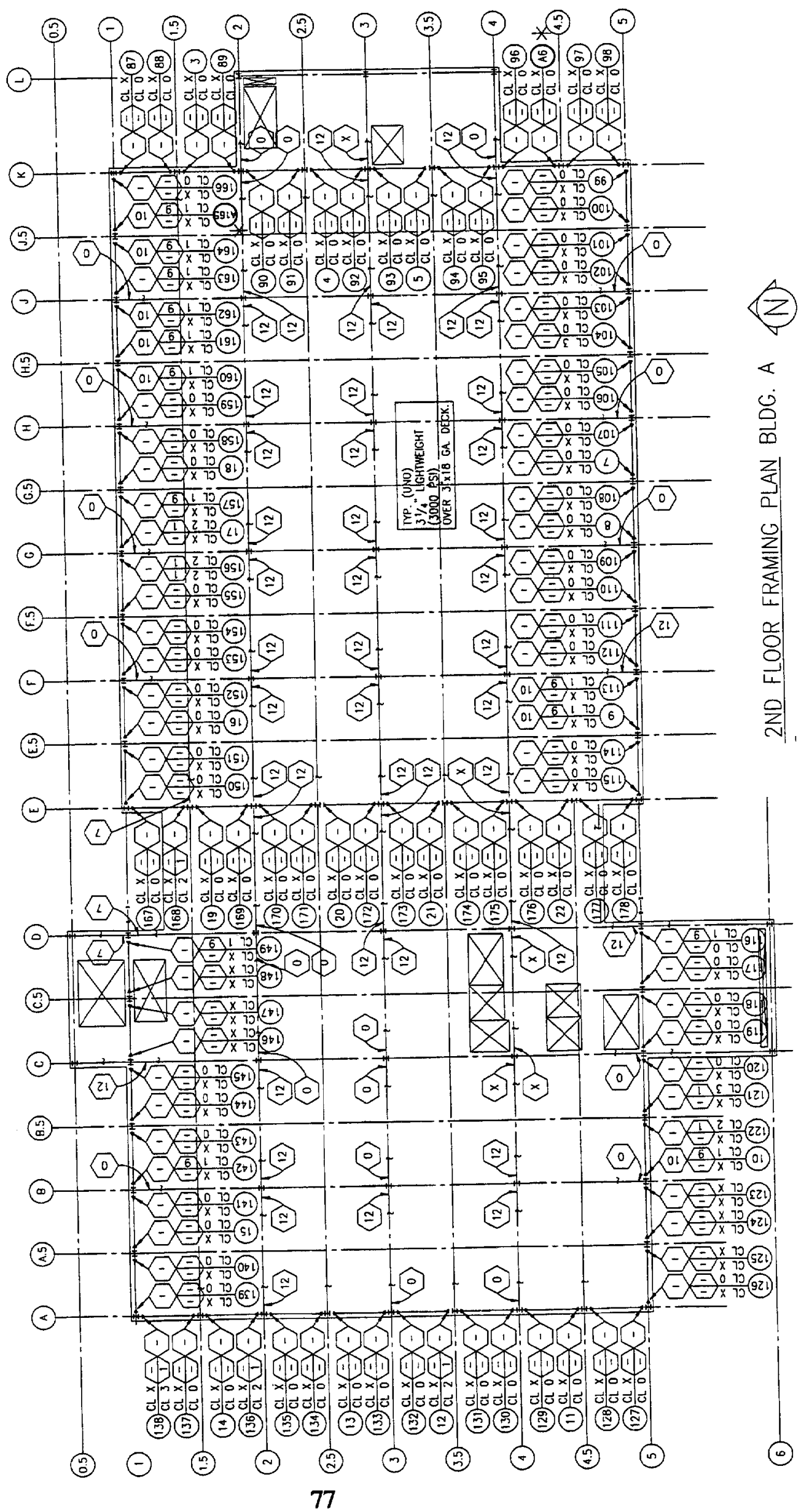




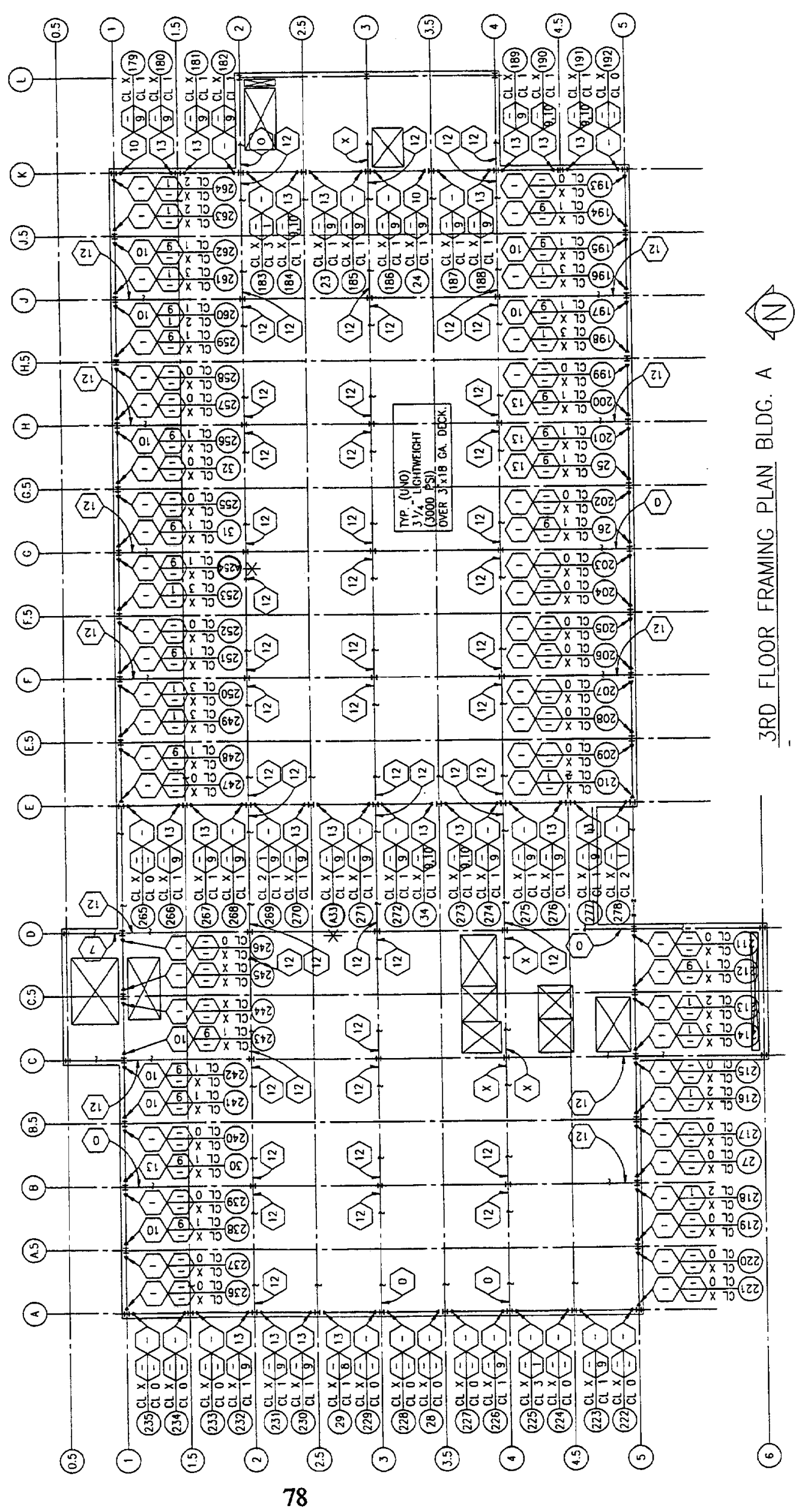




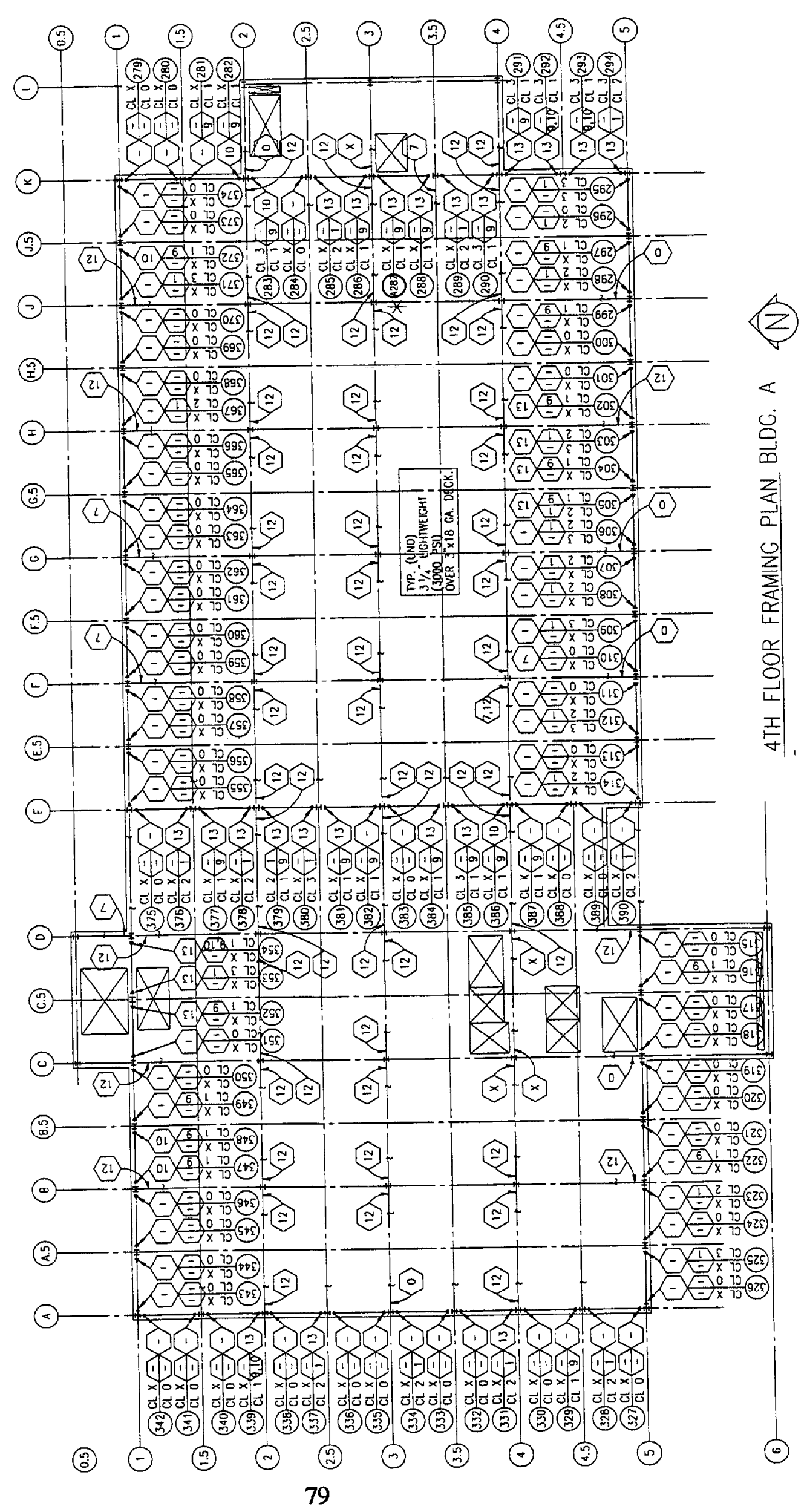




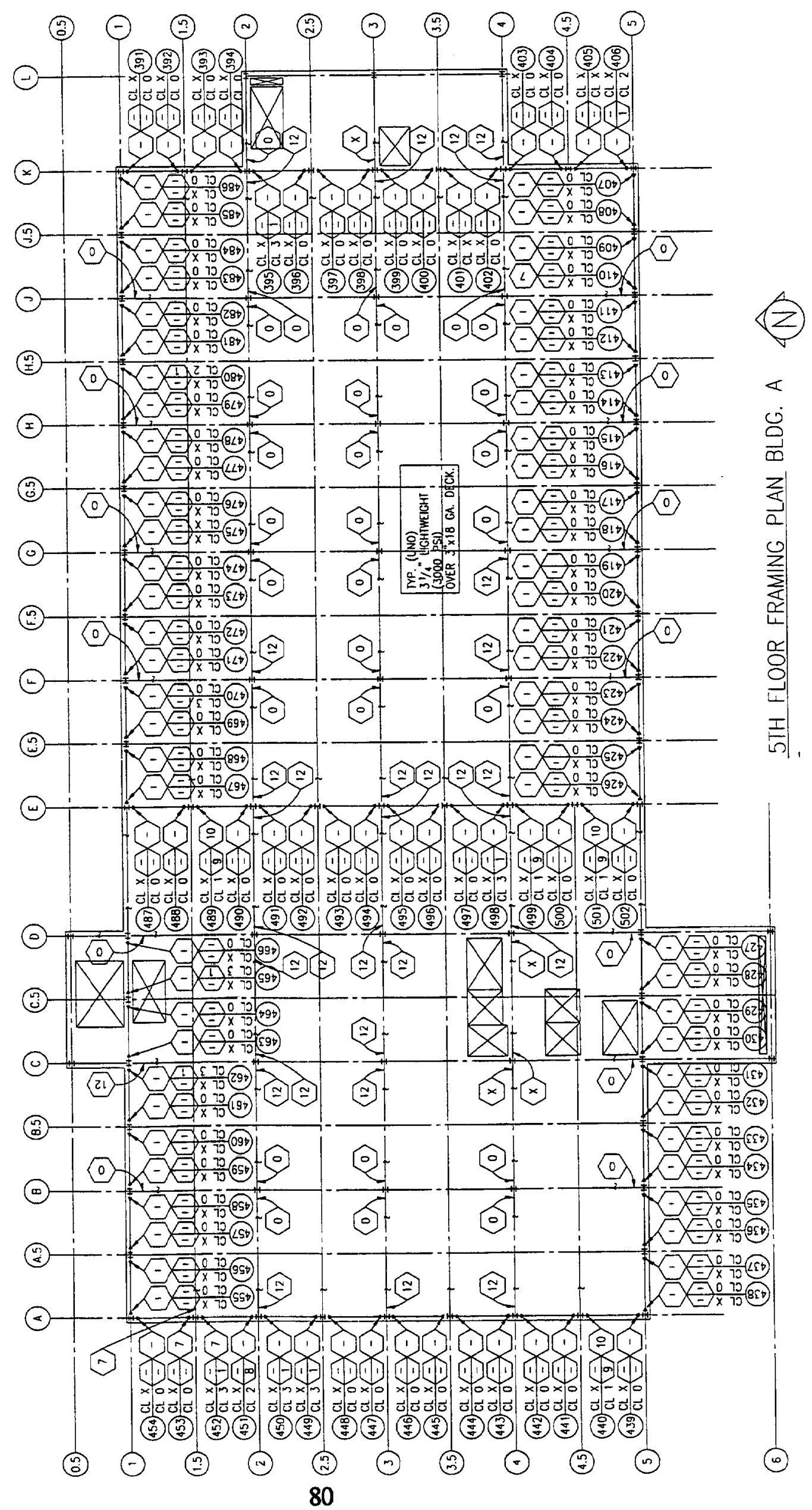




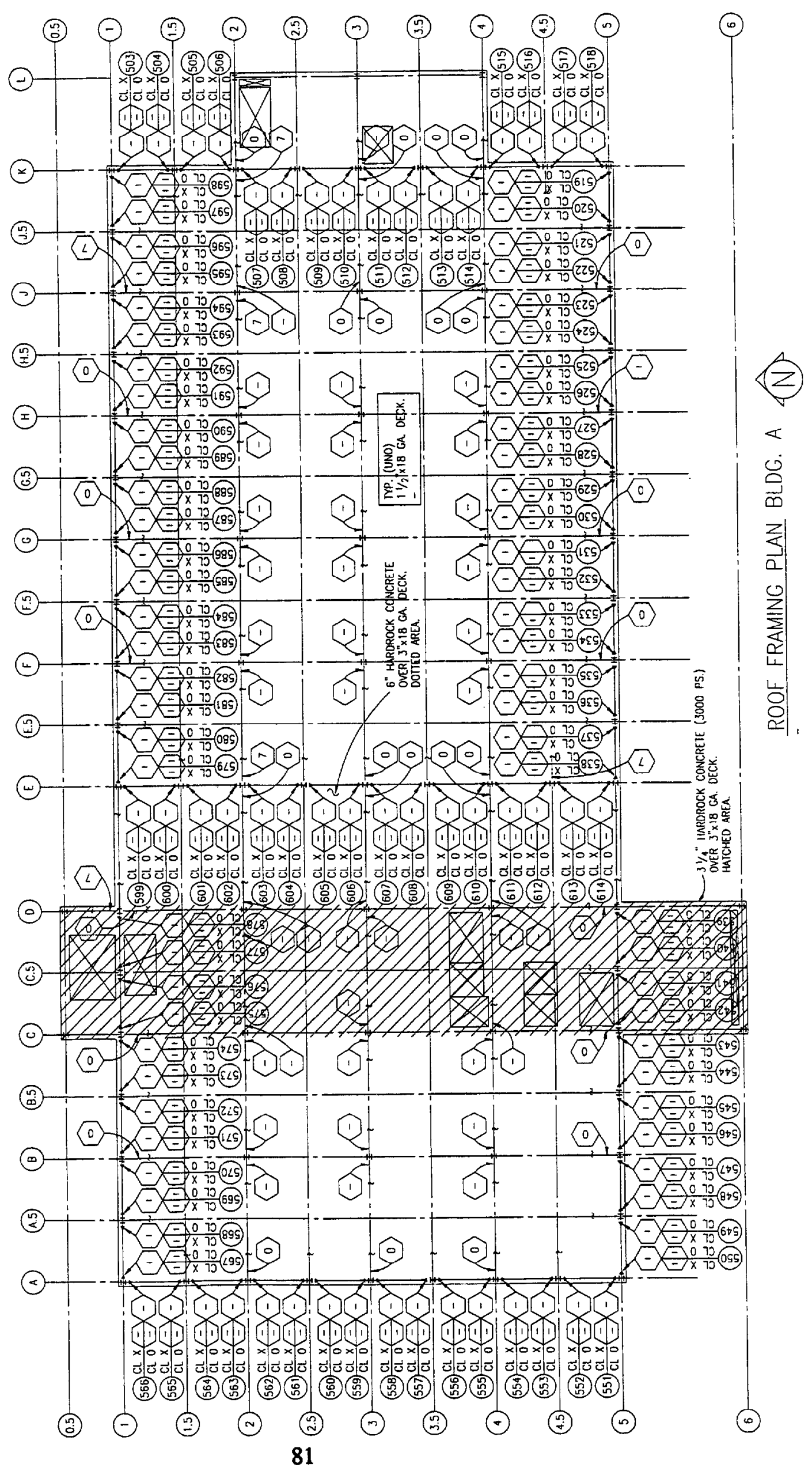




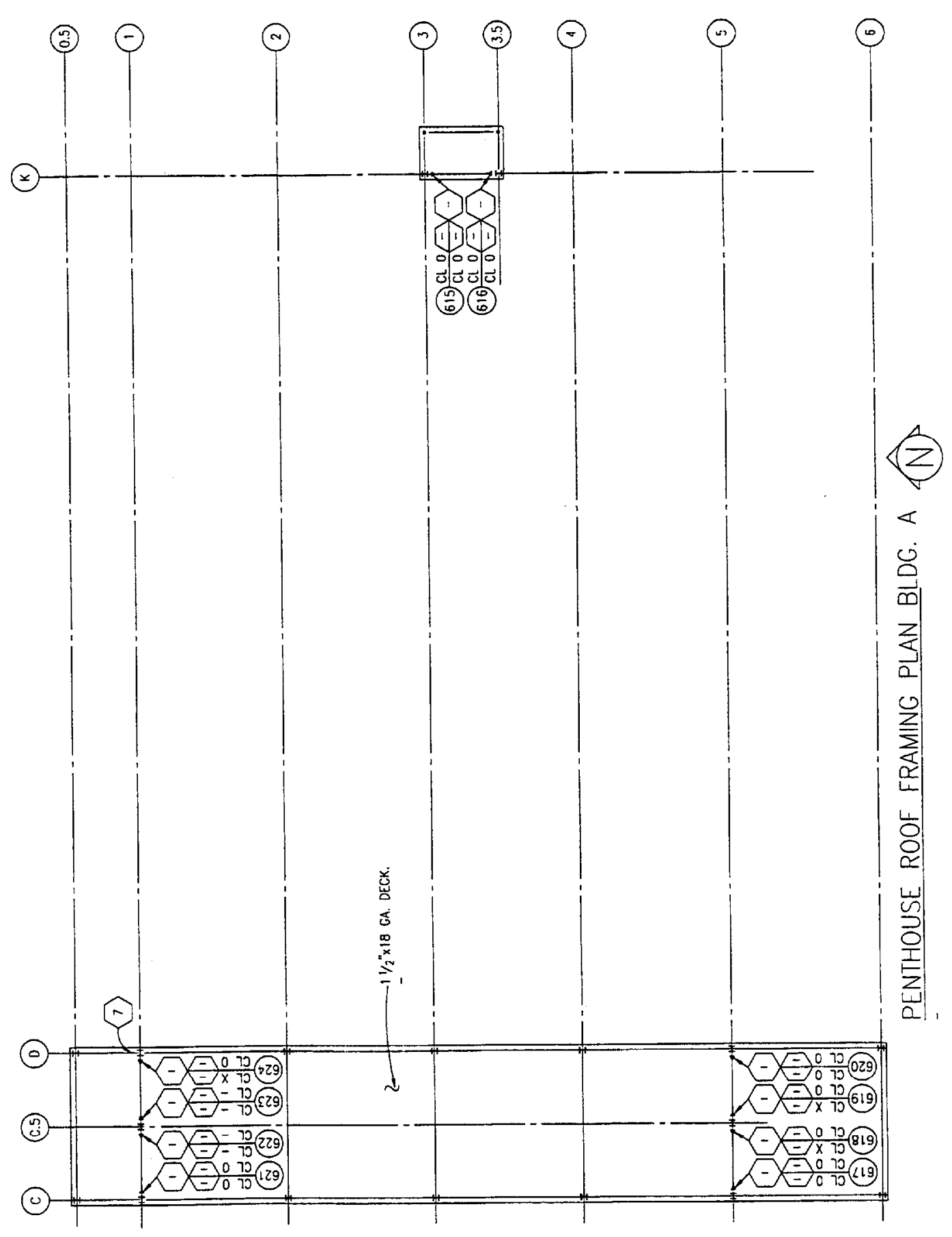




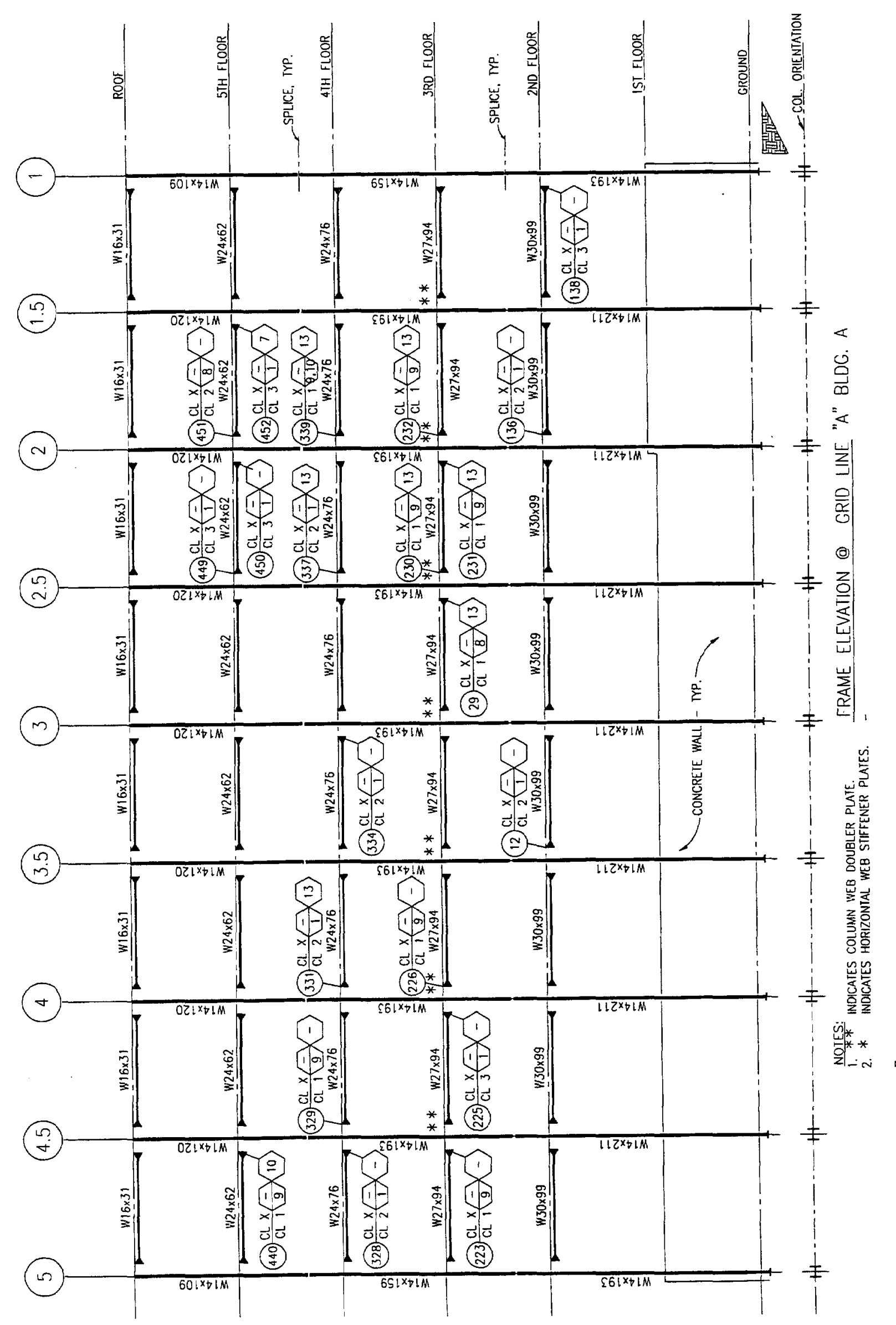




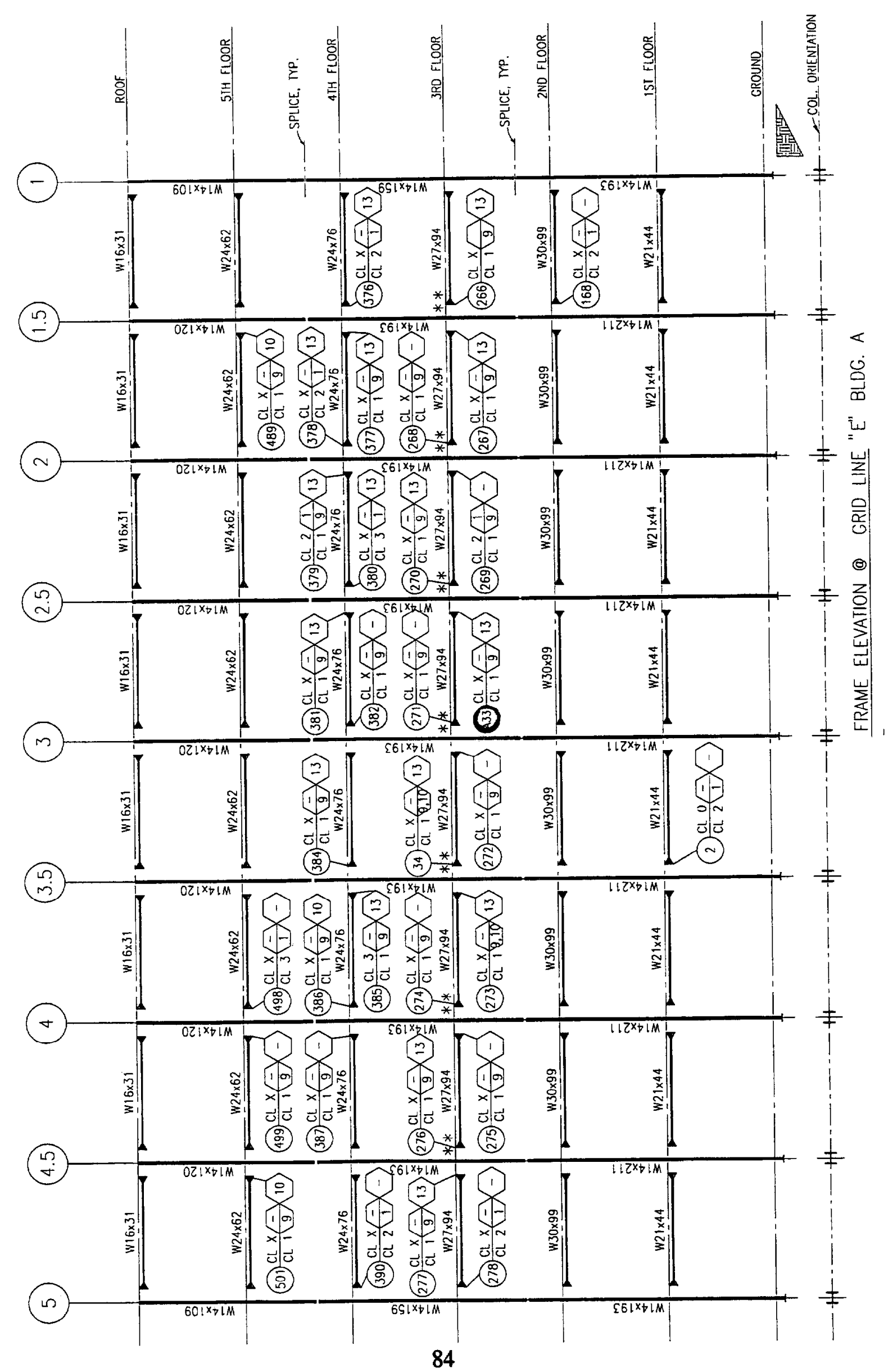




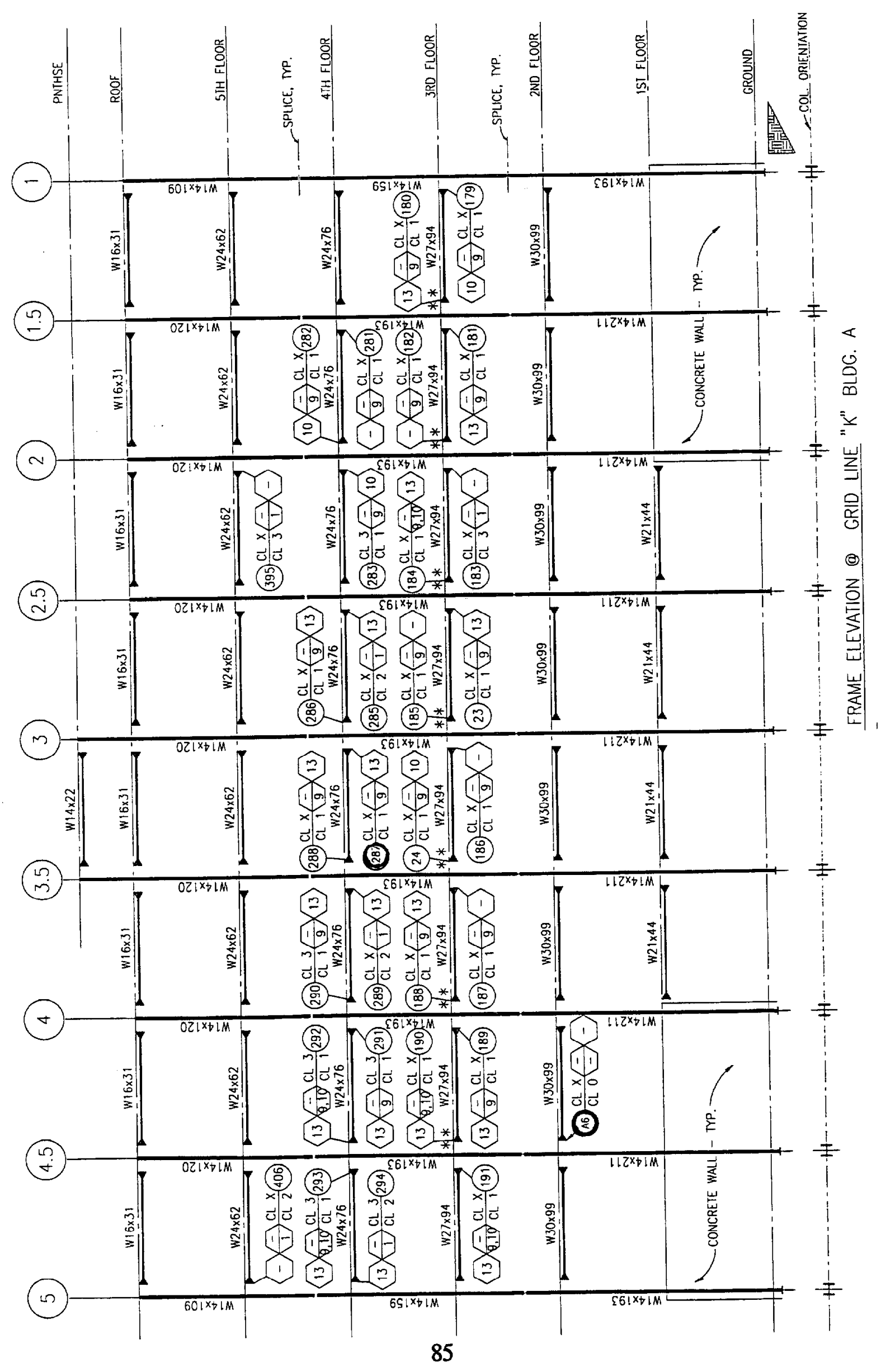




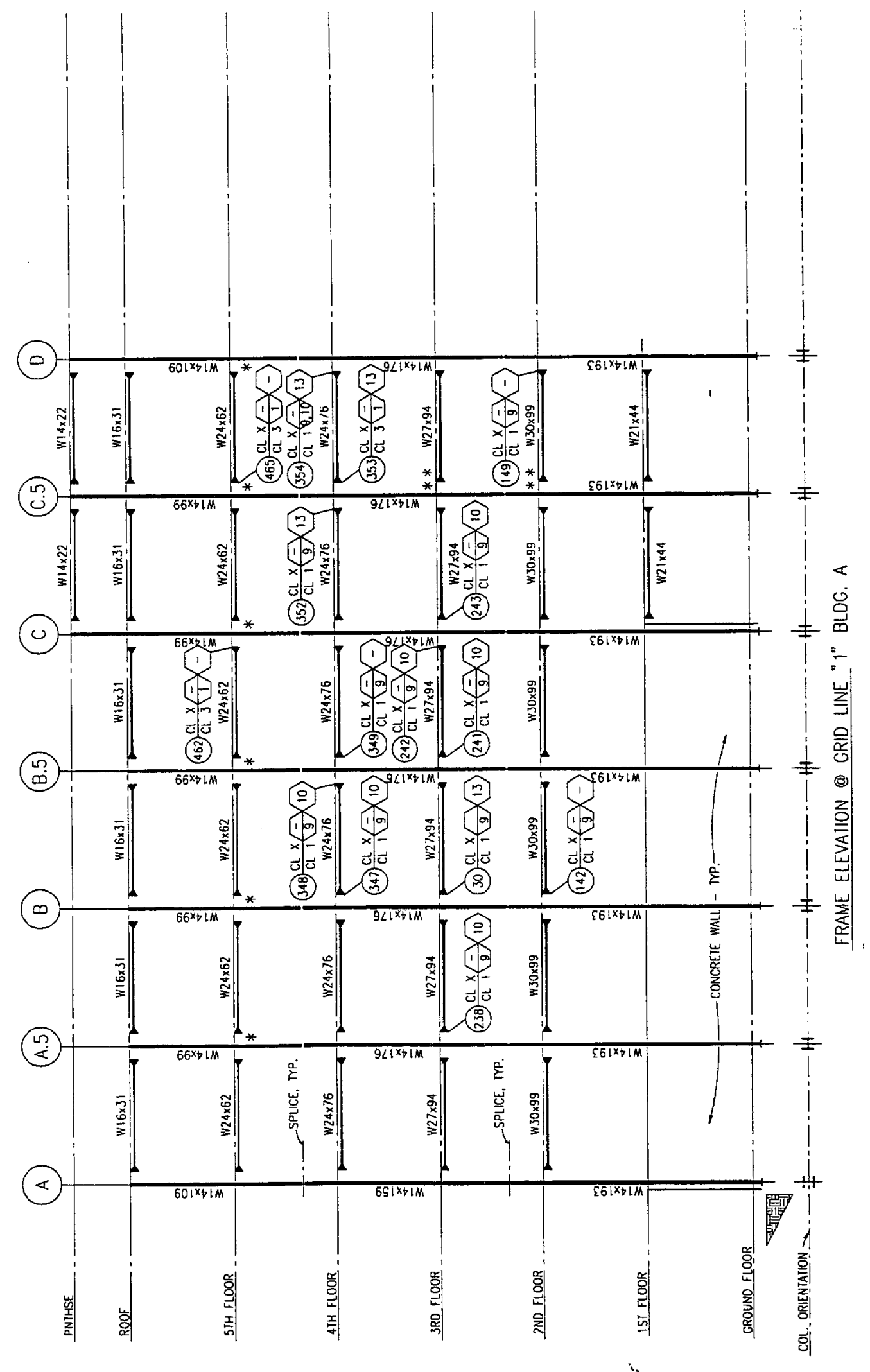




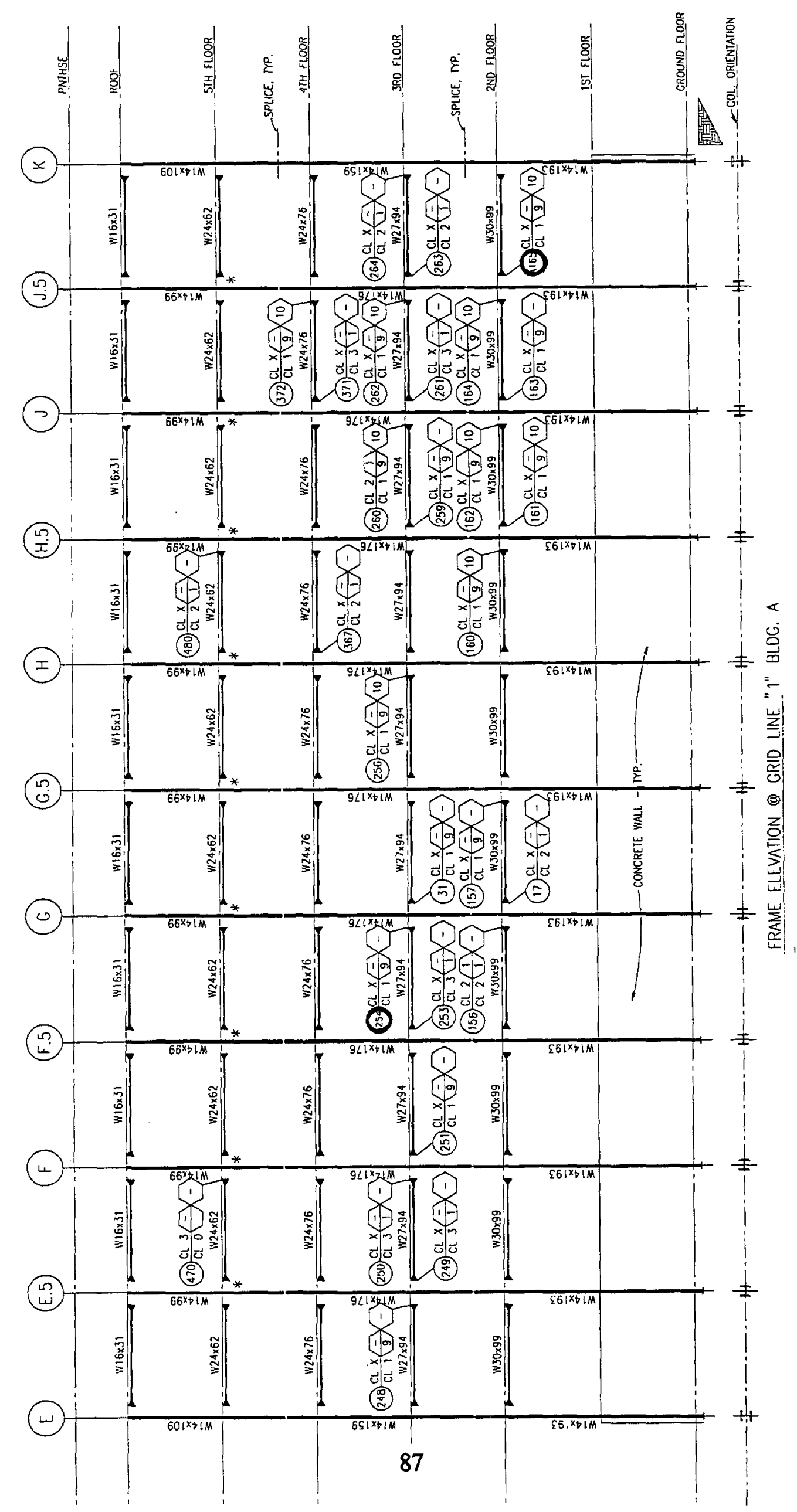




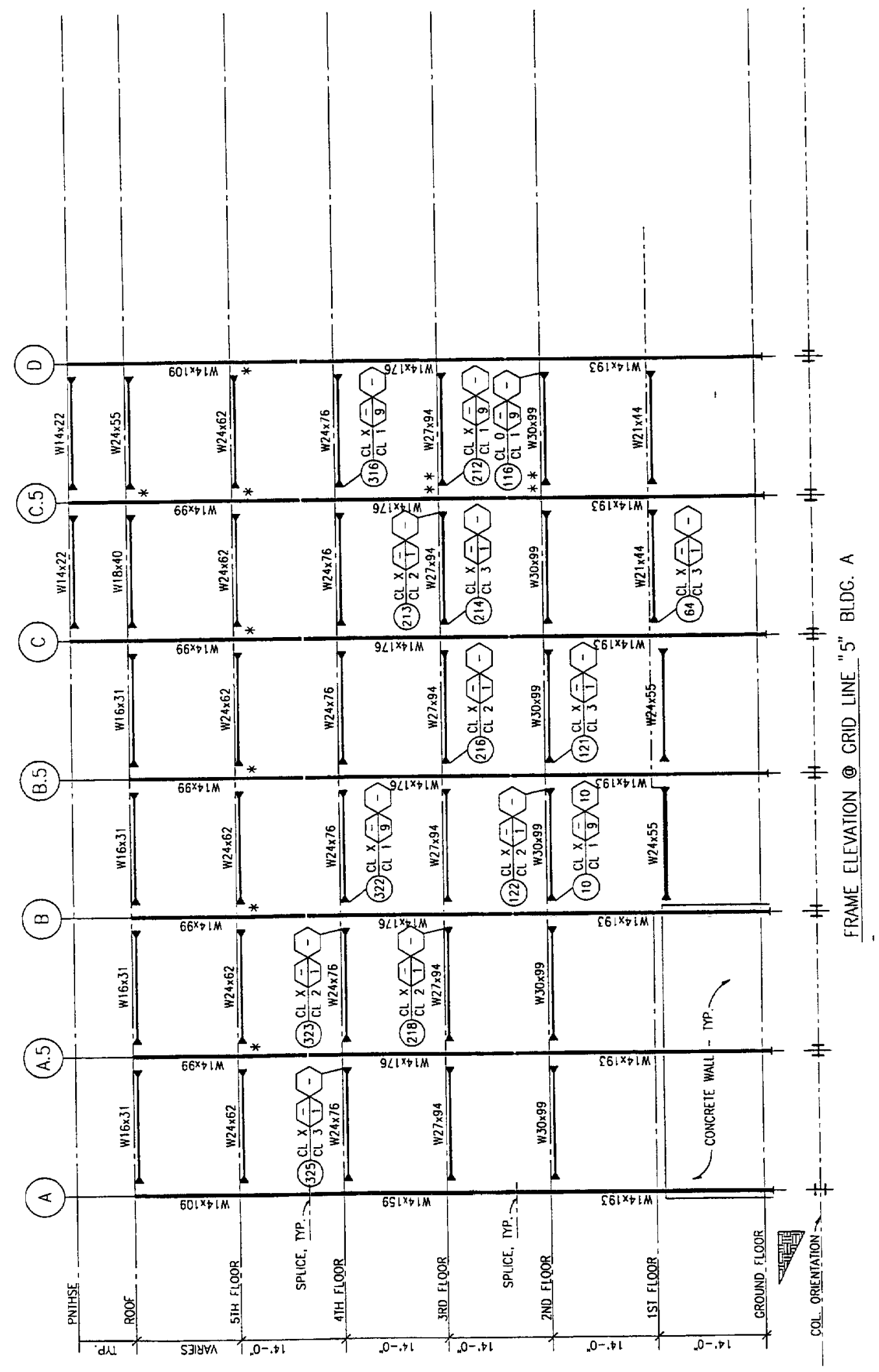




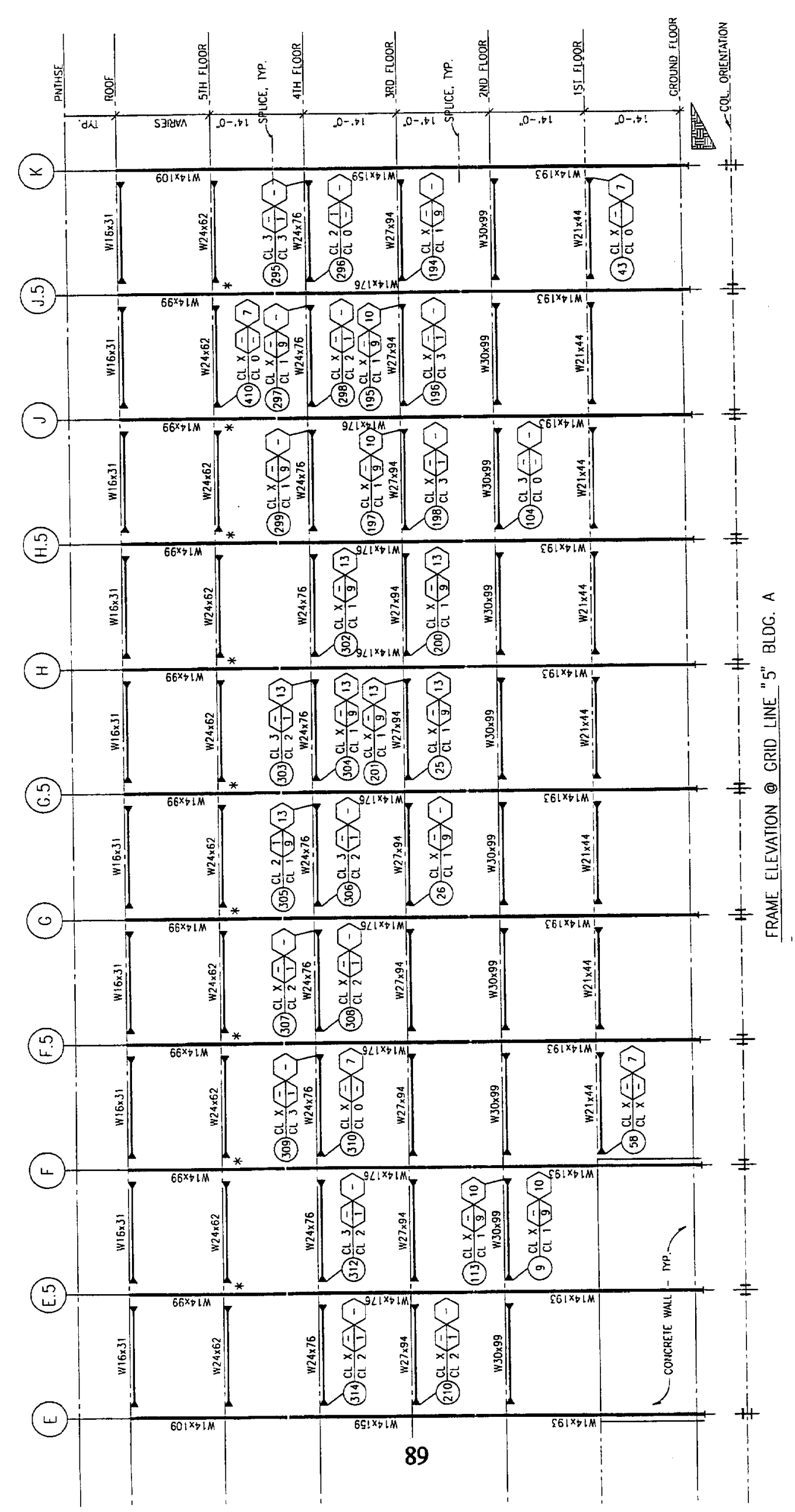


Building B 


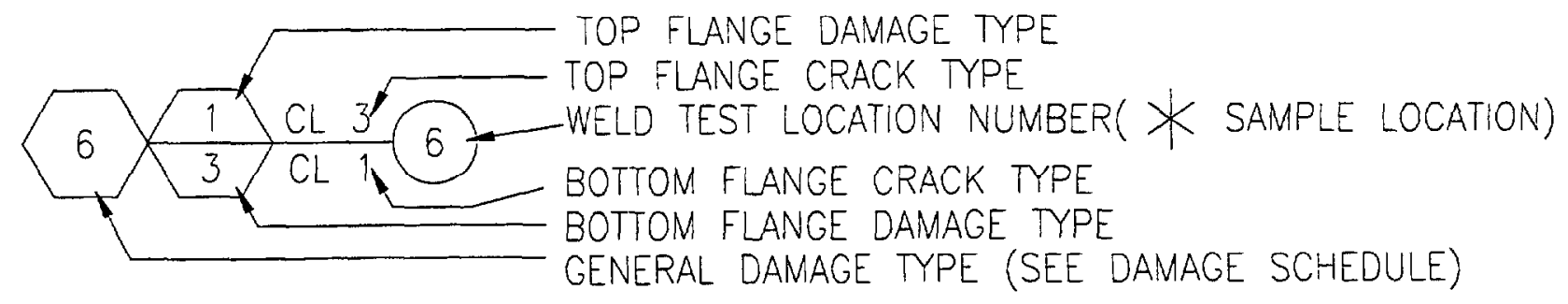

\begin{tabular}{|c|c|c|c|c|}
\hline \multicolumn{5}{|c|}{ DAMAGE SCHEDULE (BLDG. B) } \\
\hline DAMAGE & \multicolumn{2}{|c|}{ DESCRIPTION } & - & - \\
\hline & \multirow[t]{2}{*}{ PARTIAL CRACK IN WELD } & TOP FLANGE & - & - \\
\hline & & BOTTOM FLANGE & & \\
\hline \multirow{2}{*}{2} & \multirow{2}{*}{$\begin{array}{l}\text { THROUGH CRACK IN WELD } \\
\text { (NO GAP) }\end{array}$} & TOP FLANGE & & \\
\hline & & BOTTOM FLANGE & & \\
\hline \multirow{2}{*}{3} & \multirow{2}{*}{$\begin{array}{l}\text { THROUGH CRACK IN WELD } \\
\text { (WITH GAP) }\end{array}$} & TOP FLANGE & & \\
\hline & & BOTTOM FLANGE & & \\
\hline 4. & \multicolumn{2}{|l|}{ SHEAR TAB WELD CRACK } & & \\
\hline 5 & \multicolumn{2}{|c|}{ SHEAR TAB OR BEAM WEB CRACK } & & \\
\hline 6 & \multicolumn{2}{|c|}{ BENT SHEAR TAB OR BEAM WEB } & & \\
\hline 77 & \multicolumn{2}{|l|}{ LOOSE OR MISSING BOLTS } & & \\
\hline 8 & \multicolumn{2}{|c|}{$\begin{array}{l}\text { PARTIAL OR THROUGH CRACK IN COLUMN FLANGE } \\
\text { WITHIN } 45^{\circ} \text { ANGLE ZONE }\end{array}$} & & \\
\hline 9 & \multicolumn{2}{|c|}{$\begin{array}{l}\text { PARTIAL OR THROUGH CRACK IN COLUMN FLANGE } \\
\text { OUTSIDE } 45^{\circ} \text { ANGLE ZONE }\end{array}$} & & \\
\hline 10 & \multicolumn{2}{|c|}{ COLUMN WEB CRACK } & & \\
\hline (11) & \multicolumn{2}{|c|}{ LOOSE OR DAMAGED COL. OR BEAM FIREPROOFING } & & \\
\hline
\end{tabular}

'CL O' INDICATES NO CRACKS FOUND.

'CL $X$ ' INDICATES FLANGE OR PORTION OF FLANGE INACCESSIBLE DURING INITIAL TESTING. 


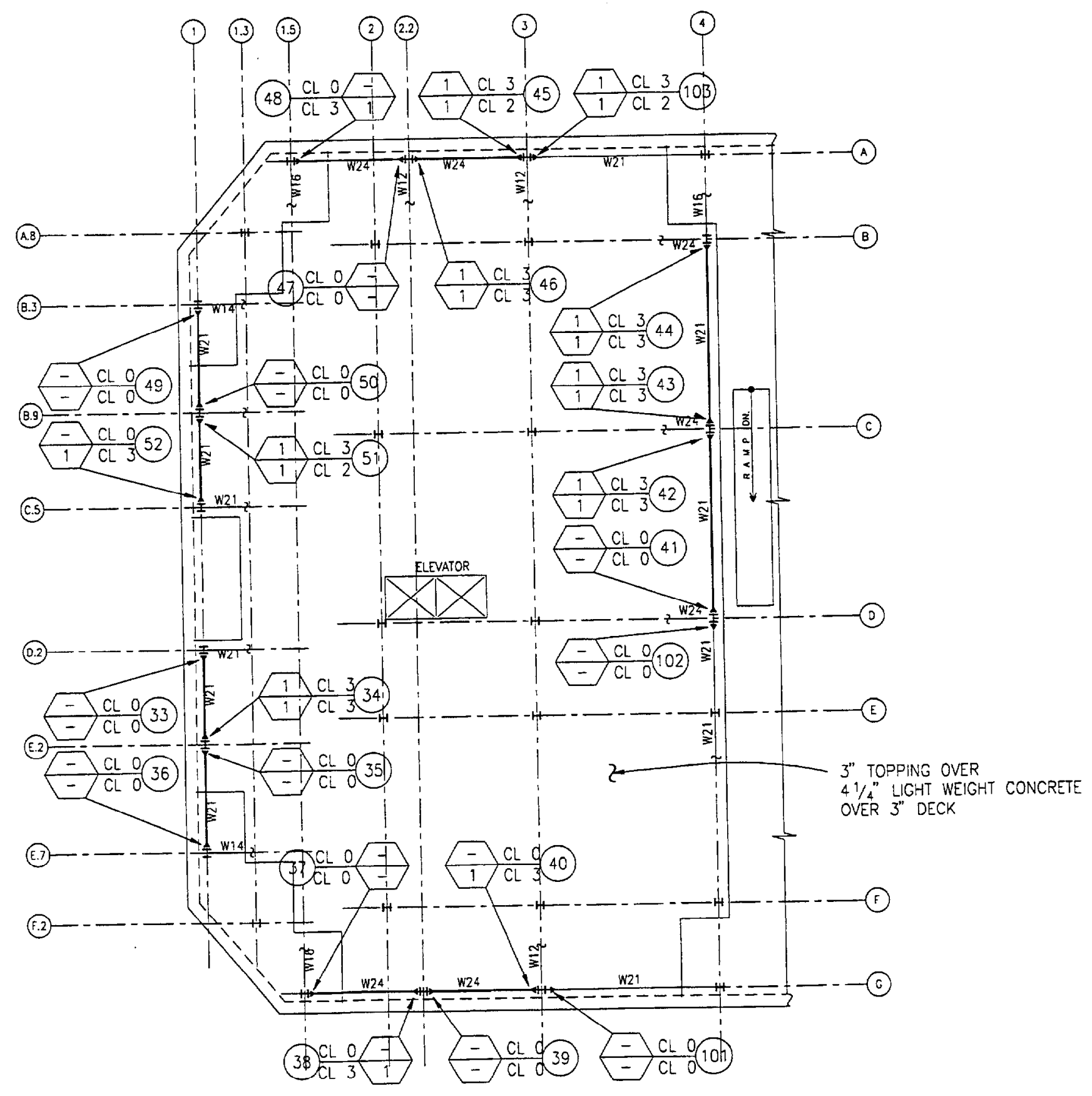

IST FLOOR FRAMING PLAN, BLDG. "B" 


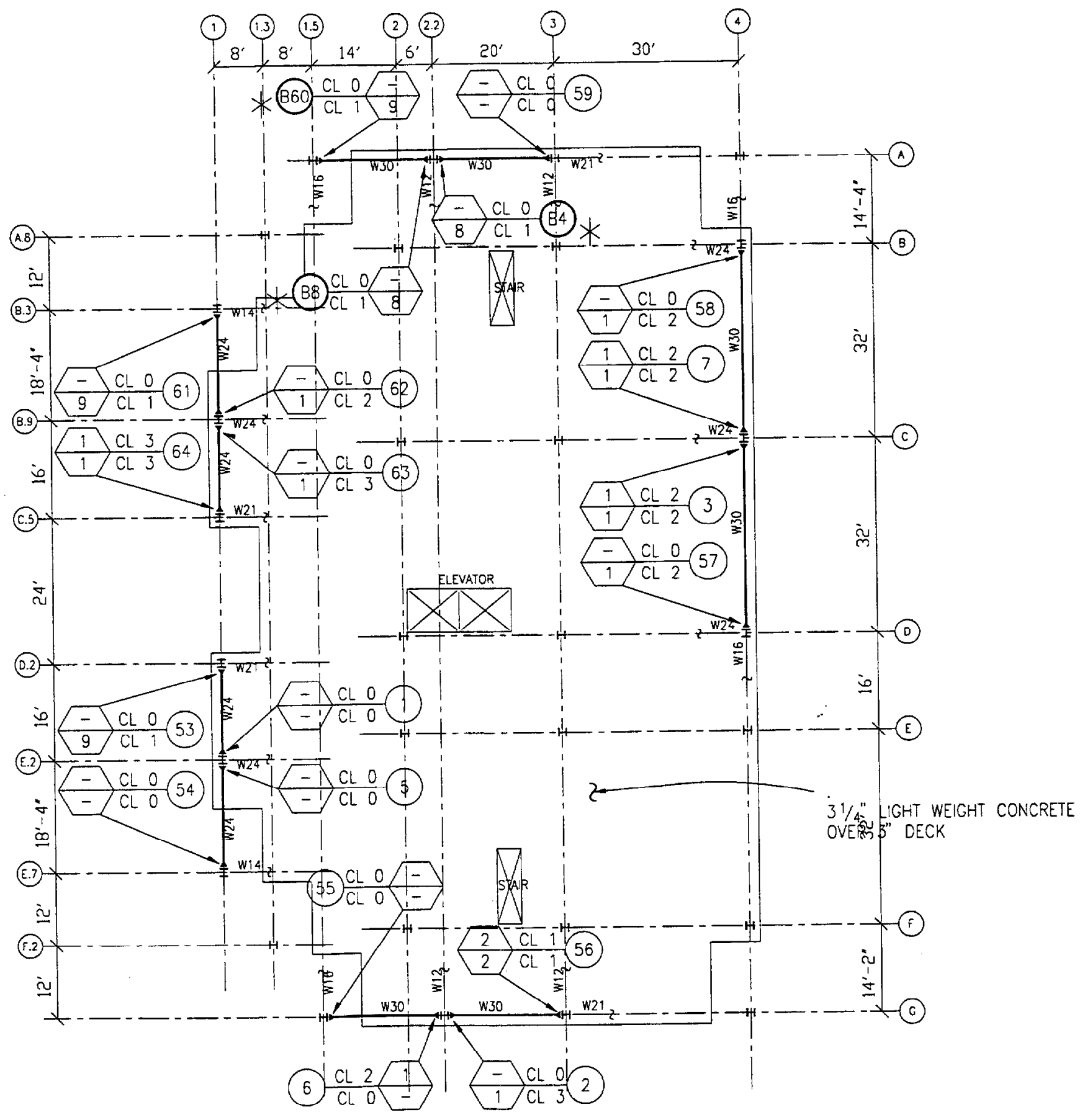

2ND FLOOR FRAMING PLAN, BLDG. "B"

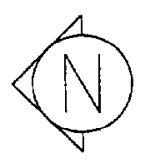




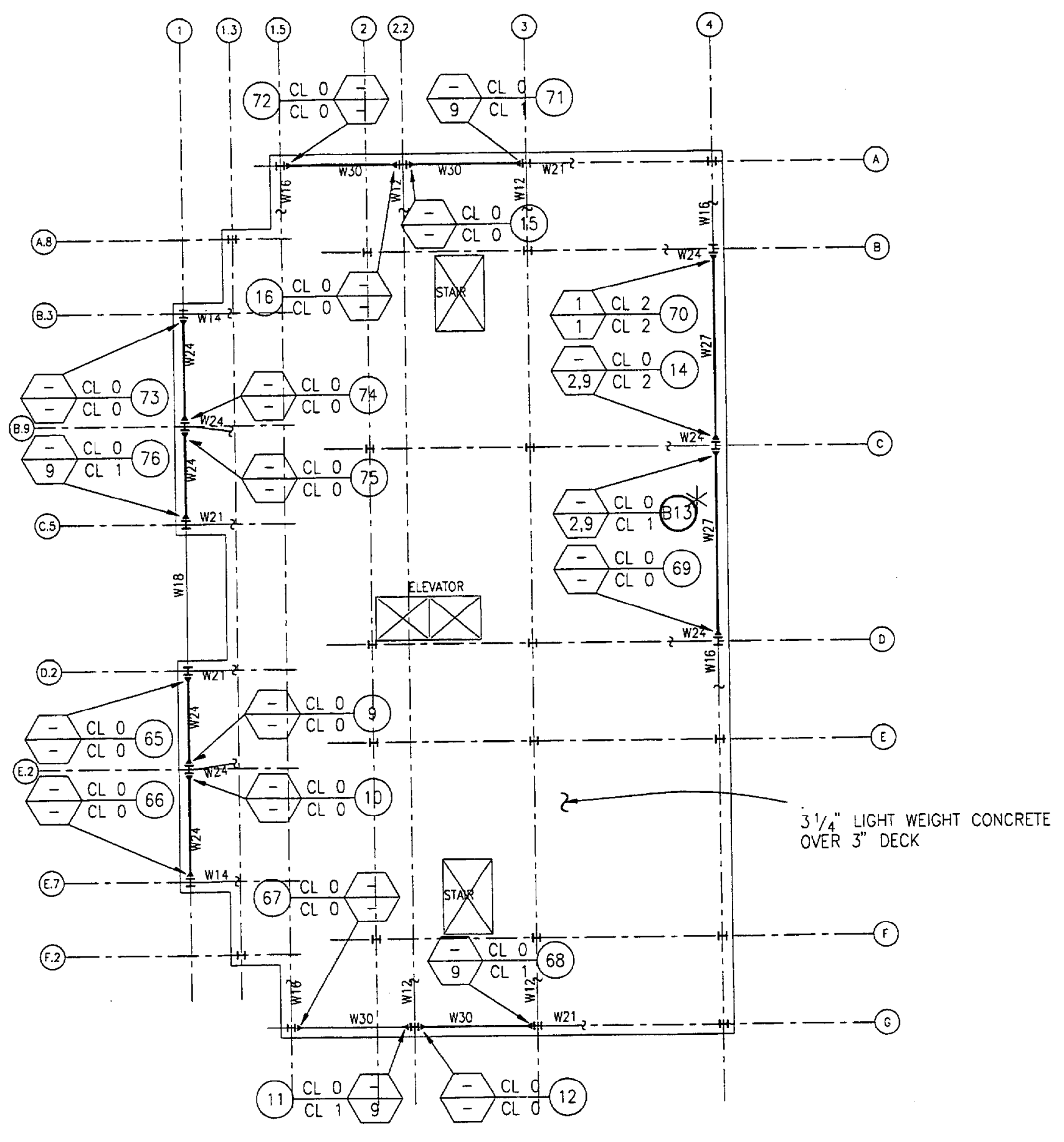

3RD FLOOR FRAMING PLAN, BLDG. "B" N 


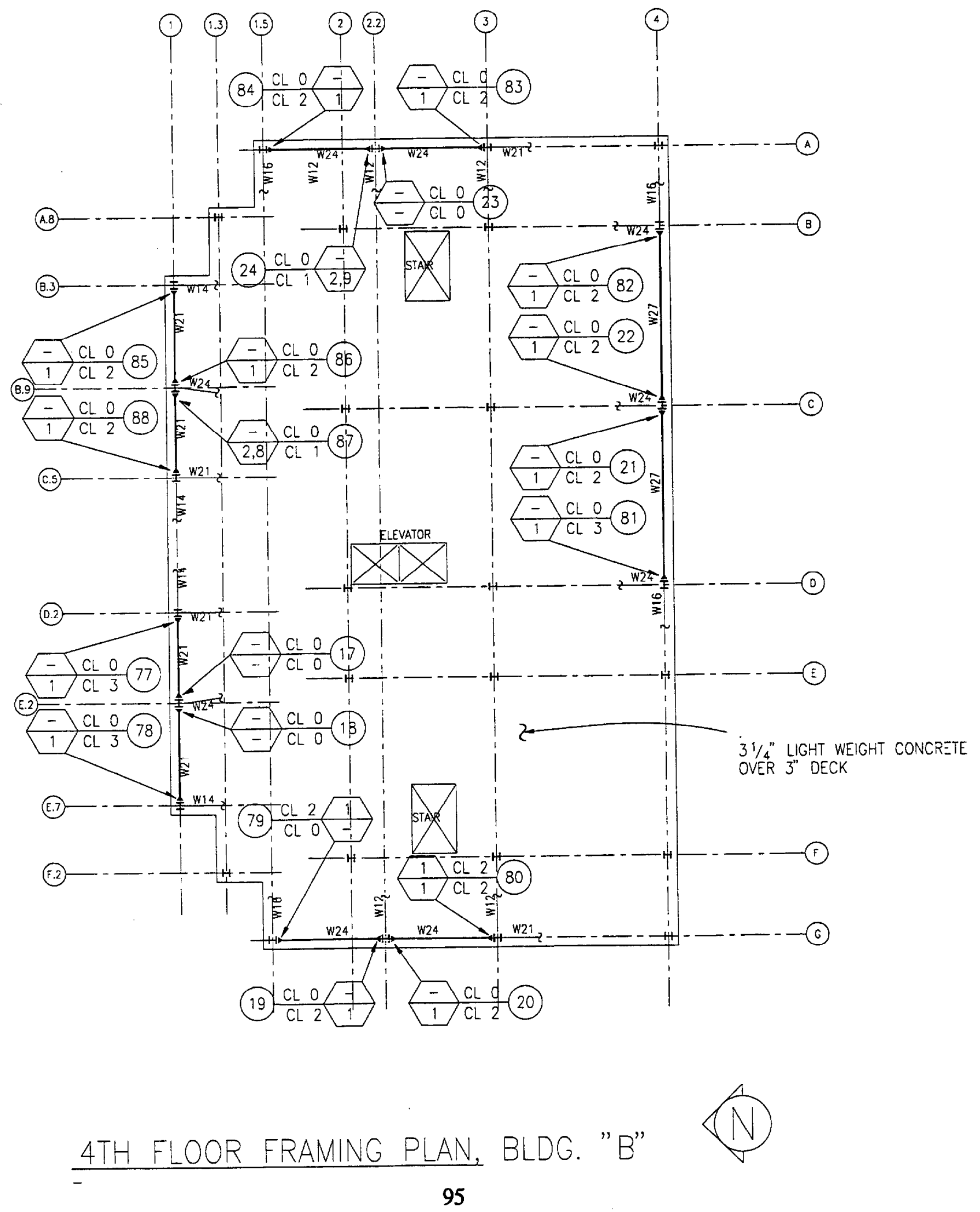




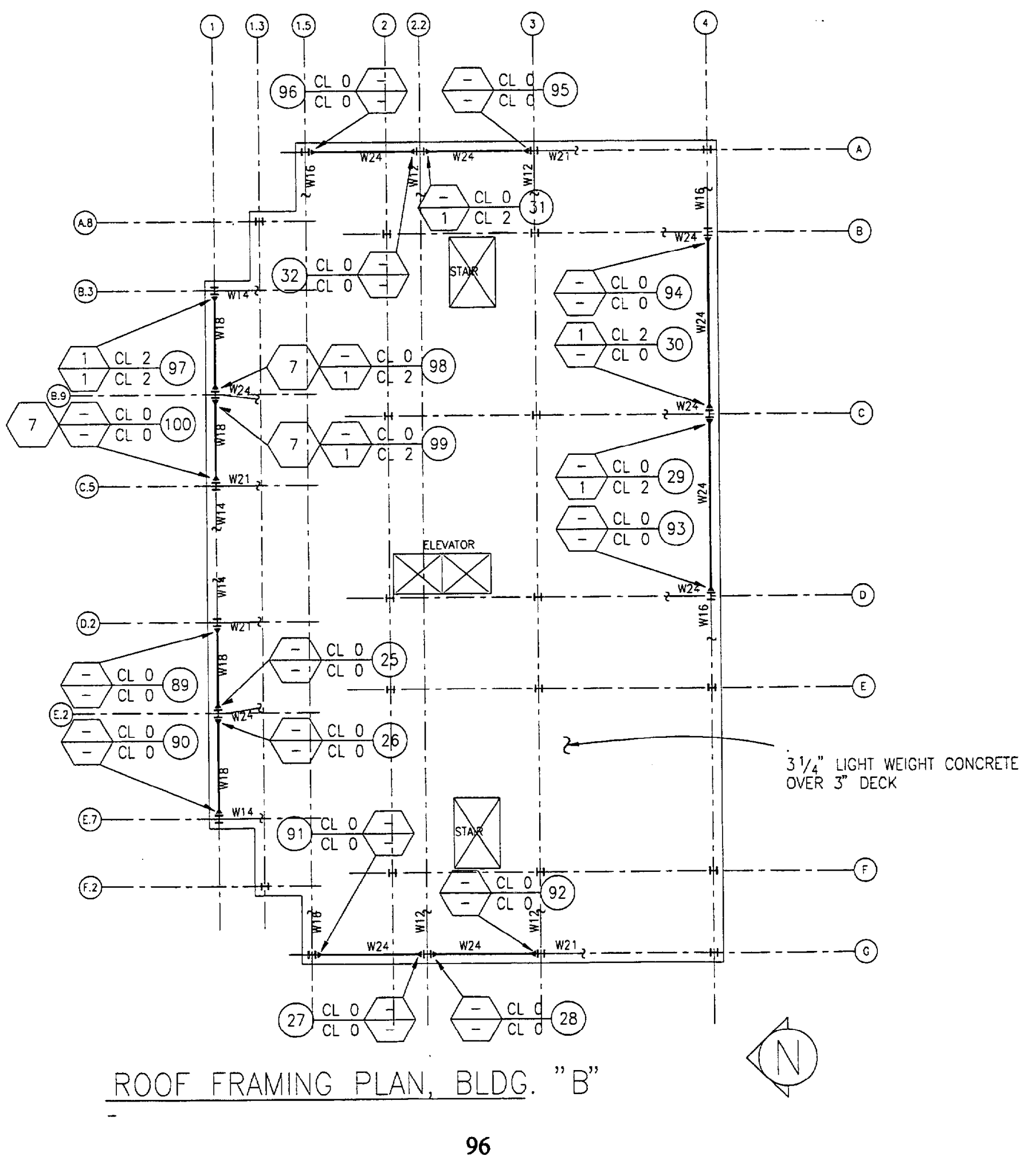




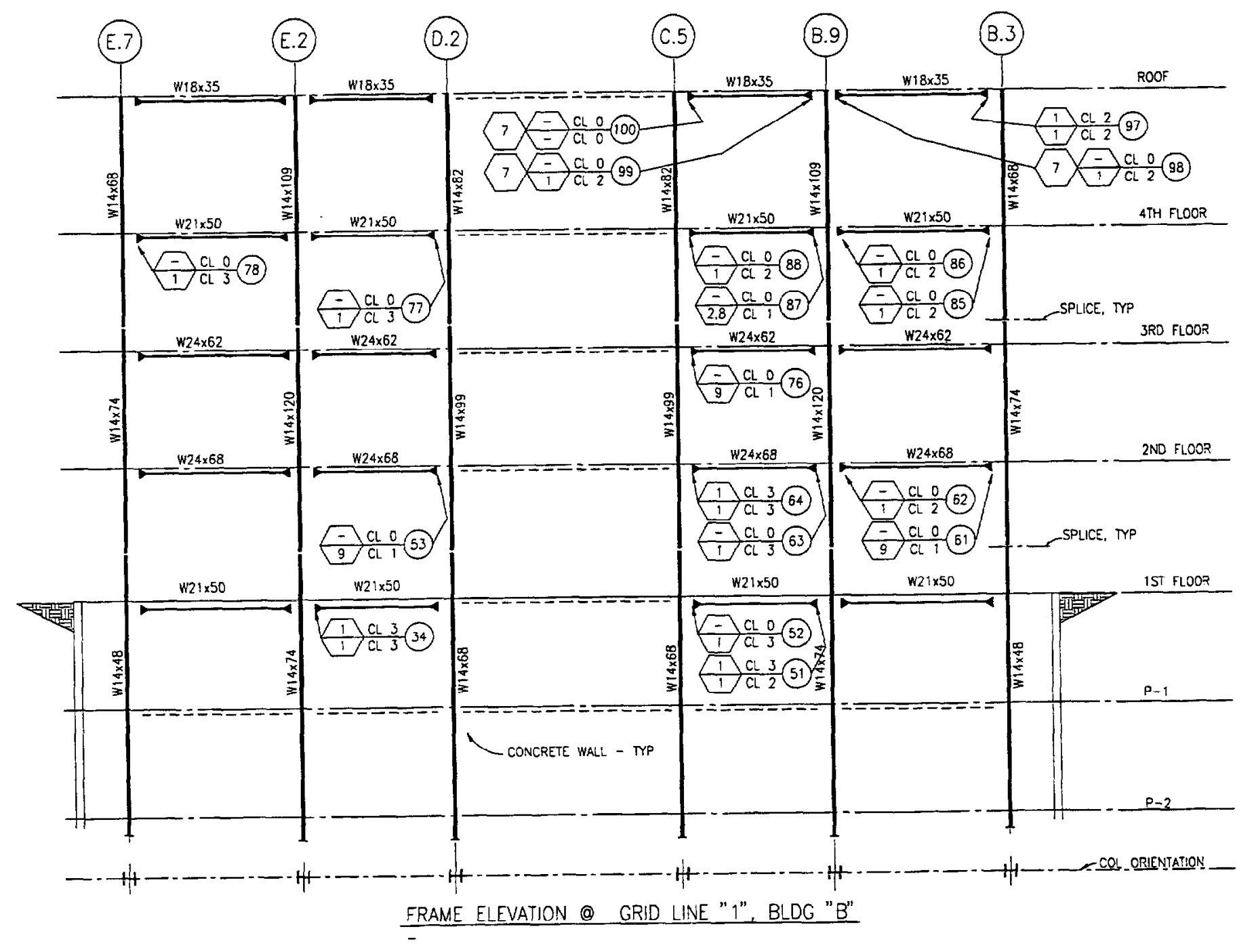




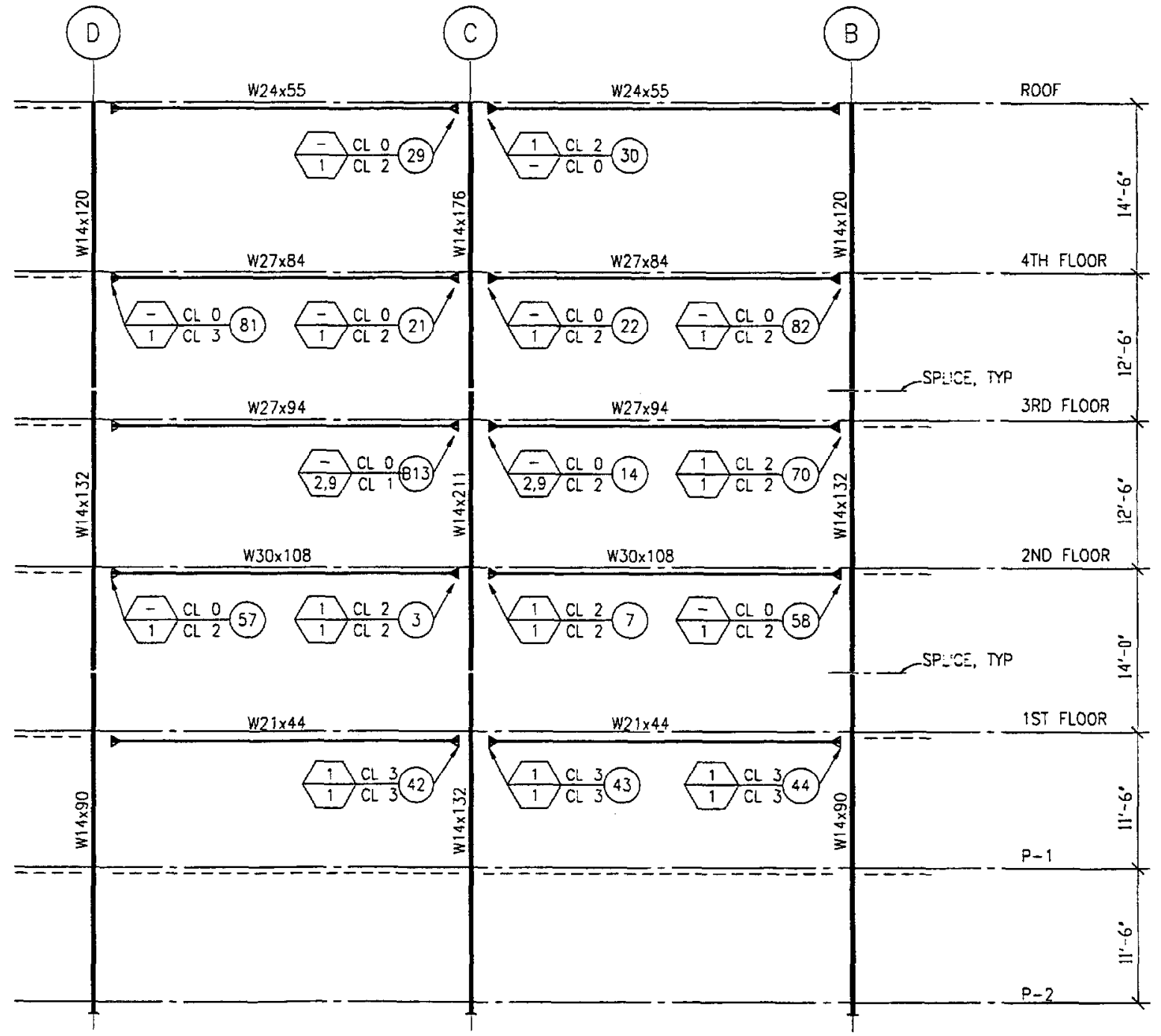

FRAME ELEVATION @ GRID LINE "4", BLDG "B" 


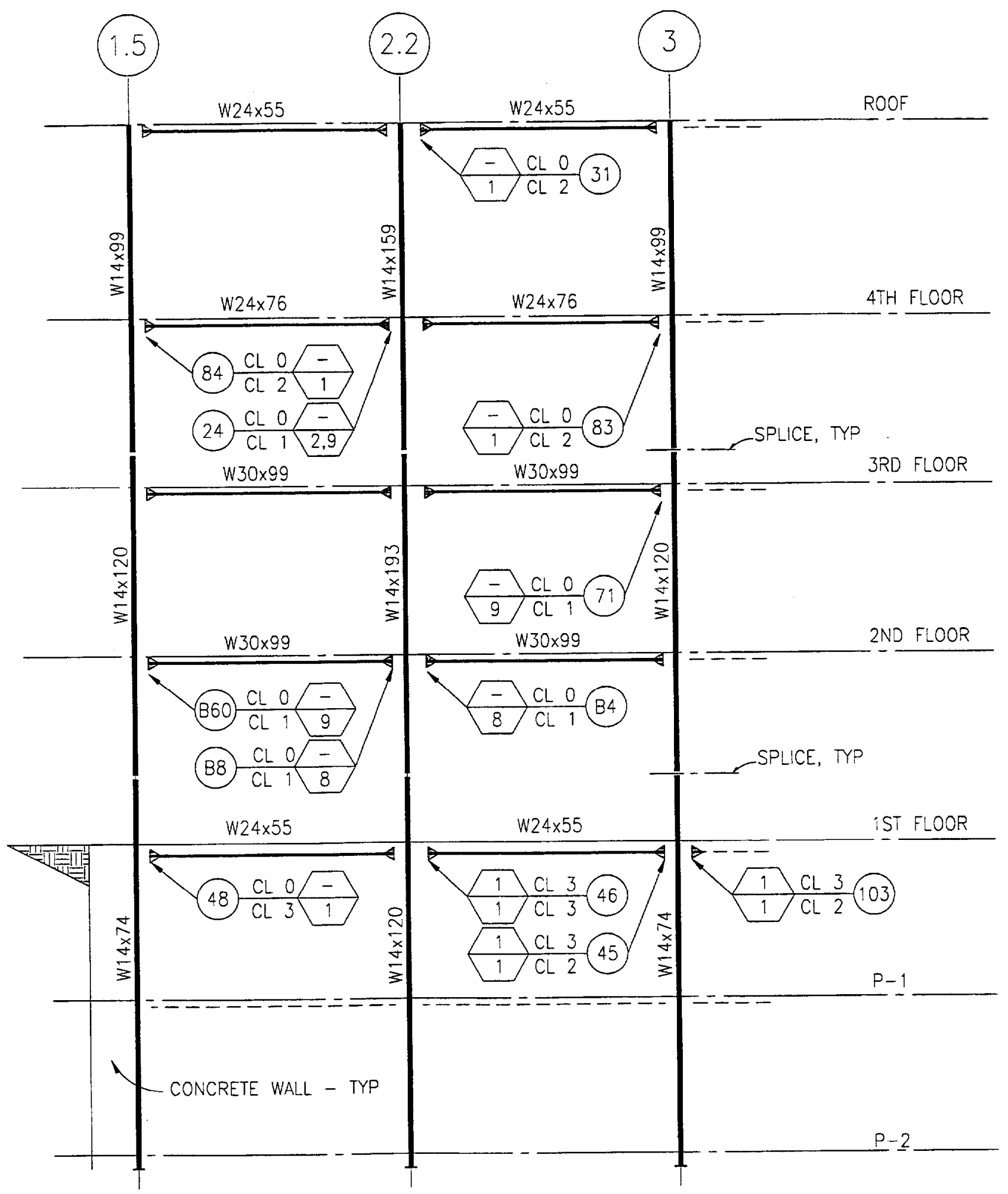

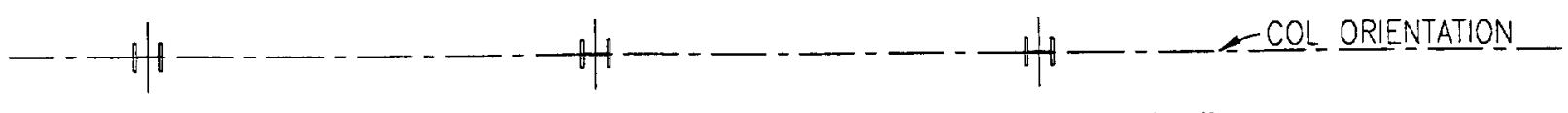
IRAME ELEVATION@ GRID LINE "A", BLDG "B" 


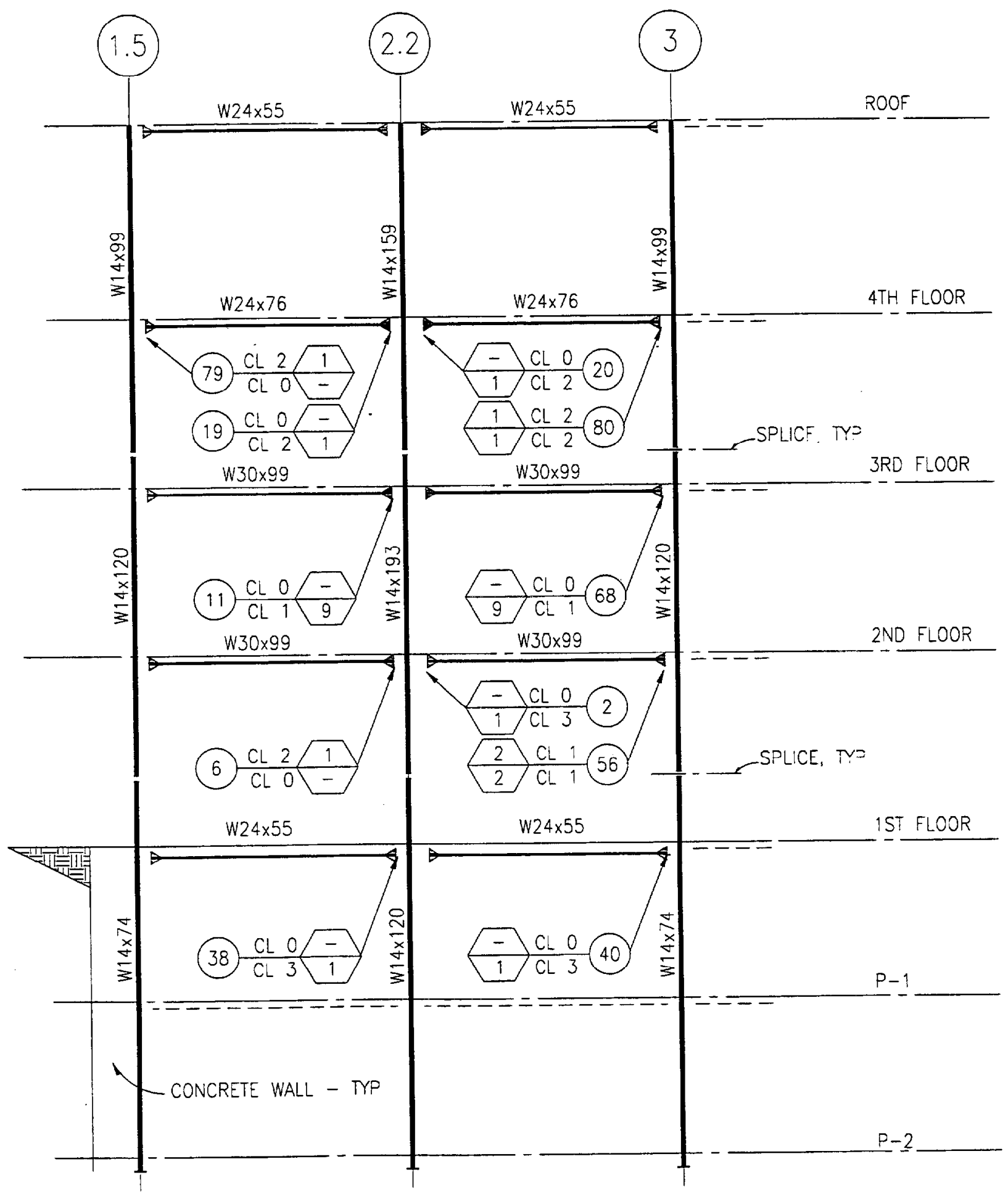

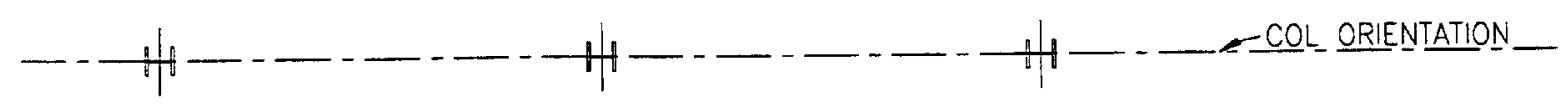
FRAME ELEVATION@ GRID LINE "C", BLDG "B" 


\section{Building C}




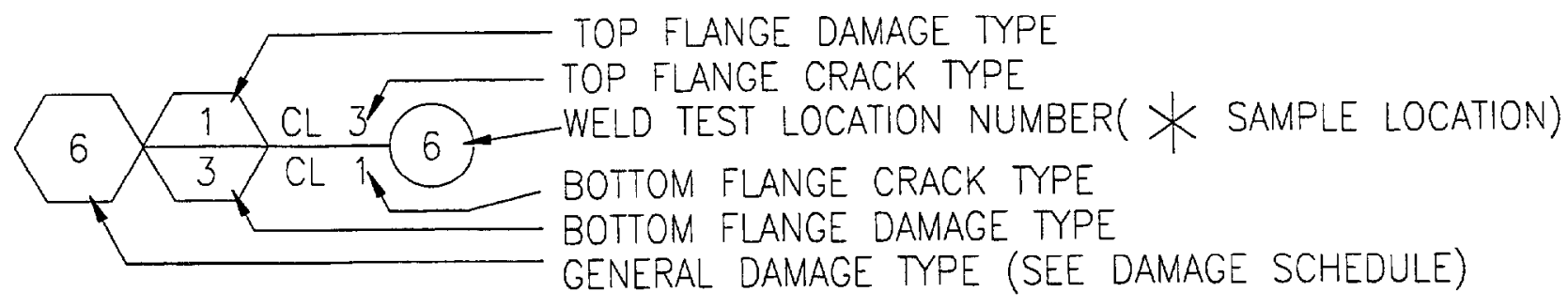

\begin{tabular}{|l|l|c|c|}
\hline \multicolumn{3}{|c|}{ DAMAGE SCHEDULE (BLDG. C) } \\
\hline $\begin{array}{c}|c| \\
\text { DAMAGE } \\
\text { TYPE }\end{array}$ & \multicolumn{1}{|c|}{ DESCRIPTION } & - \\
\hline 1 & PARTIAL CRACK IN WELD AT ROOT & - & - \\
\hline 2 & PARTIAL CRACK IN WELD ABOVE ROOT & & \\
\hline 3 & THROUGH CRACK IN WELD & & \\
\hline 4 & SHEAR TAB WELD CRACK & & \\
\hline 5 & SHEAR TAB OR BEAM WEB CRACK & & \\
\hline 6 & BENT SHEAR TAB OR BEAM WEB & & \\
\hline 7 & LOOSE OR MISSING BOLTS & & \\
\hline 8 & $\begin{array}{l}\text { PARTIAL OR THROUGH CRACK IN COLUMN FLANGE } \\
\text { WITHIN 45 ANGLE ZONE }\end{array}$ & & \\
\hline 9 & $\begin{array}{l}\text { PARTIAL OR THROUGH CRACK IN COLUMN FLANGE } \\
\text { OUTSIDE 45 ANGLE ZONE }\end{array}$ & & \\
\hline 10 & COLUMN WEB CRACK & & \\
\hline 11 & LOOSE OR DAMAGED COL. OR BEAM FIREPROOFING & & \\
\hline 12 & DAMAGED CONCRETE AT BASE PLATE & & \\
\hline
\end{tabular}

'CL O' INDICATES NO CRACKS FOUND.

'CL $X$ ' INDICATES FLANGE OR PORTION OF FLANGE INACCESSIBLE DURING INITIAL TESTING. 


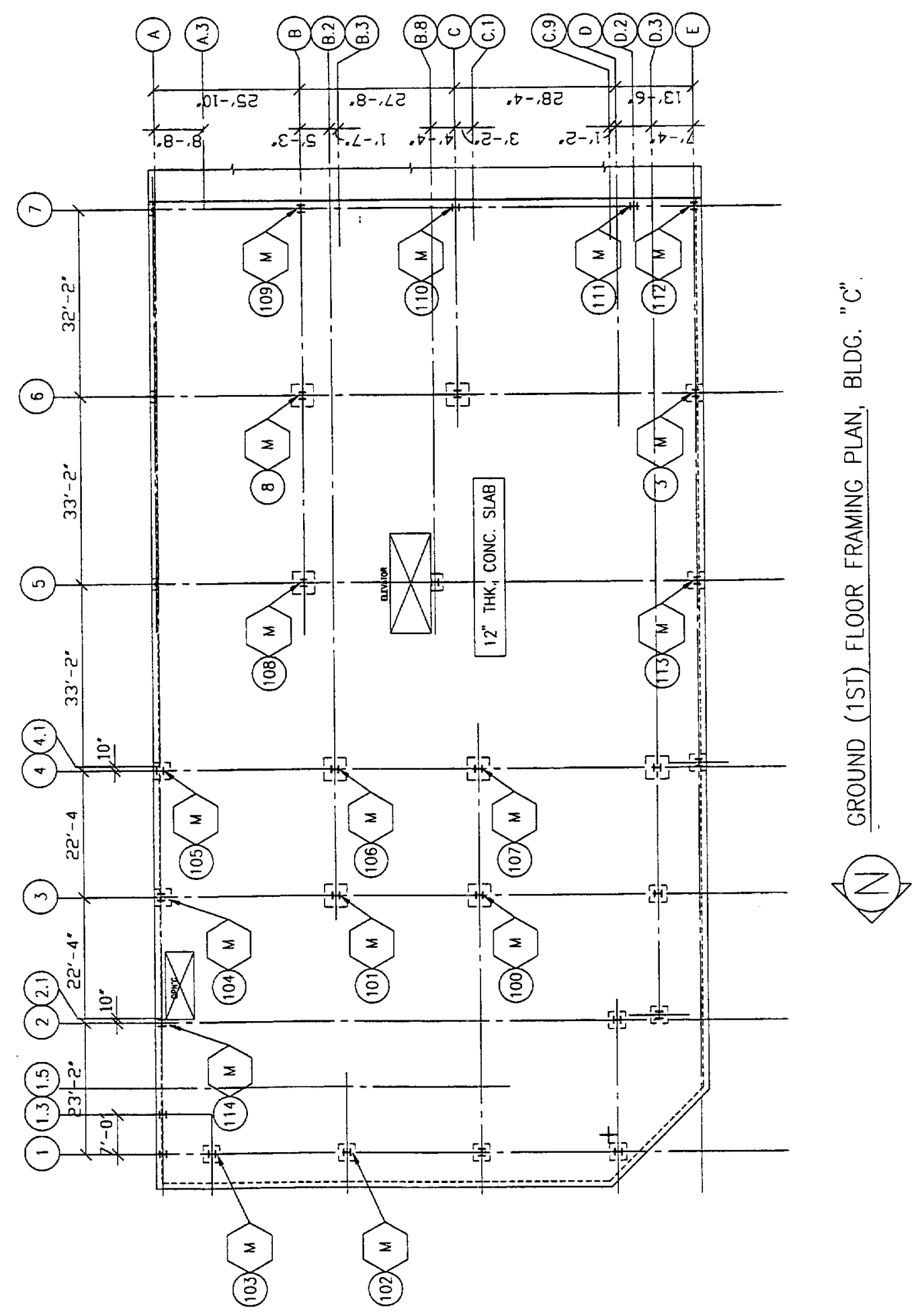




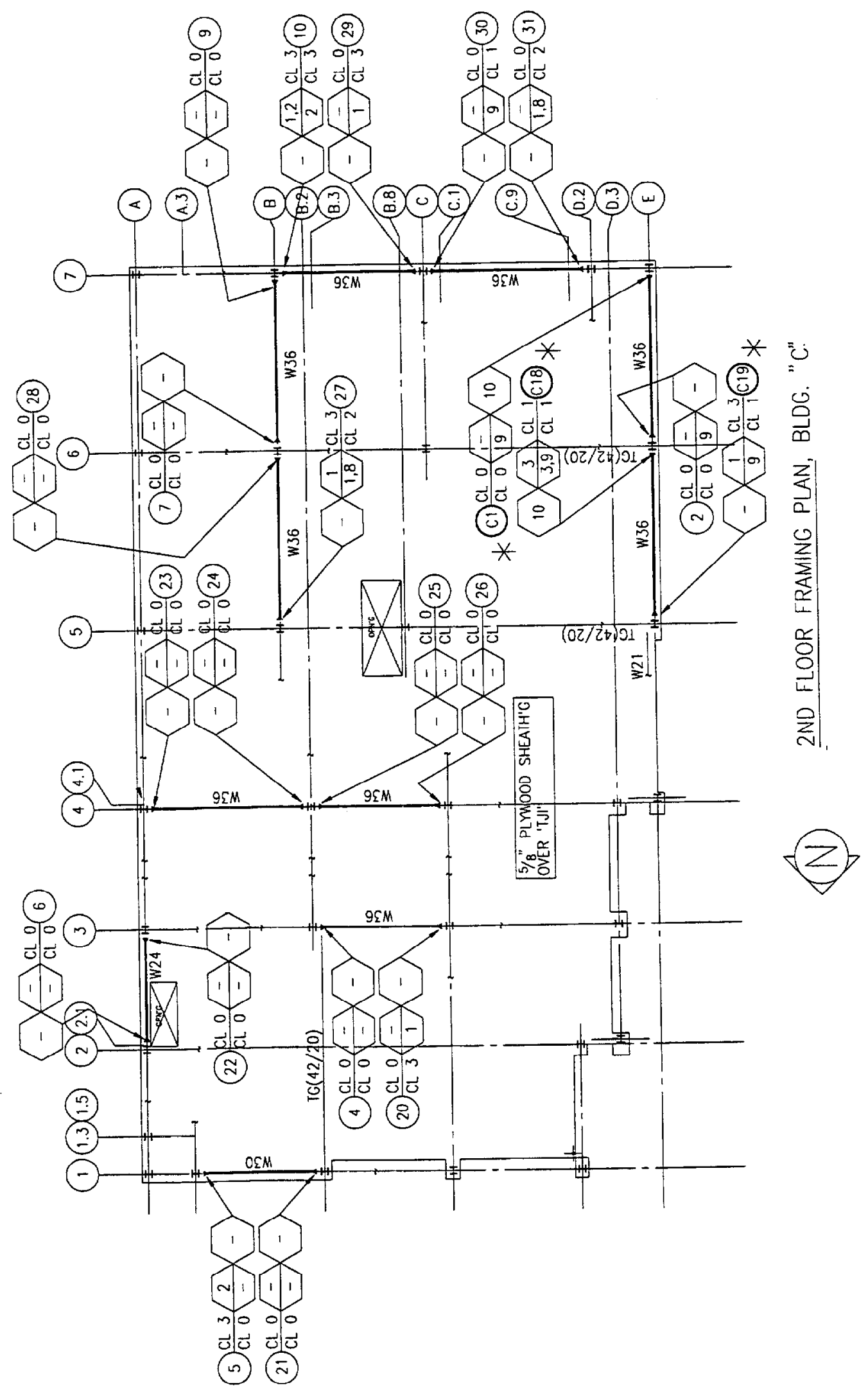




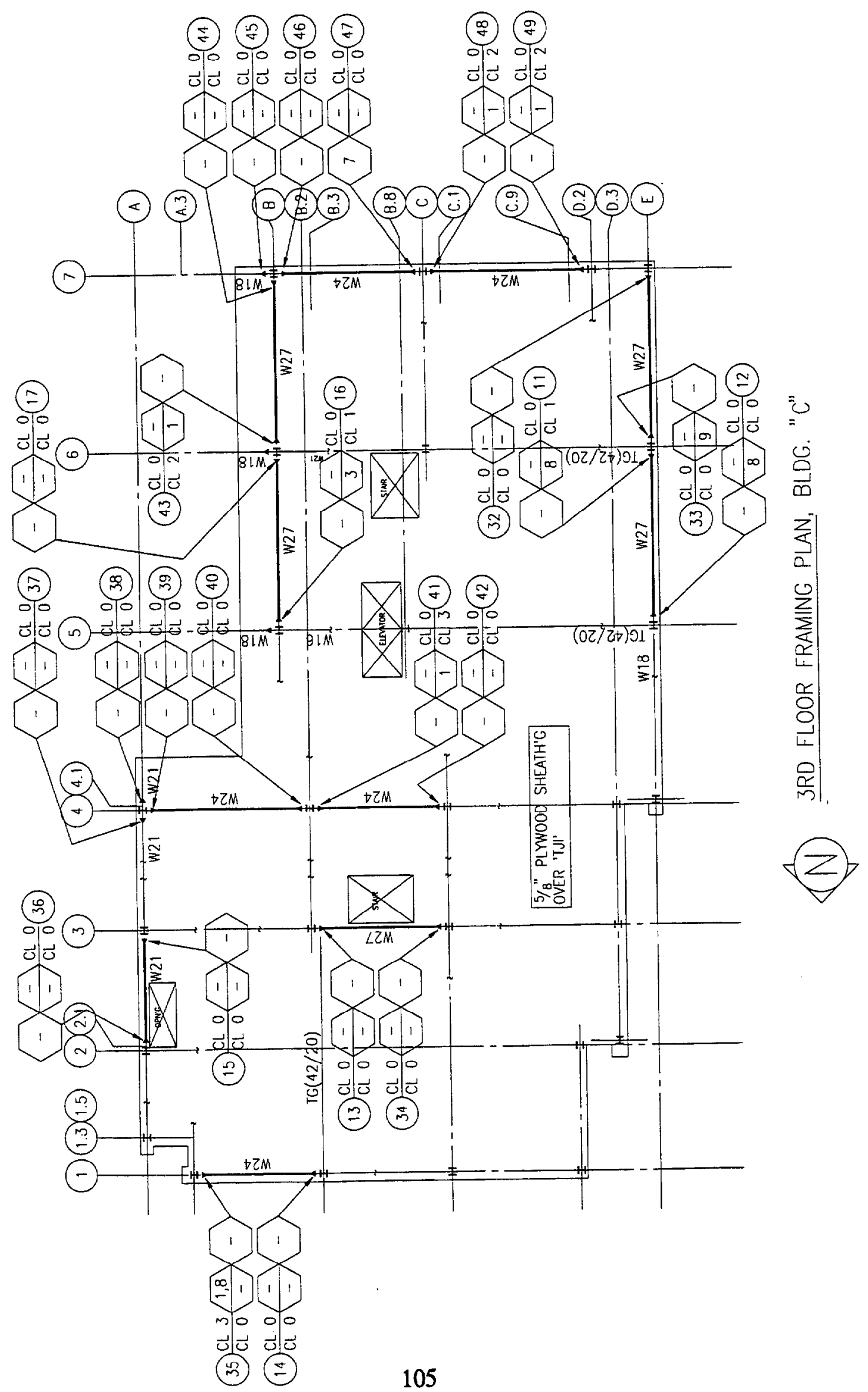




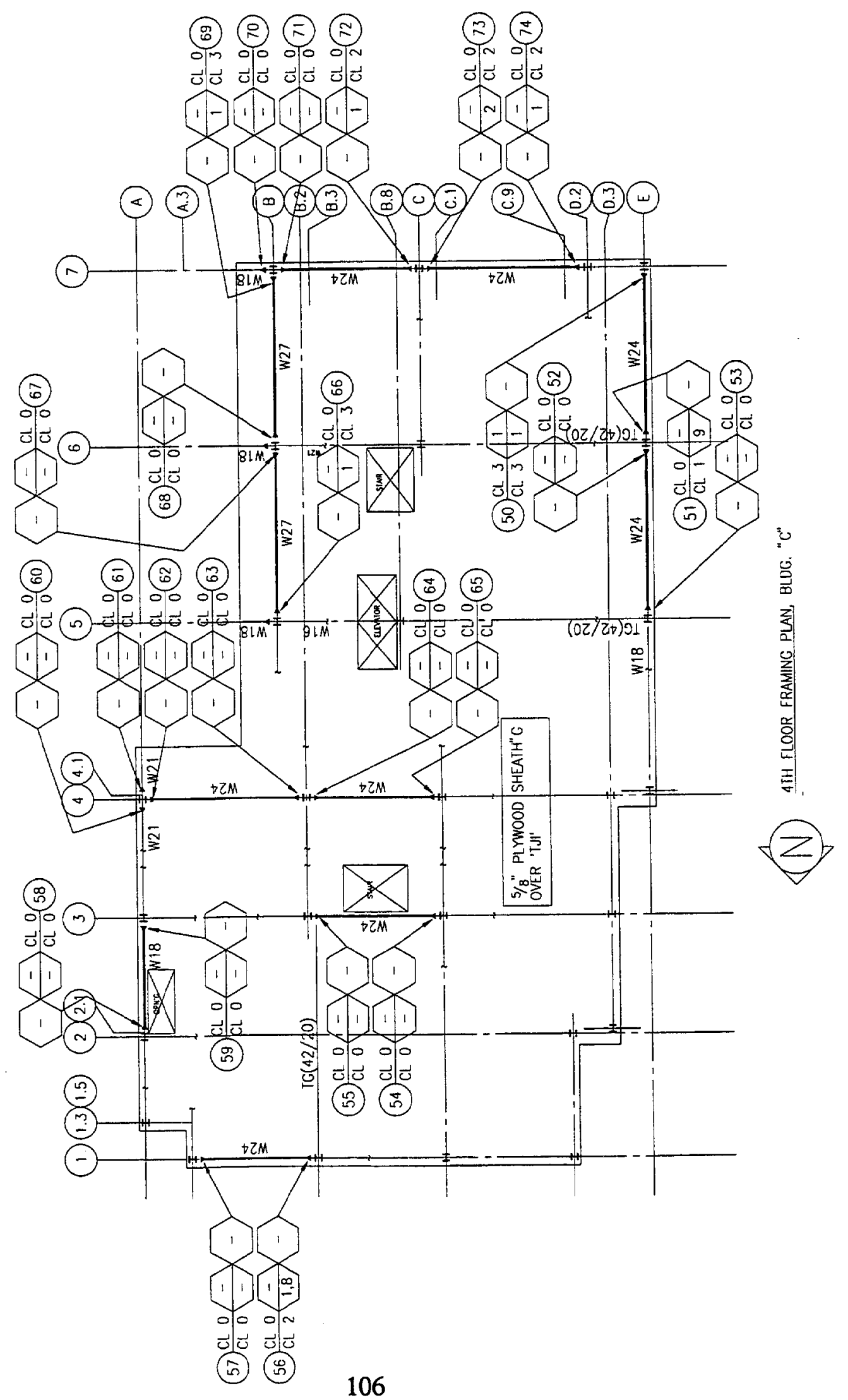




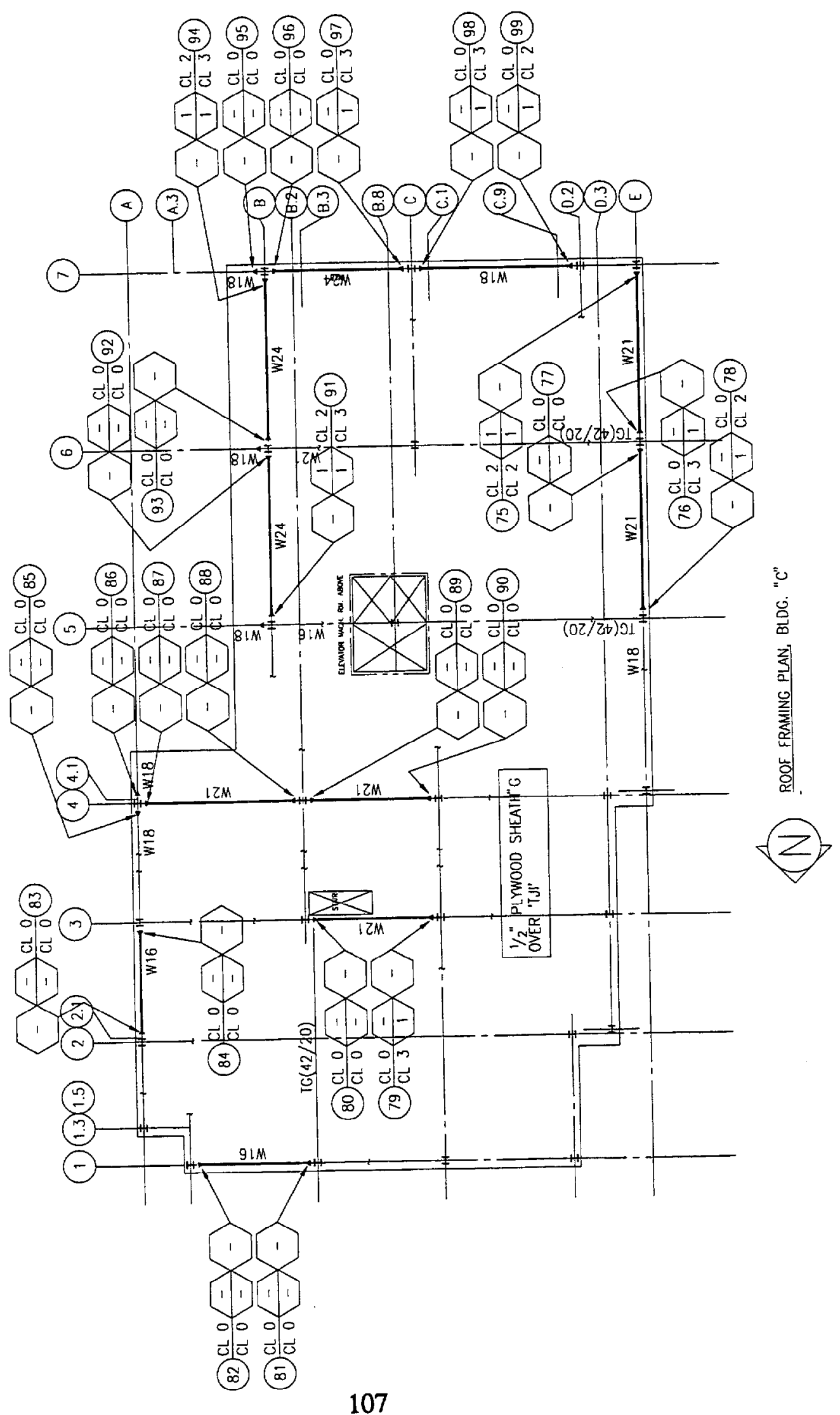




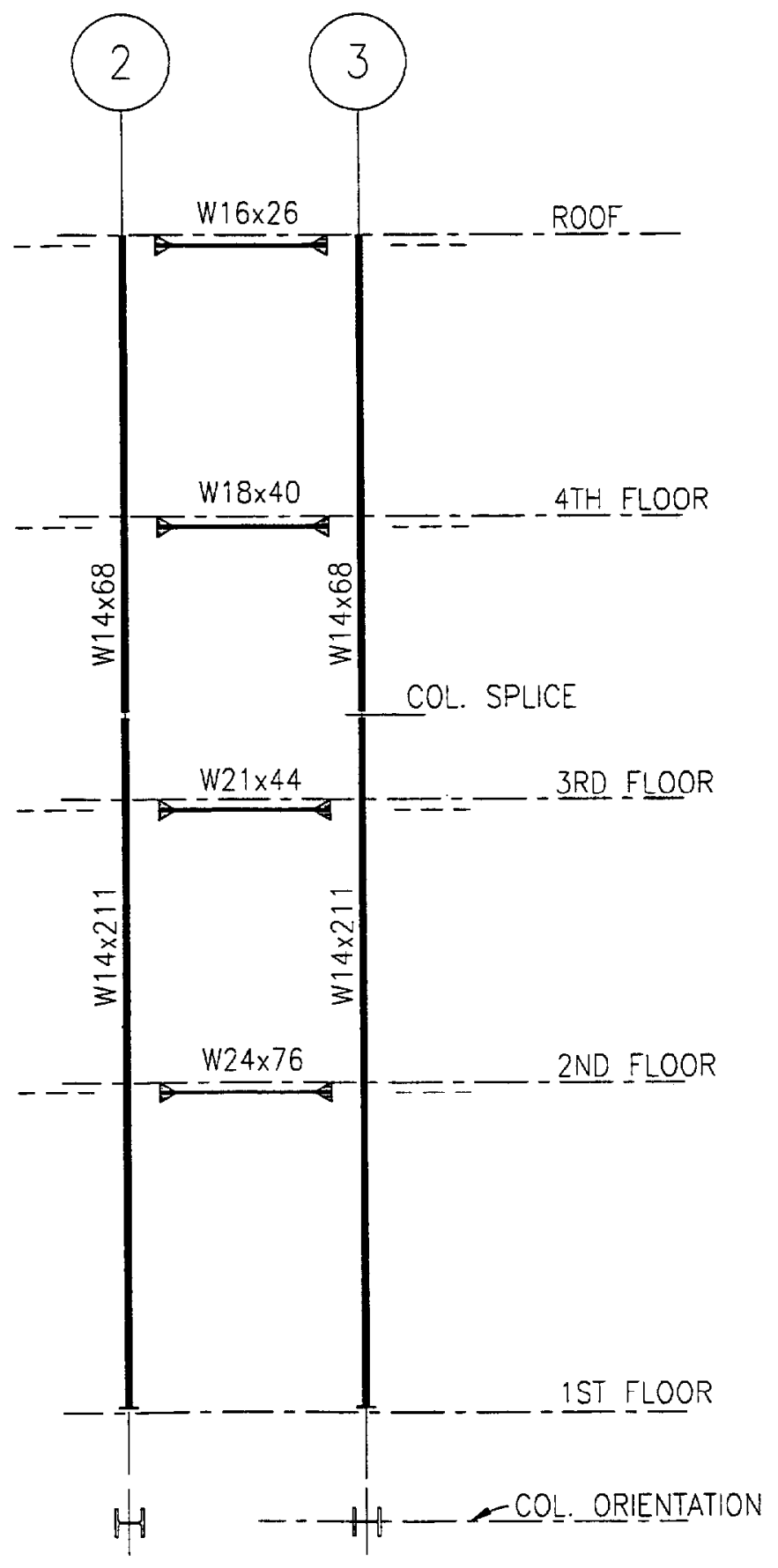

FRAME ELEVATION @ GRID LINE "A", BLDG "C" 


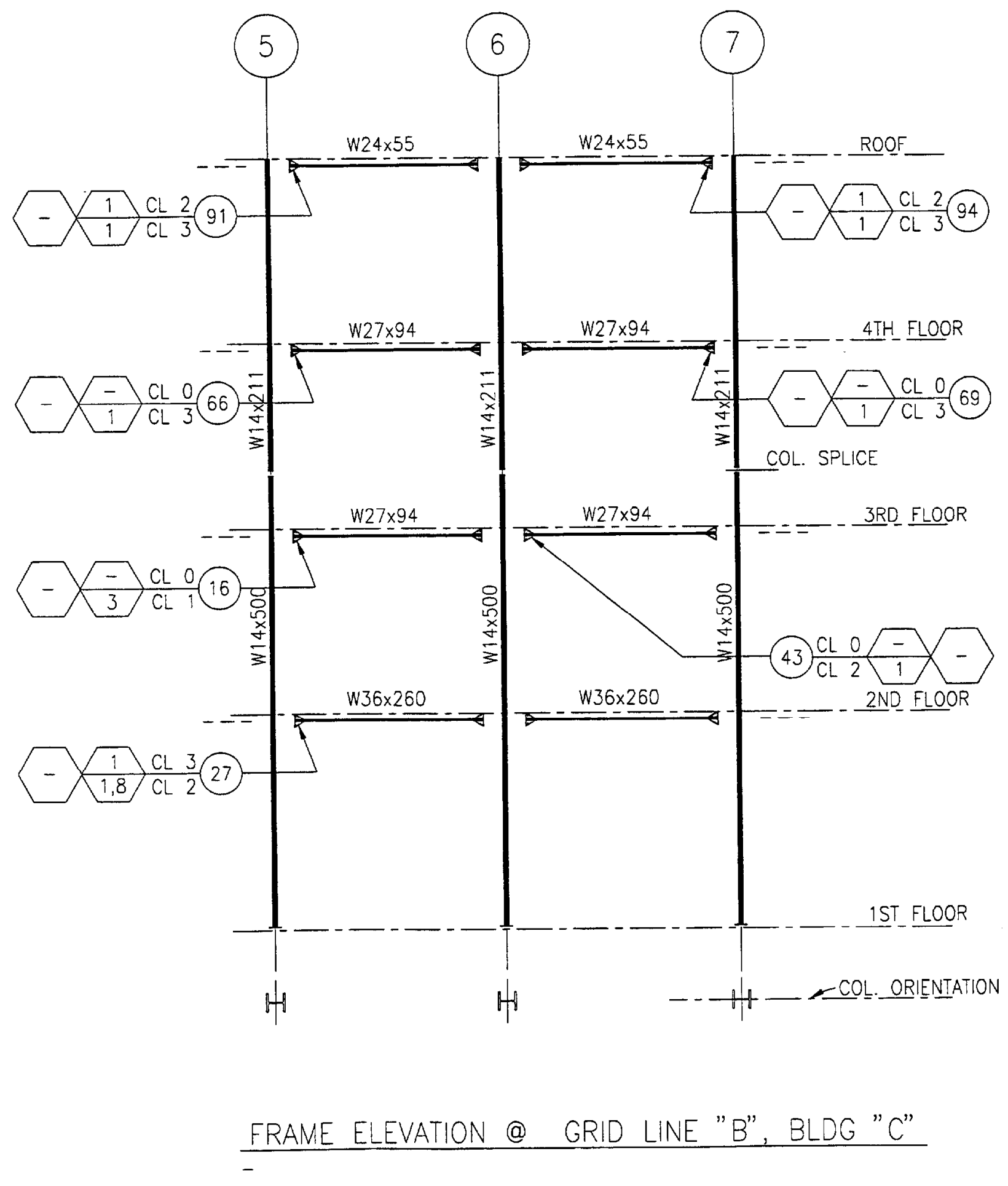




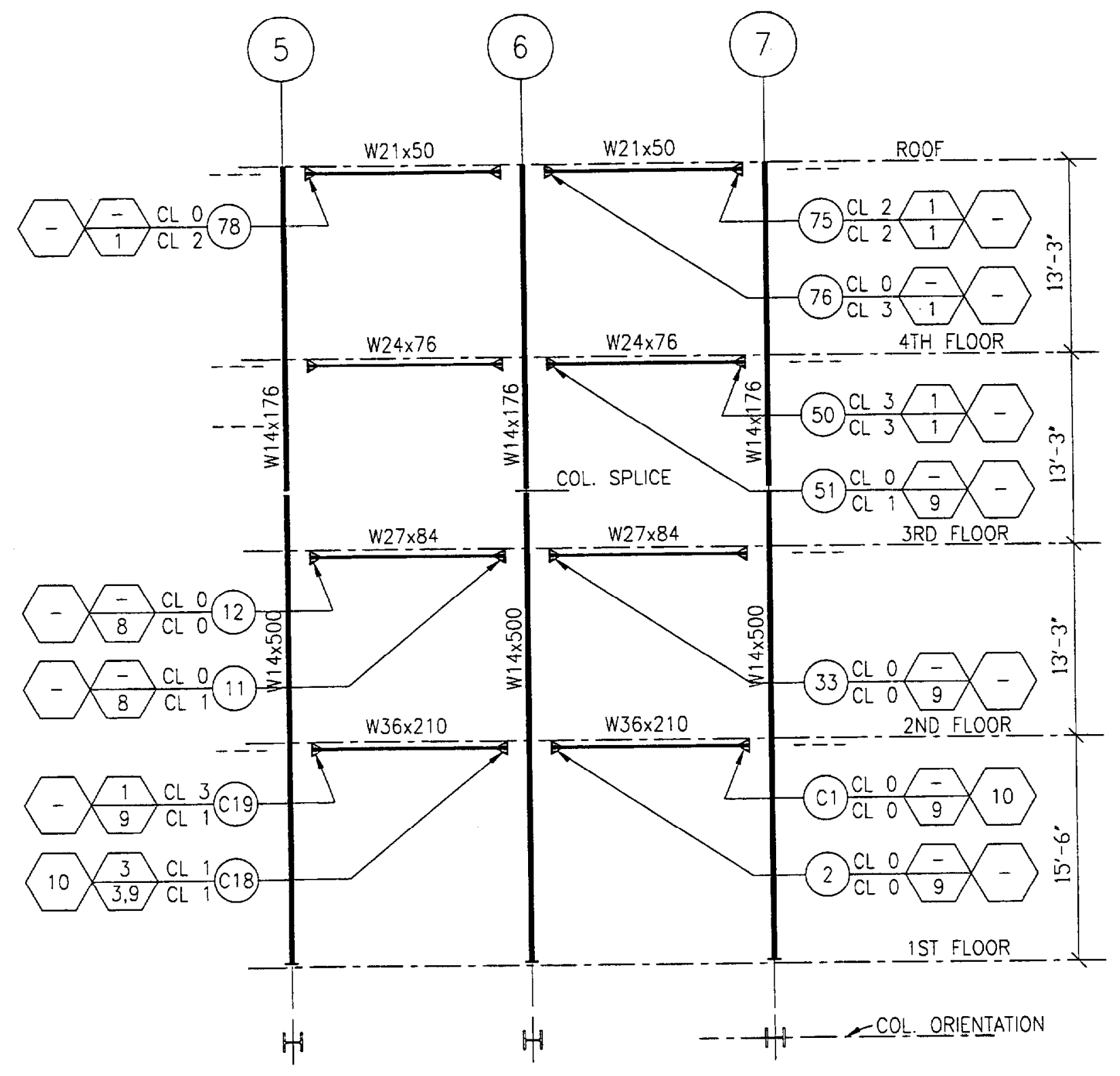

FRAME ELEVATION@ GRID LINE "E", BLDG "C" 


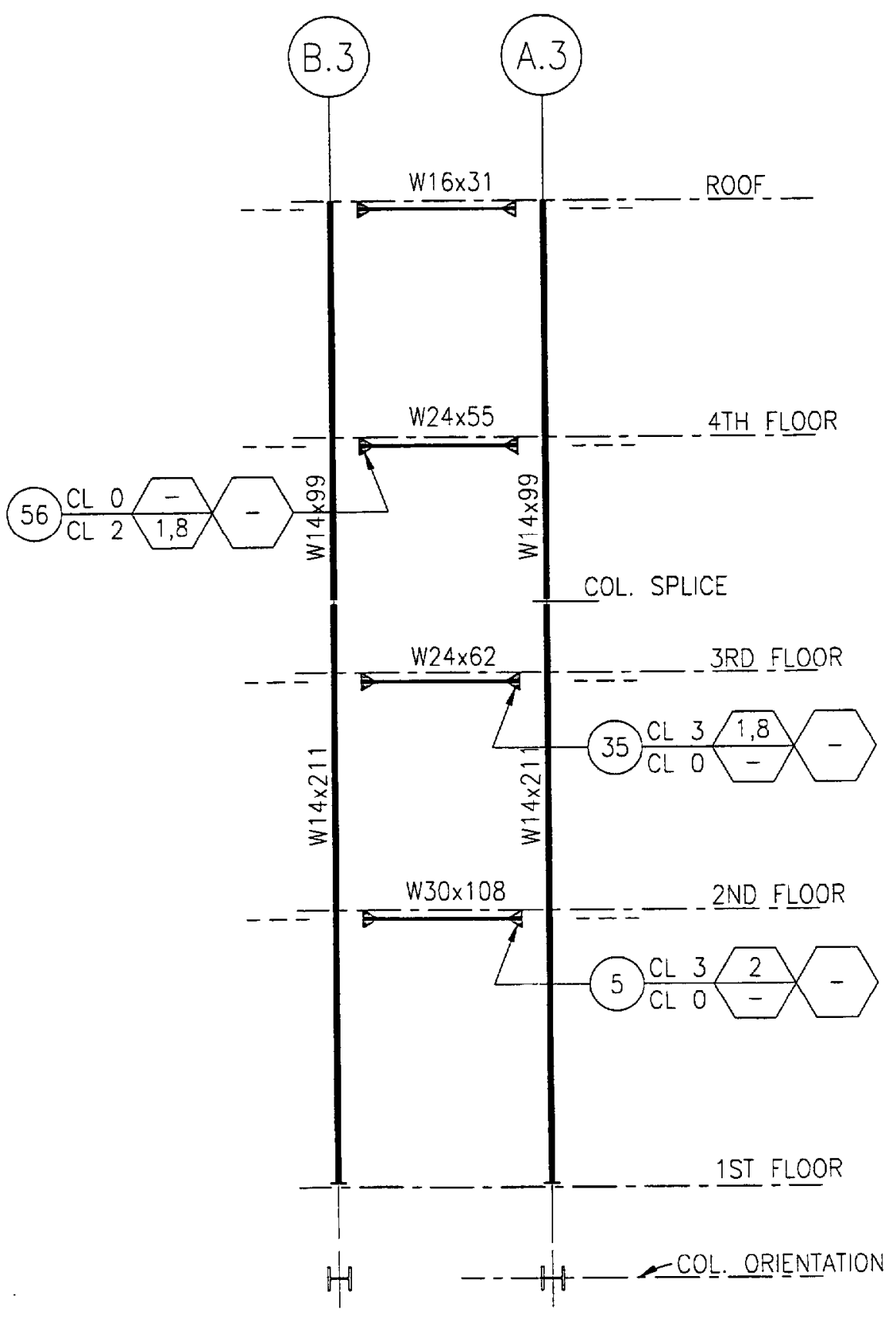

FRAME ELEVATION @ GRID LINE "1", BLDG "C" 


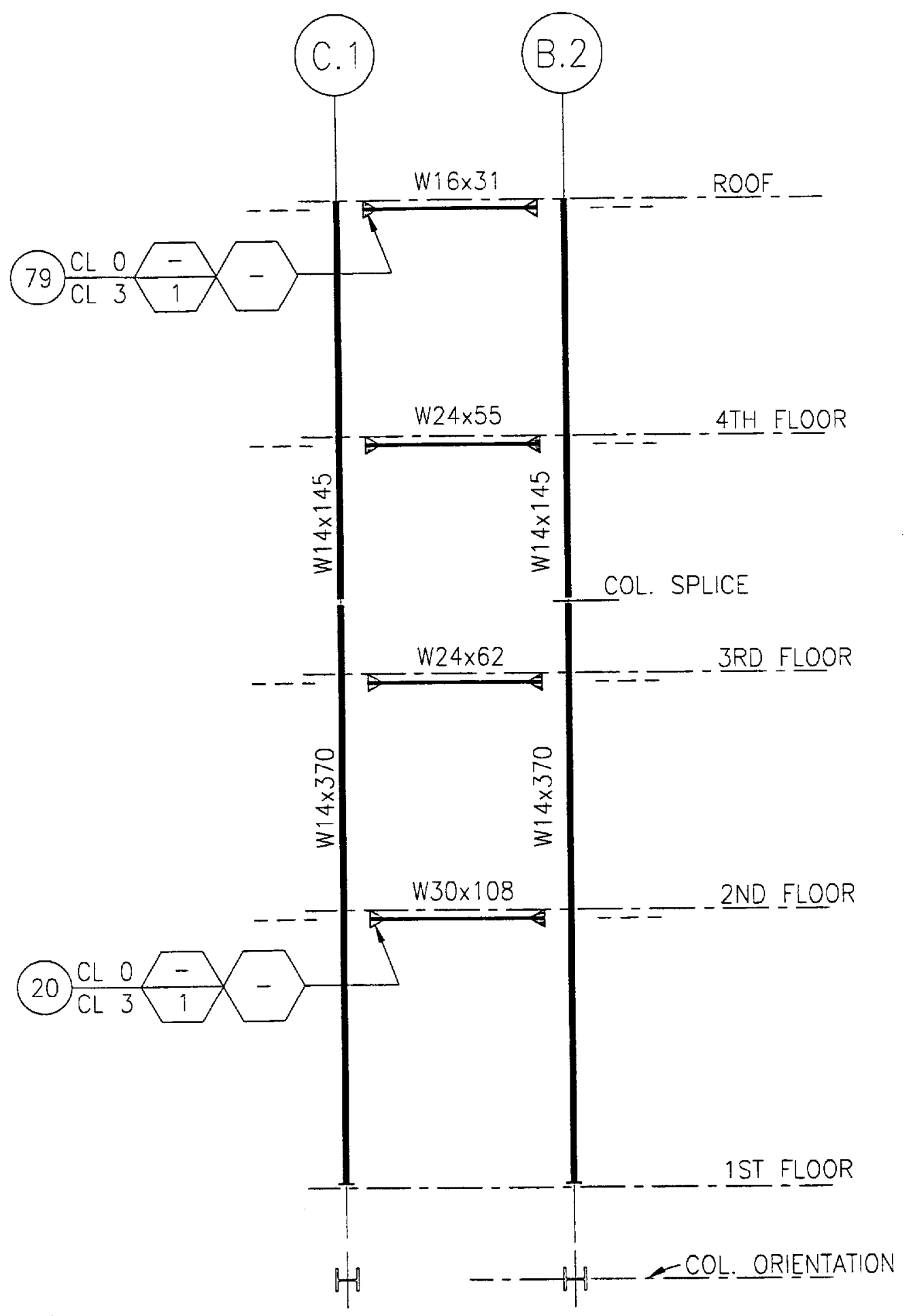

FRAME ELEVATION @ GRID LINE "3", BLDG "C" 


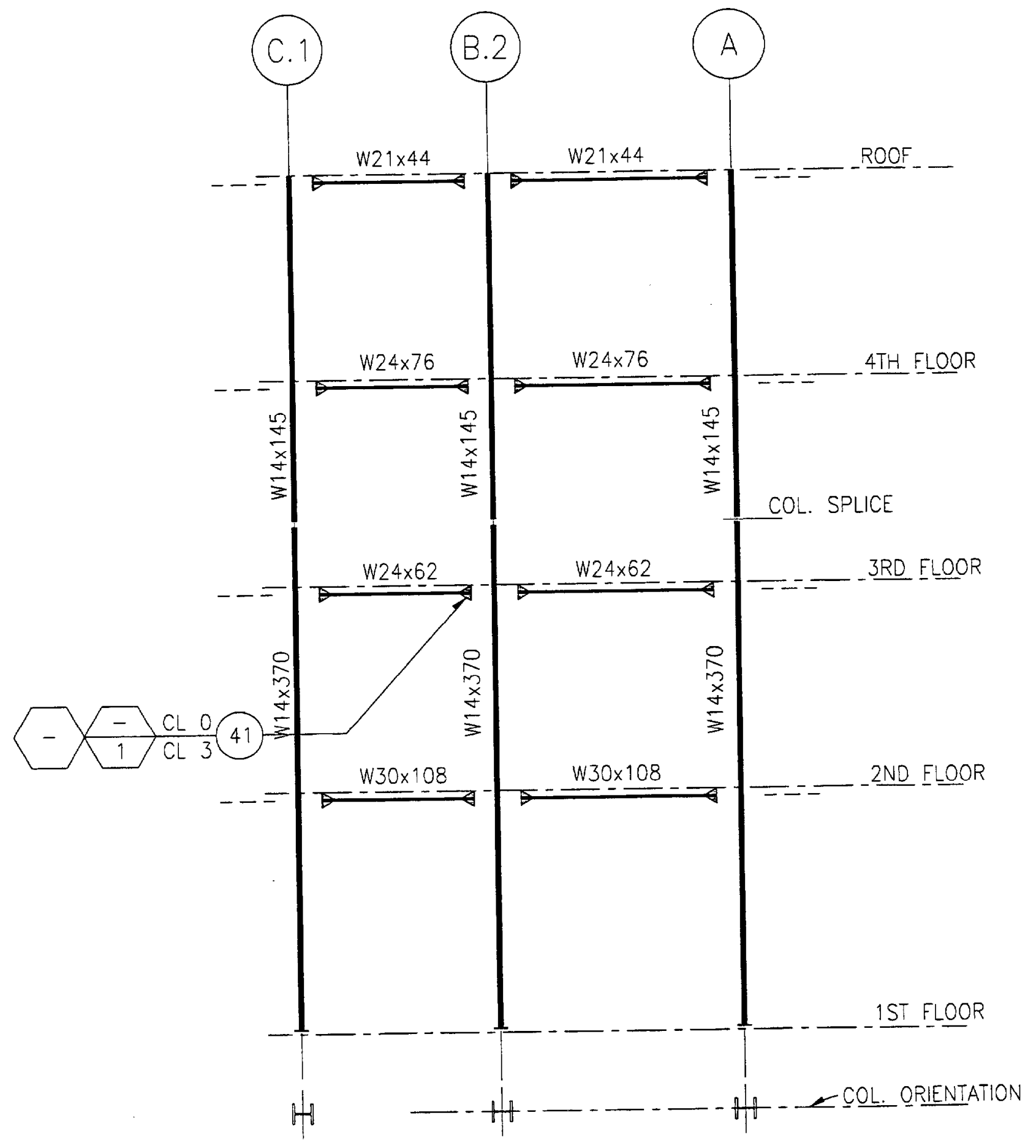

FRAME ELEVATION @ GRID LINE "4", BLDG "C" 


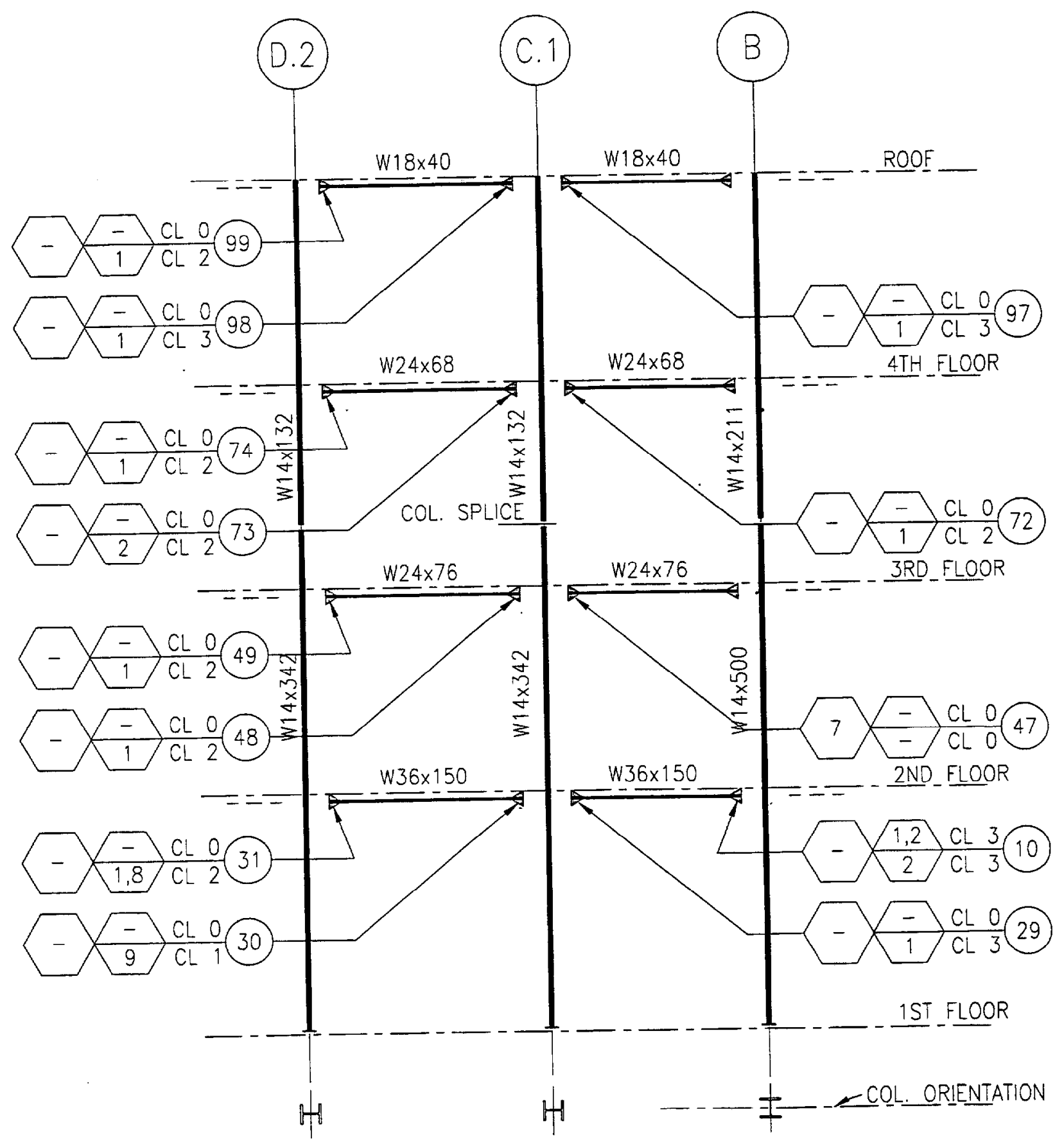

FRAME ELEVATION @ GRID LINE "7", BLDG "C" 
Building E 


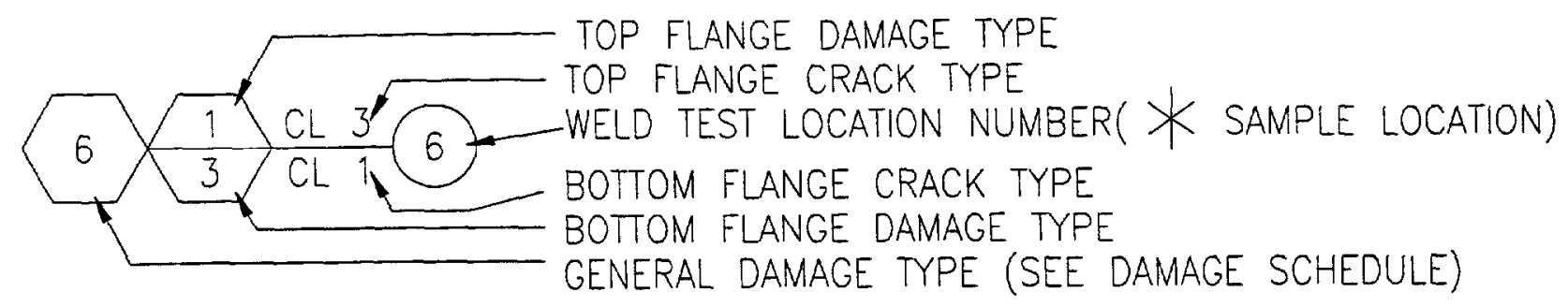

\begin{tabular}{|c|l|c|c|}
\hline \multicolumn{3}{|c|}{ DAMAGE SCHEDULE (BLDG. E) } \\
\hline $\begin{array}{c}\text { DAMAGE } \\
\text { TYPE }\end{array}$ & \multicolumn{1}{|c|}{ DESCRIPTION } & - \\
\hline 1 & PARTIAL CRACK IN WELD AT ROOT & - & - \\
\hline 2 & PARTIAL CRACK IN WELD ABOVE ROOT & & \\
\hline 3 & THROUGH CRACK IN WELD & & \\
\hline $3 A$ & THROUGH CRACK IN WELD WITH GAP & & \\
\hline 4 & SHEAR TAB WELD CRACK & & \\
\hline 5 & SHEAR TAB OR BEAM WEB CRACK & & \\
\hline 6 & BENT SHEAR TAB OR BEAM WEB & & \\
\hline 7 & LOOSE OR MISSING BOLTS & & \\
\hline 8 & $\begin{array}{l}\text { PARTIAL OR THROUGH CRACK IN COLUMN FLANGE } \\
\text { WITHIN 45 ANGLE ZONE }\end{array}$ & & \\
\hline 9 & $\begin{array}{l}\text { PARTIAL OR THROUGH CRACK IN COLUMN FLANGE } \\
\text { OUTSIDE 45 ANGLE ZONE }\end{array}$ & & \\
\hline 10 & COLUMN WEB CRACK & & \\
\hline 11 & LOOSE OR DAMAGED COL. OR BEAM FIREPROOFING & & \\
\hline 12 & BEAM FLANGE CRACK & & \\
\hline 13 & DOUBLER PLATE WELD CRACK & & \\
\hline
\end{tabular}

' $\mathrm{CL}$ O' INDICATES NO CRACKS FOUND.

'CL $X$ ' INDICATES FLANGE OR PORTION OF FLANGE INACCESSIBLE DURING INITIAL TESTING. 


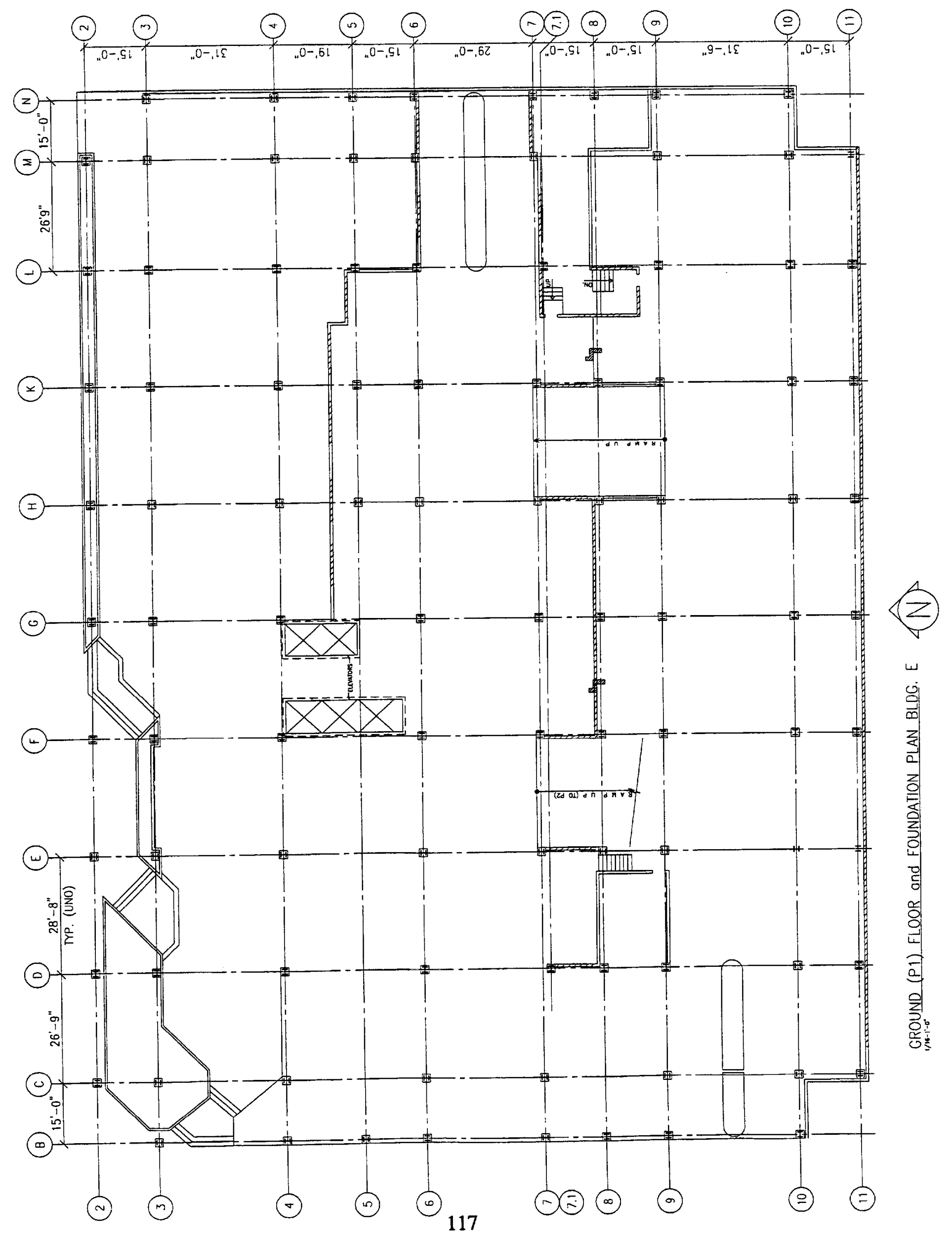




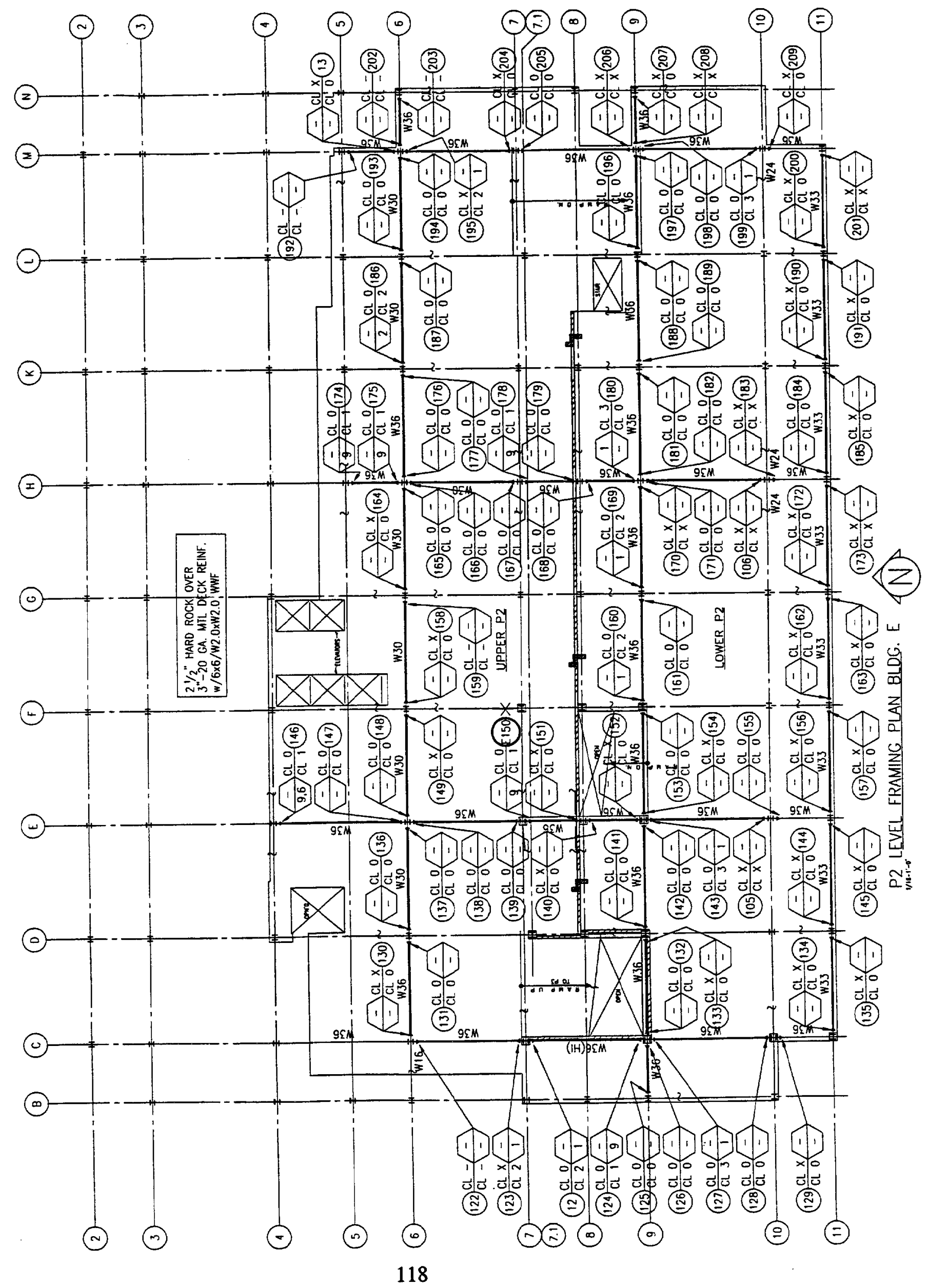




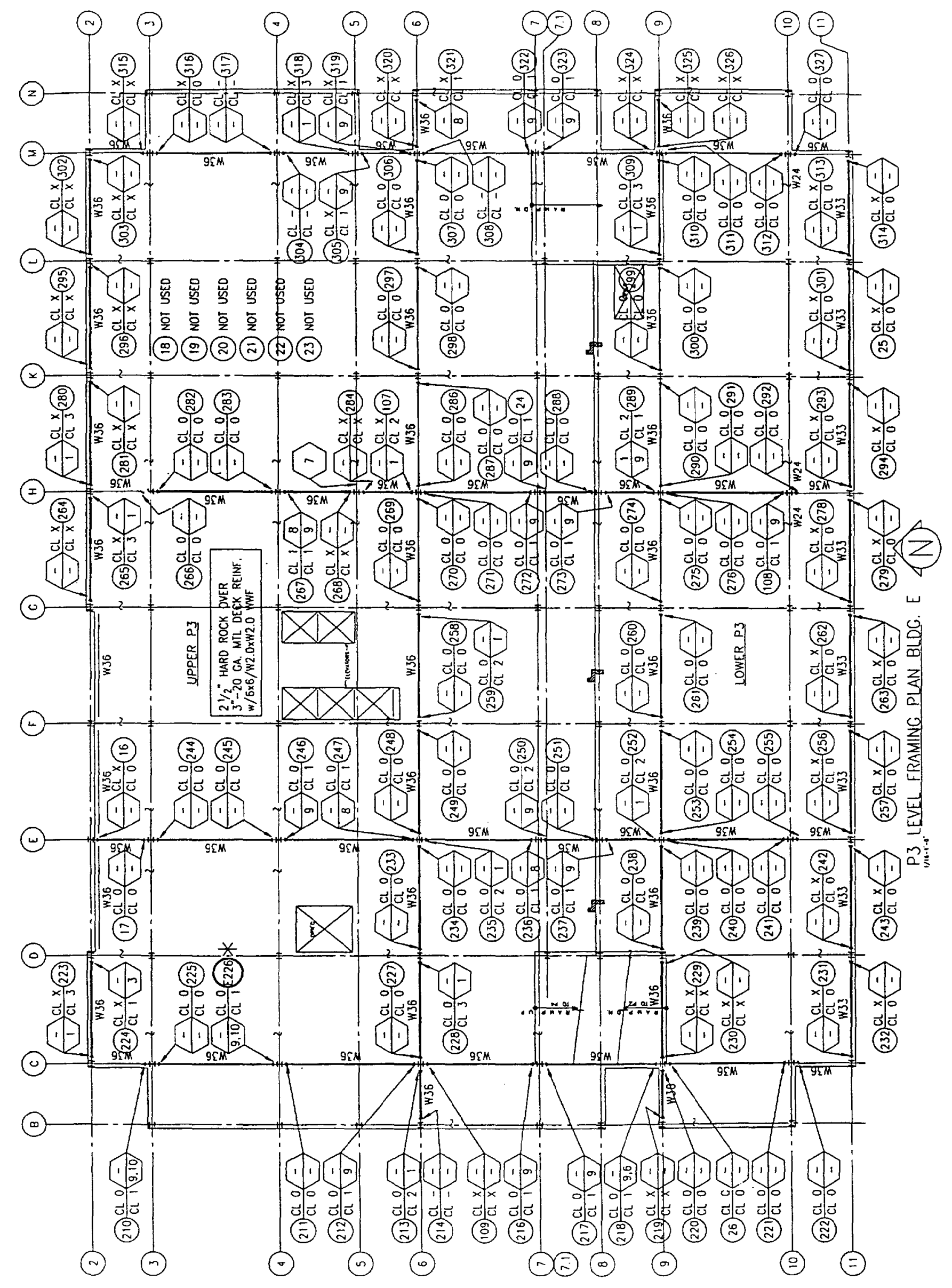




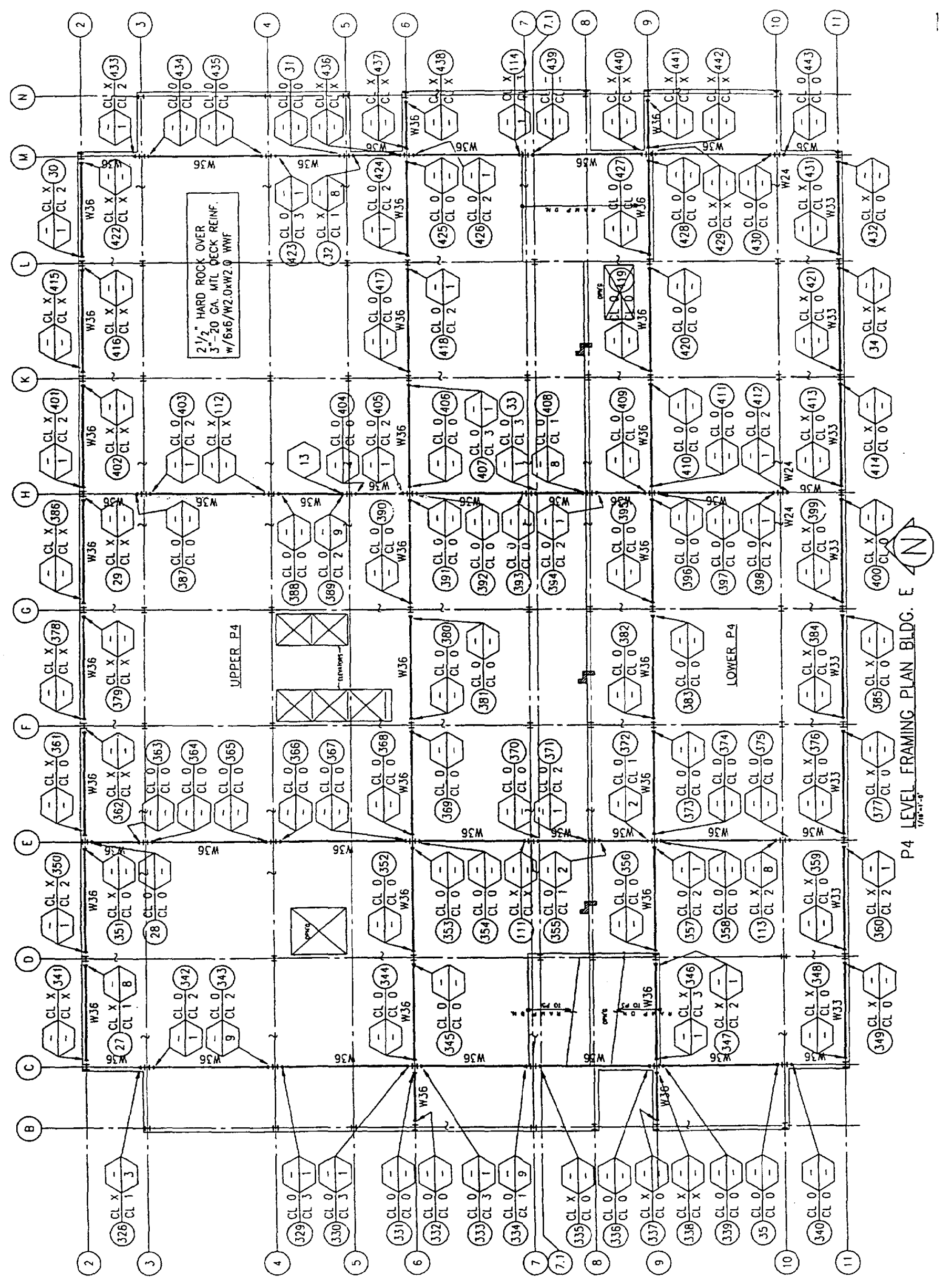




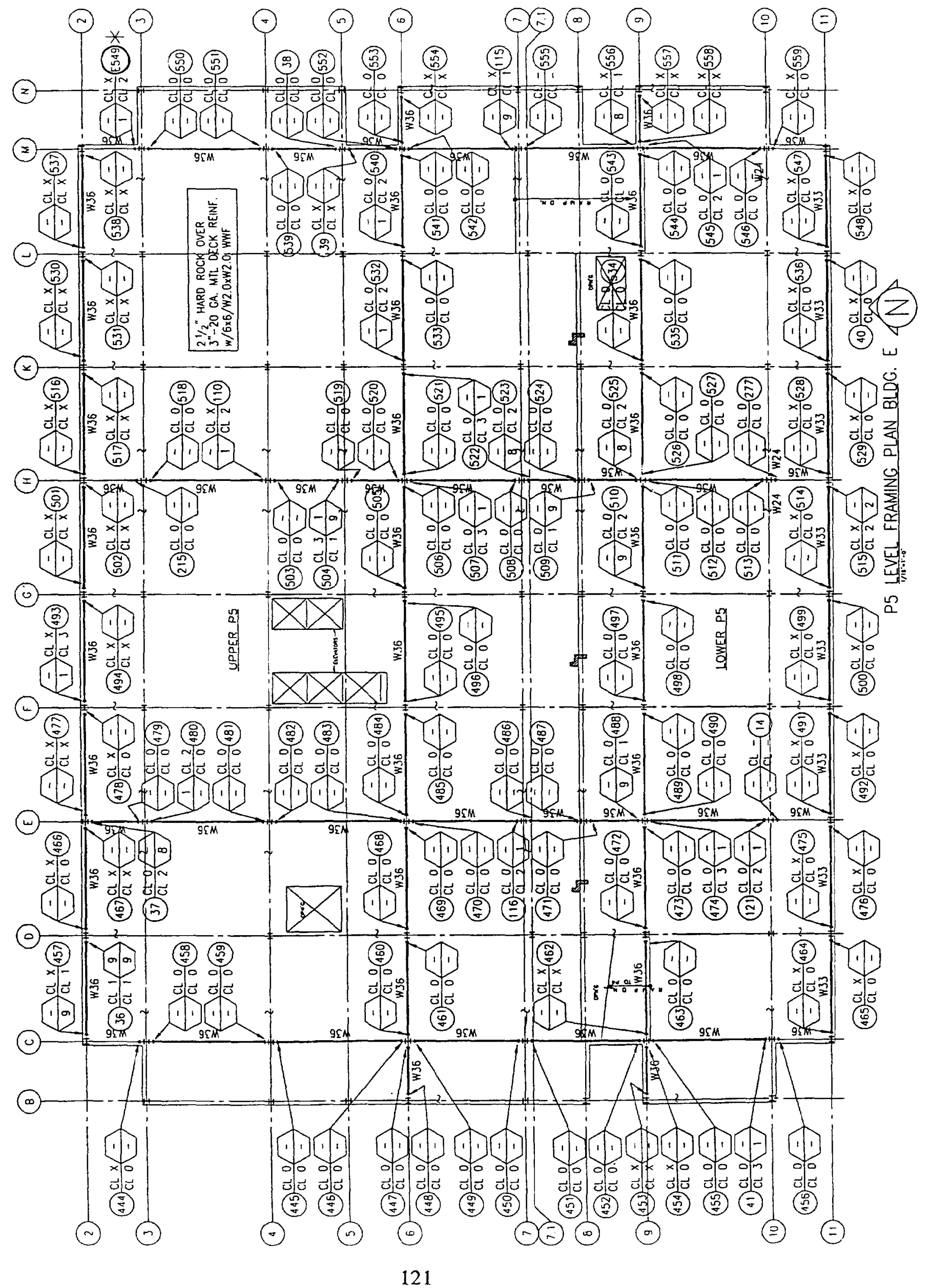




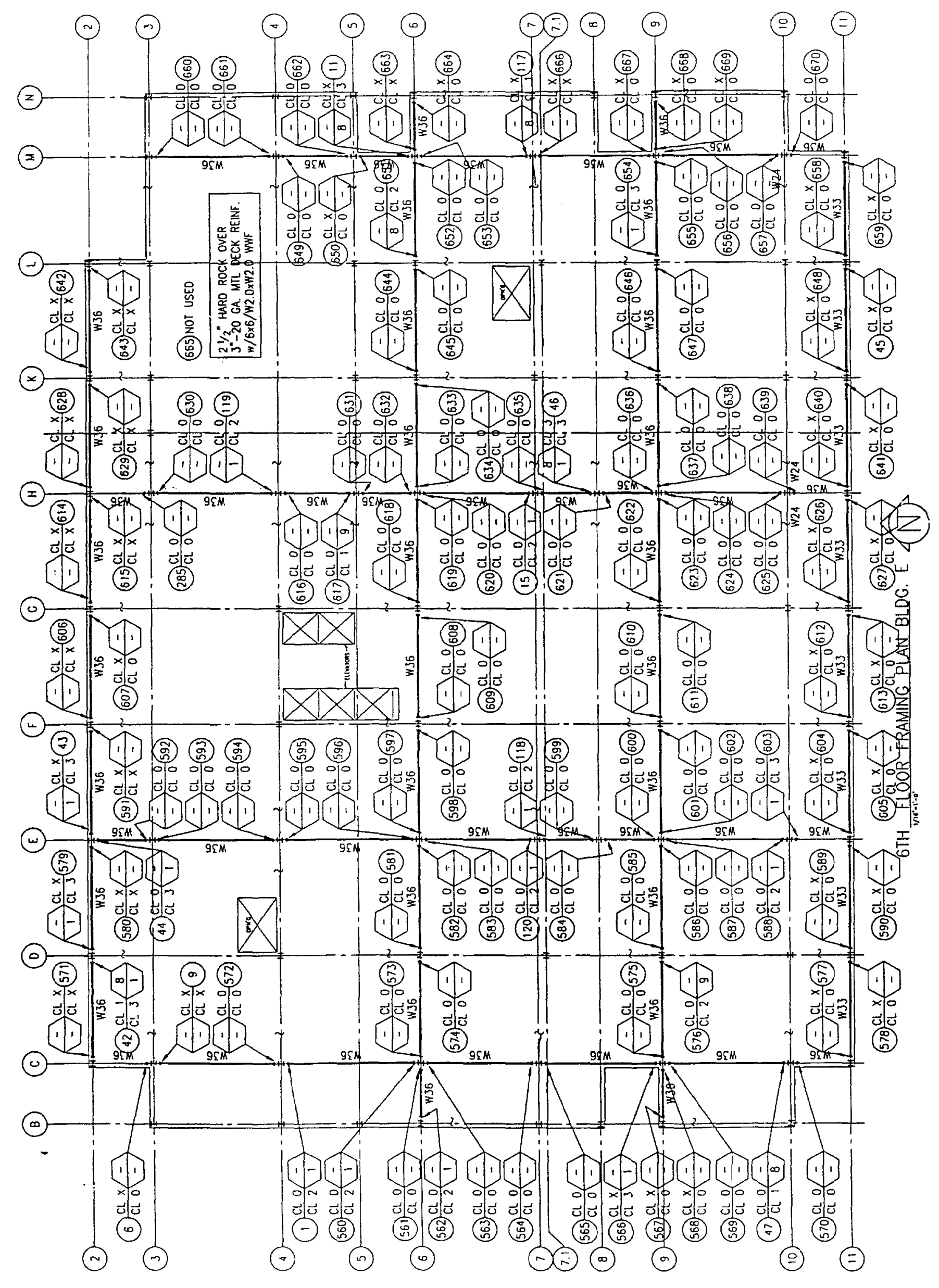




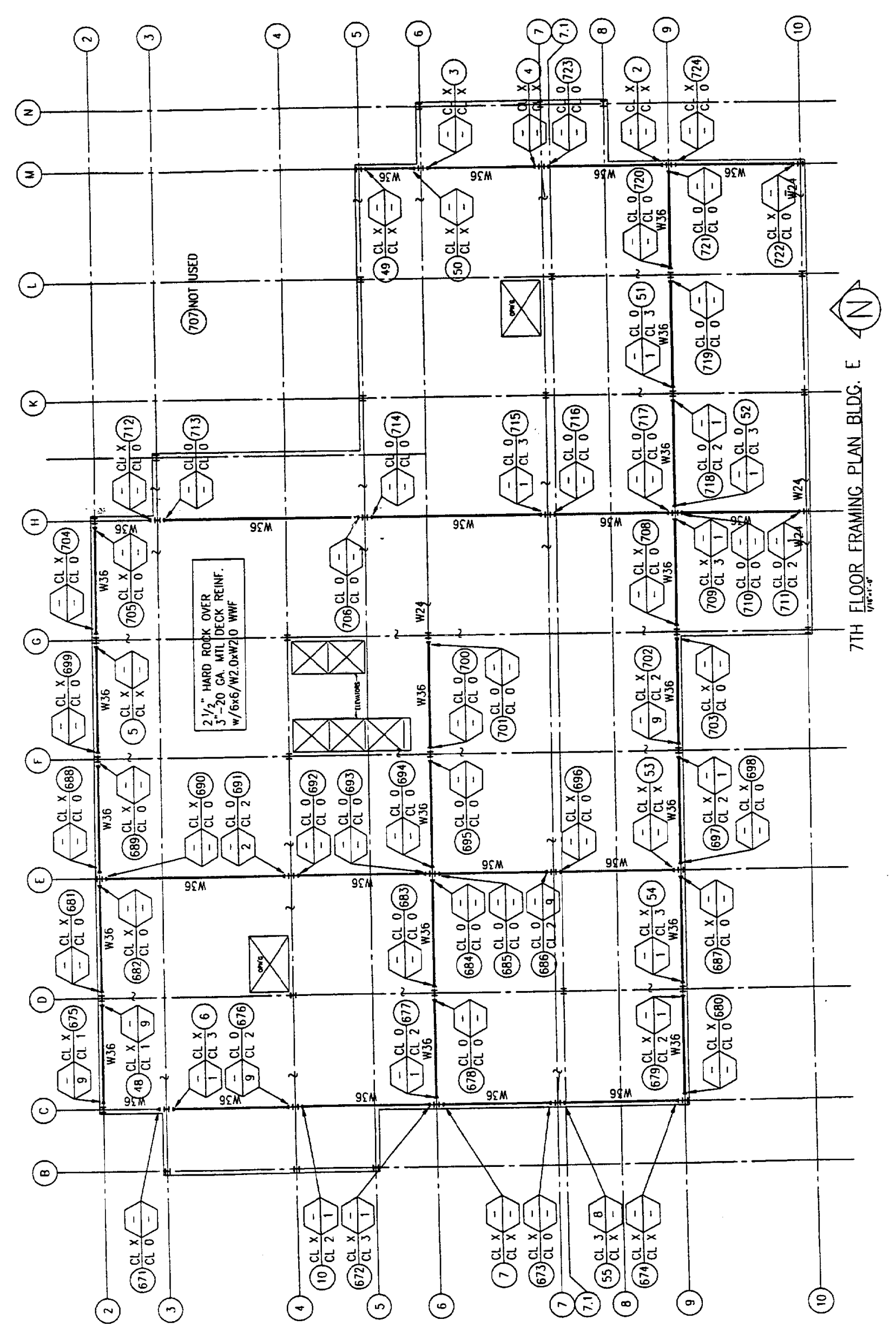




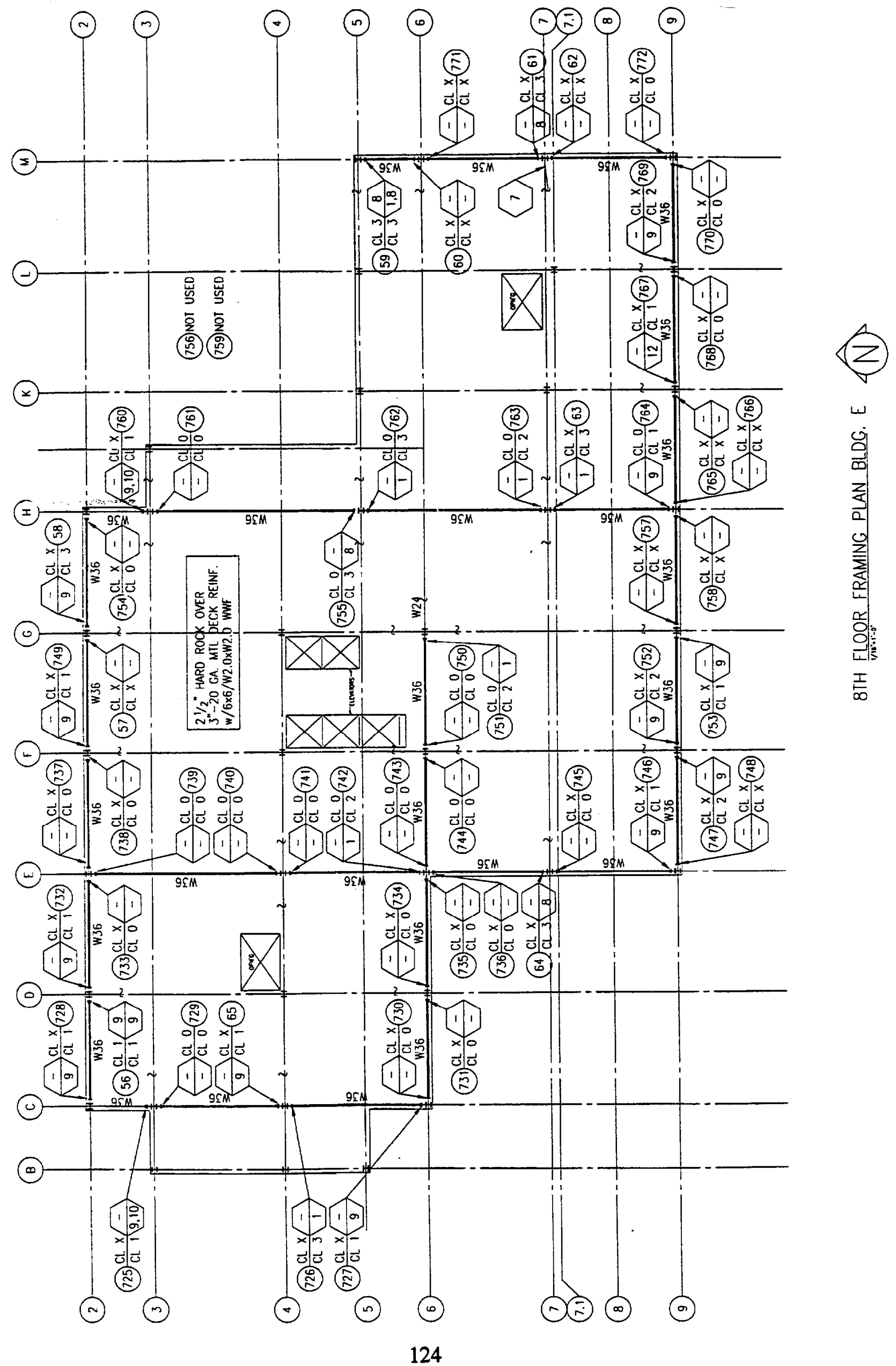




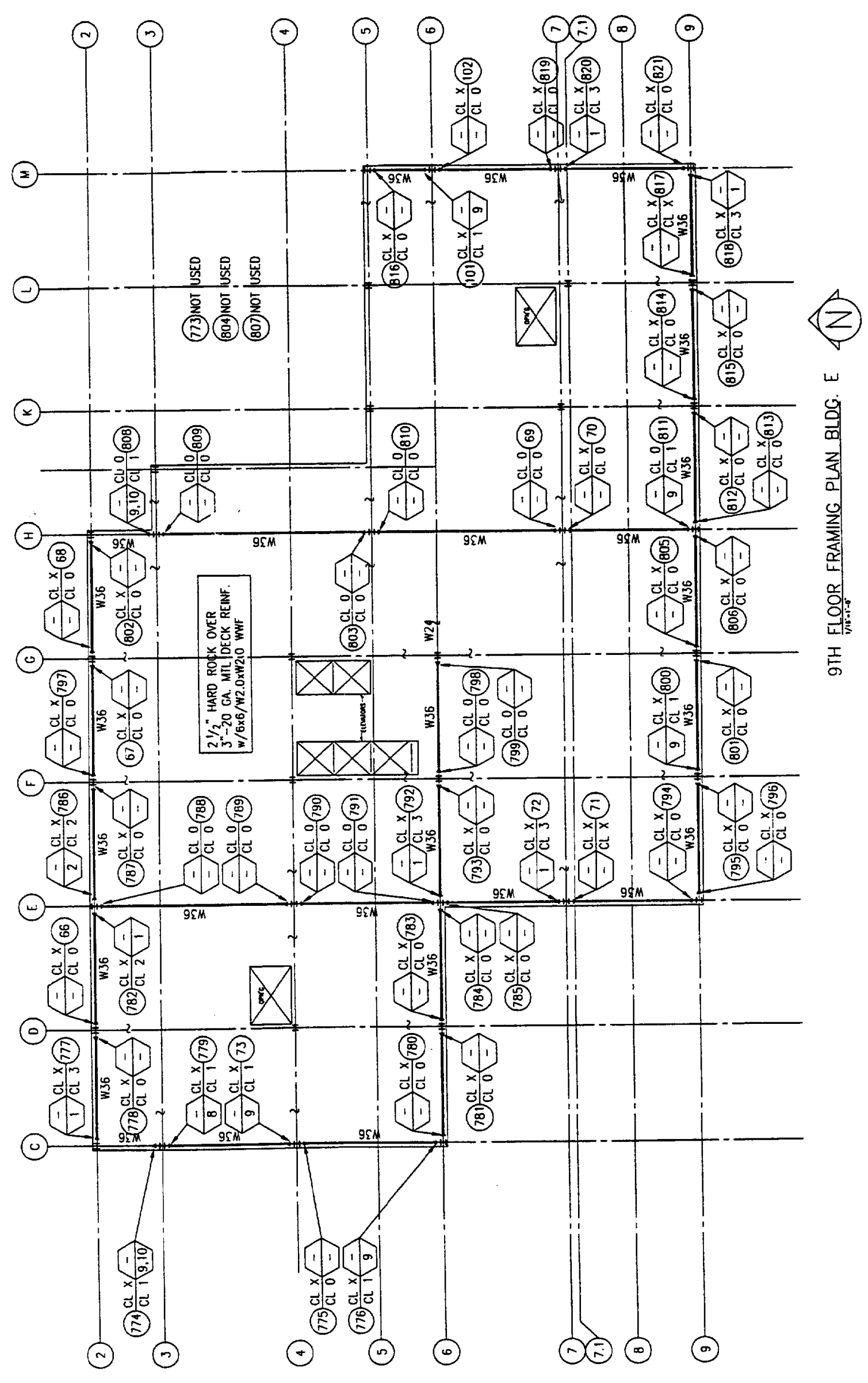




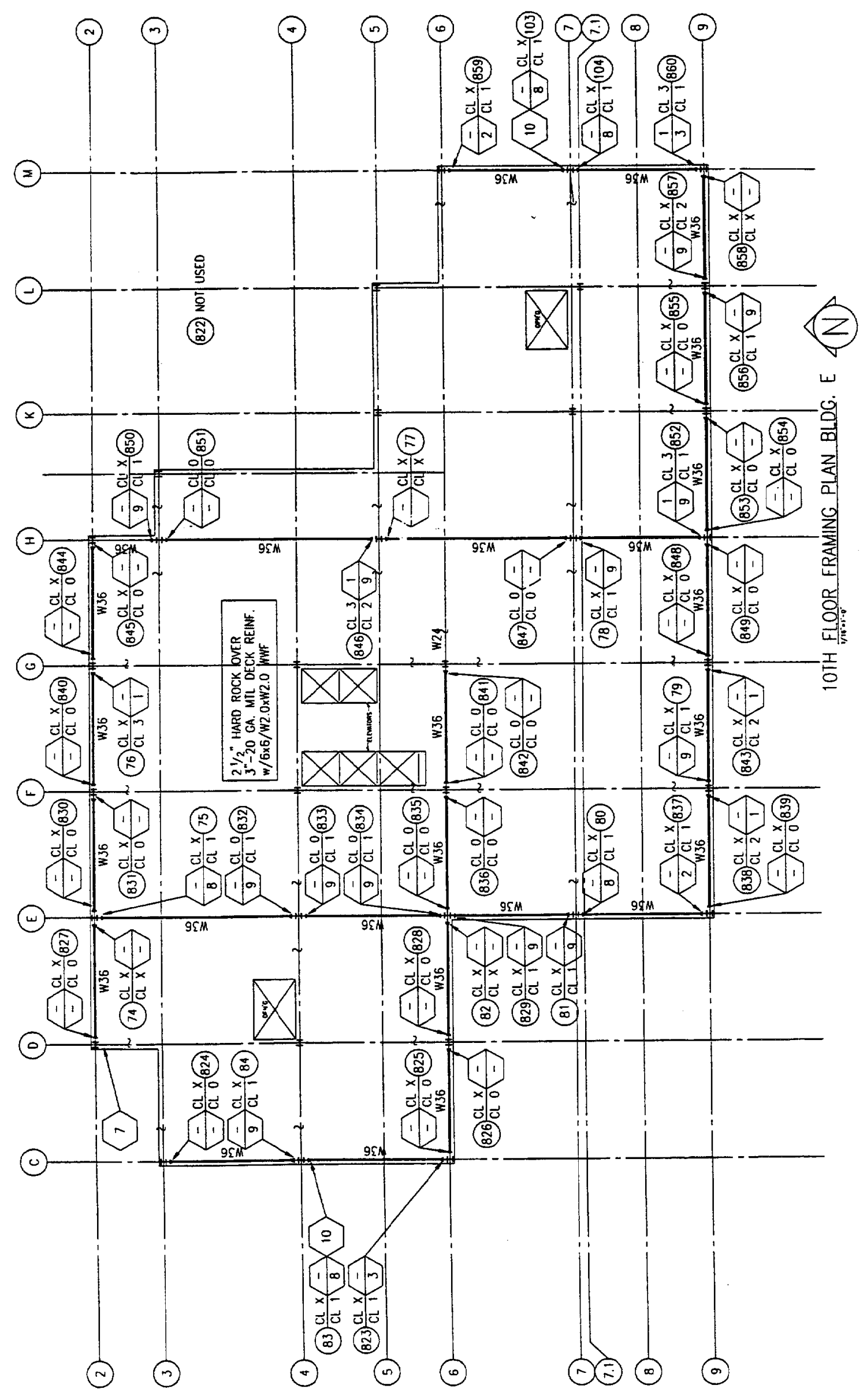




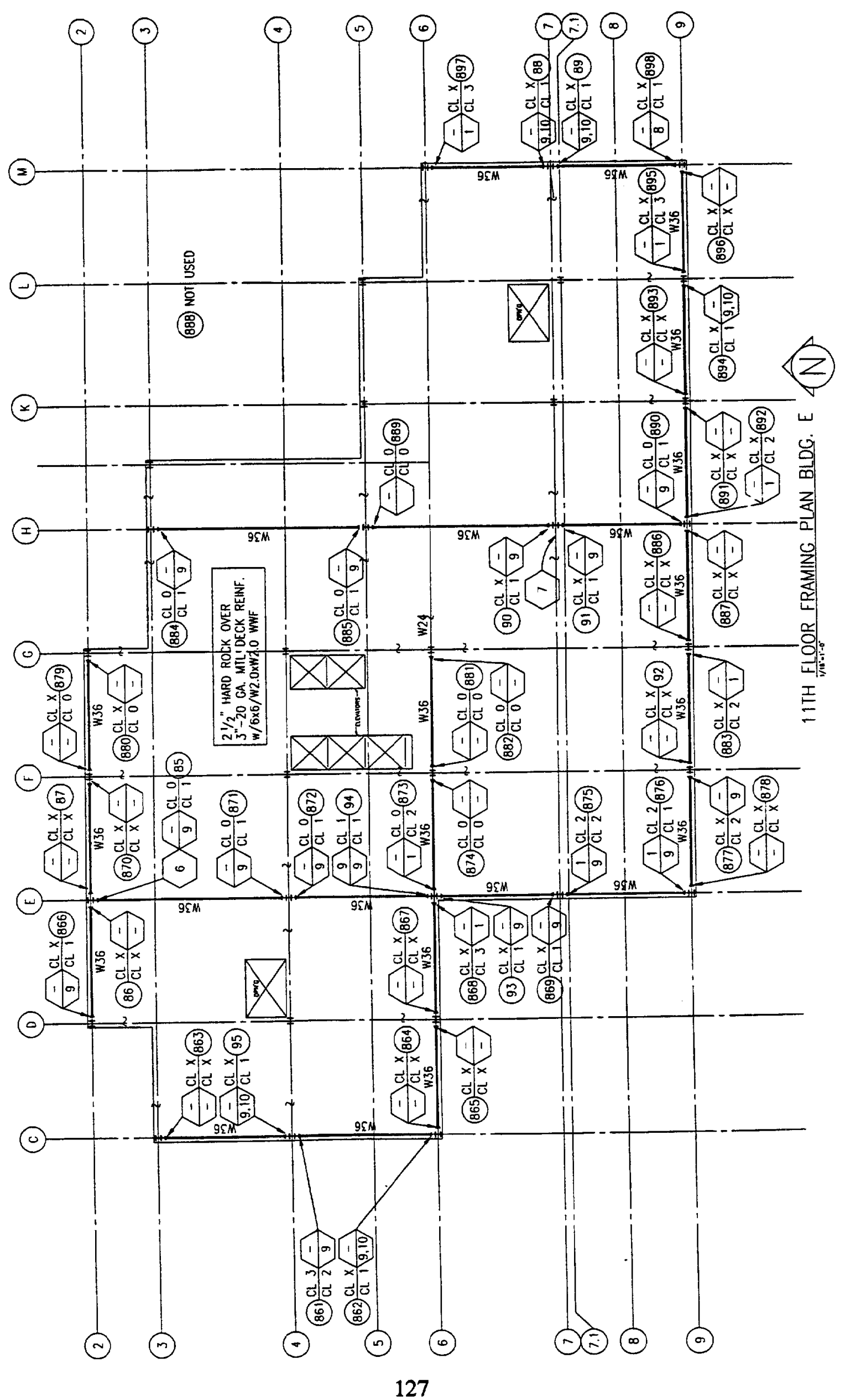




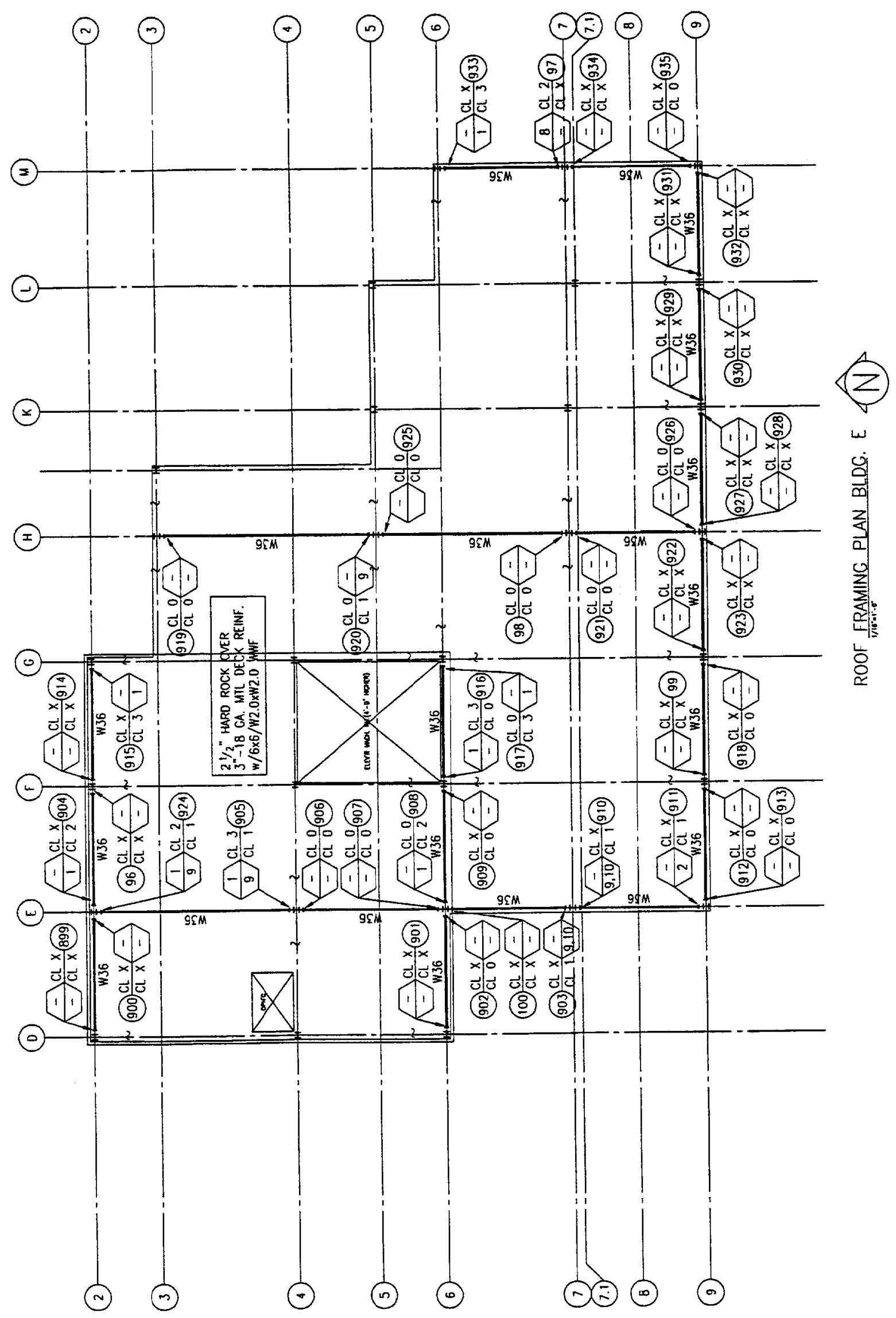




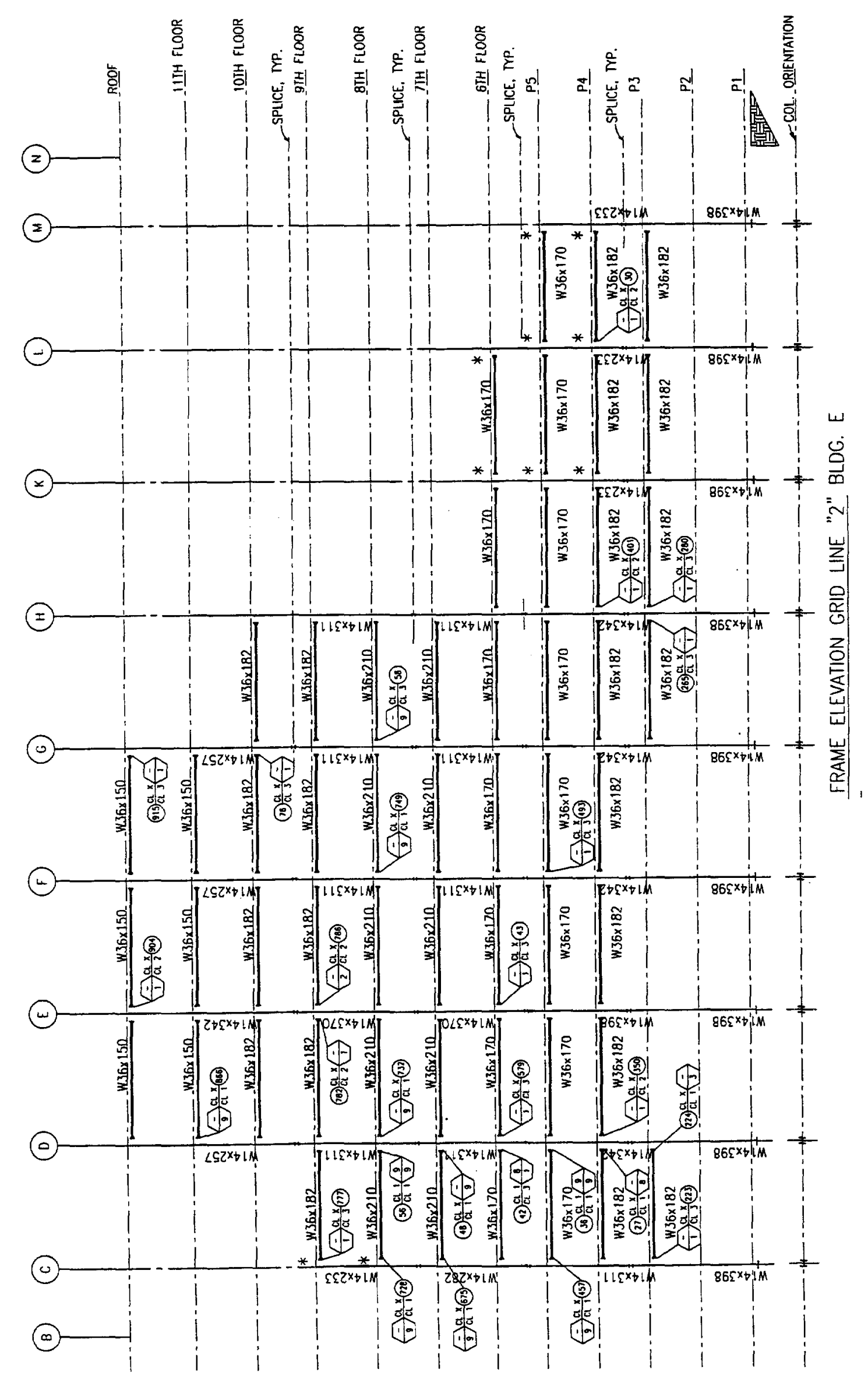




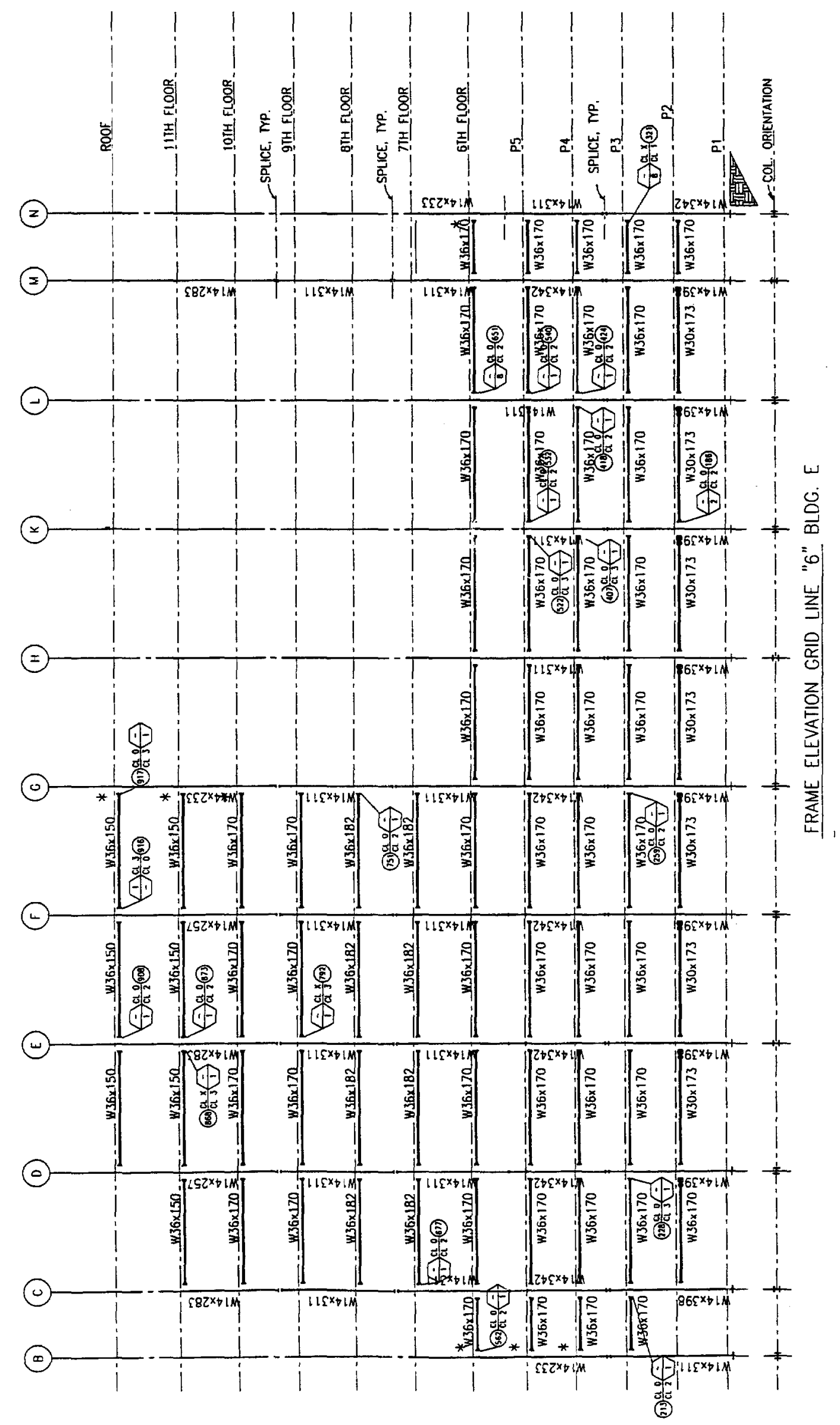




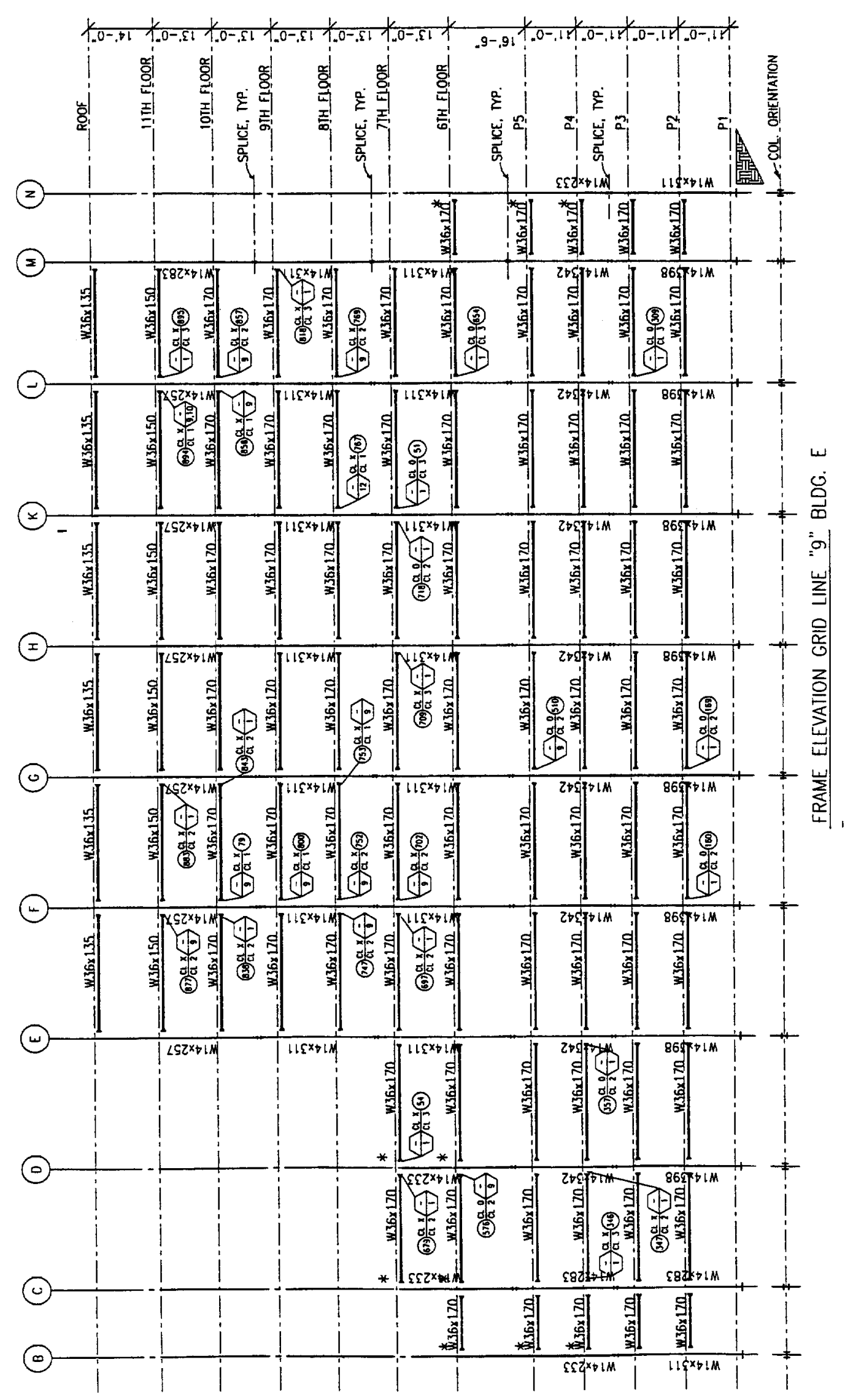




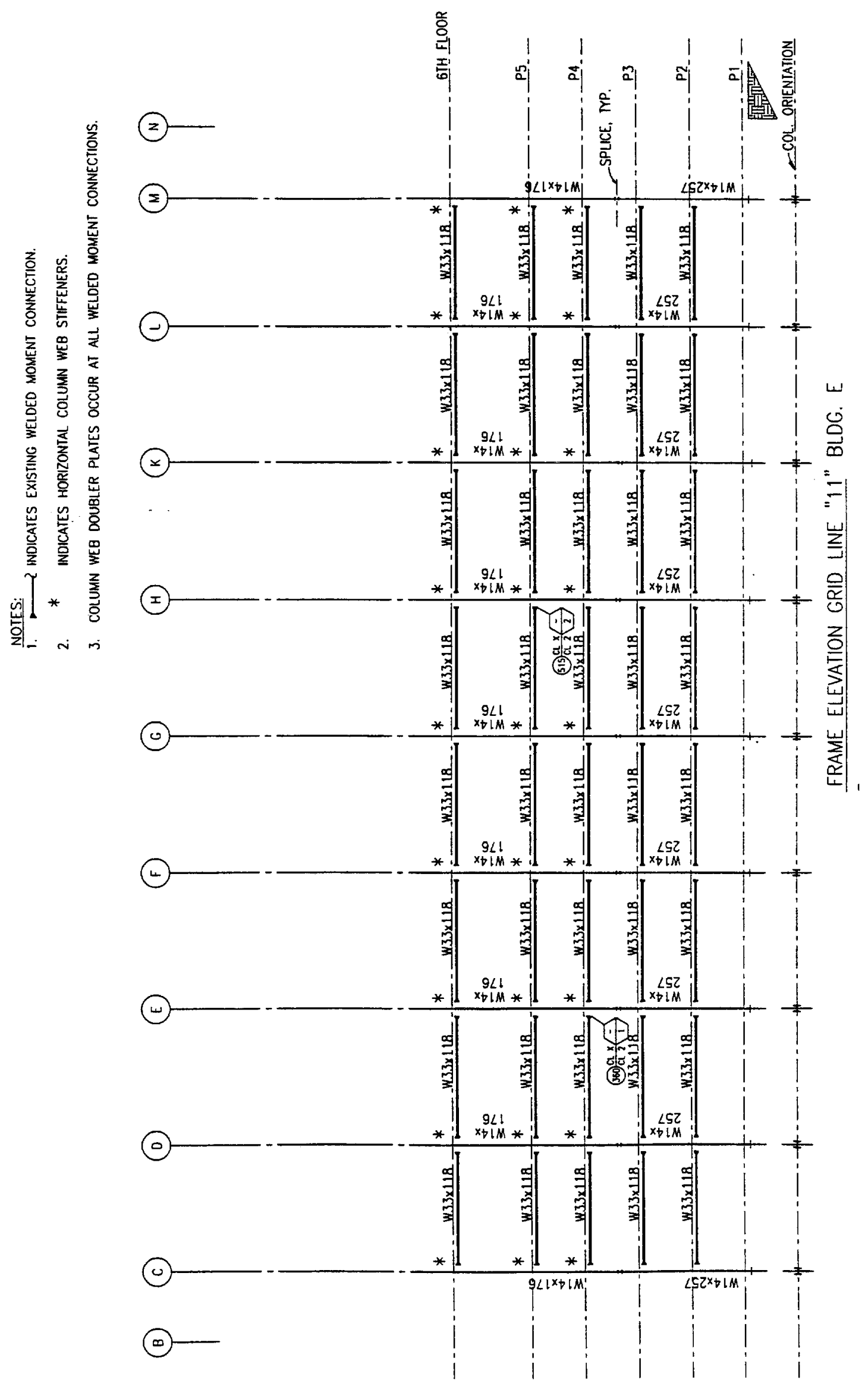




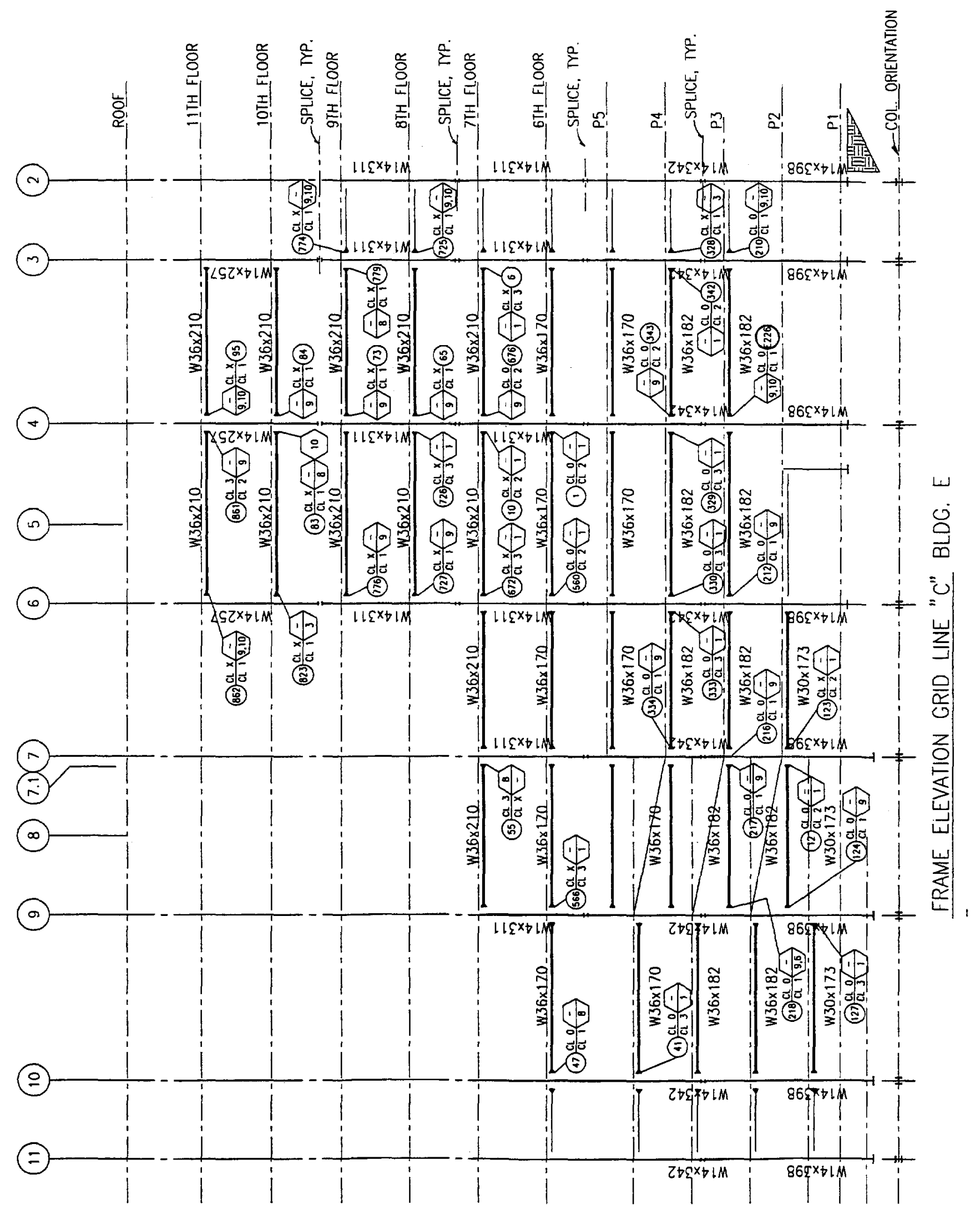




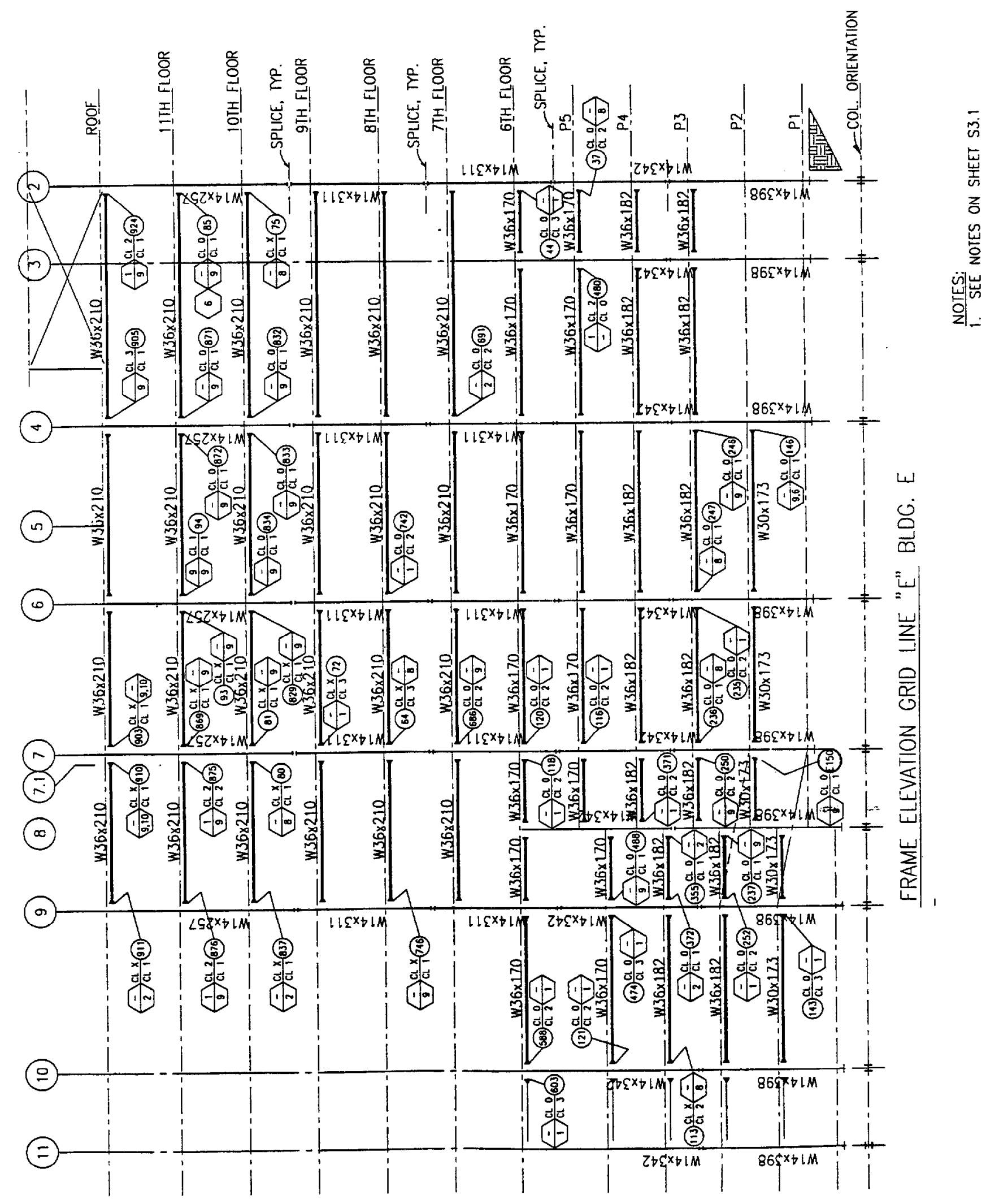




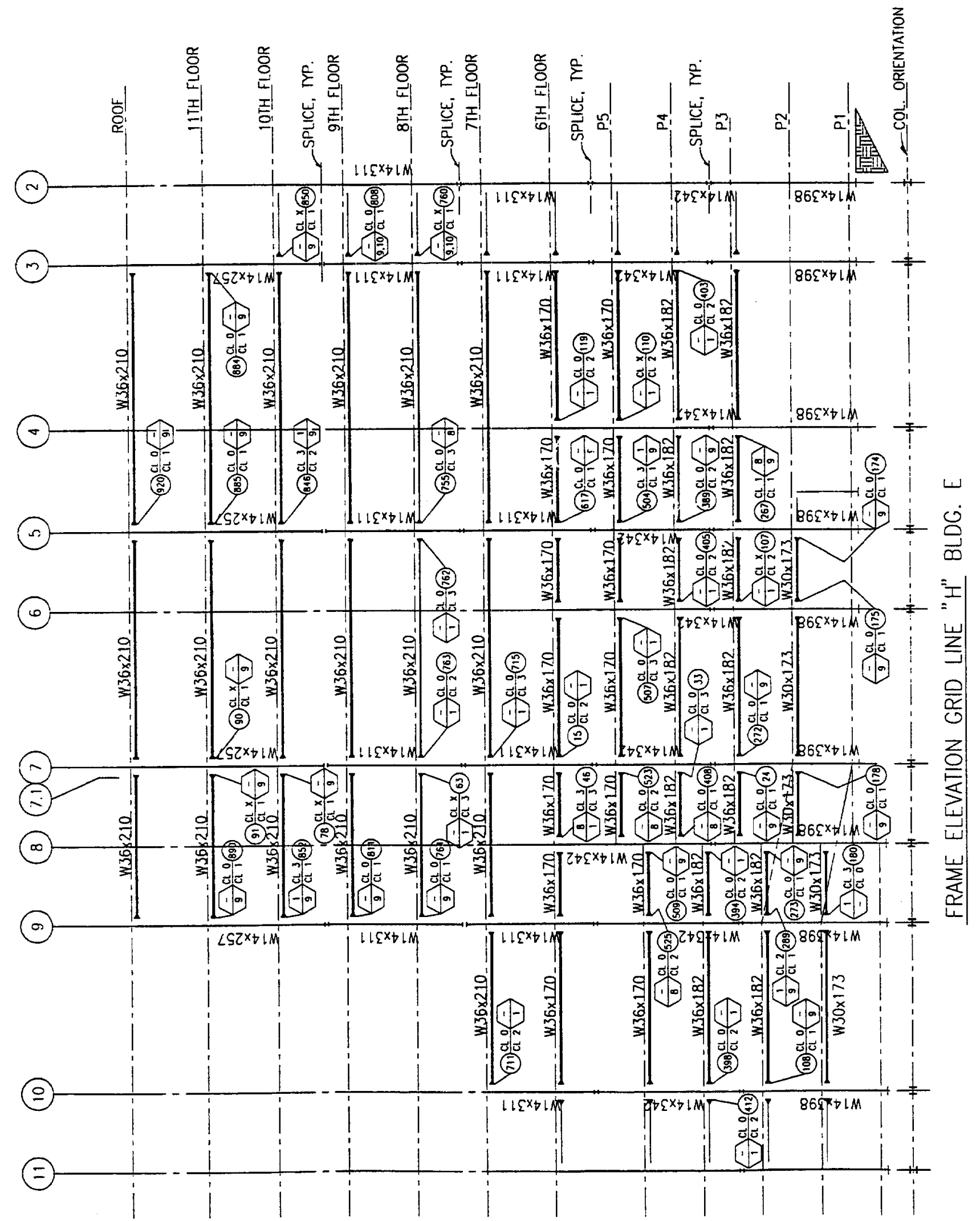




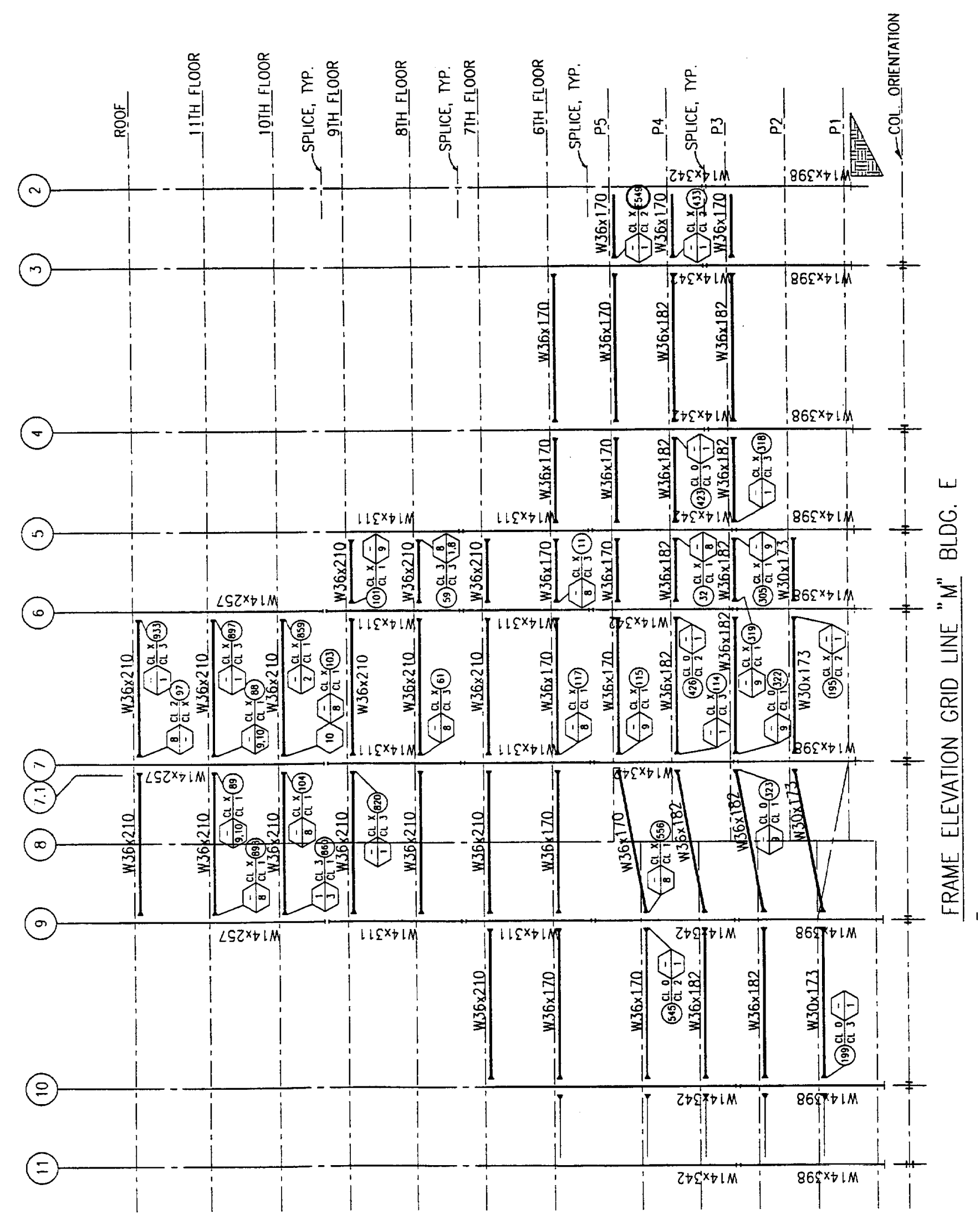




\section{Building F}




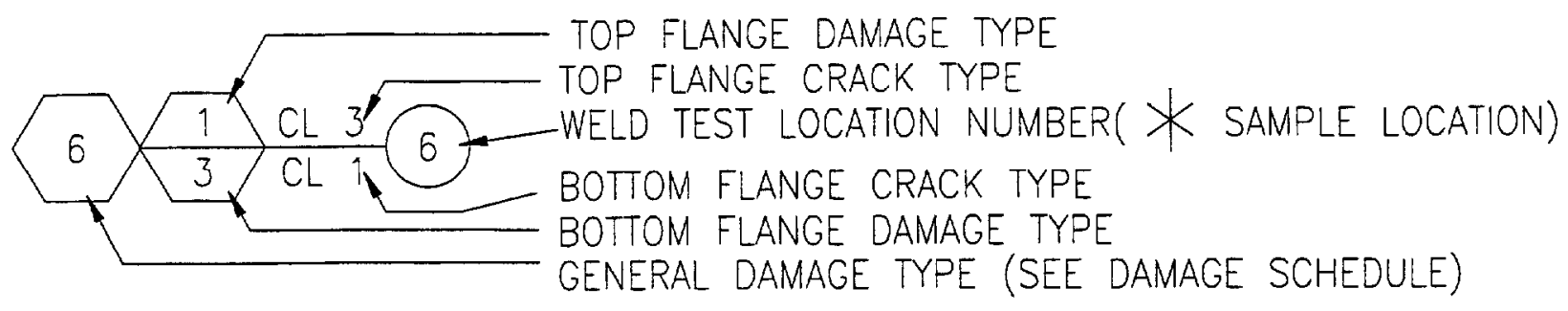

\begin{tabular}{|c|c|c|c|}
\hline \multicolumn{4}{|c|}{ DAMAGE SCHEDULE (BLDG. F) } \\
\hline $\begin{array}{l}\text { DAMAGE } \\
\text { TYPE }\end{array}$ & DESCRIPTION & - & $\begin{array}{l}- \\
-\end{array}$ \\
\hline 1 & PARTIAL CRACK IN WELD & - & - \\
\hline 2 & THROUGH CRACK IN WELD (NO GAP) & & \\
\hline & THROUGH CRACK IN WELD (WITH GAP) & & \\
\hline 4 & SHEAR TAB WELD CRACK & & \\
\hline 5 & SHEAR TAB OR BEAM WEB CRACK & & \\
\hline 6) & BENT SHEAR TAB AND/OR BEAM WEB & & \\
\hline 7 & LOOSE OR MISSING BOLTS & & \\
\hline 8 & $\begin{array}{l}\text { PARTIAL OR THROUGH CRACK IN COLUMN FLANGE } \\
\text { WITHIN } 45^{\circ} \text { ANGLE ZONE }\end{array}$ & & \\
\hline 9 & $\begin{array}{l}\text { PARTIAL OR THROUGH CRACK IN COLUMN FLANGE } \\
\text { OUTSIDE } 45^{\circ} \text { ANGLE ZONE }\end{array}$ & & \\
\hline (10) & COLUMN WEB CRACK & & \\
\hline 11. & LOOSE OR DAMAGED COL. OR BEAM FIREPROOFING & & \\
\hline 12. & STRESS RELIEF PROCEDURE (REPLACE WELD) & & \\
\hline 13. & GAP BETWEEN SHEAR TAB AND BEAM WEB & & \\
\hline
\end{tabular}

' $\mathrm{CL}$ O' INDICATES NO CRACKS FOUND.

'CL $X$ ' INDICATES FLANGE OR PORTION OF FLANGE INACCESSIBLE DURING INITIAL TESTING. 


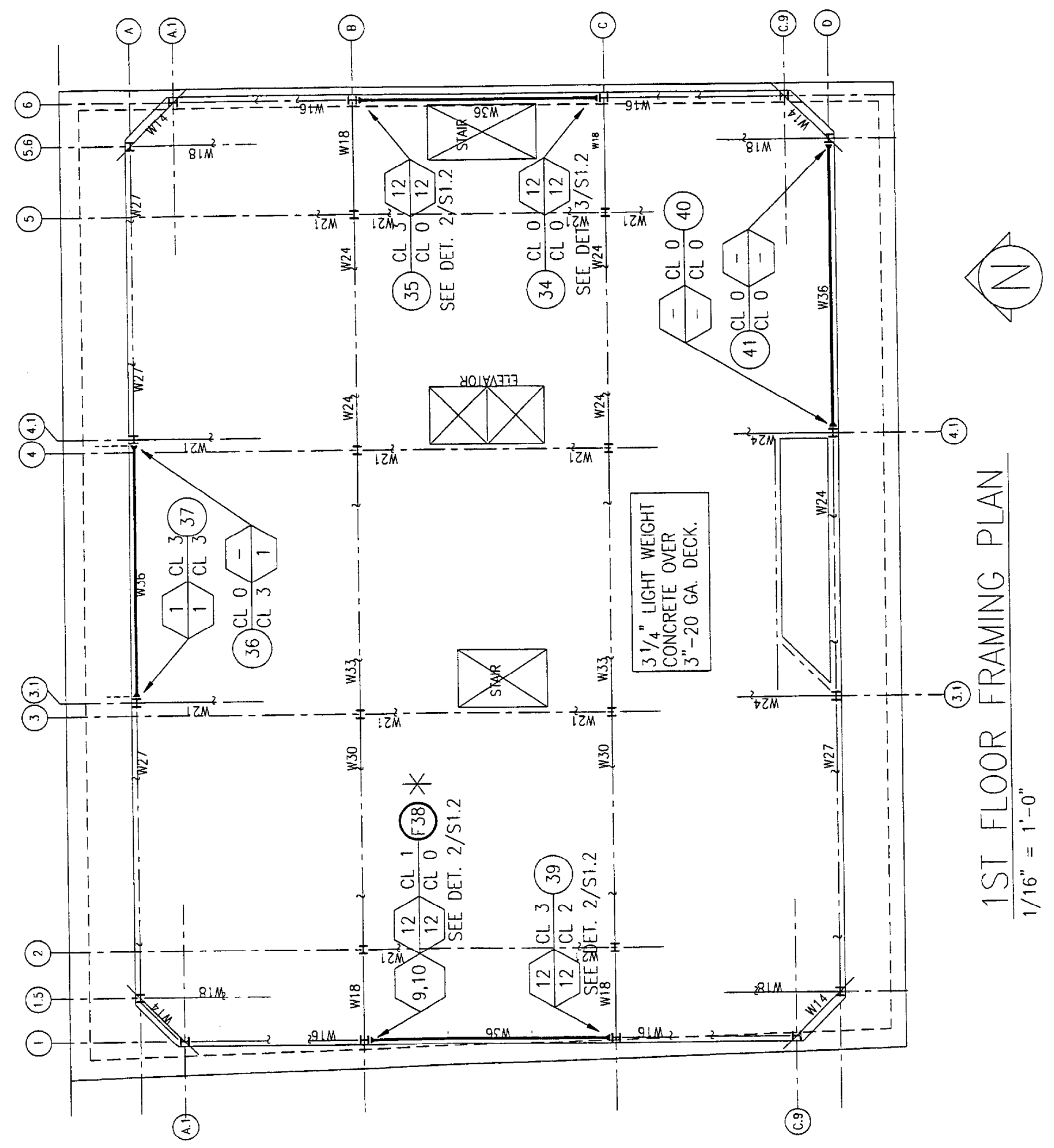




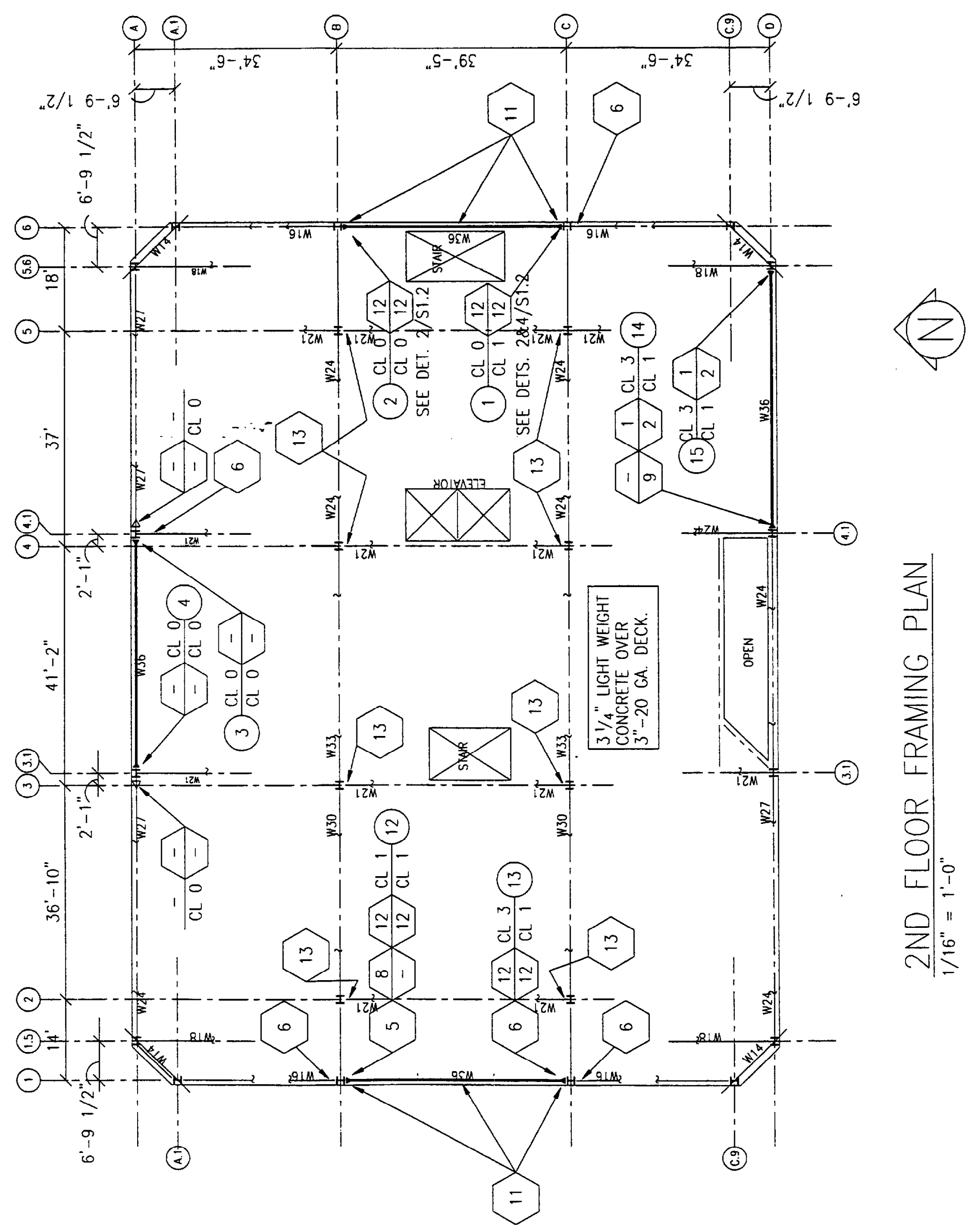




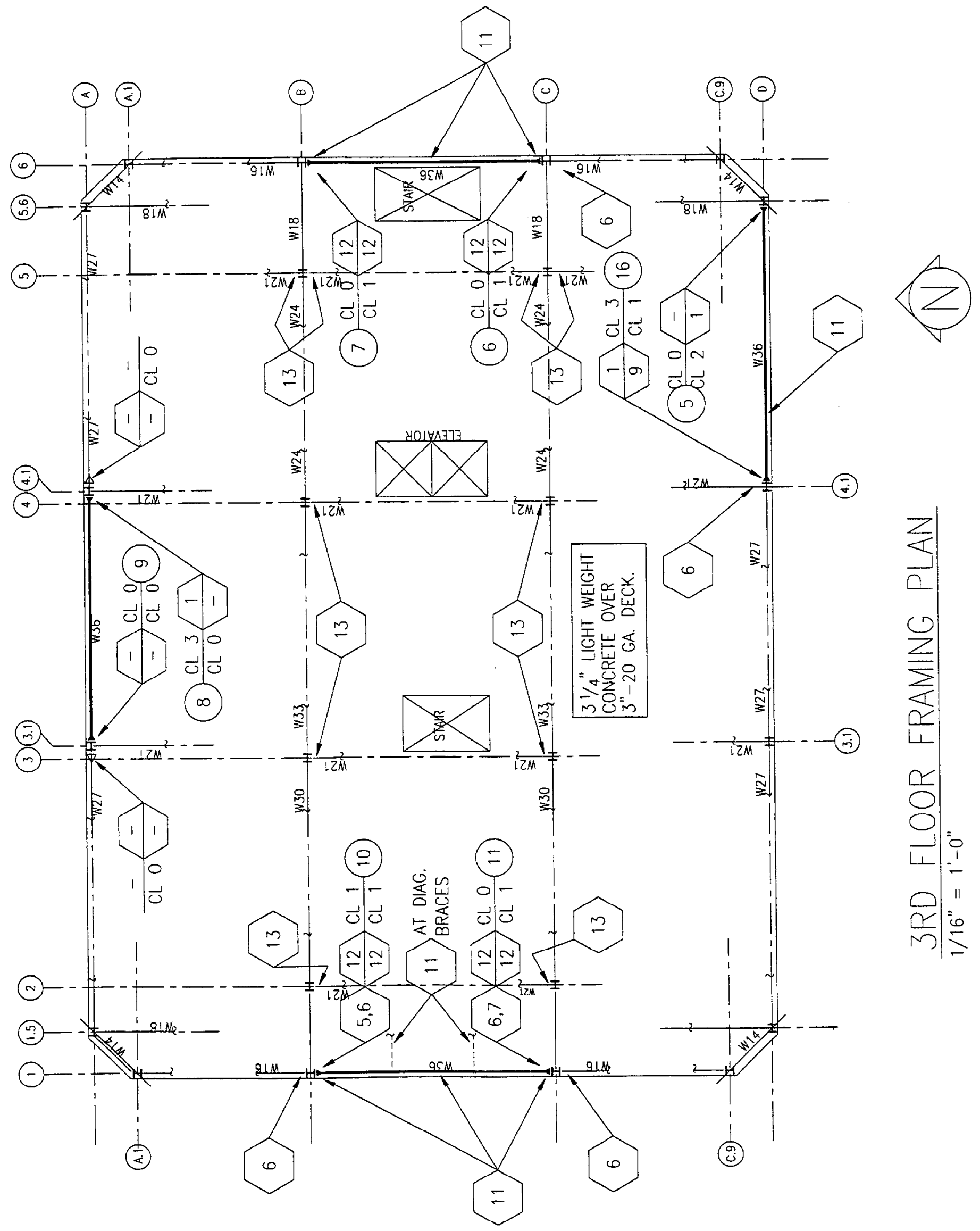




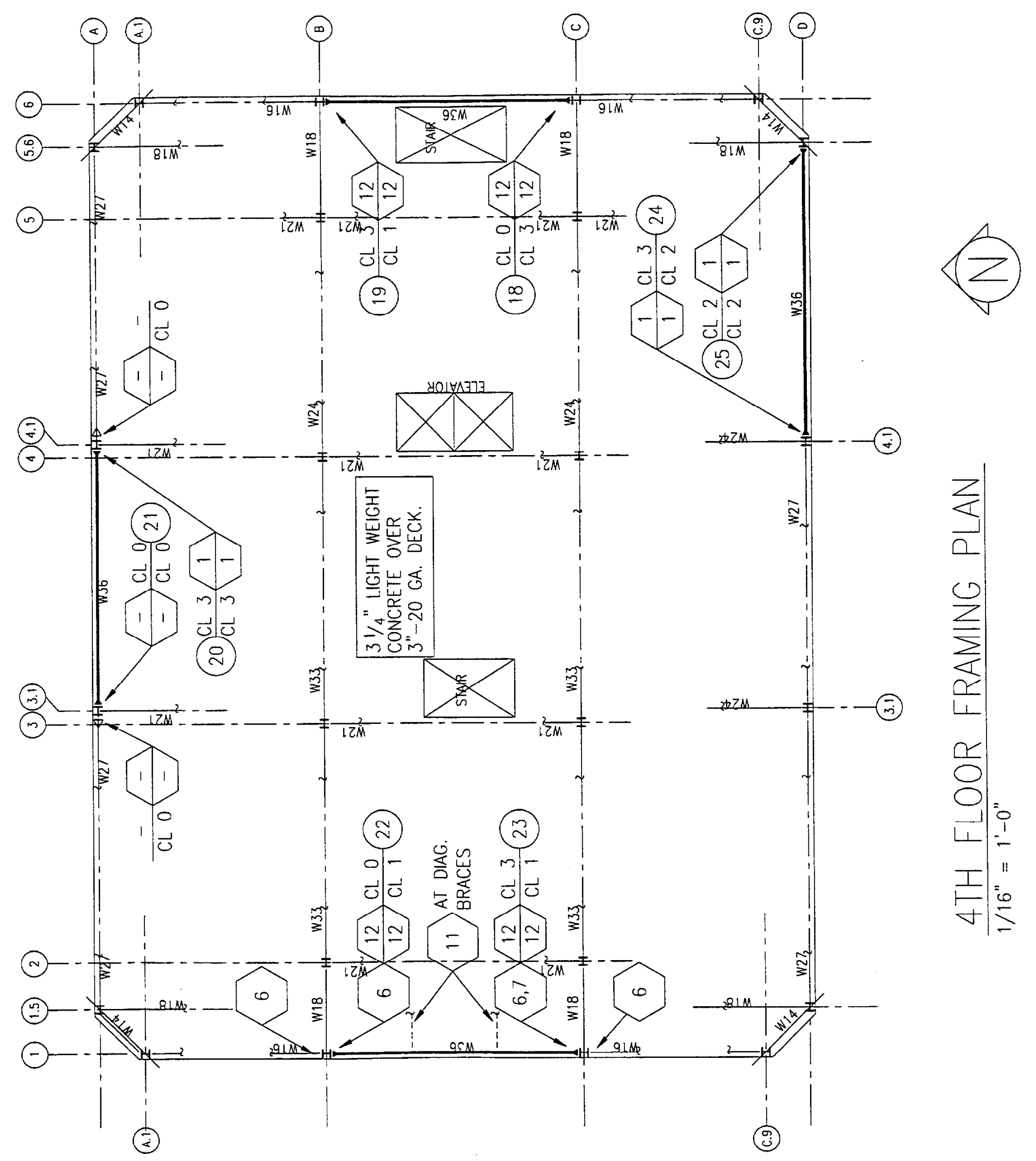




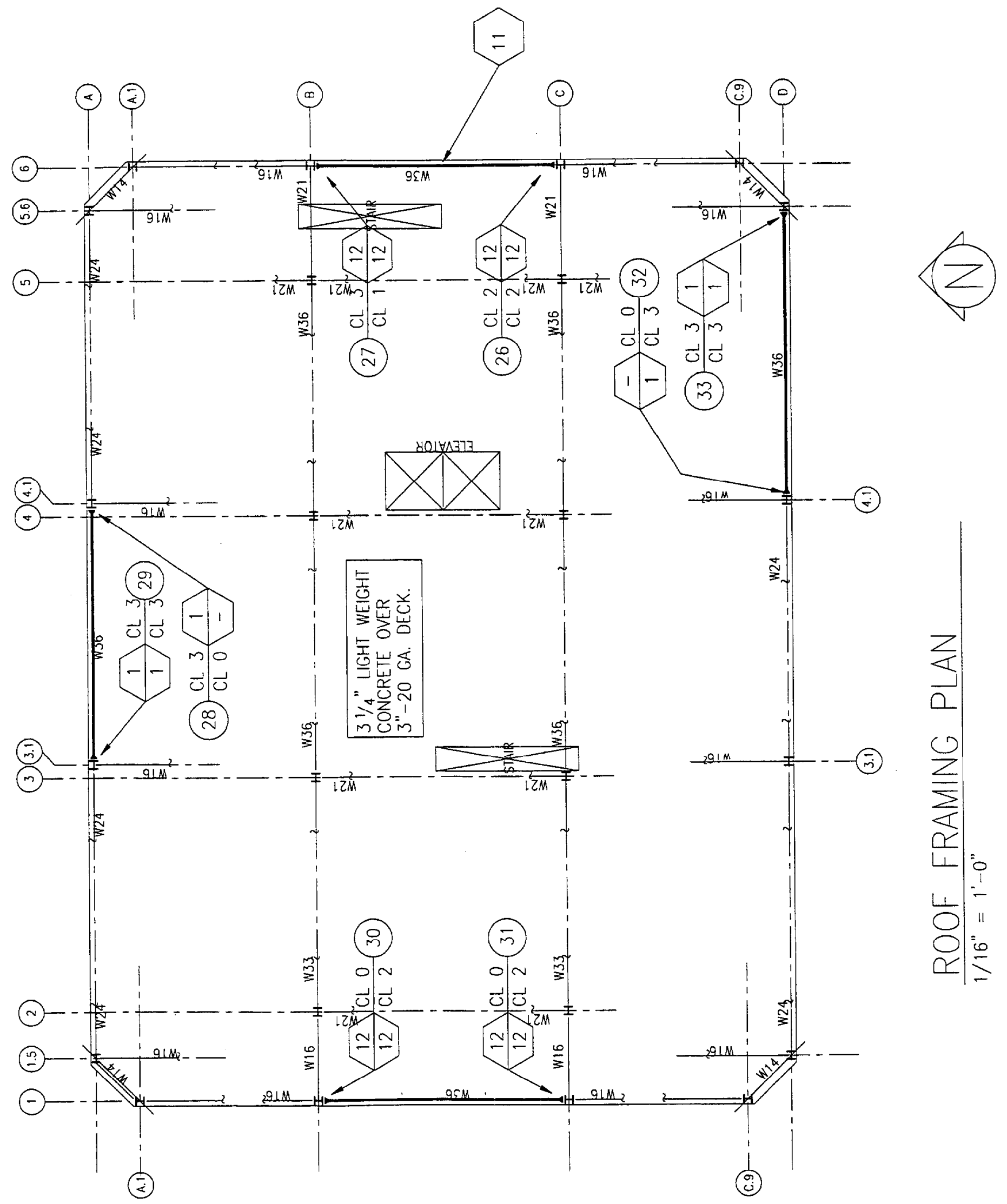




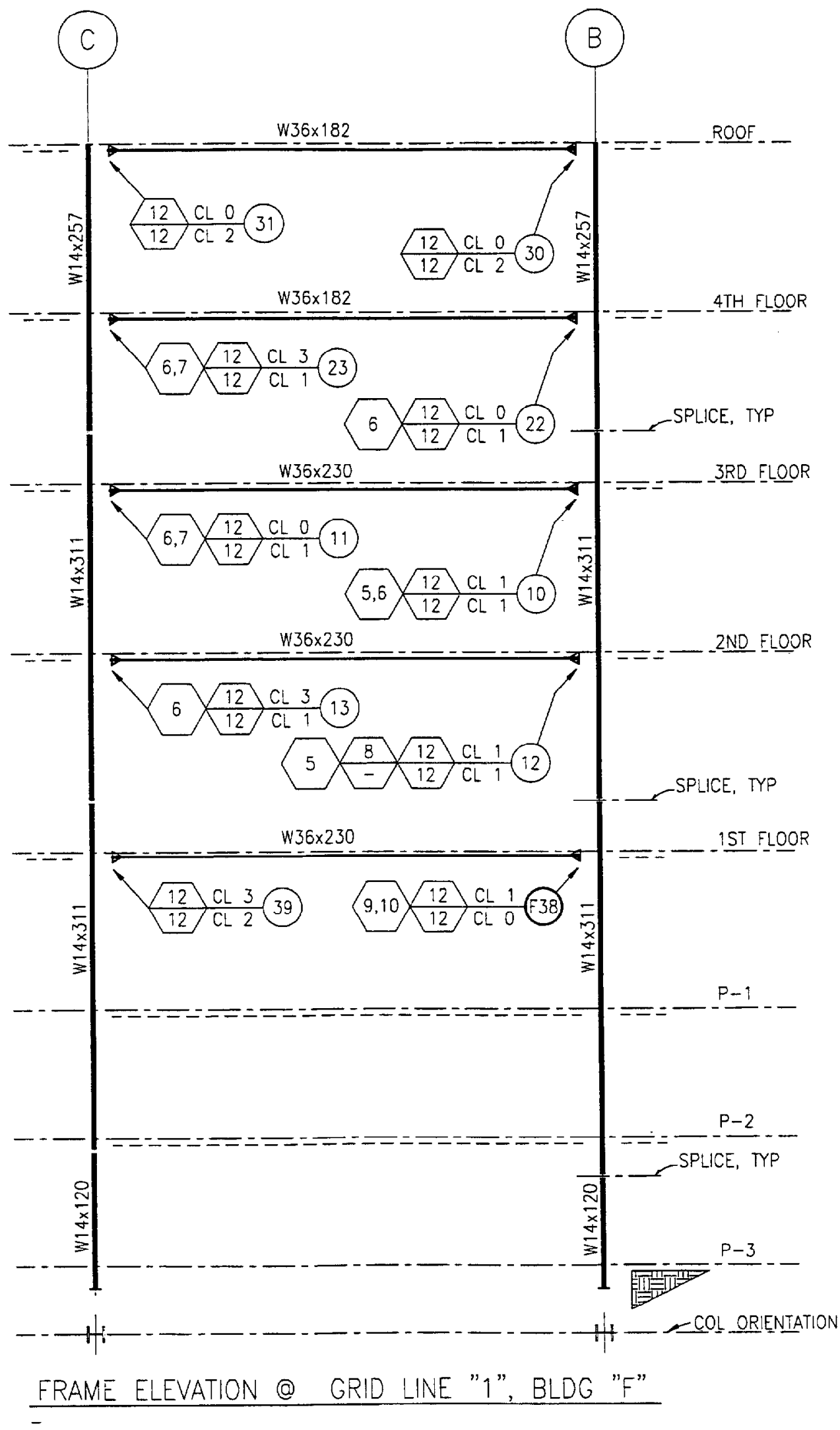




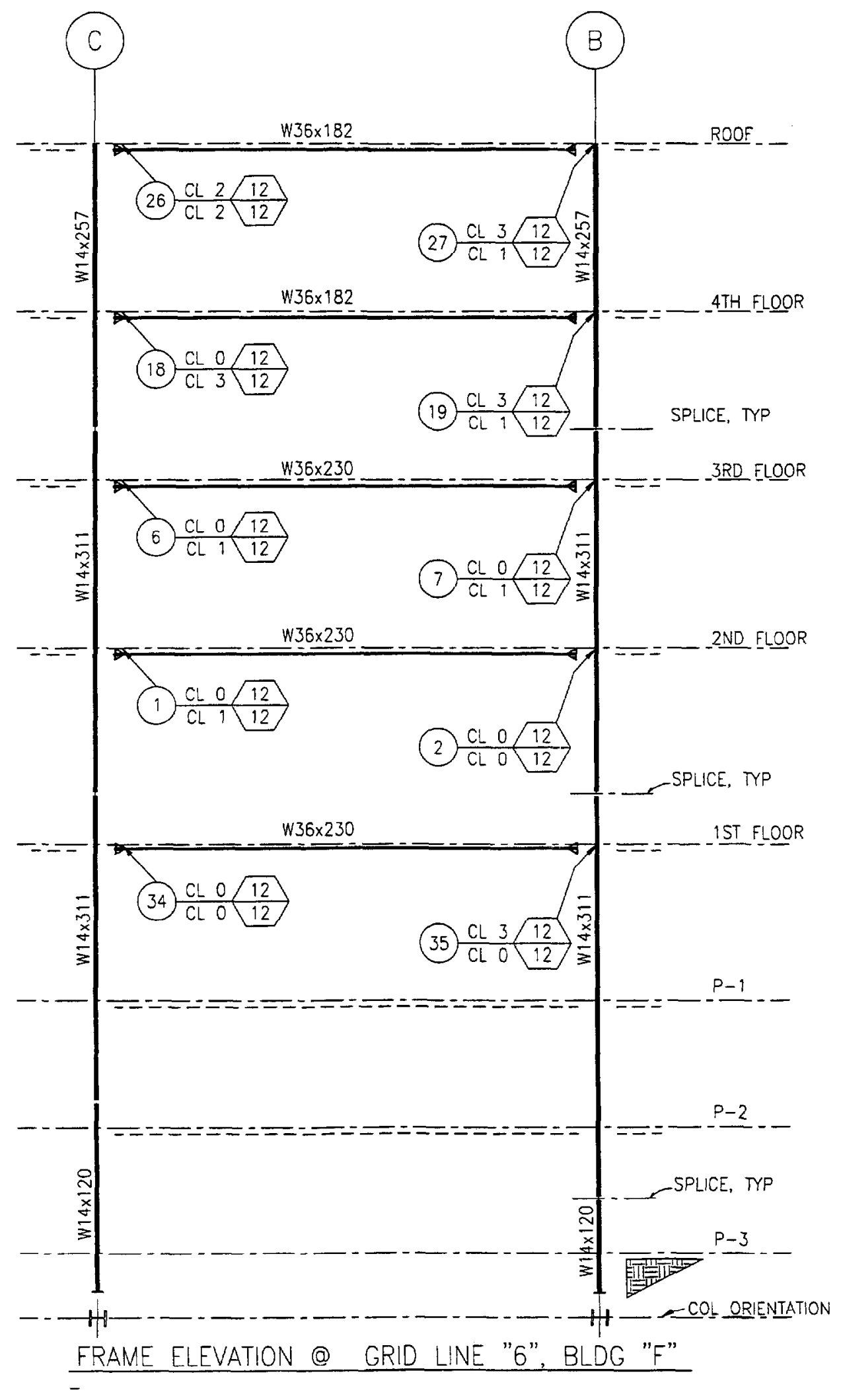




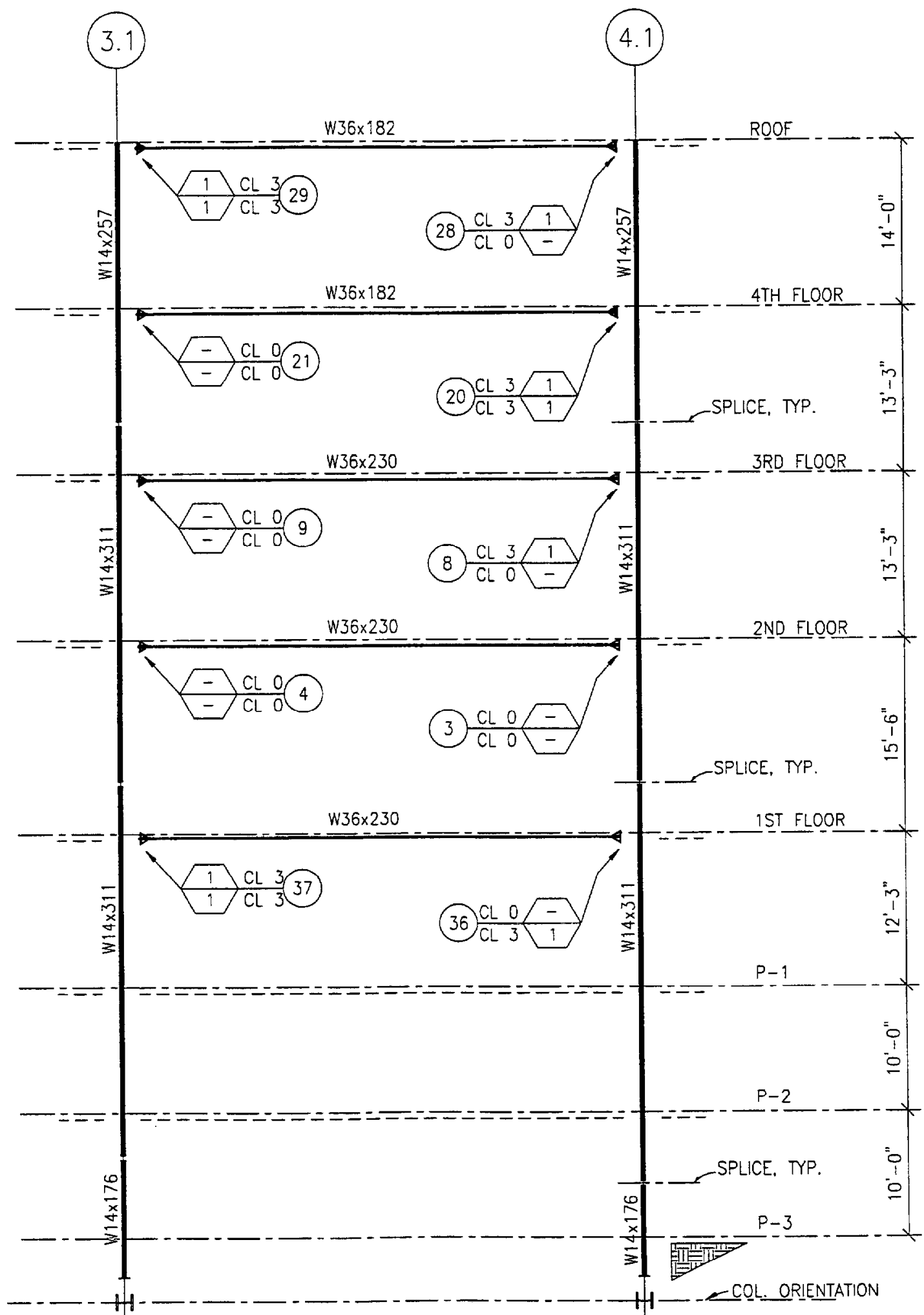

FRAME ELEVATION @ GRID LINE "A", BLDG "F" 


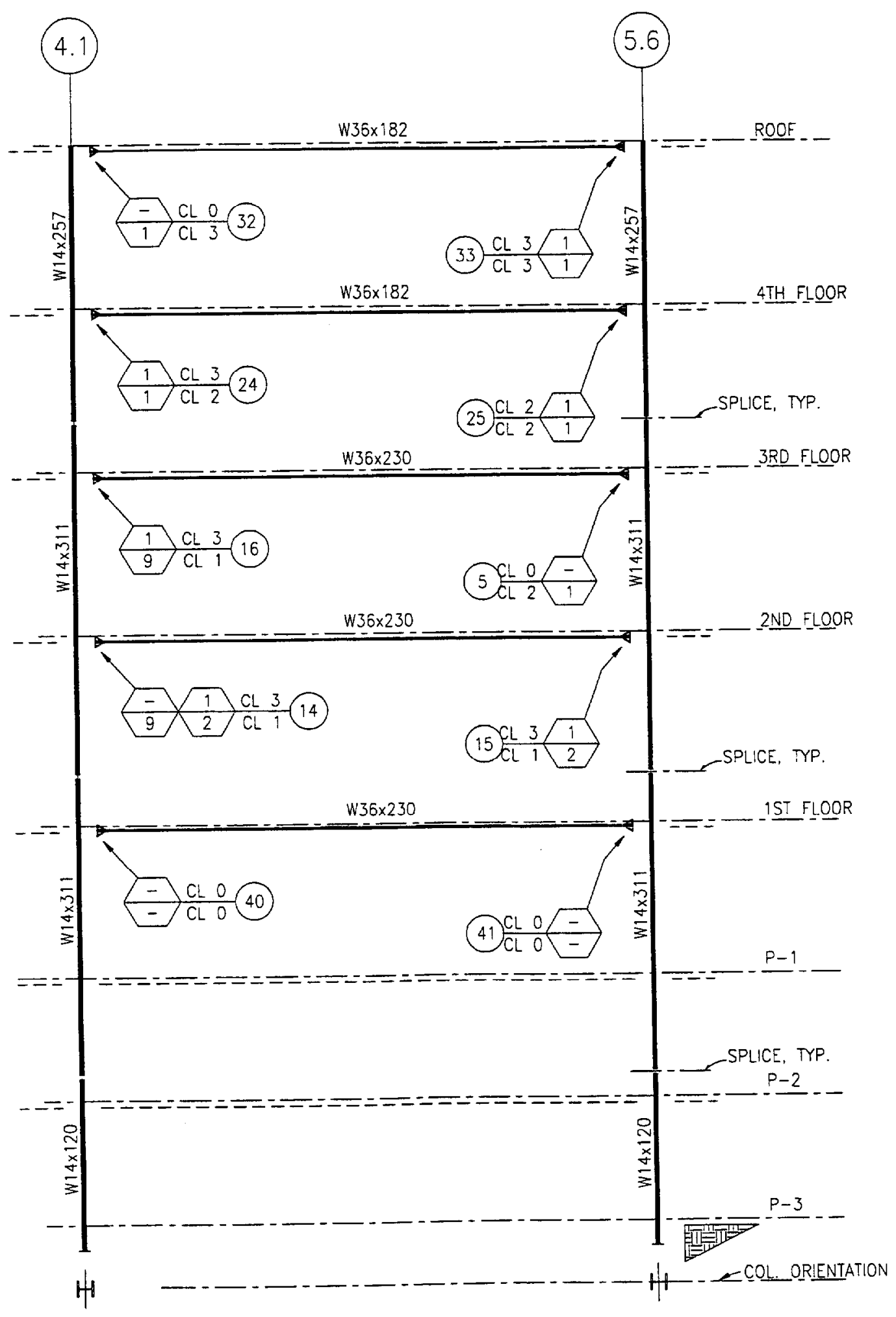

FRAME ELEVATION @ GRID LINE "D", BLDG "F" 


\section{APPENDIX B}

\section{COLUMN FLANGE CVN TEST DATA}



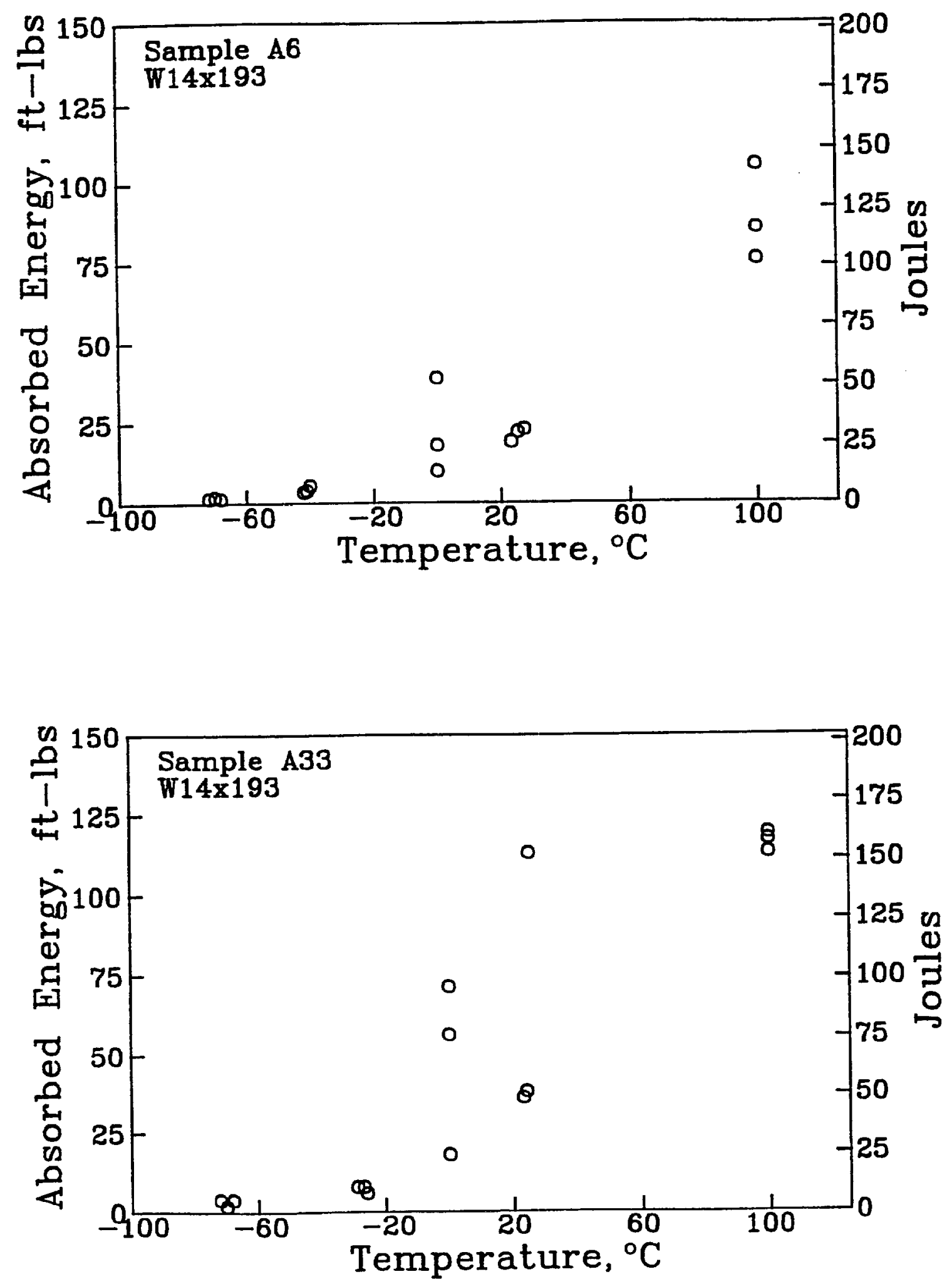

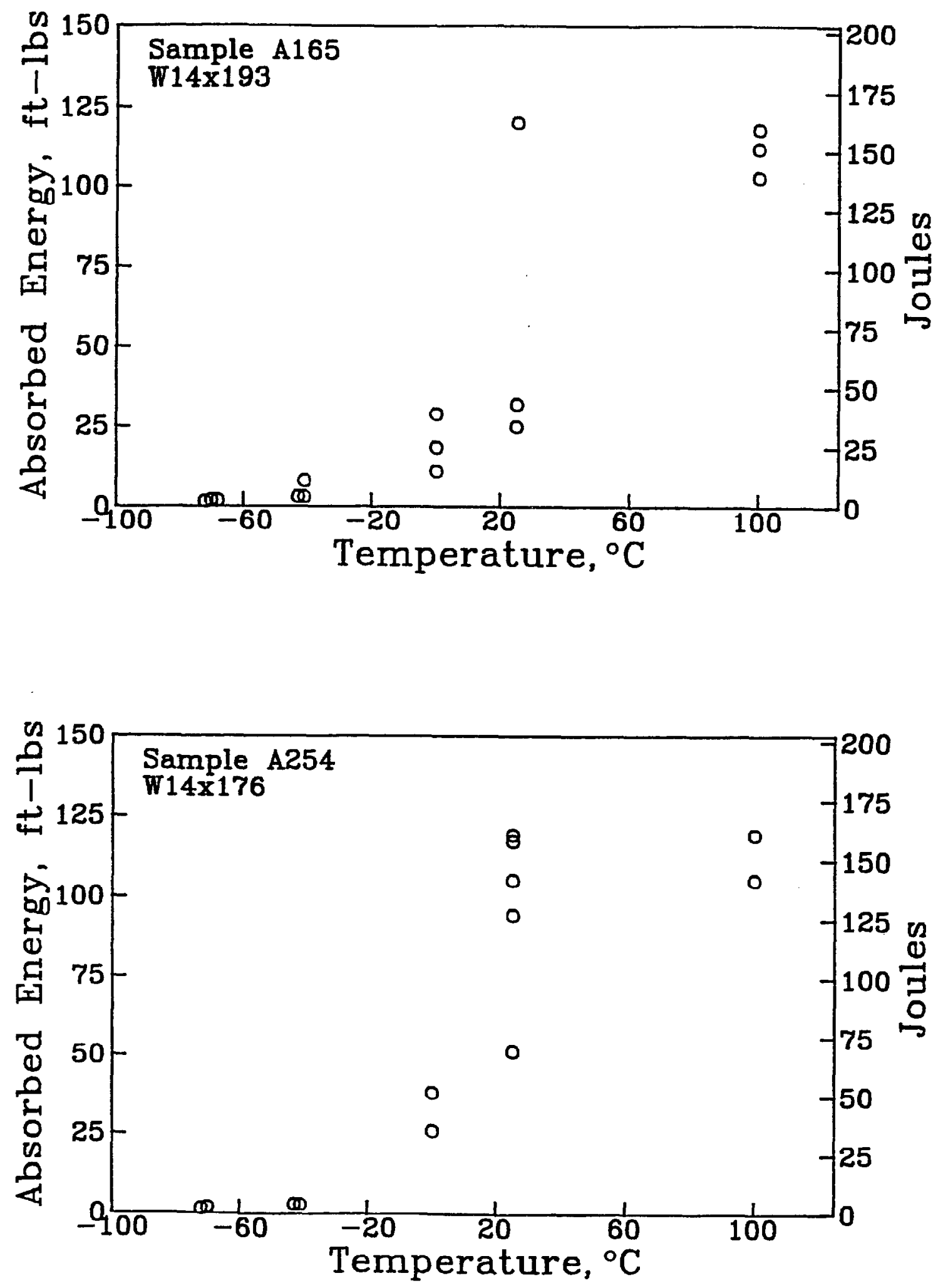

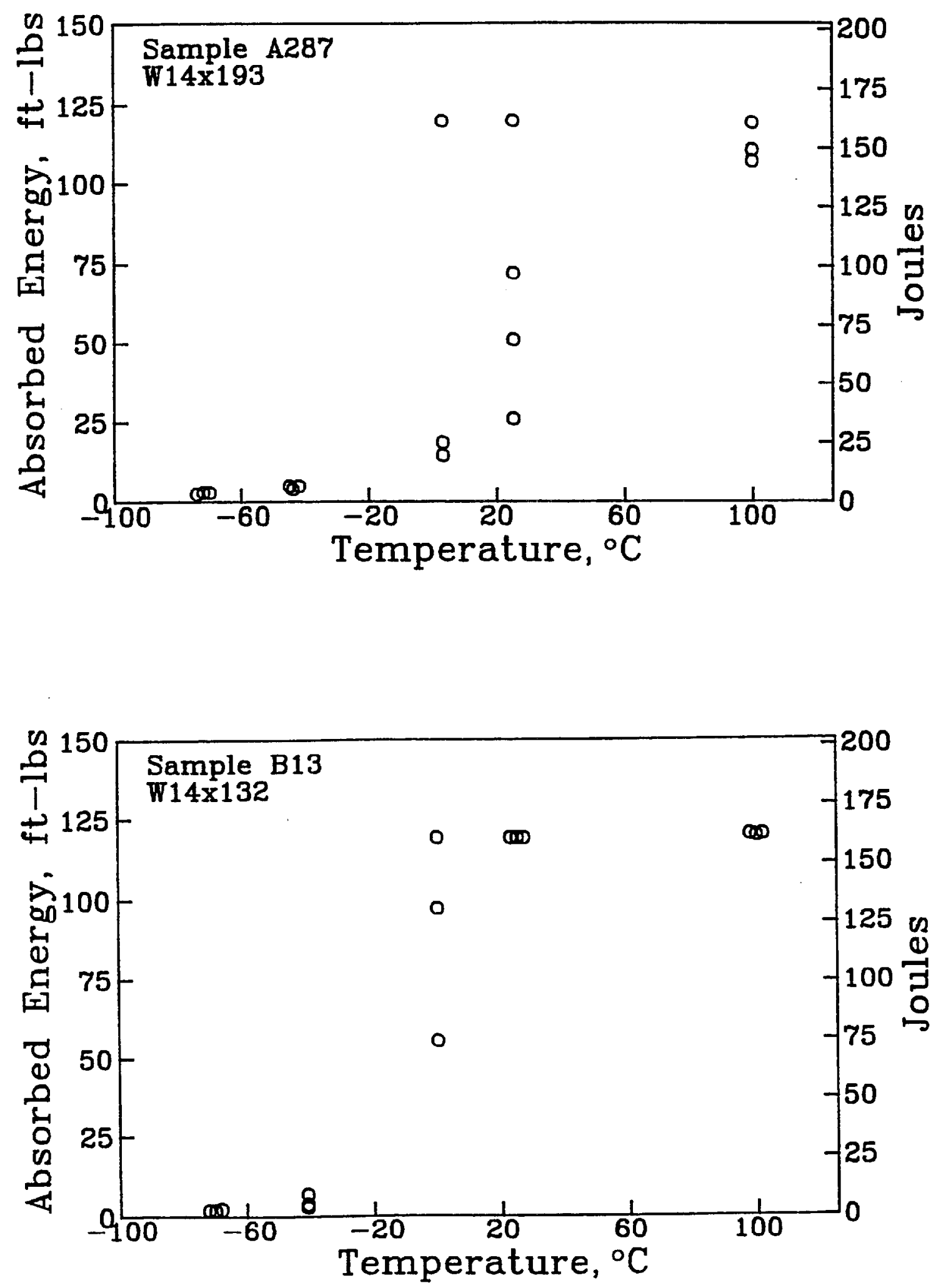

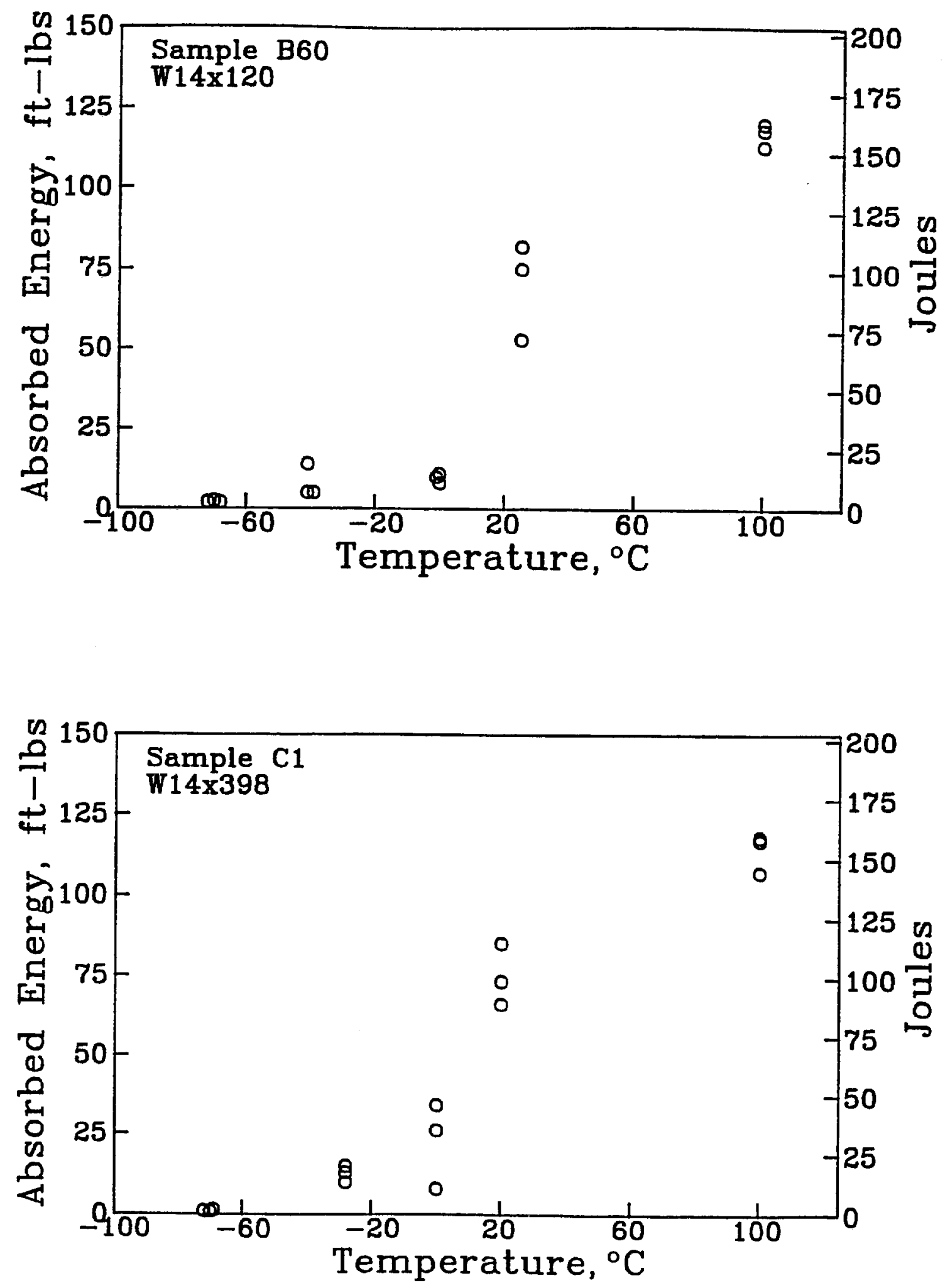

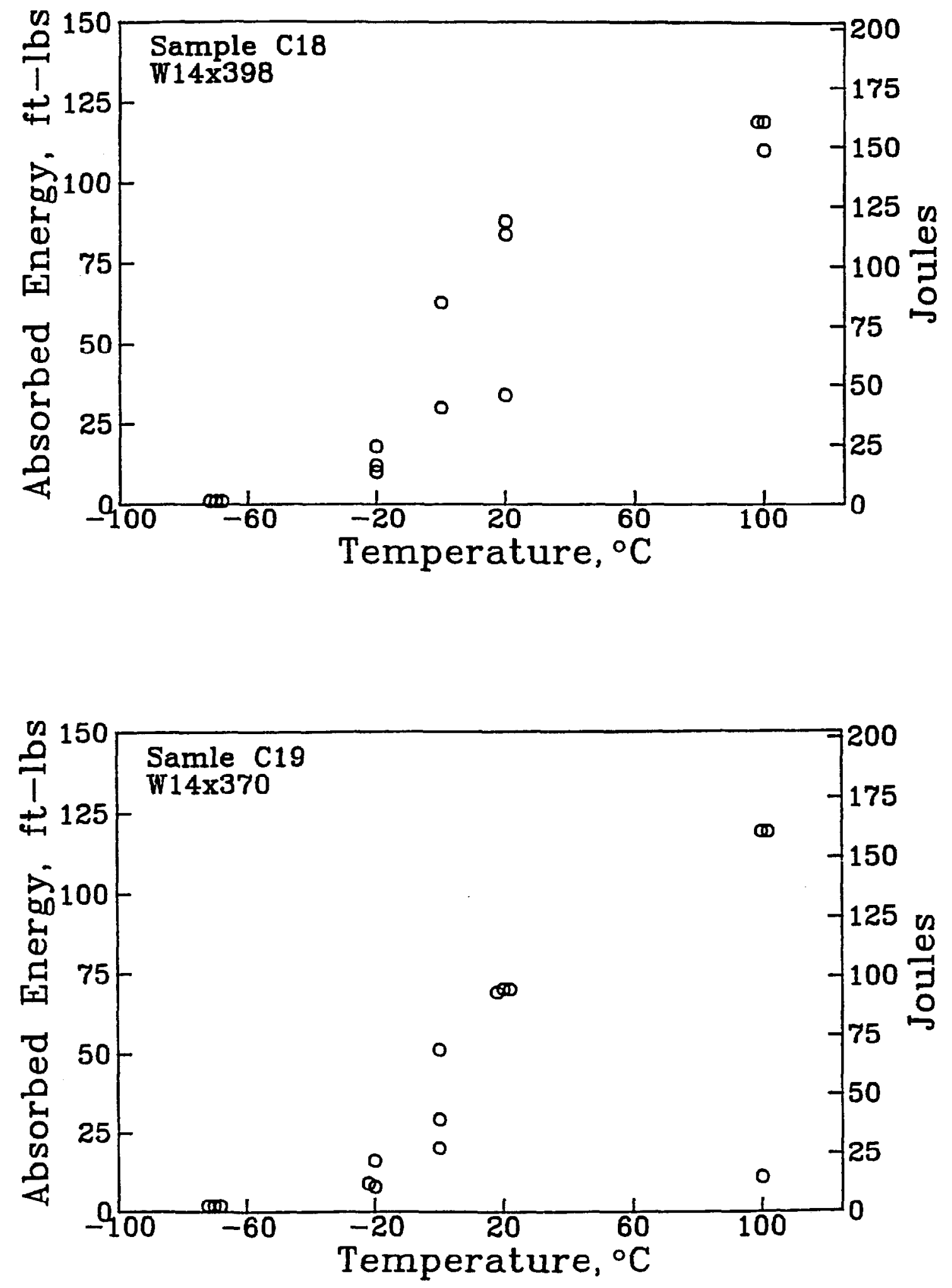

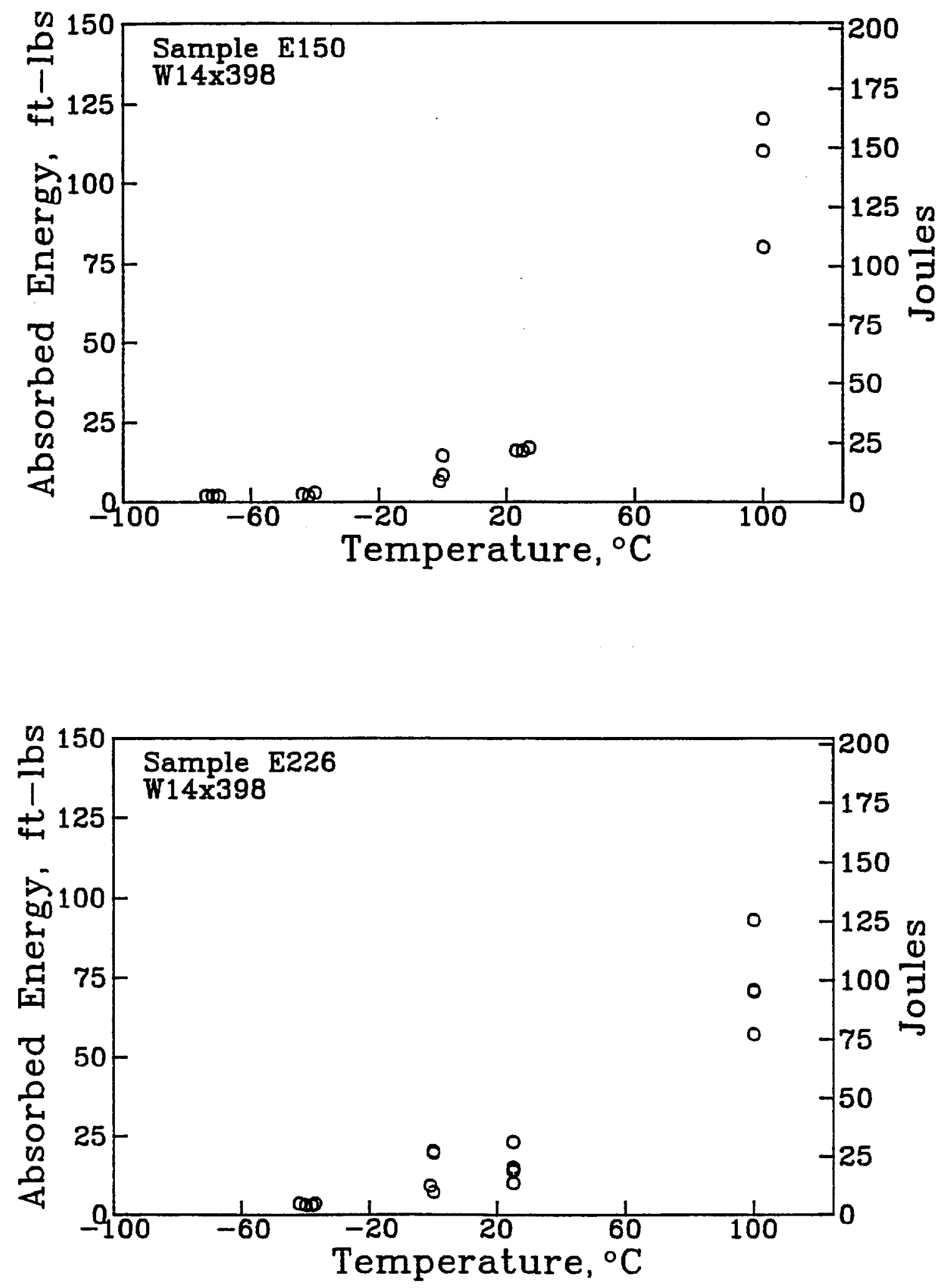

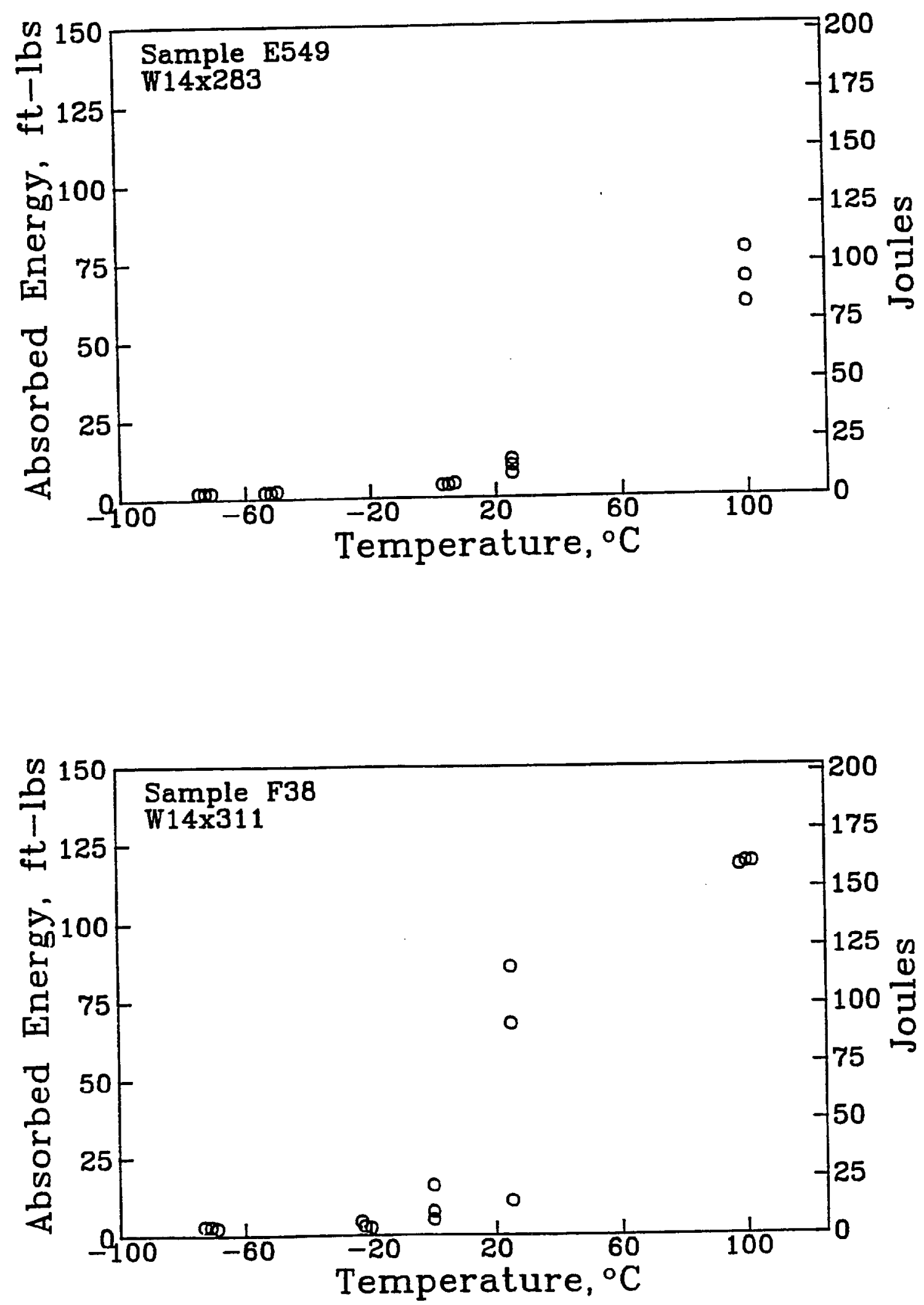


\section{APPENDIX C}

BEAM AND COLUMN FLANGE MICROSTRUCTURE 


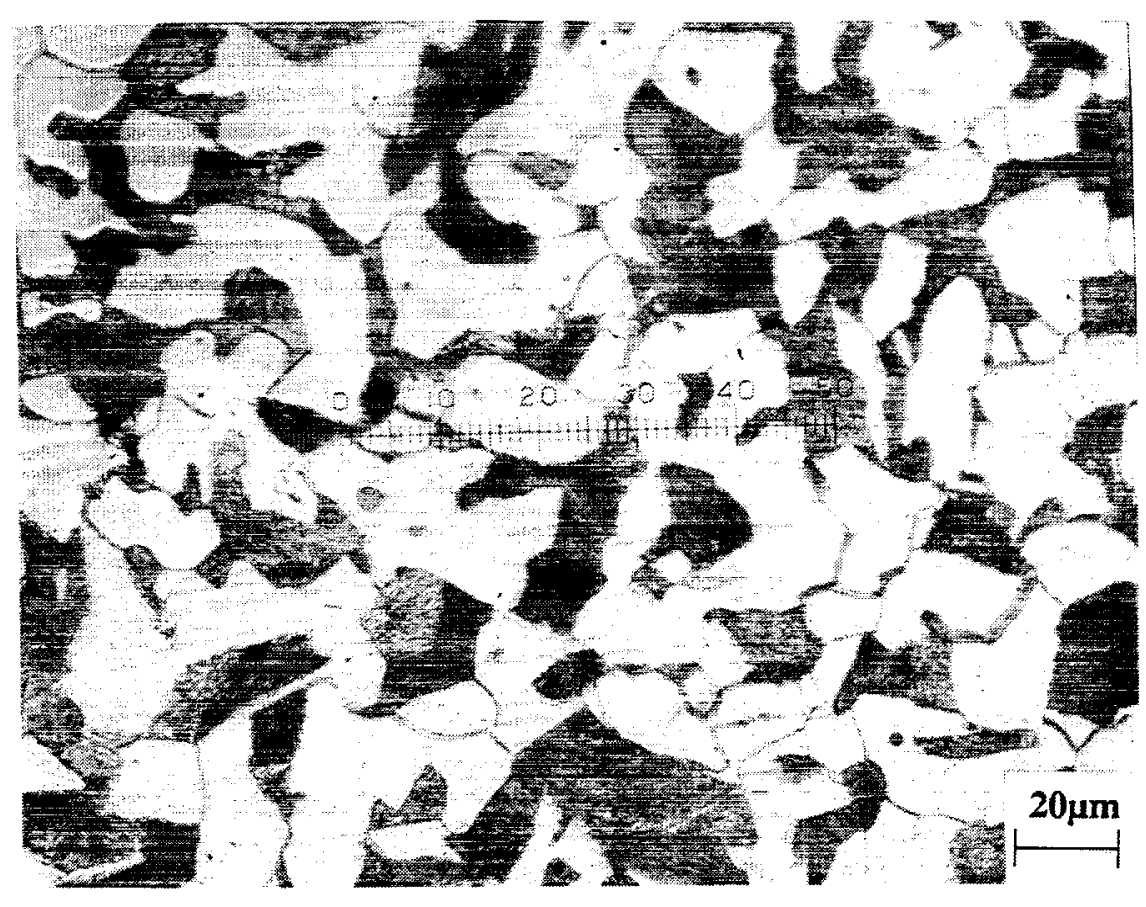

Sample A6 - Column Flange

Magnification: $500 \mathrm{X}$ Etchant: $2 \%$ Nital

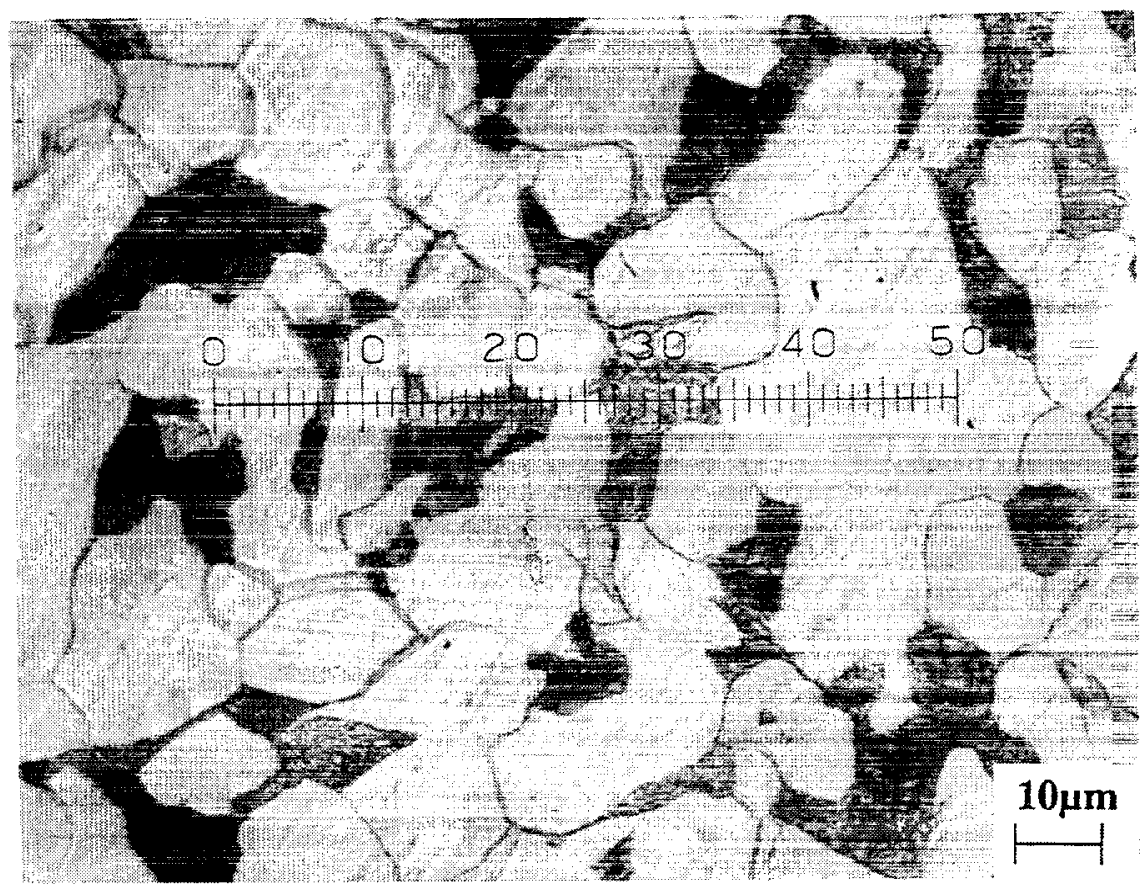

Sample A33 - Column Flange

Magnification: $750 \mathrm{X}$ Etchant: $2 \%$ Nital 


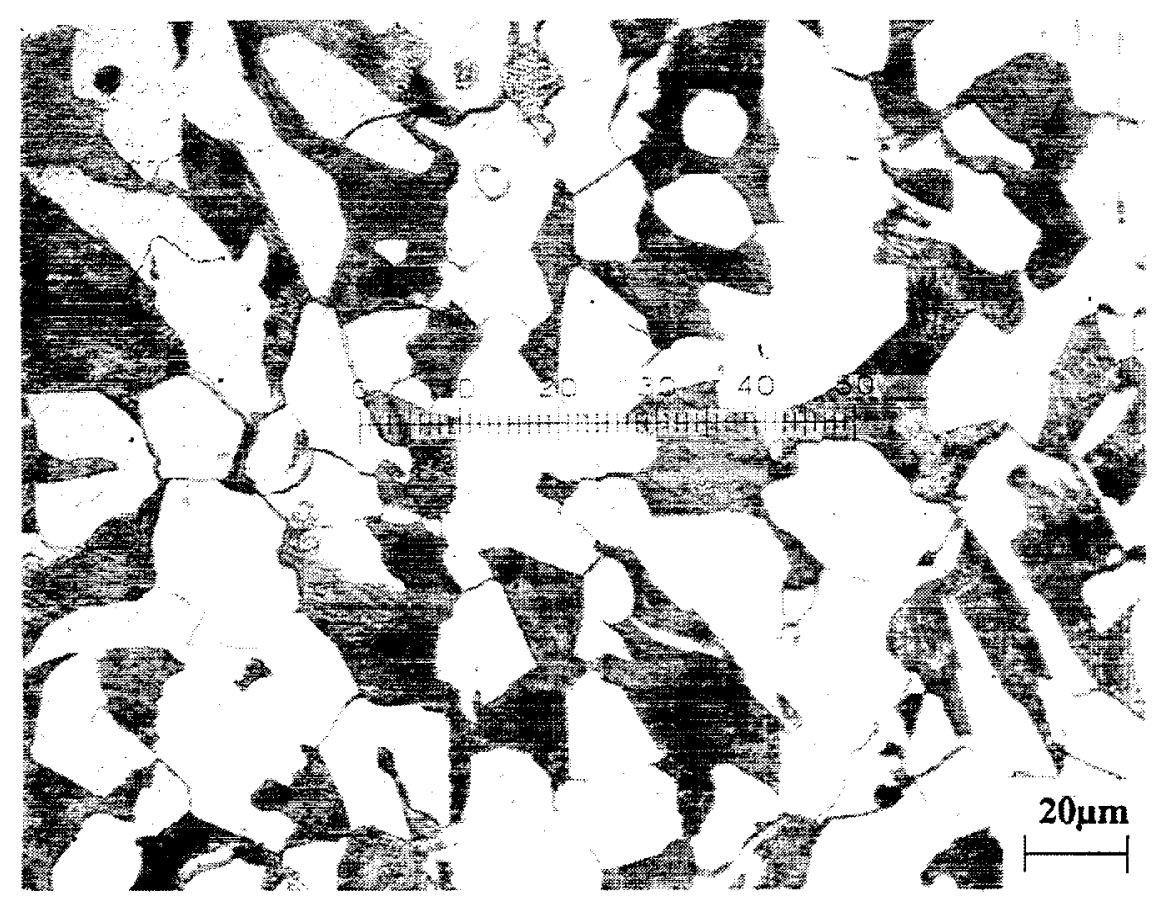

Sample A33 - Beam Flange

Magnification: 500X Etchant: $2 \%$ Nital

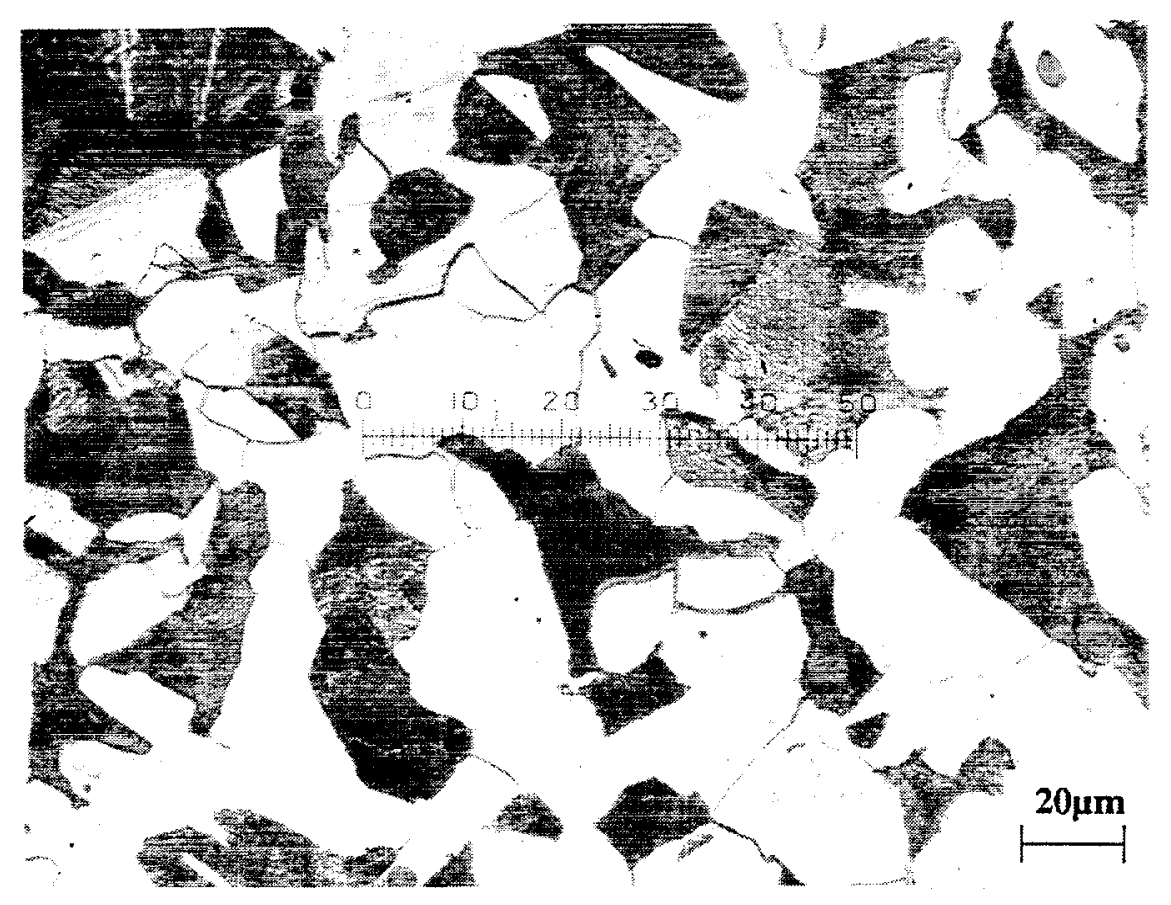

Sample A165 - Column Flange

Magnification: $500 \mathrm{X}$ Etchant: $2 \%$ Nital 


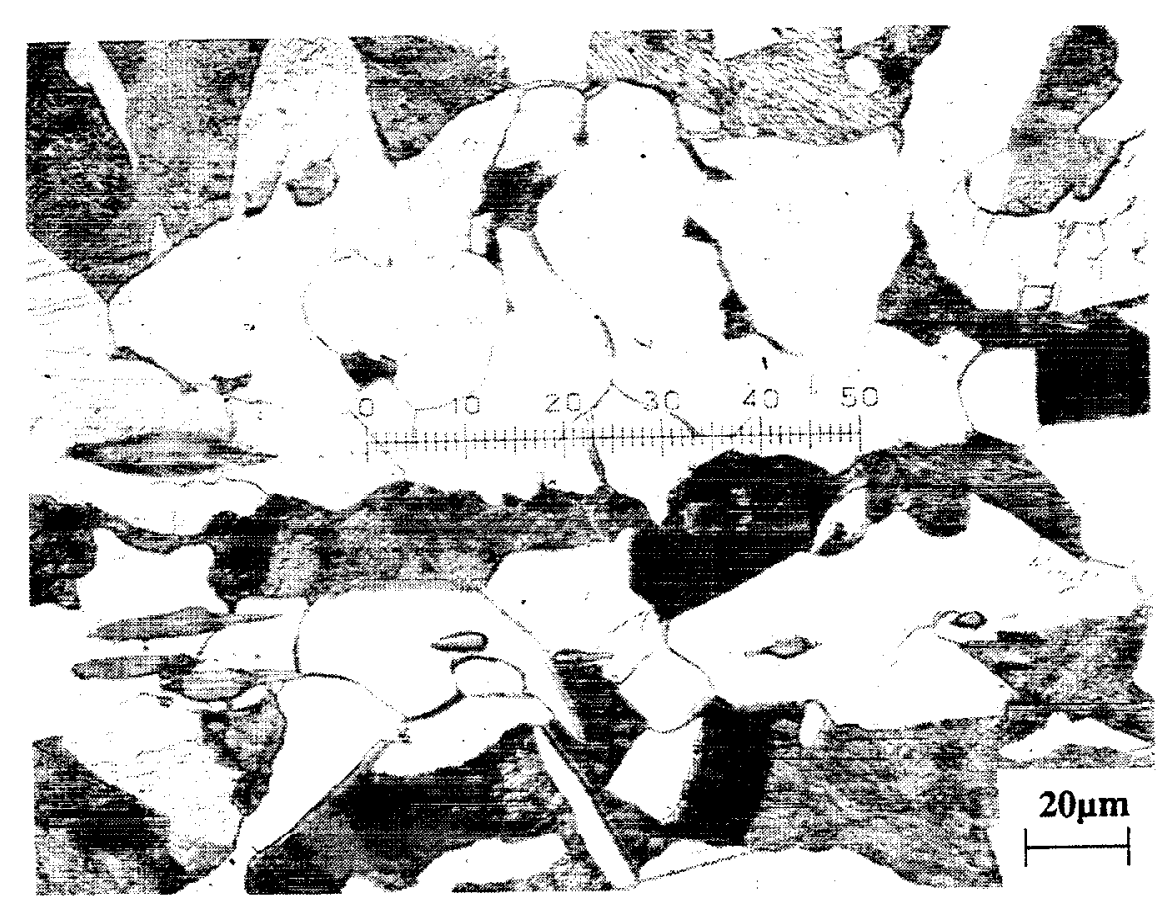

Sample A254 - Column Flange

Magnification: 500X Etchant: $2 \%$ Nital

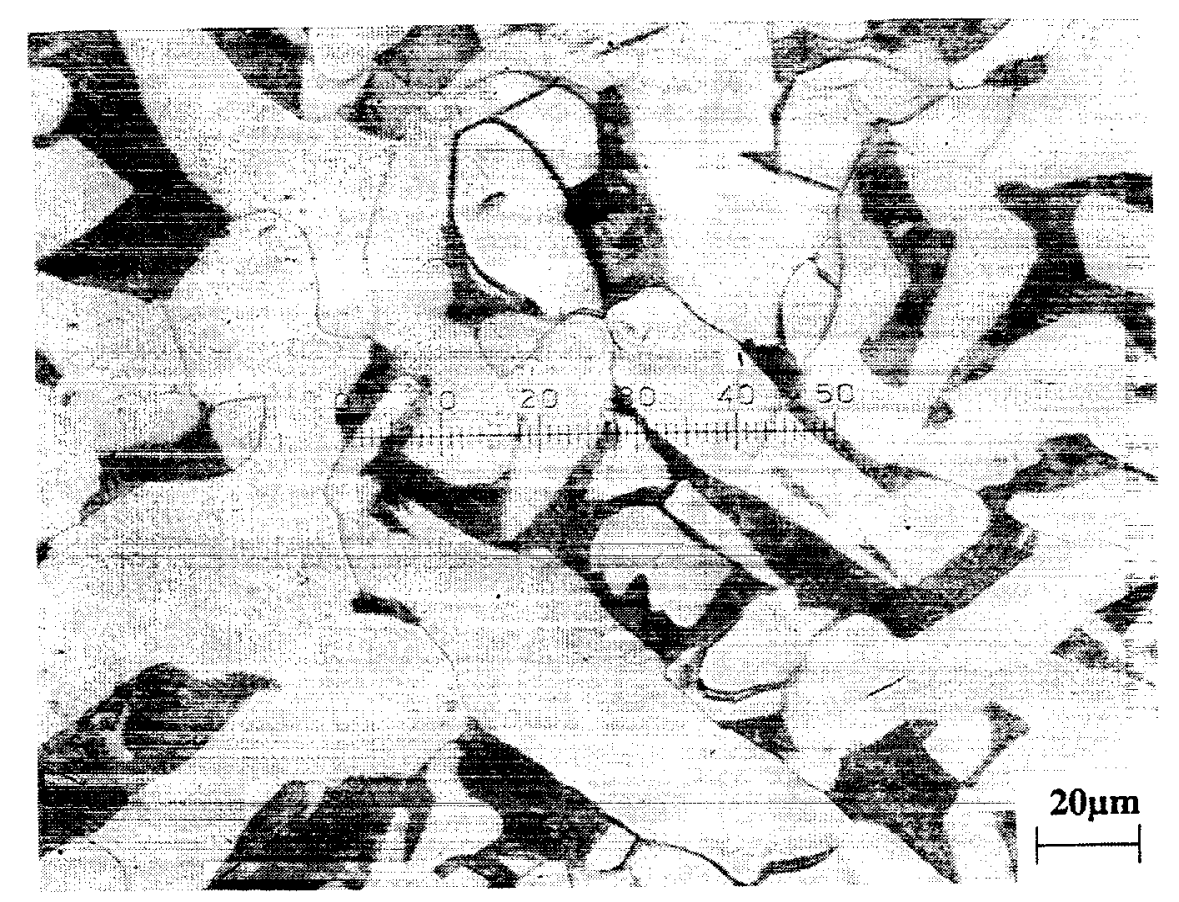

Sample A287 - Column Flange

Magnification: $500 \mathrm{X}$ Etchant: $2 \%$ Nital 


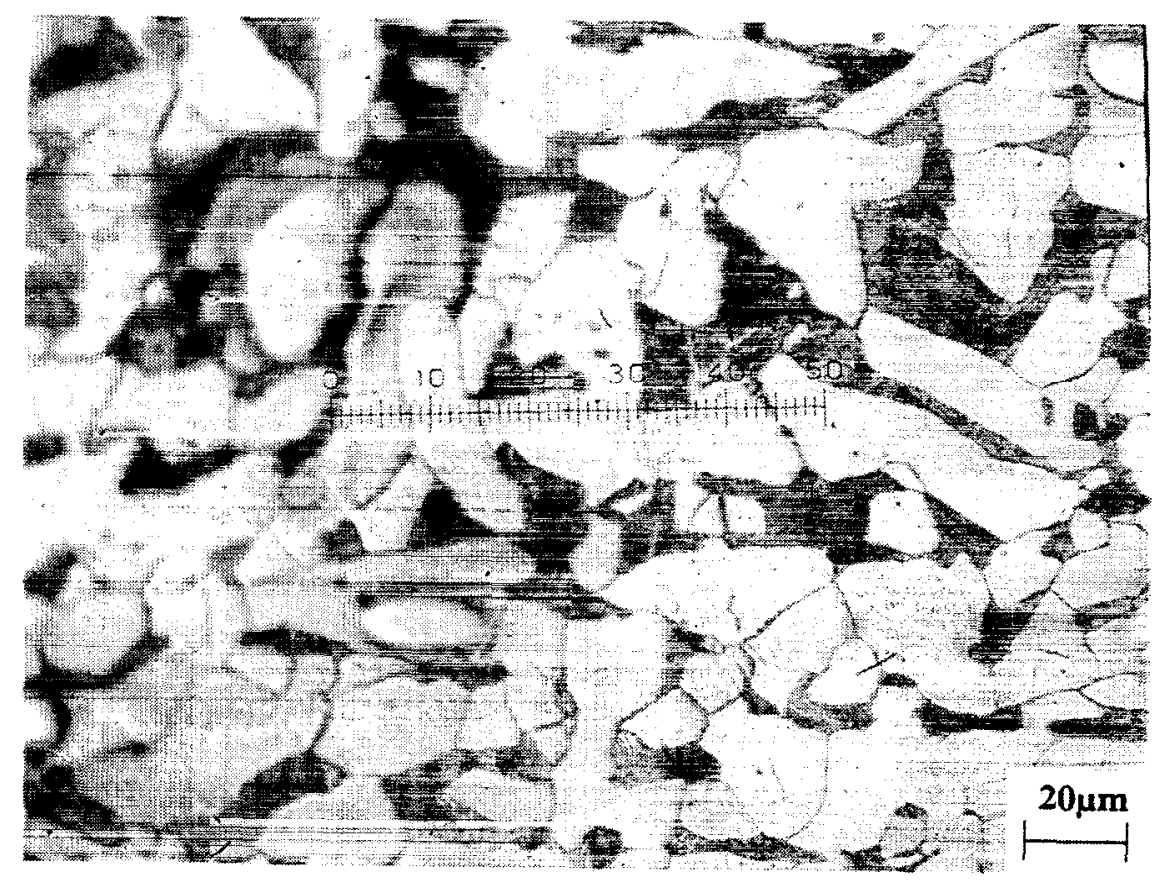

Sample A287 - Beam Flange

Magnification: 500X Etchant: 2\% Nital

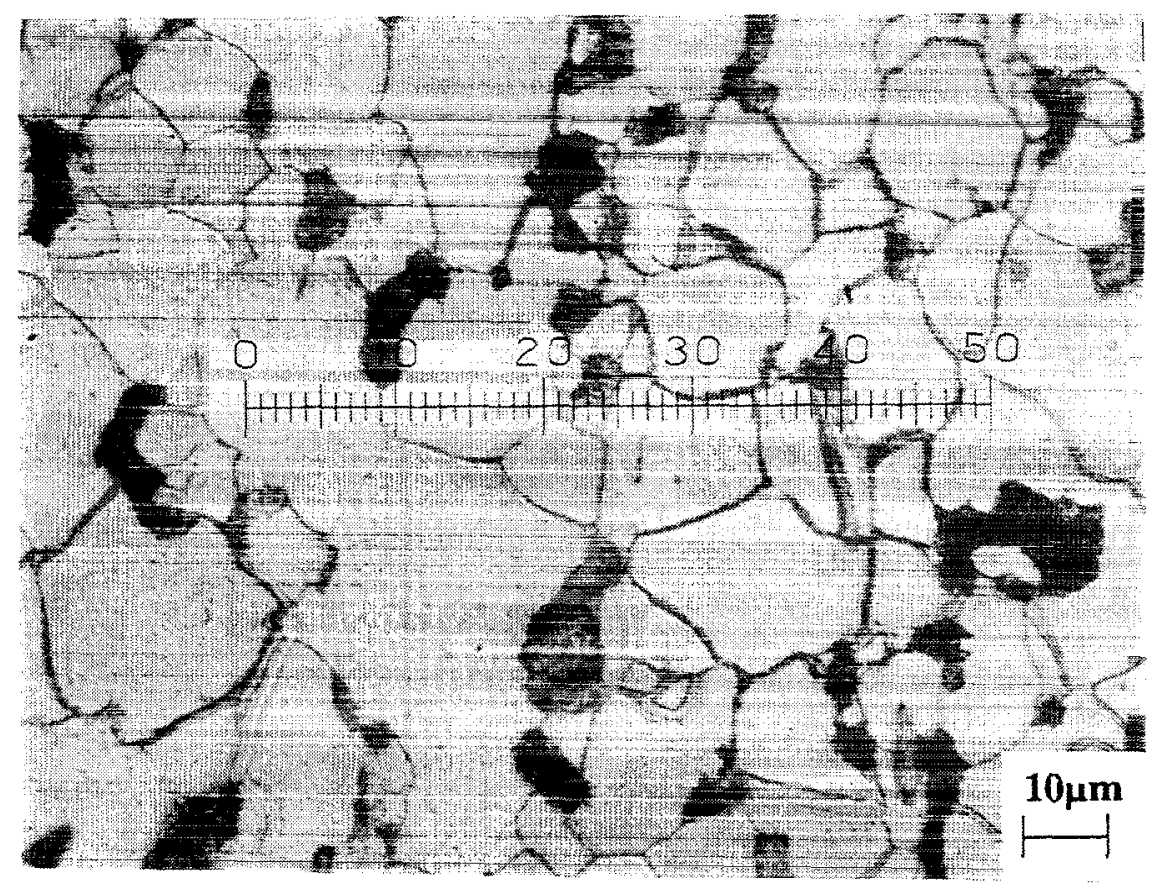

Sample B4 - Beam Flange

Magnification: $500 \mathrm{X}$ Etchant: $2 \%$ Nital 


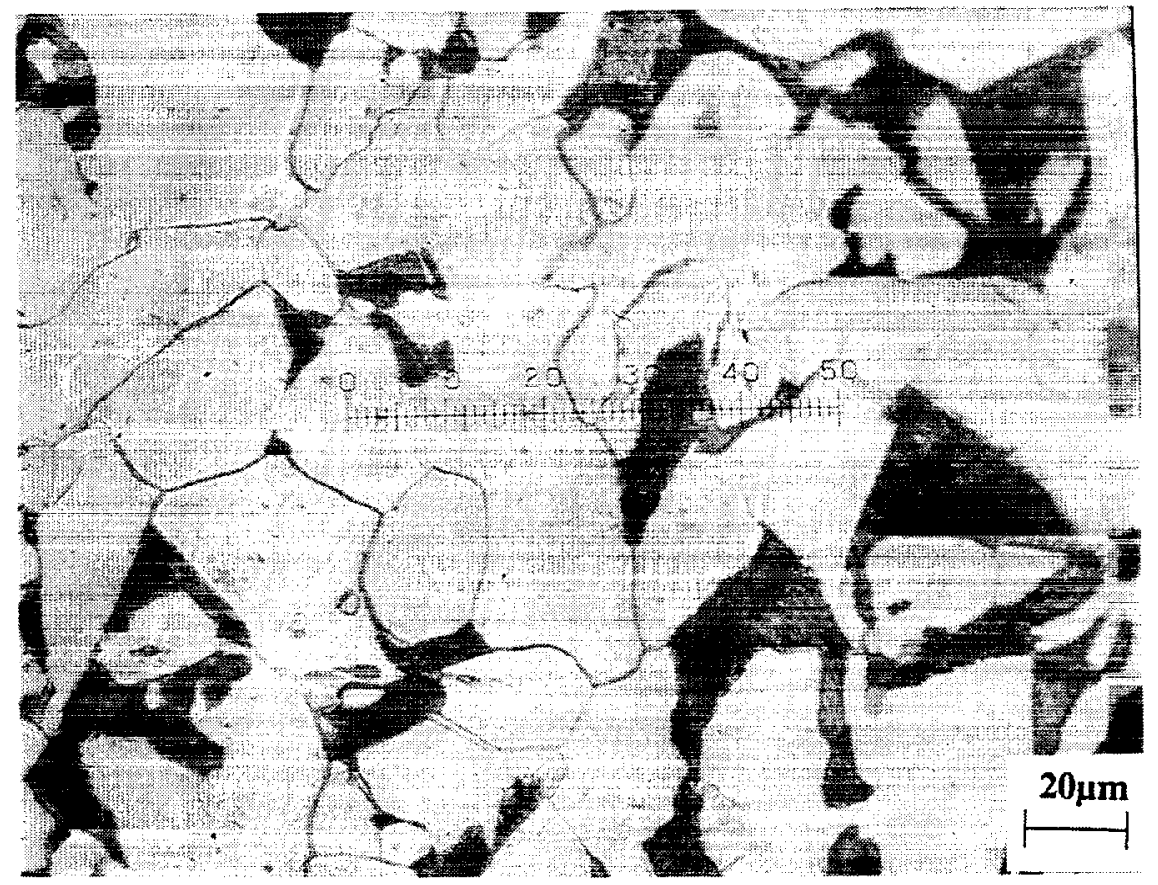

Sample B13 - Beam Flange

Magnification: 500X Etchant: $2 \%$ Nital

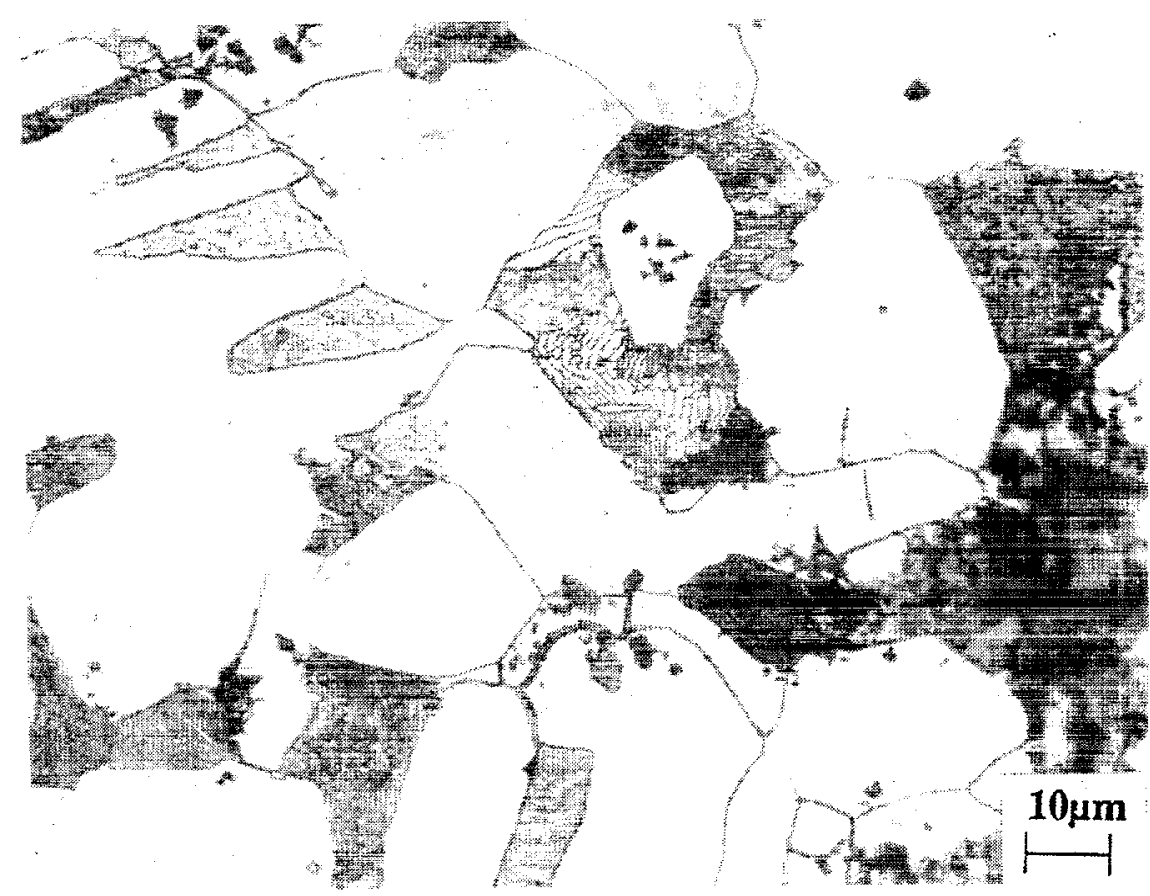

Sample B60 - Column Flange

Magnification: $750 \mathrm{X}$ Etchant: $2 \%$ Nital 


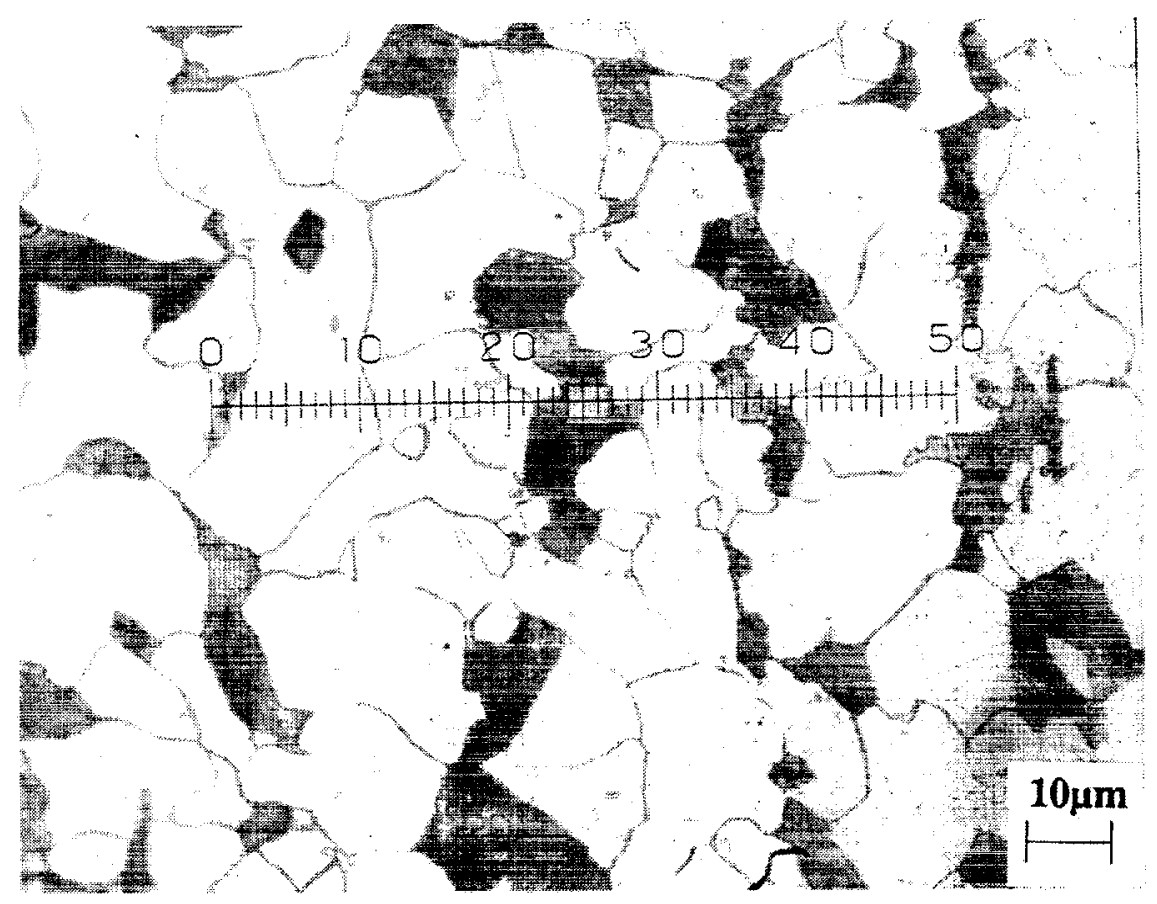

Sample C1 - Column Flange

Magnification: $750 \mathrm{X}$ Etchant: 2\% Nital

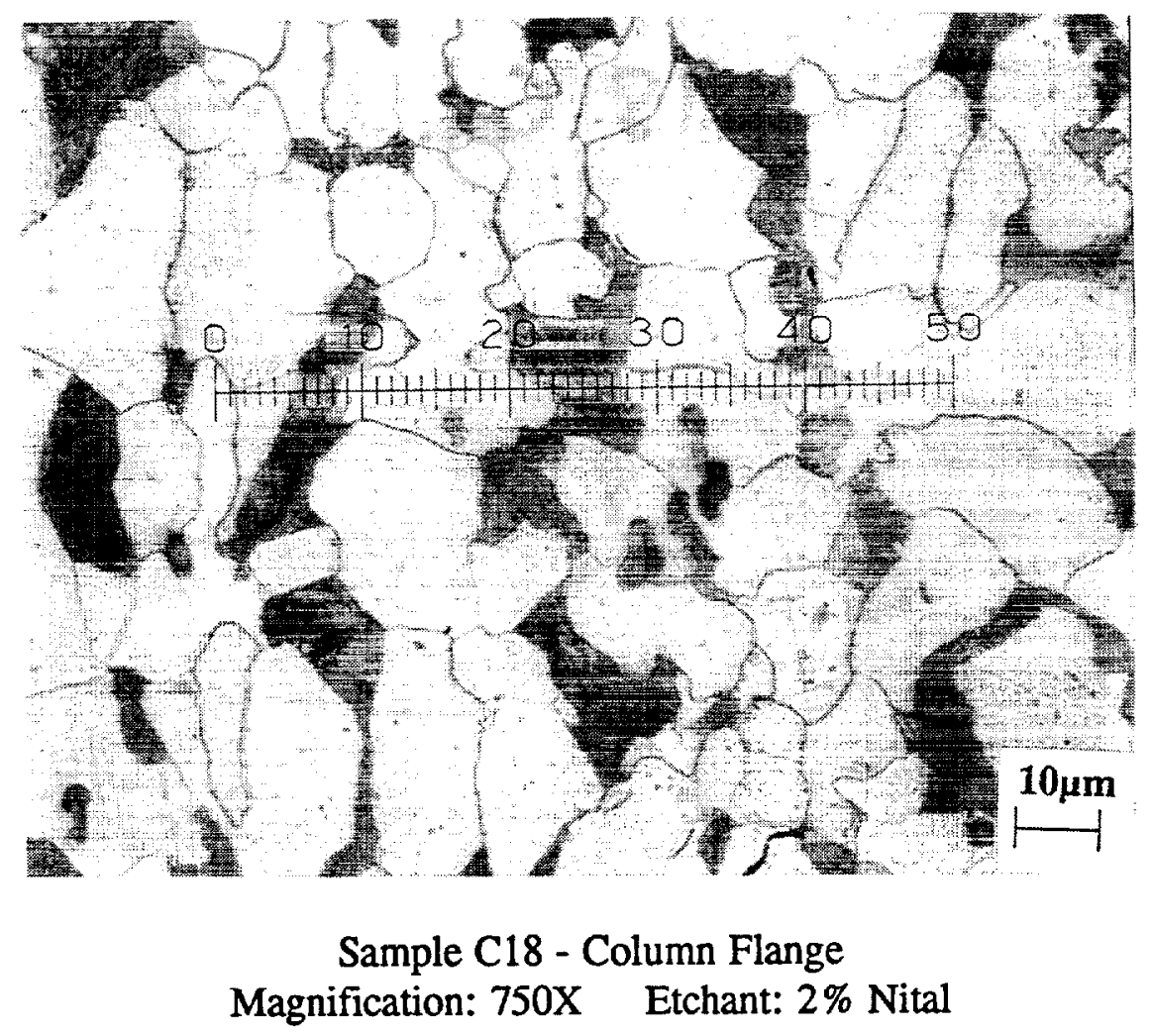




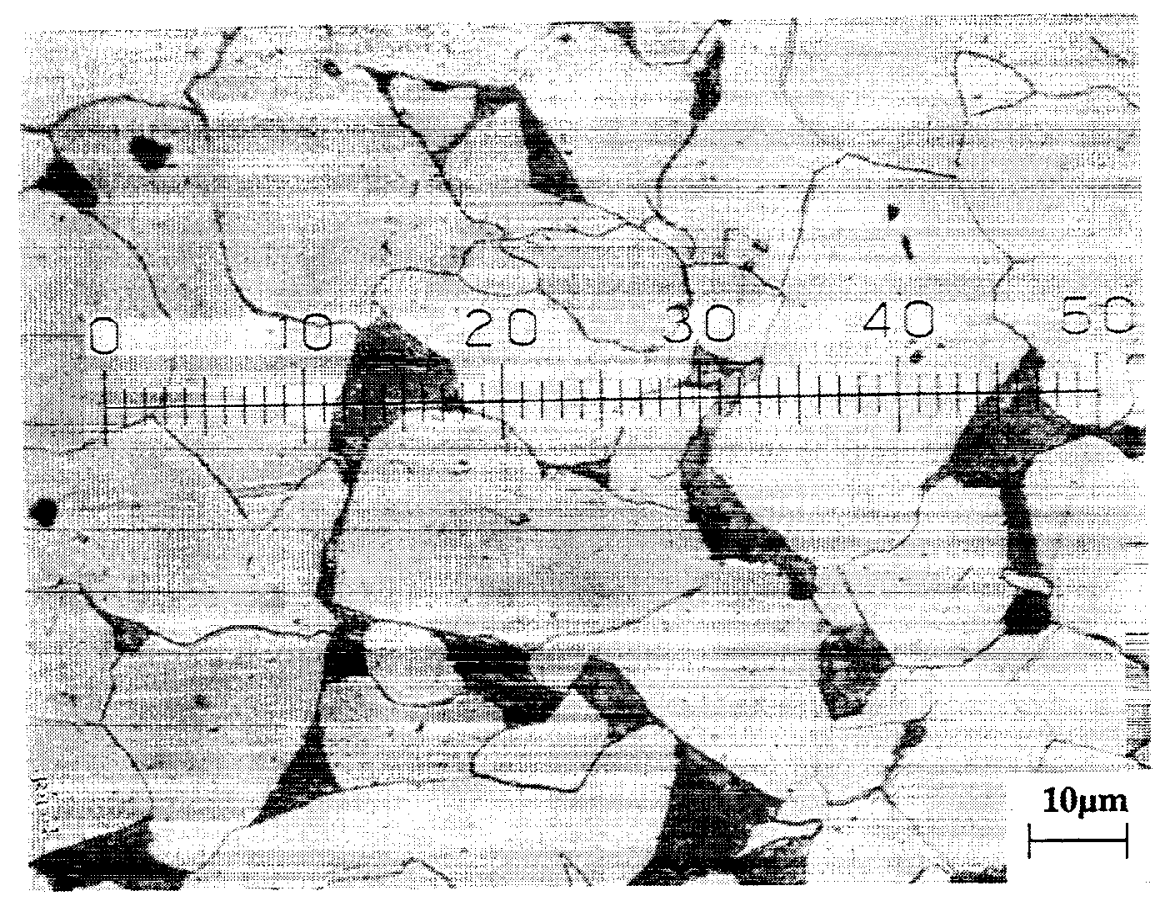

Sample C19 - Column Flange

Magnification: $1000 \mathrm{X}$ Etchant: $2 \% \mathrm{Nital}$

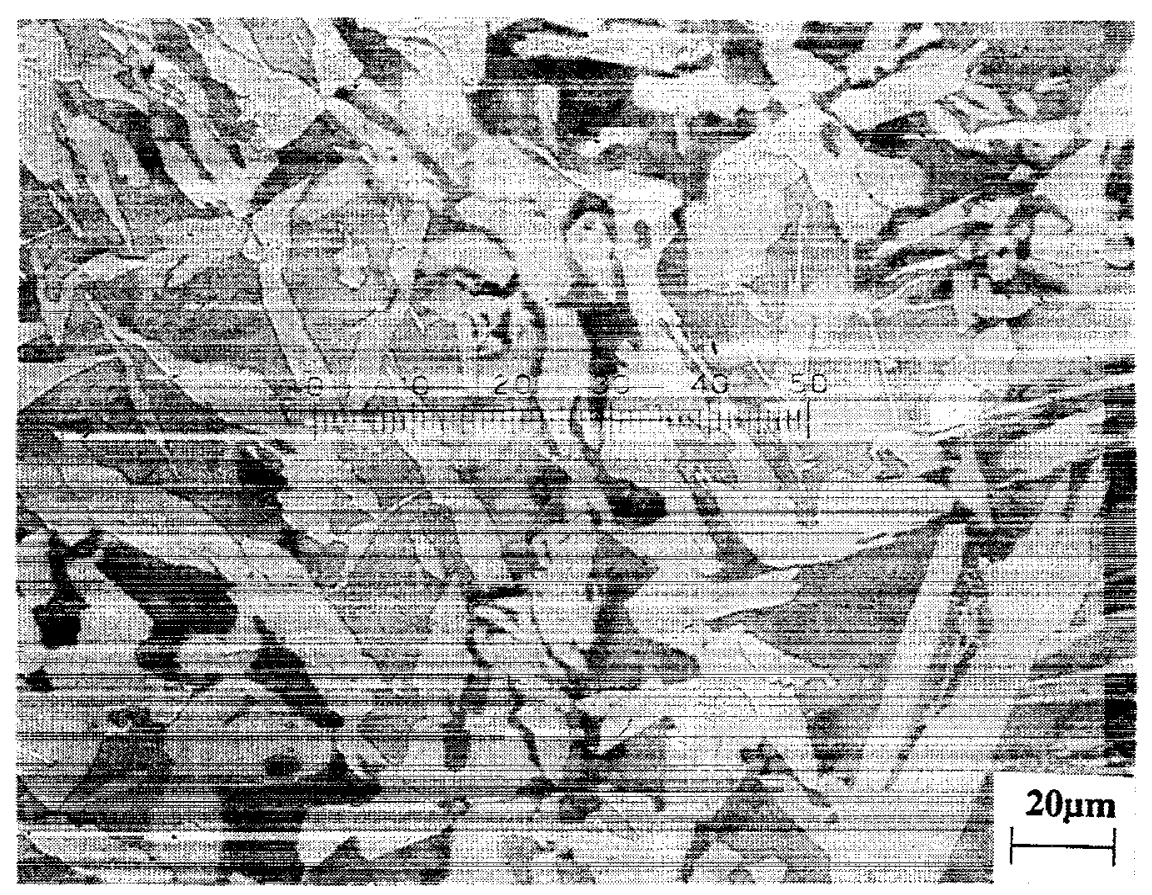

Sample E150 - Column Flange

Magnification: $500 \mathrm{X}$ Etchant: $2 \%$ Nital 


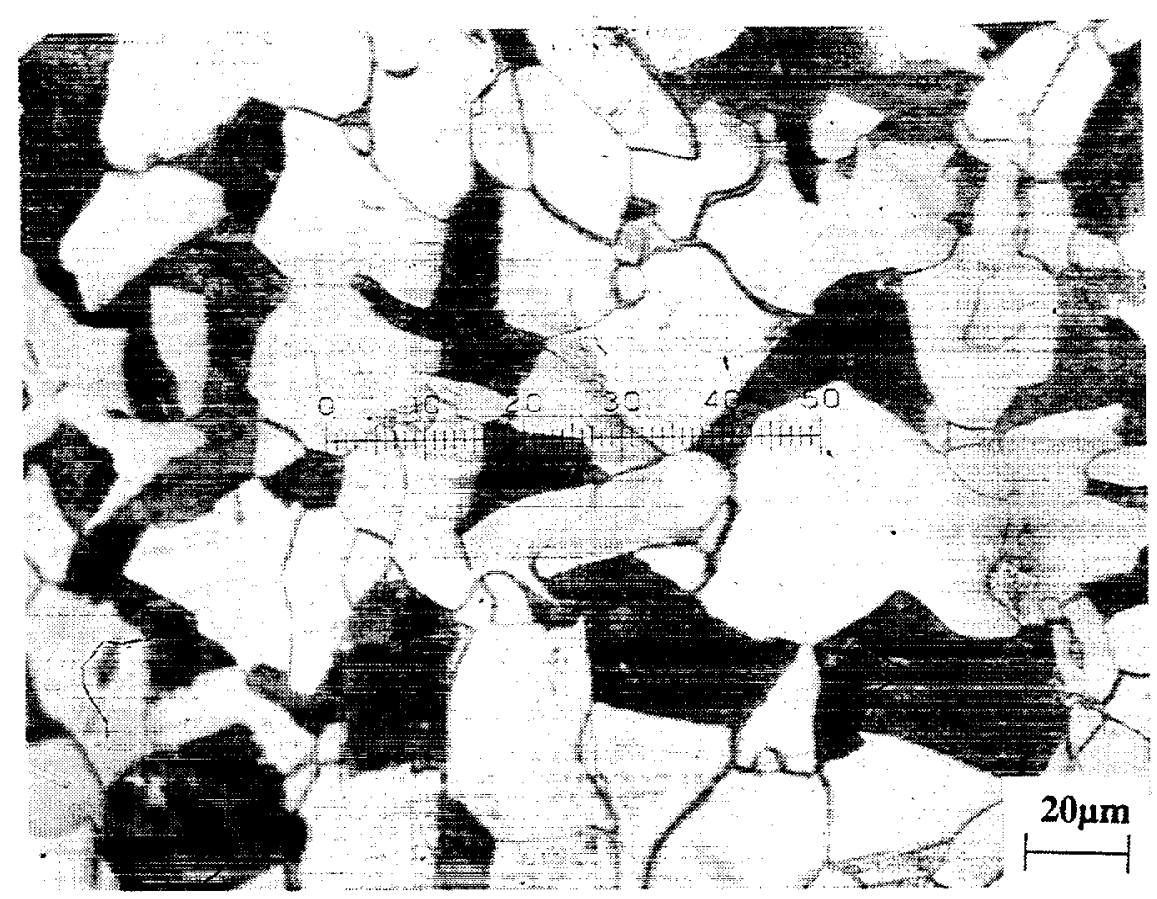

Sample E150 - Beam Flange

Magnification: 500X Etchant: 2\% Nital

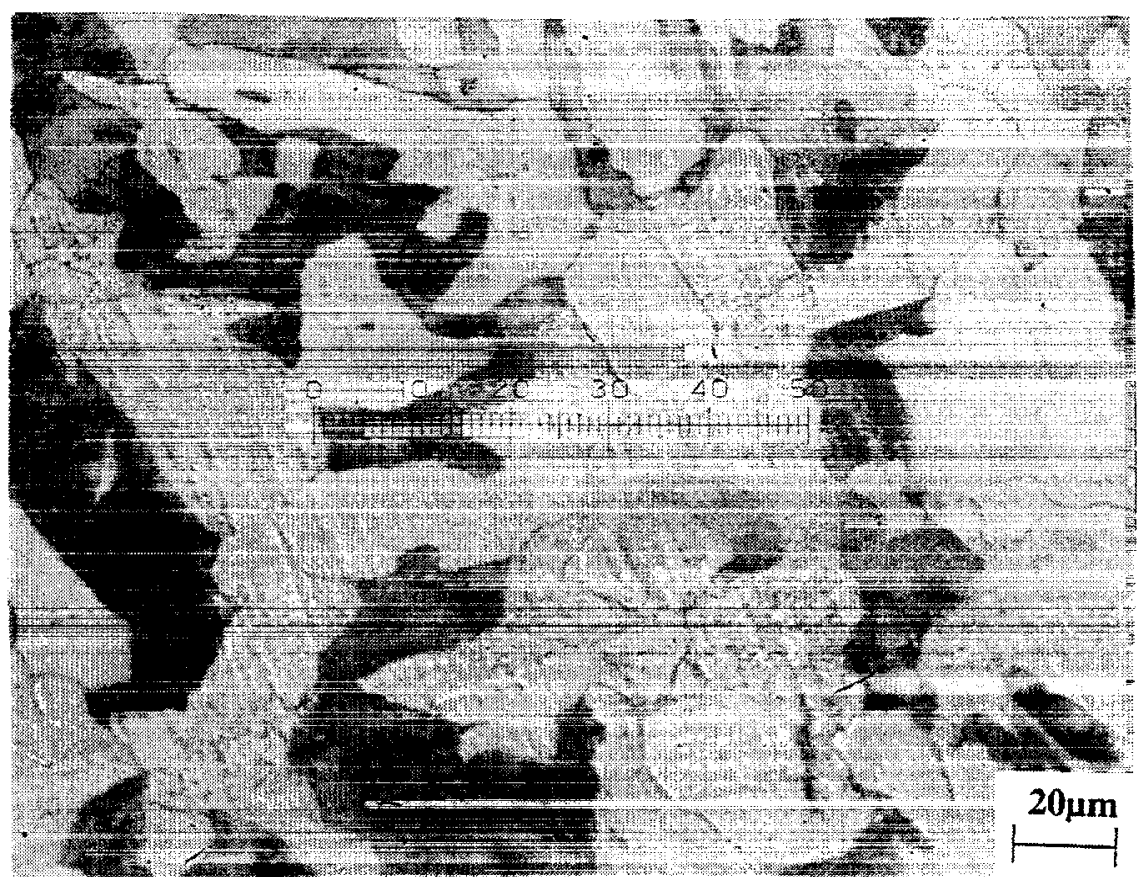

Sample E226 - Column Flange

Magnification: 500X Etchant: 2\% Nital 


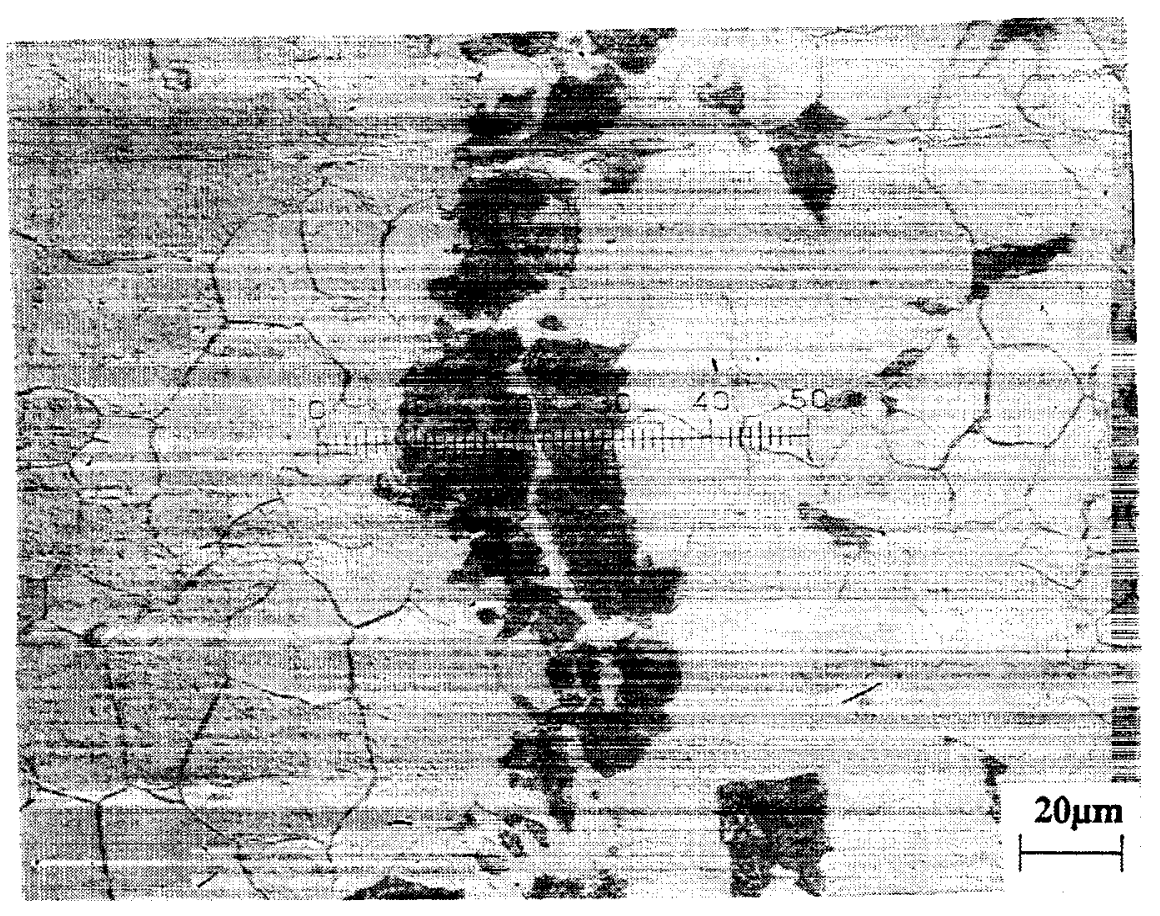

Sample E226 - Beam Flange

Magnification: 500X Etchant: 2\% Nital

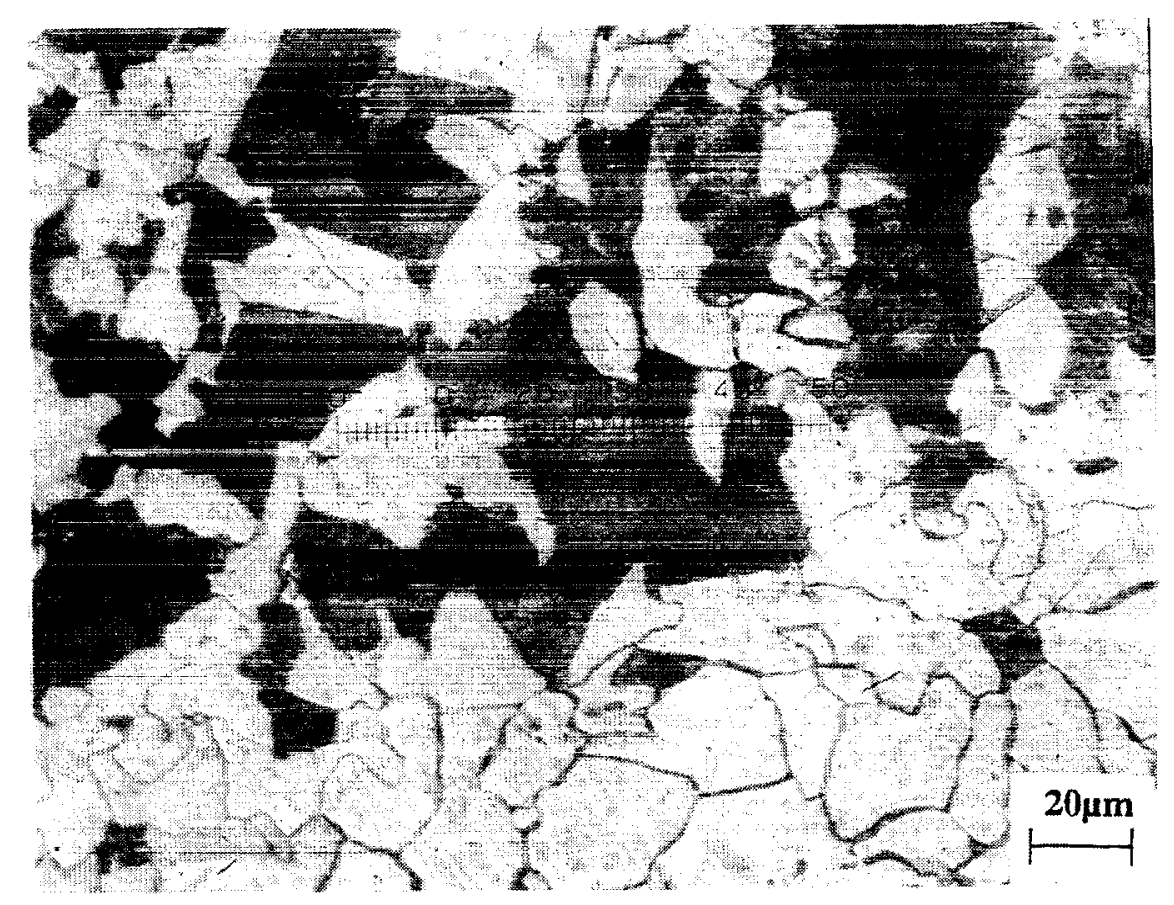

Sample E549 - Column Flange

Magnification: $500 \mathrm{X}$ Etchant: $2 \%$ Nital 


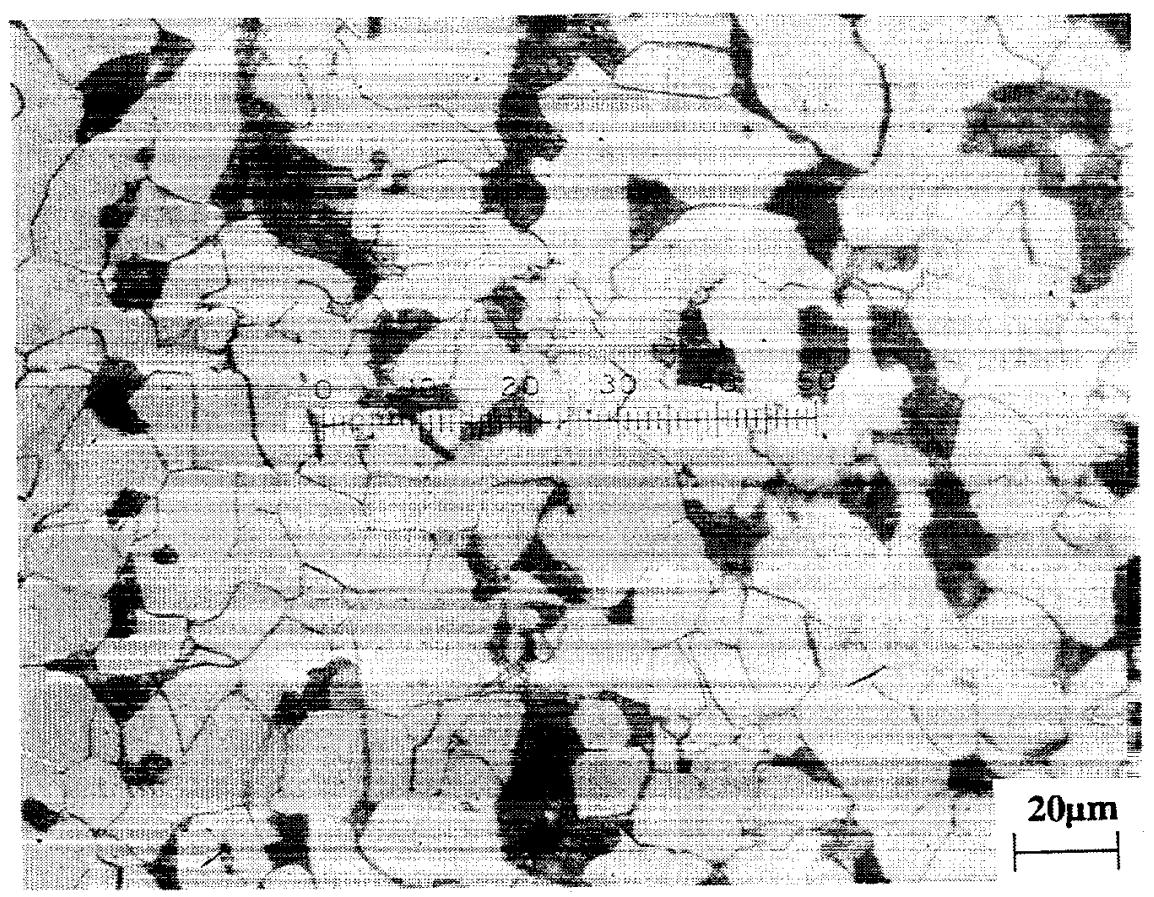

Sample E549 - Beam Flange

Magnification: 500X Etchant: $2 \%$ Nital

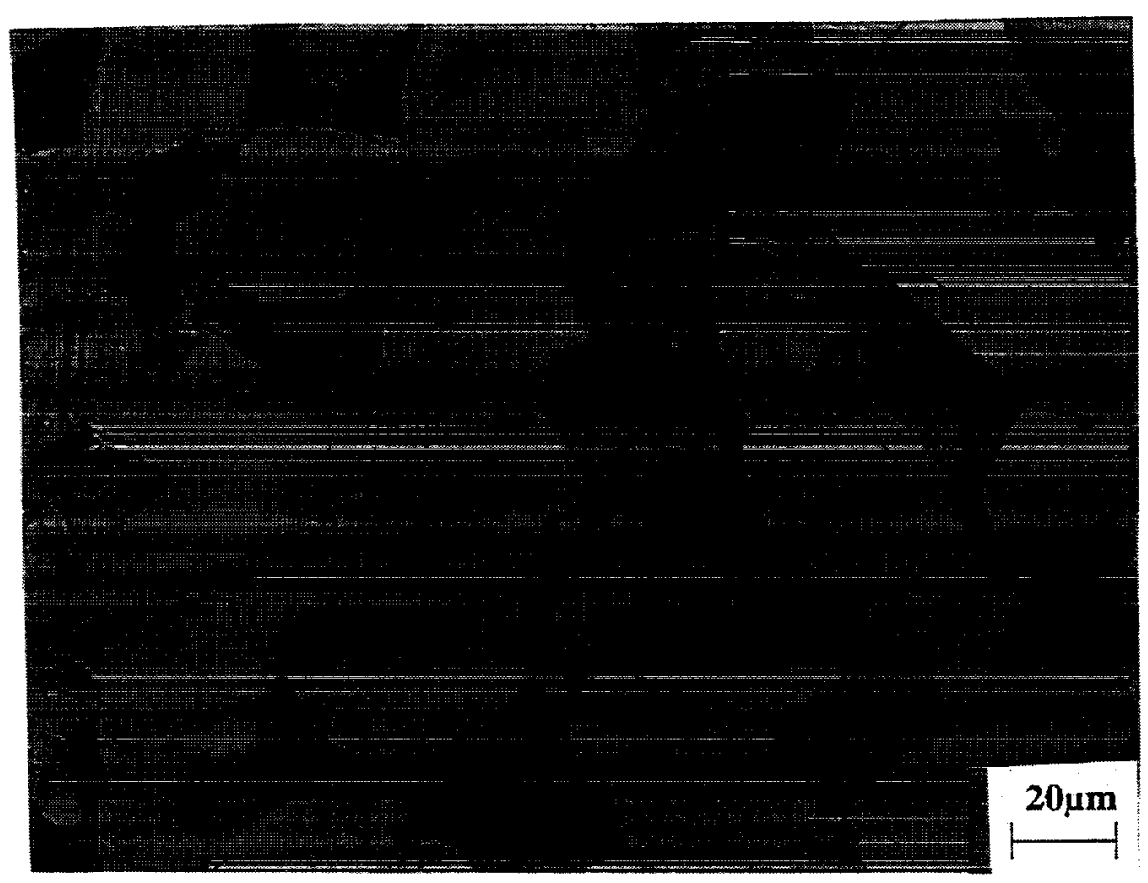

Sample F38 - Column Flange

Magnification: 500X Etchant: 2\% Nital 